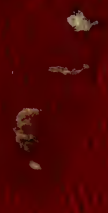


f voz 

VESTIGES

.

-

\section{THE NATURAL HISTORY}

or

\section{CREATION.}

WITH A SEQUEL.

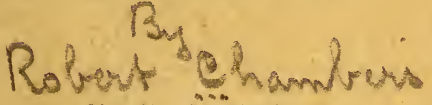

NEW YORK :

HARPER \& BROTHERS, PUBLISHER , 329 \& 331 PEARL STREET,

FRANKLIN SQUARİ.

1854. 



\section{O N T E N T S}

The Bodies of Space-their arrangements and formation - - - - - - - - - - - - - 5

Constituent materials of the Earth, and other Bodies of Space - - - - - - - - - - - 18 The Earth formed-Era of the Primary Rocks - - 26 Commencement of Organic Life-Sea Plants, Corals, \&c. - . - . - . - . - - 31

Era of the Old Red Sandstone-Fishes abundant - 37

Secondary Rocks-Era of the Carboniferous Formation-Land Formed - Commencement of Land Plants - - - - - - - - - - - -

Era of the New Red Sandstone-Terrestrial Zoology commences with Reptiles-First traces of Birds - 51

Era of the Oolite-Commencement of Mammalia - 56

Era of the Cretaceous Formation - - - - 61

Era of the Tertiary Formation - Mammalia abundant _ _ . . . _ _ _ . 66

Era of the Superficial Formations-Commencement of present Species - - - - - - - 70

General Considerations respecting the Origin of the Animated Tribes - - . - - - - - 76

Particular Considerations respecting the Origin of the A nimated Tribes - - - - - - - 86

Hypothesis of the Development of the Vegetable and Animal Kingdoms : - - - - - - 99

Macleay System of Animated Nature-This System considered in connection with the Progress of Organic Creation, and as indicating the natural status of Man - - - - - - - - 121 Early History of Mankind - - - - - - - 142 Mental Constitution of Animals - - - . - 166

Purpose and General Condition of the Animated Creation - - - - - - - - - - - 185 Note Conclusory - - _ - _ . - . - - 199 Design of the Vestiges Explained - - : - - 201 


RYPOTHEST OF THE DEVELOPMENT UV 'IT, TFGETABLE AND ANIMAT TINGDOME

OCALE OF ANIMAL KINGDOM. ORDER OF ANIMALS IN ASCENDING SERIES OF ROCKS. FOETAL HUMAN BRAIN

(Tho numbers indicate orders :)

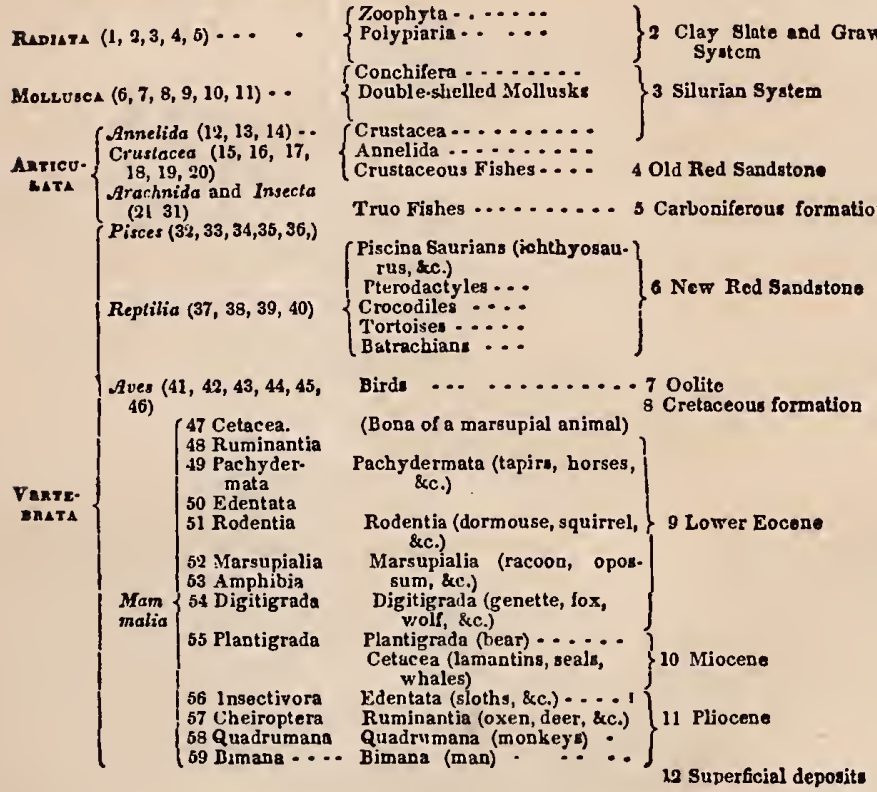

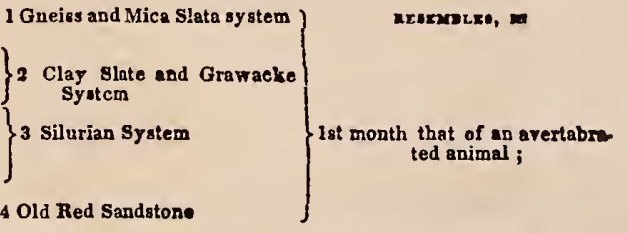

2nd month, that of a fish;

8rd month that of a turtle;

4th month, that of a bird ;

5th month, that of a rodent ;

6th month, that of a ruminant 3

7th month, that of a digitigrade animal;

Bth month that of the quadruma

9th month attains full human cre racter. 


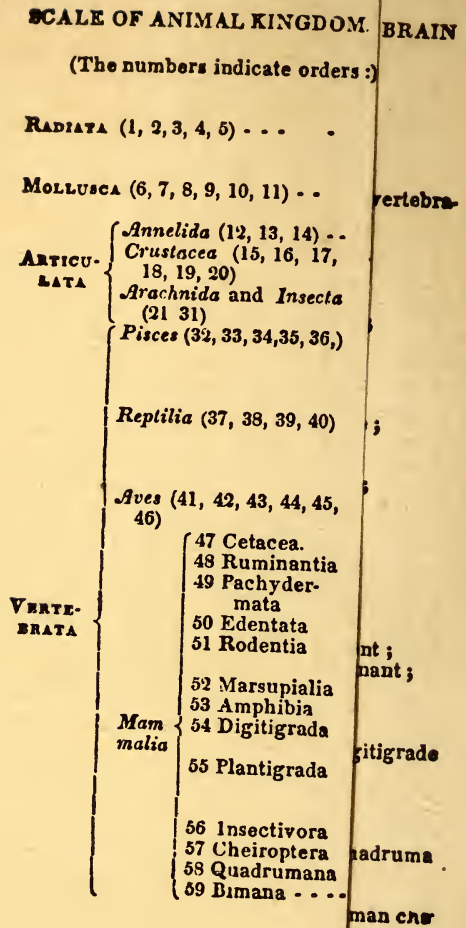




\section{- THE BODIES OF SPACE.}

\section{THEIR ARRANGEMENTS AND FORMATION}

IT is familiar knowledge that the earth which we innabit is a globe of somewhat less than 8000 miles in diameter, being one of a series of eleven which revolve at different distances around the sun, and.some of which have satellites in like manner revolving around them. The sun, planets, and satellites, with the less intelligible orbs termed comets, are comprehensively called the solar system, and if we take as the uttermost bounds of this system the orbit of Uranus, (though the comets actually have a wider range,) we shall find that it occupies a portion of space not less than three thousand six hundred millions of miles in extent. The mind fails to form an exact notion of a portion of space so immense; but some faint idea of it may be obtained from the fact, that, if the swiftest race-horse ever known had begun to traverse it, at full speed, at the time of the birth of Moses, he would only as yet have accomplished half his journey.

It has long been concluded amongst astronomers, that the stars, though they only appear to our eyes as brilliant points, are all to be considered as suns, representing so many solar systems, each bearing a general resemblance to our own. The stars have a brilliancy and apparent magnitude which we may safely presume to be in proportion to their actual size and the distance at which they are placed from us Attempts have been made to ascertain the distance of some of the stars by calculations founded on parallax, it being previously understood that If a parallax of so much as one second, or the 3600th of a degree could be ascertained in any one instance, the distance might be assumed in that instance as not less than $19,200,000$ millions of miles! In the case of the most brilliant star, Sirius, even this minute paraliax could not be found: from which of course, it was to be inferred that the distance of that star is something beyond the vast distance which has beer stated. In some others, on which 
the experiment has been tried, no sensible parallax could be detected; from which the same inference was to be made in their case. But a sensible parrallax of about one second has been ascertained in the case of the double star, $\dot{a}$ á, of the constellation of the Centaur, ${ }^{*}$ and one of the third of that amount for the double star, 61 Cygni; which gave reason to presume that the distance of the former might be about twenty thousand millions of miles, and the latter of much greater amount. If we suppose that similar intervals exist between all the stars we shall readily see that the space occupied by even the comparatively small number visible to the naked eye must be vast beyond all powers of conception.

The number visible to the eye is about three thousand; but when a telescope of small power is directed to the heavens, a great number more come into view, and the number is ever increased in proportion to the increased power of the instrument. In one place, where they are more thickly scwn than elsewhere,-Sir William Herschel reckoned that fifty thousand passed over a field of view two degrees in breadth in a single hour. It was first surmised by the ancient philosopher, Democritus, that the faintly white zone which spans the sky under the name of the Milky Way, might be only a dense collection of stars too remote to be distinguished. This conjecture has been verified by the instruments of modern astronomers, and some speculations of a most remarkable kind have been formed in connexion with it. By the joint labors of the two Herschels, the sky has been "gauged" in all directions by the telescope, so as to ascertain the conditions of different parts with respect to the frequency of the stars. The result has been a conviction that, as the planets are parts of the solar systems, so are solar systems parts of what may be called astral systems-that is, systems composed of a multitude of stars, bearing a certiin relation to each other. The astral system to which we belong, is conceived to be of an oblong, flattish form, with a space wholly or comparatively vacant, in the centre while the extremity to one direction, parts into two. The stars are most thickly sown in the outer parts of this vast ring, and these constitute the Milky Way. Our sun is believed to be placed in the southern portion of the

- By Mr. Henderson, Professor of Astronomy in the Edinburgh U niversity, and Lievtenant Meadows. 
ring, near its inner edge, so that we are preserted with many more stars, and see the Milky Way much more clearly in that direction, than towards the north, in which line our eye has to traverse the vacant central space. Nor is this all. Sir William Herschel, so curly as 1783 , detected a motion in our solar system with respect to the stars, and announced that it was tending towards the star $\lambda$, in the constellation Hercules. This has been generally verified by recent and more exact calculations, ${ }^{*}$ which fix on a point in Hercules, near the star 143 of the 17th huur, according to Piozzi's catalogue, as that towards which our sun is proceeding. It is therefore, receding from the inner edge of the ring. Motions of this kind, through such vast regions of space, must be long in producing any changes sensible to the inhabitants of our planet, and it is not easy to grasp their general character; but grounds have nevertheless been found for supposing that not only our sun, but the other suns of the system, pursue a wavy course round the ring from west to east, crossing and recrossing the middle of the annular circle. "Some stars will depart more, others less, from either side of the circumference of equilibrium, according to the places in which they are situated, and according to the direction and the velocity with which they are put in motion. Our sun is probably one of those which depart furthest from it, and descend furthest into the empty space within the ring." $\dagger$ According to this view, a time may come when we shall be much more in the thick of the stars of our astral system than we are now, and have of course much more brilliant nocturnal skies; but it may be countless ages before the eyes which are to see this added resplendence shall exist.

The evidence of the existence of other astral systems besides our own is much more decided than might be expected, sshen we consider that the nearest of them must needs b placed at a mighty interval beyond our own. The eld Herschel, directing his wonderful tube towards the sidzs of our system, where stars are planted most rarely, $u d$ raising the powers of the instrument to the

\footnotetext{
* Made by $M$ Argelander, late director of the Observatory at $A$ bo.

$\dagger$ Prorcesor Mossotti, on the Constitution of the Sidereal System, of which the Sun forms a part.-London, Edinburgh, and Duilis Fhilosophical Magazine, February, 1843.
} 
required pitch, was enabled with awe-struck mind to sec suspended in the vast empyrean astral systems, or, as he called them, firmaments, resembling our own. Like light cloudlets to a certain power of the telescope, they re. solved themselves, under a greater power, into stars, though these generally seemed no larger than the finest particles of diamond dust. The general forms of these systems are various; but one at least has been detected as bearing a striking resemblance to the supposed form of our own. The distances are also various, as proved by the different degrees of telescopic power necessary to bring them into view. The farthest observed by the astronomer were estimated by him as thirty-five thousand times more remote than Sirius, supposing its distance to be about twenty thousand millions of miles. It would thus appear, that not only does gravitation keep our earth in its place in the solar system, and the solar system in its place in our astral system, but it also may be presumed to have the mightier duty of preserving a local arrange* ment between that astral system and an immensity of others, through which the imagination is left to wander on and on without limit or stay, save that which is given by its inability to grasp the unbounded.

The two Herschels have in succession made some other most remarkable observations on the regions of space. They have found within the limits of our astral system, and generally in its outer fields, a great number of ob. jects which, from their foggy appearance, are called nebula ; some of vast extent and irregular figure, as that in the sword of Orion, which is visible to the naked eye, others of shape more defined; others, again, in which small bright nuclei appear here and there over the surfave Between this last form and another class of objects, which appear as clusters of nuclei with nebulous matter around each nucleus, there is but a step in what appears a chain of related things. Then, again, our astral space shows what are called nebulous stars-namely, luminous spherical objects, bright in the centre and dull towards the ex. tremities. These appear to be only an advanced conds. tion of the class of objects above described. Finally, ne. bulous stars exist in every stage of corcentration, down to that state in which we see only a common star with a slight bur around it. It may be plesumed that all these are. but stages in a progress, just as if, seeing a child, a 
boy, a youth, a middle-aged, and an old man together, we inight presume that the whole were only variations of one being. Are we to suppose that we have got a glimpse of the process through which a sun goes between its original eondition, as a mass of diffused nebulous matter, and its full-formed state as a compact body? We shall see how far such an idea is supported by other things known with regard to the occupants of space, and the laws of niatter.

A superficial view of the astronomy of the solar system gives us only the iảea of a vast luminous body (the sun) in the centre, and a few smaller, though various sized bodies, revolving at different distances around it; some of these, again, having smaller planets (satellites) revolving around them. 'There are, however, some general features of the solar system which, when a profounder attention makes us acquainted with them, strike the mind very forcibly.

It is, in the first place, remarkable, that the planets all move nearly in one plane, corresponding with the centre of the sur's body. Next, it is not less remarkable, that the motion of the sun on its axis, those of the planets around the sun, and the satellites around their primaries, ${ }^{*}$ and the motions of all on their axis, are in one direction -namely, from west to east. Had all these matters been - left to accident, the chances against the uniformity which we find would have been, though calculable, inconceivably great Laplace states them at four miliions of millions to one It is thus powerfully impressed on us, that the uniformity of the motions, as well as their general adjustment to one plane, must have been a consequence of some cause acting throughout the whole system.

Some of the other relations of the bodies are not less remarkable. The primary planets show a progressive increase of bulk and dimanition of density, from the one nearest to the sun to that which is most distant. With respect to the density alone, we find, taking water as a measure and counting it as one, that Saturn is 33 , or less

* The orbitual revolutions of the satellites of Uranus have not as yot been clearly scanned. It has been thought that their path is retrograde compared with the rest. Perhaps this may be owing to a bouleversement of the primary, for the inclination of its equator to the ecliptic is admitted to be unusually high ; but the subject is al together so obscure that rothing can be founded on it. 
than half; Jupiter, $\mathbf{1}_{24}^{1}$; Mars, $3 \frac{3}{7}$; Earth, $4 \frac{\pi}{2}$; Venus, $5 \frac{1}{1}$; Mercury, $9 \frac{9}{1}$, or about the weight of lead. Then the distances are curiously relative. It has been found that if we place the following line of numbers-

$\begin{array}{llllllll}6 & 3 & 6 & 12 & 24 & 48 & 96 & 192,\end{array}$ and add 4 to each we shall have a series denoting the respective distances of the planets from the sun. It will stand thus-

$\begin{array}{llllllll}4 & 7 & 10 & 16 & 28 & 52 & 100^{\circ} & 196\end{array}$

Merc. Venus. Earth. Mars. Jupiter. Saturn. Uranus It will be observed that the first row of figures goes on from the second on the left hand in a succession of duplications, or multiplications by 2. Surely there is here a most surprising proof of the unity which I am claiming for the solar system. It was remarked when this curious relation was first detected, that there was the want of a planet corresponding to 28 ; the difficulty was afterwards considered as in a great measure overcome, by the discovery of four small planets revolving at nearly one mean distance from the sun, between Mars and Jupiter. The distances bear an equally interesting mathematical relation to the times of the revolutions round the sun. It has been found that, with respect to any two planets, the squares 0. the times of revolutions are to each other in the same proportion as the cubes of their mean distances-a most surprising result, for the discovery of which the world was indebted to the illustrious Kepler. Sir John Herschel truly observes "When we contemplate the constituents of the planetary system from the point of view which this relation affords us, it is no longer mere analogy which strikes us, no longer a general resemblance arnong them, as individuals independent of each other, and circulating about the sun, each according to his own peculiar nature, and connected with it by its own peculiar tie. The resemblance is now perceived to be a true family likeness ; they are bound up in one chain,interwoven in one web of mutual relation and harmonious agreement, subjected to one pervading influence, which extends from the centre to the farthest limits of that great system, of which all of them, the Earth included, must henceforth be regarded as members.*

Connecting what has been observed of the series of nebulous stars with this wonderful relationship seen to

*Astronomy, Lardner's Cyclopædia. 
exist among the constituents of our system: and further taking advantage of the light afforded by the ascertained iaws of matter, modern astronorners have suggested the followng hypothesis of the formation of that system.

Of nebulous matter in its original state we know too little to enable us to suggest how nuclei should be established in it. But supposing that from a peculiarity in its constitution, nuclei are formed, we know very well how, by virtue of the law of gravitation, the process of an aggregation of the neighbouring matter to those nuclei should proceed, until masses more or less solid should become detached from the rest. It is a well known law in physics that, when fluid matter collects towards or metets in a centre, it establishes a rotary motion. See minor results of this law in the whirlwind and the whirlpool-nay, on so humble a scale as the water sinking through the aperture of a funnel. It thus becomes certain that when we arrive at the stage of a nebulous star, we have a rotation on an axis commenced.

Now, mechanical philosophy informs us that the instant a mass begins to rotate, there is generated a tendency to fling off its outer portions-in other words, the law of centrifugal force begins to operate. There are, then, two forces acting in opposition to each other, the one attracting to, the other throwing from, the centre. While these remain exactly counterpoised, the mass necessarily continues entire; but the least excess of the centrifugal over the attractive force would be attended with the effect of separating the mass and its outer parts. These outer parts would then be left as a ring round the central body, which ring would continue to revolve with the velocity possessed by the central mass at the moment of separation, but not necessarily participating in any changes afterwards undergone by that body. This is a process which might be repeated as soon as a new excess arose in the centrifugal over the attractive forces working in the parent mass. It might, indeed, continue to be repeated, until the mass attained the ultimate limits of the condensation which its constitution imposed upon it. From what cause might arise the periodical occurrence of an excess of the centrifugal force? If we suppose the agglomeration of a nebulous mass to be a process attended by refrigeration or cooling, which many facts render likely, we can easily understand why the outer parts, hardening 
under this process, might, by virtue of the greater solidity thence acquired, begin to present some resistance to the attractive force. As the solidification proceeded, this resistance would become greater, though there would still be a tendency to adhere. Meanwhile, the condensation of the central mass would be going on, tending to produce a separation from what may now be termed the solidifying crust. During the contention between the attractions of these two bodies, or parts of one body, there would probably be a ring of attenuation between the mass and its crust. At length when the central mass had reached a certain stage in its advance towards solidification, a separation would take place, and the crust would become a detached ring. It is clear, of course, that some law presiding over the refrigeration of heated gaseous bodies would determine the stages at which rings were thus formed and detached. We do not know any such law but what we have seen assures us it is one observing, and reducible to, mathematical formula.

If these rings consisted of matter nearly uniform throughout, they would probably continue each in its original form; but there are many chances against their being uniform in constitution. The unavoidable effects of irregularity in their constitution would be to cause them to gather tow ards centres of superior solidity, by which the annular form would, of course, be destroyed. The ring would, in short, break into several masses the largest of which would be likely to attract the lesser into itself: The whole mass would then necessarily settle into a spherical form by virtue of the law of gravitation; in short, would then become a planet revolving round the sur. Its rotatory motion would, of course, continue, and satellites might then be thrown off in turn from its body in exactly the same way as the primary planets had been thrown off from the sun. The rule, if I can be allowed so to call it, receives a striking support from what appears to be its exceptions. While there are many chances against the matter of the rings being sufficiently equable to remain in the annular form till they were consolidated, it might nevertheless be-otherwise in some instances; that is to say, the equableness might, in those instances, be sufficiently great. Such was probably the case with the two rings around the body of Saturn, which remain a living picture of the arrangement, if not the condition, in 
which all the planetary masses at one time stood. It may also be admitted that, when a ring broke up, it was possible that the fragments might spherify separately. Such seems to be the actual history of the ring between Jupiter and Mars, in whose place we now find four planets much beneath the smallest of the rest in size, and moving nearly at the same distance from the sun, though in orbits so elliptical, and of such different planes, that they keep apart.

It has been seen that there are mathematical proportions in the relative distances and revolutions of the planets of our system. It has also been suggested that the periods in the condensation of the nebulous mass, at which rings were disengaged, must have depended on some particular crisis in the condition of that mass, in connexion with the laws of centrifugal force and attraction. M. Comte, of Paris, has made some approach to the verification of the hypothesis, by calculating what ought to have been the rotation of the solar mass at the successive times when its surface extended to the various planetary orbits. He ascertained that that rotation corresponded in every case with the actual sidereal revolution of the planets, and that the rotation of the primary planets in like manner corresponded with the orbitual periods of the secondaries. - The process by which he arrived at this conclusion is not to be readily comprehended by the unlearned; but those who are otherwise, allow that it is a powerful support to the present hypothesis of the formation of the globes of space.*

* M. Comte combined Huygens's theorems for the measures of centrifugal force with the law of gravitation, and thus formed a simple fundamental equation between the duration of the rotation of what he calls the producing star, and the distance of the star produced. The constants of this equation were the radius of the central star, and the intensity of gravity at its surface which is a direct consequence of its mass. It leads directly to the third law of Kepler, which thus becomes susceptible of being conceived a pri. ori in a cosmogonical point of view. M. Comte first applied it to the moon, and found, to his great delight, that the periodic time of that satellite agrees within an hour or two with the duration which the revolution of the earth ought to have had at the time when the lunar distance formed the limit of the earth's atmosphere. He found the coincidence less exact, but still very striking, in every other case, In those of the planets he obtained for the duration of the corresponding solar rotations a value always a little less than their actual periodic times. "It is remarkable," says he, "that this difference, though increasing as the planet is more distant, preserves very nearly the same relation to the corresponding periodic 
The nebular hypothesis, as it has been called, obtains a remarkable support in what would at first seem to militate against it-the existence in our firmament of several thousands of solar systems, in which there are more than one sun. These are called double and triple stars. Some double stars, upon which careful observations have been made, are found to have a regular revolutionary motion round each other in elipses. This kind of solar system has also been observed in what appears to be its rudimental state, for there are examples of nebulous stars containing two and three nuclei in near association. At a certain point in the confluence of the matter of these nebulous stars, they would all become involved in a common revolutionary motion, linked inextricably with each other, though it might be at sufficient distances to allow of each distinct centre having afterwards its attendant planets. We have seen that the law which causes rotation in the single solar masses, is exactly the same which produces the familiar phenomenon of a small whirlpool or dimple in the surface of a stream. Such dimples are not always single. Upon the face of a river where there are various contending currents, it may often be observed that two or more dimples are formed near each other with more or less regularity. These fantastic eddies, which the musing poet will sometimes watch abstractedly for an hour, little thinking of the law which produces and conects them, are an illustration of the wonders of binary and ternary solar systems.

The nebular hypothesis is, indeed, supported by so many ascertained features of the celestial scenery, and so many calculations of exact science, that it is impossible for a candid mind to refrain from giving it a cordial receptior, if not to repose full reliance upon it, even with-

time, of which it commonly forms the forty-fifth part"-showing, we may suppose, that only some small elements of the question had been overlooked by the calculator. The defect changes to an excess in the different systems of the satellites, where it is proportionally greater than in the planets, and unequal in the different systems. "From the whole of these comparisons," says he, "I deduced the following general result: Supposing the mathematical limit of the solar atmosphere successively extended to the regions where the different planets are now found, the duration of the sun's rotation was, at each of those epochs, sensibly equal to that of the actual sidereal revolution of the corresponding planet; and the same is true for each planetary atmosphere in relation to the diffe. rent satellites -Cours de Philosophie Positif. 
out seeking for it support of any other kind. Some other support I trust yet to bring to it: but in the meantime, assuming its truth, let us see what idea it gives of the constitution of what we term the universe, of the development of its various parts, and of its original condition.

Reverting to a former illustration - if we could suppose number of persons of various ages presented to the inspection of an intelligent being newly introduced into the world, we cannot doubt that he would soon become convinced that men had once been boys, that boys had once been infants, and, finally, that all had been brought into the world in exactiy the same circumstances. Precisely thus, seeing in our astral system many thousands of worlds in all stages of formation, from the most rudimental to that immediately preceding the present condition of those we deem perfect, it is unavoidable to conclude that all the perfect have gone through the various stages which we see in the rudimental. This leads us at once to the conclusion that the whole of our firmament was at one time a diffused mass of nebulous matter, extending through the space which it stili occupies. So also, of course, must have been the other astral systems. Indeed, we must presume the whole to have been originally in one connected mass, the astral systems being only the first division into parts, and solar systems the second.

The frst idea which all this impresses upon us is, that the formation of bodies in space is still and at present in progress. We live at a time when many have been formed, and many are still forming, Our own solar system is to be regarded as completed, supposing its perfection to consist in the formation of a series of planets, for there are mathematical reasons for concluding that Mercury is the nearest planet to the sun, which can, according to the laws of the system, exist. But there are other solar systems within our astral system, which are as yet in a less advanced state, and even some quantities of nebulous matter which have scarcely begun to advance towards the stellar form. On the other hand, there are vast numbers of stars which have all the appearance of being fully formed systems, if we are to judge from the complete and definite appearance which they present to our vision through the telescope. We have no means of judging of the seniority of systems ; but it is reasonable to suppose that, among the many, some are older than 
ours. There is, indeed, one piece of evidence for th. probability of the comparitive youth of our system, altogether apart from human traditions and the geognostic appearances of the surface of our planet. This consists in a thin nebulous matter, which is diffused around the sun to nearly the orbit of Mercury, of a very oblately spheroidal shape.

This matter, which sometimes appears to our naked eyes, at sunset, in the form of a cone projecting upwards in the line of the sun's path, and which bears the name of Zodiacal Light, has been thought a residuum or last remnant of the concentrating matter of our system, and thus may be supposed to indicate the comparative recent. ness of the principal events of our cosmogony. Supposing the surmise and inference to be correct, and they may be held as so far supported by more familiar evidence, we might with the more confidence speak of our system as not amongst the elder born of Heaven, but one whose various phenomena, physical and moral, as yet lay undeveloped, while myriads of others iwere fully fashioned, and in comp?ete arrangement. Thus, in the sublime chronology to which we are directing our inquiries, we first find ourselves called upon to consider the globe which we inhabit as a child of the sun, elder than Venus and her younger brother Mercury, but posterior in date of birth to Mars, Jupiter, Saturn, and Uranus; next to regard our whole systern as probably of recent formation in comparison with many of the stars of our firmament. We must, however, be on our guard against supposing the earth as a recent globe in our ordinary conceptions of tirne. From evidence afterwards to be adduced, it will be seen that it cannot be presumed to be less than many hundreds of centuries old. How much older Uranus may be, no one can tell, far less how much more aged may bo many of the stars of our firmament, or the stars of other firmaments than ours.

Another and more important consideration arises from the hypothesis; namely, as to the means by which the grand process is conducted. The nebulous matter collects around nuclei by virtue of the law of attraction. The agglomeration brings into operation another physical law, by force of which the separate masses of matter are either made to rotate singly, or, in addition to that single motion, are set into a coupled revolntion in ellipses. Next 
centrifugal force comes into play, flinging off portions of the rotating masses, which become spheres by virtue of the same law of attraction, and are held in orbits of revolution round the central body by means of a composition between the centrifugal and gravitating forces. All, we see, is done by certain laws of matter, so that it becomes a question of extreme interest, what are such laws ? All that can yet be said, in answer, is, that we see certain natural events proceeding in an invariable order under certain conditions, and thence infer the existence of some fundamental arrangement which, for the bringing about of these events, has a force and certainty of action similar to, but more precise and unerring than those arrangements which human society makes for its own benefit, and calls laws. It is remarkable of physical laws, that we seee them operating on every kind of scale as to magnitude, with the same regularity and perseverance. The tear that falls from childhood's cheek is globular, through the efficacy of that same law of mutual attraction of particles which made the sun and planets round. The rapidity of Mercury is quicker than that of Saturn, for the same reason that, when we wheel a ball round by a string and Inake the string wind up round our fingers, the ball always flies quicker and quicker as the string is shortened Two eddies in a stream, as has been stated, fall into a mutual revolution at the distance of a couple of inches, through the same cause which makes a pair of suns link in mutual revolution at the distance of millions of miles. There is, we might say, a sublime simplicity in this indifference of the grand regulations to the vastness or minuteness of the field of their operation. Their being uniform, too, throughout space, as far as we can scan it, and their being so unfailing in their tendency to operate, so that only the proper conditions are presented, afford to our minds matter for the gravest consideration. Nor should it escape our careful notice that the regulations on which all the laws of matter operate, are established on a rigidly arcurate mathematical basis. Proportions of numbers and geometrical figures rest at the bottom of the whole. All these considerations, when the mind is thoroughly prepared for them, tend to raise our ideas with respect to the character of physical laws, even though we do not go a single step further in the investigation. But it is impossible for an intelligent mind to stor there. We ad- 
rance from law to the cause of law, and ask, What is that? Whence have come all these beautiful regulations? Here science leaves us, but only to conclude, from other grounds, that there is a First Cause to which all others are secondary and ministrative, a primitive almighty will, of which these laws are merely the mandates. That great Being, who shall say where is his dwelling-place, or what his history! Man pauses breathless at the contemplation of a subject so much above his finite faculties, and only can wonder and adore!

\section{CONSTITUENT MATERIALS OF THE EARTH,}

\section{AND OF THE OTHER BODIES OF SPACE.}

The nebular hypothesis almost necessarily supposes matter to have originally formed one mass. We have seen that the same physical laws preside over the whole. Are we also to presume that the constitution of the whole was uniform?-that is to say, that the whole consisted of similar elements. It seems difficult to avoid coming to this conclusion, at least under the qualification that, possibly, various bodies, under peculiar circumstances, attending their formation, may contain elements which are wanting, and lack some which are present, in others, or that some may entirely consist of elements in which others are entirely deficient.

What are elements? This is a term applied by the chemist to a certain limited number of substances (fiftyfour or fifty-five are ascertained,) which, in their combinations, form all the matters of every kind present in and about our globe. They are called elements, or simple substances, because it has hitherto been found impossible to reduce them into others, wherefore they are presumed to be the primary bases of all matters. It has, indeed, been surmised that these so-called elements are only modifications of a primordial form of matter, brought about under certain conditions; but if this should prove to be the case, it would little affect the view which we are taking of cosmical arrangements. Analogy would lead us to conclude that the combinations of the primordial matter, forming our so-called elements, are as uni- 
versal, or as liable to take place everywhere, as are the laws of gravitation and centrifugal force. We must therefore presume that the gases, the metals, the earths, and other simple substances (besides whatever more of which we have no acquaintance) exist, or are liable to come into existence under proper conditions, as well in the astral system, which is thirty-five thousand times more distant than Sirius, as within the bounds of our own solar system or our own globe.

Matter, whether it consists of about fifty-five ingred1ents, or only one, is liable to infinite varities of condition under different circumstances, or to speak more philosophically under different laws. As a tamiliar illustration, water, when subjected to a temperature under $32^{\circ}$ Fahrenheit, becomes ice; raise the temperature to $212^{\circ}$ and it becomes steam, occupying a vast deal more space than it formerly did. The gasses, when subjected to pressure beco re liquids; for example, carbonic acid gas, when subjucted to a weight equal to a column of water 1230 feet high, at a temperature of $32^{\circ}$, takes this form; the other gasses require various amounts of pressure for this transformation, but all appear to be liable to it when the pressure proper in each case is administered. Heat is a power greatly concerned in regulating the volume and othe: conditions of matter. A chemist can reckon with considerable precision what additional amount of heat would be required to evaporize all the water of our globe; how much more to disengage the oxygen which is diffused in nearly a proportion of one-half throughout its solids; and, finally, how much more would be required to cause the whole to become vapcriform, which we may consider as equivalent to its being restored to its original nebulous state. He can calculate with equal certainty what would be the effect of a considerakle diminution of the earth's temperature-what changes would take place in each of its component substances, and how much the whole would shrink in bulk.

The earth and all its various substances have at present a certain volume in consequence of the temperature which actually exists. When, then, we find that its matter and that of the associate planets, was at one time diffused throughout the whole space now circumscribed by the orbit of Uranus, we cannot doubt, after what we know of the power of heat, that the nebulous form of matter was at- 
tended by the condition of a very high temperature. 'The nebulous matter of space, previously to the formation of siellar and planetary bodies, must have been a universal Fire Mist, an idea which we can scarcely comprehend, though the reasons for arriving at it seem irresistible. The formation of systems out of this matter implies a change of some kind with regard to the condition of the heat. Had this power continued to act with its full original repulsive energy, the process of agglomeration by attraction could not have gone on. We do rot know enough of the laws of heat to enable us to surmise how the necessary change in this respect was brought about, but we can trace some of the steps and consequences of the process. Uranus would be formed at the time when the heat of our system's matter was at the greatest, Saturn at the next and so on. Now this tallies perfectly with the exceeding diffuseness of the matter of those elder planets, Saturn being not more dense or heavy than the substance cork. It may be that a sufficiency of heat still remains in those planets to make up for their distance from the sun, and the consequent smallness of the heat which they derive from his rays. And it may equally be, since Mercury is twice the density of the earth, that its matter exists under a degree of cold for which that planet's large enjoyment of the sun's rays is no more than a compensation. Thus there may be upon the whole, a nearly equal experience of heat amongst all these children of the sun. Where, meanwhile, is the heat once diffused through the system over and above what remaing in the planets? May we not rationally presume it to have gone to constitute that luminous envelope of the sun, in which his warmth-giving power is now held to reside. It could not be destroyed-it cannot be supposed to have gone off into space-it must have simply been reserved to constitute, at the last, a means of sustaining the many operations of which the planets were destined to be tho theatre.

The tendency of the whole of the preceding considerations is to bring the conviction that our globe is a specimer, of all the similarly-placed bodies of space, as respects its constituent matter and the physical and chemical laws governing it, with only this qualification, that there are vossibly shades of variatinn with respect to the component uiaterials, and undoubtedly with respect to the conditions 
under which the laws operate, and consequently the effects which they produce. Thus, there may be substances here which are not in some other bodies, and substances here solid may be elsewhere liquid or vaporiform. We are the more entitled to draw such conclusions, seeing that there is nothing at all singular or special in the astronomical situation of the earth. It takes its place third in the series of planets, which series is only one of numberless other systmes forming one group. It is strikingly, if I may use such an expression, a member of a democracy. Hence, we cannot suppose that there is any peculiarity about it which does not probably attach to multitudes of other bodies, in fact, to all that are analogous to it in respect of cosmical arrangements.

It therefore becomes a point of great interest-what are the materials of this specimen? What-is the constitutional character of this object, which may be said to be a sample, presented to our immediate observation, of those crowds of worlds which seem to us as the particles of the desert sand-cloud in number, and to whose profusion there are no conceivable local limits?

The solids, liquids, and aeriform fluids of our globe are all, as has been stated, reducible into fifty-five substances hitherto called elementary. Six are gases; oxygen, hydrogen, and nitrogen being the chief. Forty-two are metals, of which eleven are remarkable as composing, in comoination with oxygen, certain earths, as magnesia lime, alumin. The remaining six, including carbon, silicon, sulphur, have not any general appellation.

The gas oxygen is considered as by far the most abundant substance in our globe. It constitutes a fifth part of our atmosphere, a third part of water, and a large proportion of every kind of rock in the crust of the earth. Hydrogen, which forms two-thirds of water, and enters into some mineral substances, is perhaps next. Nitrogen, of which the atmosphere is four-fifths composed, must be considered as an abundant substance. The metal silicium which unites with oxygen in nearly equal parts to form silica, the basis of nearly half of the rocks in the earth's crust, is, of course, an important ingredient. Aluminium the metallic basis of alumin, a large material in many rccks, is another abundant elementary substance. So, also, is carbon, a small ingredient in the atmosphere, but the chief constituent of animal and vegetable substances, and of all fossiis which ever were in the latter condition, 
amongst which coal takes a conspicuous place. The fa. niliarly-known metals, as iron, tin, lead, silver, gold, art elements of comparatively small magnitude in that exterior part of the earth's body which we aie able to investigate.

It is remarkable of the simple substances that they are generally in some compound form. Thus, oxygen and nitrogen, though in union they form the aerial envelope of the globe, are never found separate in nature. Carbon is pure only in the diamond. And the metallic bases of the earths, though the chemist can disengage them, may well be supposed unlikely to remain long uncombined, seeing that contact with moisture makes them burn. Combination and re-combination are principles largely pervading nature. There are few rocks, for example, that are not composed of at least two varieties of matter, each of which is again a compound of elementary substances. What is still more wonderful with respect to this principle of combination, all the elementary substances observe certain mathematical proportions in their unions. One volume of them uniles with one, two, three, or more volumes of another, any extra quantity being sure to be left over, if such there should be. It is hence supposed that matter is camposed of infinitely minute particles or atoms, each of which belonging to any one substance, can only (through the operation of some as yet hidden law) associate with a certain number of the atoms of any other. There are also strange predilections amonst substances for each other's company. One will remain combined in solution with another, till a third is added, when it will abandor the former and attach itself to the latter. A fourth being added, the third will perhaps leave the first and join the new comer.

Such is an outline of the information which chemistry gives us regarding the constituent materials of our globe. How infinitely is the knowledge increased in interest when we consider the probability of such being the materials of the whole of the bodies of space, and the laws under which these everywhere combine, subject only to local and accidental variations.

In considering the cosmogonic arrangements of our globe, our attention is called in a special degree to the moon.

"In the nebular hypothesis, satellites are considereủ dy 
masses thrown off from their primaries, exactly as the primaries had previously been from the sun. The orbit of any satellite is also to be regarded as marking the bounds of the mass of the primary at the time when that satellite was thrown off; its speed likewise denotes the rapidity of the rotatory motion of the primary at that particular juncture. For example, the outermost of the four satellites of Jupiter revolves round his body at the distance of $1,180,582$ miles, showing that the planet was once. $3,675,501$ miles in circumference, instead of being, as now only 89,170 miles in diameter. This large mass took rather more than sixteen days six hours and a half (the present revolutionary period of the outermost satellites) to rotate on its axis. The innermost satellite must have been formed when the planet was reduced to a circumference of 309,075 miles, and rotated in about forty-two hours and a half.

From similar inferences, we find that the mass of the earth, at a certain point of time, after it was thrown off from the sun, was no less than 482,000 miles in diameter, being sixty times what it has since shrunk to. At that time the mass must have taken rather more than twentynine and a half days to rotate, (being the revolutionary period of the moon,) instead of, as now, rather less than twenty-four hours.

The time intervening between the formation of the moon and the earth's diminution to its present size, was probably one of those vast sums in which astronomy deals so largely, but which the mind altogether fails to grasp.

The observations made upon the surface of the moon by telescopes tend strongly to support the hypothesis as to all the bodies of space being composed of similar matters subject to certain variations. It does not appear that our satellite is provided with that gaseous envelope which, on earth, performs so many important functions. Neither, is there any appearance of water upon the surface; yet that surface is, like that of our globe, marked by inequalities and the appearance of volcanic operations. These inequalities and volcanic operations are upon a scale far greater than any which now exist upon the earth's surface. Although, from the greater force of gravitation upon its exterior, the mountains, other circumstances being equal, might have been expected to be much smaller than ours, they are, in many instances, 
equal in height to nearly the highest of our Andes. They are generally of extreme steepness, and sharp of outline, a peculiarity which might be looked for in a planet deficient in water and atmosphere, seeing that these are the agents which wear down ruggedness on the surface of our earth. The volcanic operations are on a stupendous scale. They are the cause of the bright spots of the moon, while the want of them is what distinguishes the duller portions, usually but erroneously called seas. In some parts, bright volcanic matter, besides covering one large patch, radiates eut in long streams, which appear studded with subordinate foci of the same kind of energy. Other objects of a most remarkable character are ring-mountains, mounts like those of the craters of earthly volcanoes, surrounded immediately by vast and profound circular pits, hollowed under the general surface, these again being surrounded by a circular wall of mountain, rising far above the cen- tral one, and in the inside of which are terraces about the same height as the inner eminence. The well-known bright spot in the south-east quarter, called by astronomers, Tycho, and which can be readily distinguished by the naked eye, is one of these ring-mountains. There is one of 200 miles in diameter, with a pit 22,000 feet deep; that is, twice the height of Etna. It is remarkable, that the maps given by Humboldt of a volcanic district in South America, and one illustrative of the formerly volcanic district of Auvergne, in France, present features strikingly like many parts of the moon's surface, as seen through a good glass.

These characteristics of the moon forbid the idea that it can be at present a theatre of life like the earth, and almost seem to declare that it never can become so. But we must not rashly draw any such conclusions. The moon may be only in an earlier stage of the progress through which the earth has already gone. The elements which seem wanting may be only in combinations different in those which exist here, and may yet be deve. loped as we here find them. Seas may yet fill the profound hollows of the surface; an atmosphere may spread over the whole. Should these events take place, meteorological phenornena, and all the phenomena of organic life will commence, and the moon, like the earth, will become a green and inhabited world.

It is unavoidably held as a strong proof in favor of any 
nypothesis, when all the relative phenomena are in har mory with it. This is eminently the case with the nebulous hypothesis, for here the associated facts eannot be explained on any other supposition. We Kave seen reason to conclude that the primary condition of matter was that of a diffused mass, in which the component molecules were probably kept apart through the efficacy of heat: that portions of this agglomerated into suns, which threw off planets; that these planets were at first very much diffused, but gradually contracted by cooling to their present dimensions. Now as to our own globe, there is a remarkable proof of its having been in a fluid state at the time when it was finally solidifying, in the fact of its being bulged at the equator, the very form which a soft revolving body takes, and must inevitably take, under the influence of centrifugal force. This bulging makes the equatorial exceed the polar diameter as 230 to 229 , which has been demonstrated to be precisely the departure from a correct sphere which might be predicted from a knowledge of the amount of the mass and the rate of rotation. There is an almost equally distinct memorial of the original high temperature of the materials, in the store of heat which still exists in the interior. The immediate surface of the earth, be it observed, exhibits only the temperature which might be expected to be imparted to such materials, by the heat of the sun. There is a point very short way down, but varying in different climes, where all effects from the sun's rays ceases. Then, however, commences a temperature from an entirely different cause, one which evidently has its source in the interior of the earth, and which regularly increases as we descend to greater and greater depths, the rate of increment being about one degree Fahrenheit for every sixty feet; and of this high temperature there are other evidences in the phenomena of volcanoes and thermal springs, as well as in what is ascertained with regard to the density of the entire mass of the earth. "This, it will be remembered, is four and a half times the weight of water; but the actual weight of the principal solid substances composing the outer crust is as two and a half times the weight of water; and this, we know, if the globe were solid and cold, should increase vastly towards the centre, water acquiring the density of quir.ksilver at 362 miles below the surface, and other things in proportion, and these densities becoming much 
greater at greater depths; so that the entire mass of a cool globe should be of a gravity infinitely exceeding four and a half times the weight of water. The only alternative supposition is, that the central materials are greatly expanded or diffused by some means; and by what means could they be so expanded but by heat! Indeed, the existence of this central heat, a residuum of that which kept all matter in a vaporiform chaos at first, is amongst the most solid discoveries of modern science, ${ }^{*}$ and the support which it gives to Herschel's explanation of the formation of worlds is most important. We shall hereafter see what appear to be traces of an operation of this heat upon the surface of the earth in very remote times ; an effect, however, which has long passed entirely away. The central heat has, for ages, reached a fixed point, at which it will probably remain for ever, as the non-conducting quality of the cool crust absolutely prerents it from suffering any diminution.

\section{THE EARTH FORMED-ERA OF THE PRIMARY ROCKS.}

Althougr the earth has not been actually penetrated to a greater depth than three thousand feet, the nature of its substance can, in many instances, be inferred for the depth of many miles by other means of observation. We see a mountain composed of a particular substance, with strata, or beds of other rock, lying against its sloped sides: we, of course, infer that the substance of the mountain dips away under the strata which we see lying against it. Suppose that we walk away from the mountain across the turned up edges of the stratified rocks, and that for many miles we continue to pass over other stratified rocks, all disposed in the same way, till by and bye we come to a place where we begin to cross the opposite edges of the same beds; after which we pass over these rocks all in reverse order, till we come to another extensive mountain composed of similar material to the first, and shelving away under the strata in the same way. We should then infer, that the stratified rocks occupied a ba-

* The researches on this subject were conducted chiefly by the tate Baron Fourier, perpetual secretary to the Academy of Sciences of Paris See his Theorie Anulytique de la Chaleur, 18.22. 
sin formed by the rock of these two mountains, arid by calculating the thickness right through these strata, could be able to say to what depth the rock of the mountain extended below. By such means, the kind of rock existing many miles below the surface can often be inferred with considerable confidence.

The interior of the globe has now been inspected in this way in many places, and a tolerably distinct notion of its general arrangements has consequently been arrived at. It appears that the basis rock of the earth, as it may be called, is of hard texture, and crystalline in its constitution. Of this rock granite may be said to be the type, though it runs into many varieties. Over this, except in the comparitively few places where it projects above the general level in mountains, other rocks are disposed in sheets or strata, with the appearance of having been deposited originally from water; but these last rocks have nowhere been allowed to rest in their original arrangement. Uneasy movements from below have broken them up in great inclined masses, while in many cases there has been projected through the rents rocky matter more or less resembling the great inferior crystalline mass. This rocky matter must have been in a state of fusion at the time of its projection, for it is often found to have run into and filled up lateral chinks in these rents. There are even instances where it has been rent again, and a newer melled matter of the same character sent through the opening. Finally, in the crust as thus arranged there are, in many places, chinks containing veins of metal. Thus, there is first a great inferior mass, composed of crystalline rock, and probably resting immediately on the fused and expanded matter of the interior: next, layer or strata of aqueous origin; next, irregular masses of melted inferior rock that have been sent up volcanically and confusedly at various times amongst the aqueous rocks, breaking up these into masses, and tossing them out of their original levels. This is an outline of the arrangements of the crust of the earth, as far as we can observe it. It is, at first sight, a most confused scene; but after some careful observation, we readily detect in it a regularity and order from which much instruction in the history of our globe is to be derived.

The deposition of the aqueous rocks, and the projection of the volcanic, have unquestionably taken place since the 
settiement of the earth in its present form. They are in deed of an order of events which we see going on, under the agency of more or less intelligible causes, even down to the present day. We may therefore consider them generally as comparatively recent transactions. Abstracting them from the investigations before us, we arrive at the Idea of the earth in its first condition as a globe of its present size-namely, as a mass, externally at least, consist. ing of the crystalline kind of rock, with the waters of the present seas and the present atmosphere around it, though these were probably in considerably different conditions, both as to temperature and their constituent materials from what they now are. We are thus to presume that that crystalline texture of rock which we see exemplified in granite is the condition into which the great bulk of the solids of our earth were agglomerated directly from the nebulous or vaporiform state. It is a condition eminently of combination, for such rock is invariably composed of two or more of four substances-silica, mica, quartz and hornblende-which associate in it in the form of grains or crystals, and which are themselves each composed of a group of the simple or elementary substances.

Judging from the results and from still remaining con. ditions, we must suppose that the heat retained in the interior of the globe was more intense, or had greater freedom to act in some places than in others. These became the scenes of volcanic operations, and in time marked their situations by the extrusion of traps and basalts from below-namely, rocks composed of the crystalline matter rused by intense heat, and developed on the surface in various conditions, according to the partiular circumstan. ces under which it was sent up ; some, for example, being thrown up under water, and some in the open air, which conditions are found to have made considerable difference in its texture and appearance. The great stores of subterranean heat also served an important purpose in the formation of the aqueous rocks. These rocks might, according to Sir John Herschel, become subject to heat in the following manner;-While the surface of a particular mass of rock forms the bed of the sea, the heat is kept at a certain distance from that surface by the contact of the water ; philosophically speaking, it radiates away the heat into the sea, and (to resort to common language) is cooled a good way down. But when new sediment set. 
tles at the bottom of that sea, the heat rises up to what was formerly the surface; and when a second quantity of sediment is laid down, it continues to rise through the first of the deposits, which then becomes subjected to those changes which heat is calculated to produce. This process is precisely the same as that of putting additional coats upon our own bodies; when, of course, the internal heat rises through each coat in succession, and the third (supposing there is a fourth above it) becomes as warm as perhaps the first originally was.

In speaking of sedimentary rocks, we may be said to be anticipating. It is necessary, first, to show how such rocks were formed, or how stratification commenced.

Geology tells us as plainly as possible that the original crystalline mass was not a perfectly smooth ball, with air and water playing round it. There were vast irregularities in the surface-irregularities trifling, perhaps, compared with the whole bulk of the globe, but assuredly vast in comparison with any which now exist upon it. These irregularities might be occasioned by inequalities in the cooling of the substance, or by accidental and local sluggishness of the materials, or by local effects of the concentrated internal heat. From whatever cause they arose, there they were, enormous granitic mountains, intespersed with seas which sunk to a depth equally profound, and by which, perhaps, the mountains were wholly or partially covered. Now, it is a fact of which the very first principles of geology assure us, that the solids of the globe cannot for a moment be exposed to water, or to the atmosphere, without becoming liable to change. They instantly begin to wear down. This operation, we may be assured, proceeded with as much certainty in the earliest ages of our earth's history, as it does now, but upon a much more magnificent scale. There is the clearest evidence that the seas of those days were not in some instances less than a hundred miles in depth, however much more. The subaqueous mountains must necessarily have been of at least equal magnitude. The system of disintegration consequent upon such conditions would be enormous. The matters worn off, being carried into the neighboring depths, and there deposited, became the components of the earliest stratified rocks, the first series of which is the Gneiss and Mica Slate System, or series, examples of wnich are exposed to view in the Highlands of Scotland and in the 
West of England. The vast thickness of these beds, in some instances, is what attests the profoundness of the primeval oceans in which they were formed; the Pennsylvanian grawacke, a member of the next highest series, is not less than a hundred miles in direct thickness. We have also evidence that the earliest strata were formed in the presence of a stronger degree of heat than what operated in subsequent stages of the world, for the laminæ of the gneiss and of the mica and chlorite scists are contorted in a way which could only be the result of a very high temperature. It appears as if the seas in which these deposits were formed, had been in the troubled state of a caldron of water nearly at boiling heat. Such a condition would probably add not a little to the disintegrating power of the ocean.

The earliest stratified rocks contain no matters which are not to be found in the primitive granite. They are the same in material, but only changed into new forms and combinations; hence they have been called by Mr. Lyell, metamorphic rocks. But how comes it that some of them are composed almost exclusively of one of the materials of granite; the mica schists, for example, of mica-the quartz rocks, of quartz, \&c. ? For this there are both chemical and mechanical causes. Suppose that a river has a certain quantity of material to carry down, it is evident that it will soonest drop the larger particles, and carry the lightest farthest on. To such a cause it is owing that some of the materials of the worn-down granite have settled in one place and some in another. ${ }^{*}$ Again, some of these materials must be presumed to have been in a state of chemical solution in the primeval seas. It would be, of course, in conformity with chemical laws, that certain of these materials would be precipitated singly, or in modified combinations, to the bottom, so as to form rocks by themselves.

The rocks hitherto spoken of contain none of those petrified remains of vegetables and animals which abound so much in subsequently formed incks, and tell so wondrous a tale of the past history of our globe. They simply contain, as has been said, mineral materials derived from the primitive mass, and which appear to have been formed into strata in seas of vast depth. The absence from these rocks of all traces of vegetable and animal life, * Delabeche's Geological Researches. 
joined to a consideration of the excessive temperature which seems to have prevailed in their epoch, has led to the inference that no plants or animals of any kind then existed. A few geologists have indeed endeavored to show that the absence of organic remains is no proof of the globe having been then unfruitful or uninhabited, as the heat to which these rocks have been subjected at the time of their solidification, might have obliterated any remains of either plants or animals which were included in them. But this is only an hypothesis of negation; and it certainly seems very unlikely that a degree of heat sufficient to obliterate the remains of plants or animals when dead, would ever allow of their coming into or continuing in existence.

\section{COMMENC EMENT OF ORGANIC LIFE-SEA PLANTS, CORALS, ETC.}

WE can scarcely be said to have passed out of these rocks, when we begin to find new conditions in the earth. It is here to be observed that the subsequent rocks are formed, in a great measure, of matters derived from the substance of those which went be "ore, but contain also beds of limestone, which is to no s tall extent composed of an ingredient which has not hith sto appeared. Lime stone is a carbonate of lime, a se ondary compound of which one of the ingredients, carbonic acid gas, presents the element carbon, a perfect novelty in our progress. Whence this substance? The question is the more interesting, from our knowing that carbon is the main ingredient in organic things. There is reason to believe that its primeval condition was that of a gas, confined in the interior of the earth, and diffused in the atmosphere. The atmosphere still contains about a two-thousandth part of carbonic acid gas, forming the grand store from which the substance of each year's crop of herbage and grain is derived, passing from herbage and grain into animal sub stance, and from animals again rendered back to the atmosphere in their expired breath, so that its amount is never impaired. Knowing this, when we hear of carbon beginning to appear in the ascending series of rocks, we are unavoidably led to consider it as marking a time of some importance in the earth's history, a new era of natural 
conditions, one in which organic life has probably played a part.

It is not easy to suppose that, at inis period, carbon was adopted directly in its gaseous form into rocks ; for, if so, why should it not have been taken into earlier ones also? But we know that plants take it in, and transform it into substance; and we also know that there are classes of animals (marine polypes) which are capable of appropriating it, in connection with lime (carbonate of lime) from the waters of the ocean, provided it be there in solution ; and this substance do these animals deposit in masses (coral reefs) equal in extent to many strata. It has even been suggested, on strong grounds of probability, that a class of limestone beds are simply these reefs subjected to subsequent heat and pressure.

The appearance, then, of limestone beds in the early part of the stratified series, may be presumed to be connected with the fact of the commencement of organic life upon our planet, and, indeed, a consequent and a symptom of it.

It may not be out of place here to remark, that carbon is presumed to exist largely in the interior of the earth, from the fact of such considerable quantities of it issuing at this day, in the form of carbonic acid gas, from fissures and springs. The primeval and subsequent history of this element is worthy of much attention, and we shall have to revert to it as a matter greatly concerning our subject Delabeche estimates the quantity of carbonic acid gas locked up in every cubic yard of limestone, at 16,000 cubic feet. The quantity locked up in coal, in which it forms from 64 to 75 per cent., must also be enormous. If all this were disengaged in a gaseus form, the constitution of the atmosphere would undergo a change, of which the first effect would be the extinction of life in all land animals. But a large proportion of it must have at one time been in the atmosphere. The atmosphere would then, of course, be incapable of supporting life in land animals. It is important, however, to observe that such an atmosphere would not be inconsistent with a luxuriant, land vegetation; for experiment has proved that plants will flourish in air containing one-twelfth of this gas, or 166 times more than the present charge of our atmosphere. The results which we observe are perfectly consistent with, and may be said to presuppose an atmosphere highly charged with this gas, from about the close of the prima- 
ry non-fossiliferous rocks to the termination of the carboniferous series, for there we see vast deposits (coal) containing carbon as a large ingredient, while at the same time the leaves of the Stone Book present no record of the contemporaneous existence of land animals.

The hypothesis of the connection of the first limestone beds with the commencement of organic life upon our planet is supported by the fact, that in these beds we find the first remains of the bodies of animated creatures. My hypothesis may indeed be unsound; but, whether or not, it is clear, taking organic remains as upon the whole a faithful chronicle, that the deposition of these limestone beds was coeval with the existence of the earliest, or all but the earliest, living creatures upon earth.

And what were those creatures? It might well be with a kind of awe that the uninstructed inquirer would wait for an answer to this question. But nature is simpler than man's wit would make her, and behold, the interrogation only brings before us the unpretending forms of various zoophytes and polypes, together with a few single and double-valved shell-fish, (mollusks,) all of them creatures of the sea. It is rather surprising to find these before any vegetable forms, considering that vègetables appear to us as forming the necessary first link in the chain of nutrition; but it is probable that there were sea plants, and also some simpler forms of animal life, before this period, although of too slight a substance to leave any fossil trace of their existence.

The exact point in the ascending stratified series at which the first traces of organic life are to be found is not clearly determined. Dr. M'Culloch states that he found fossil orthocerata (a kind of shell-fish) so early as the gneiss tract of Loch Eribol, in Sutherland; but Messrs. Sedgwick and Murchison, on a subsequent search, could not verify the discovery. It has also been stated, that the gneiss and mica tract of Bohemia contains some seams of grawacke, in which are organic remains; but British geologists have not as yet attached much importance to this statement. We have to look a little higher in the series for indubitable traces of organic life.

Above the gneiss and mica slate system, or group of strata, is the Clay Slate and Grawacke Slate System; that is to say, it is higher in the order of supraposition, though very often it rests immediately on the primitive 
granite The sub-groups of this system are is the following succession upwards :- 1 , hornblende slate; 2 , chiastolite slate; 3 , clay slate; 4, Snowdon rocks (grawacke and conglomerates); 5, Bala limestone; 6, Plynlymmon rocks, (grawacke and grawacke slates, with beds of conglomerates.) This system is largely developed in the west and north of England, and it has been well examined, partly because some of the slate beds are extensively quarried for domestic purposes. If we overlook the dubious statements respecting Sutherland and Bohemia, we have in this "system" the first appearances of life upon our planet. The animal remains are chiefly confined to the slate beds, those named from Bala, in Wales, being the most prolific. Zoophyta, polyparia, crinoidea, conchifera, and crustacea, ${ }^{*}$ are the orders of the animal kingdom thus found in the earliest of earth's sepulchres. The orders are distinguished without difficulty, from the general characters of the creatures whose remains are found; but it is only in this general character that they bear a general resemblance to any creatures now existing. When we come to consider specific characters, we see that a difference exists-that, in short, the species and even genera are no longer represented upon earth. More than this it will be found that the earliest species comparatively soon gave place to others, and that they are not represented even in the next higher group of rocks. One important remark has been made, that a comparatively small variety of species is found in the older rocks, although of some particular ones the remains are very abundant; as, for instance, of a species of asaphus, which is found between the laminæ of some of the slate rocks of Wales, and the corresponding rocks of Normandy and Germany, in enor. mous quantities.

Ascending to the next group of rocks, we find the traces of life become more abundant, the number of species extended, and important additions made in certain vestiges of fuci, or sea plants, and of fishes. This group of rocks has been called by English geologists, the Silurian

"In the Cumbrian limestone occur "calamoporæ, lithodendra, cyathophylla, and orbicula."-Philips. The asaphus and trinucleus (crustacea) have been found respectively in the slate rocks of Wales, and the limestone beds of the grawacke group in Bohemia That fragments of crinoidea, though of no determinate species oc cur in this system, we have the authority of Mr. Murchison.Silurian System, p. 710 
System, because largely developed at the surface of a district of western England, formerly occupied by a people whom the Roman historians called Silures. It is a series of sandstones, limestones, and beds of shale, (hardened mud,) which are classed in the following sub-groups, beginning with the undermost : -1 , Llandillo rocks (darkish calcareous flagstones;) 2 and 3 , two groups called $\mathrm{Ca}$ radoc rocks ; 4, Wenlock shale ; 5 , Wenlock limestone; 6, Lower Ludlow rocks (shales and limestones;) 7, Aymestry limestone; 8, Upper Ludlow rocks (shales and limestone, chiefly micaceous.) From the lowest beds upwards, there are polypiaria, though most prevalent in the Wenlock limestone; conchifera, a vast number of genera, but all of the order brachipoda (including terebratula, pentamerus, spirifer, or this, leptæna ;) mollusca, of several orders and many genera (including turritella, orthoceras, nautilus, bellerophon ;) crustacea, all of them trilobites (including trinucleus, asaphus, calamene.) A little above the Llandillo rocks, there have been discovered certain convo!'ted forms, which are now established as annelids, or sea-wo. $n s$, a tribe of creatures still existing (nereidna and serpulina,) and which may often be found beneath stones on a sea-beach. One of these, figured by $\mathrm{Mr}$. Murchison, is furnished with feet in vast numbers all along its body, like a centipede. The occurrence of annelids is important, on account of their character and status in the animal kingdom. They are red-blooded and hermaphrodite, and form a link of connexion between the anrulosa (white-blooded worms) and a humble class of the vertebrata. * The Wenlock limestone is most remarkable amongst all the rocks of the Silurian system, for organic remains. Many slabs of it are wholly composed of corals, shells, and trilobites, held together by shale. It contains many genera of crinoidea and polypiaria, and it is thought that some beds of it are wholly the production of the latter creatures, or are, in other words, coral reefs transformed by heat and pressure into rocks. Remains of fishes, of a very minute size, have been detected by $\mathrm{Mr}$. Philips in the Aymestry limestone, being apparently the first examples of vertebrated animals which breathed upon our planet. In the upper Ludlow rocks, remains of six genera of fish have been for a longer period known; they belong to the order of cartilaginous fishes, an order of

* Such as amphioxus and myxene. 
mean organization and ferocious habits, of which the st:ark and sturgeon are living specimens. "Some were furnished with long palates, and squat, firmly-based teeth, well adapted for crushing the strong cased zoophytes and shells of the period, fragments of which occur in the fuecal remains; some with teeth that, like the fossil sharks of the latter formations, resemble lines of miniature pyramids, larger and smaller alternating; some with teeth sharp, thin, and so deeply serrated, that every individual tooth resembles a row of poniards set up against the walls of an armory; and these last says Agassiz, furnished with weapons so murderous, must have been the pirates of the period. Some had their fins guarded with long spines, hooked like the beak of an eagle; some with spines of straiter and more slender form, and ribbed and furrowed longitudinally like columns; some were shielded by an armor of bony points, and some thickly covered with glistening scales."*

The traces of fuci in this system are all but sufficient to allow of a distinction of genera. In some parts of North A merica, extensive though thin beds of them have been found. A distinguished Frmen geologist, M. Brogniart, has shown that all existing marine plants are classifiable with regard to the zones of climate; some being fitted to the torrid zone, some for the temperate, some for the frigid. And he establishes that the fuci of these early rocks speak of a torrid climate, although they may be found in what are now temperate regions; he also states that those of the higher rocks betoken, as we ascend, a gradually diminishing temperature.

We thus early begin to find proofs of the general uniformity of organic life over the surface of the earth, at the time when each particular system of rocks was formed. Species identical with the remains in the Wenlock limestone occur in the corresponding class of rocks in the Eifel, and partially in the Harz, Norway, Russia, and Brittany. The situations of the remains in Russia are fifteen hundred miles from the Wenlock beds ; but at the distance of between six and seven thousand from thosenamely, in the vale of Mississippi, the same species are discovered. Uniformity in animal life over large geographical areas, argues uniformity in the conditions of animal life; and hence arise some curious inferences. Speries, in the same low class of animals are now much more * Miller's "New Walks in an Old Field." 
linited; for instance, the Red Sea gives different polypiaria, zoophytes, and shell-fish, from the Mediterranean. It is the opinion of $\mathrm{M}$. Brogniart, that the uniformity which existed in the primeval times can only be attribu. ted to the temperature arising from the internal heat, which had yet as he supposes, been sufficiently great to overpower the ordinary meteorological influences, and spread a tropical clime all over the globe.

\section{ERA OF THE OLD RED SANDSTONE- FISHES ABUNDANT.}

WE advance to a new chapter in this marvellous history - the era of the Old Red Sandstone System. This term has been recently applied to a series of strata of enormous thickness in the whole mass, largely developed in Herefordshire, Shropshire, Worcestershire, and South Wales; also in the counties of Fife, Forfar, Moray, Cromarty. and Caithness; and in Russia and North America, if not in many other parts of the world. The particular strata forming the system are somewhat different in different countries ; but there is a general character to the extent of these being a mixture of flagstones, marly rocks, and sandstones, usually of a laminous structure, with conglomerates. There is also a schist showing the presence of bitumen ; a remarkable new ingredient, since it is a vegetable production. In the conglomerates, of great extent and thickness, which form, in at least one district the basis or leading feature of the system, inclosing waterworn fragments of quartz and other rocks, we have evidence of the seas of that period having been subjected to a violent and long-continued agitation, probably from volcanic causes. The upper members of the series bear the appearance of having been deposited in comparatively tranquil seas. The English specimens of this system show a remarkable freedom from those disturbances which result in the interjection of trap; and they are thus defective in mineral ores. In some parts of England the oldred sandstone system has been stated at 10,000 feet in thickness.

In this era, the forms of life which existed in the Silurian are continued: we have the same orders of marine 
creatures, zoophyta, polypiaria, conchifera, crustacea ; but to these are added numerous fishes, some of which are of the most extraordinary and surprising forms. Several of the strata are crowded with remains of fish, showing that the seas in which those beds were deposited had swarmed with that class of inhabitants. The investigation of this system is recent ; but already* M. Agassiz has acertained about twenty genera, and thrice the number of species. And it is remarkable, that the Silurian fishes are here only represented in genera; the whole of the species of that era had already passed away. Even throughout the subgroups of the system itself, the species are changed; and these are phenomena observed throughout all the subsequent systems of geological eras; apparently arguing that, during the deposition of all the rocks, a gradual change of physical conditions was constantly going on. A varying temperature, or even a varying depth of sea, would at present be attended with similar changes in marine life; and by analogy, we are entitled to assume, that such variations in the ancient seas might be amongst the causes of that constant change of genera and species in the inahabitants of those seas, to which the organic contents of the rocks bear witness.

Some of the fossils of this system-the cephalaspis, coccosteus, pterichthys, holoptychius-are, in form and structure, entirely different from any fishes now existing, only the sturgeon family having any trace of affinity to them in any respect. They seem to form a sort of connecting link between the crustacea and true fishes.

The cephalaspis may be considered as making the smallest advance from the crustacean character ; it very much resembles in form the asaphus of lower formations, having a longish tail-like body inserted within the cusp of a large crescent-shaped head, somewhat like a saddler's cuttingknife. The body is covered with strong plates of bone, enamelled, and the head was protected on the upper side with one large plate, as with a buckler-hence the name, implying buckler-head. A range of small fins conveys the idea of its having been as weak in motion as it is strong in structure. The coccosteus may be said to marir the next advance to fish creation. 'The outline of its body is of the form of a short thick coffin, rounded covered with strong bony plates, and terminating in a long tail * June, 1842. 
which seems to have been the sole organ of motion It is very remarkable, that, while the tail establishes this creature among the vertebrata and the fishes, its mouth has been opened vertically, like those of the crustaceans, but which is contrary to the mode of vertebrata generally. This seems a pretty strong mark of the link character of the coccosteus between these two great departments of the animal kingdom. The pterichthys has also strong bony plates over its body, arranged much like those of a tortoise, and has a long tail ; but its most remarkable feature, and that which has suggested its name, is a pair of long and narrow-wing like appendages attached to the shoulders, which the creature is supposed to have erected for its defence when attacked by an enemy.

The holoptychius is of a flat oval form, furnished with fins, and ending in a long tail ; the whole body covered with strong plates, which overlap each other, and the head forming only a slight rounded projection from the general figure. The specimens in the lower beds are not above the size of a flounder; but in the higher strata, to judge by the size of the scales or plates which have been found, the creature attained a comparatively monstrous size.

The other fishes of the system-the osteolepis, glyptolepis, dipterus, \&c., are, in general outline, much like fishes still existing, but their organization has, nevertheless, some striking peculiarities. They have been entirely covered with bony scales or plates, enamelled externally; their spines are tipped with bone, and, as one striking and unvarying feature, the tail is only finned on the lower side. The internal skeleton, of which no traces have been preserved, is presumed to have been cartilaginous. They therefore unite the character of cartilaginous fishes with a character peculiar to themselves, and in which we see pretty clear vestiges of the pre-existent crustaceous form.

With regard to the link character of these animals, some curious facts are mentioned. It appears that in the imperfect condition of the vertebral column, and the inferior situation of the mouth in the pterichthys, coccosteus, \&cc., there is an analogy to the form of the dorsal cord and position of the muuth in the embryo of perfect fishes. The one-sided form of the tail in the osteolepis, \&c., finds i similar analogy in the form of the tail, in the embryo of 
the salmon. It is not premature to remark, how broadly these facts seem to hint at a parity of law affecting the progress of an individual fœtus of one of the more perfect animals.

It is equally ascertained of the types of being prevalent in the old red, as of those of the preceding system, that they are uniform in the corresponding strata of distant parts of the earth; for instance, Russia and North America.

In the old red sandstone, the marine plants, of which faint traces are observable in the Silurians, continue to appear. It would seem as if less change took place in the vegetation than in the animals of those early seas; and for this, as Mr. Miller has remarked, it is easy to imagine reasons. For example, an infusion of lime into the sea would destroy animal life, but be favorable to vegetation.

As yet there were no land animals or plants, and for this the presumable reason is, that no dry land as yet existed. We are not left to make this inference solely from the absence of land animals and plants ; in the ar. rangement of the primary (stratified) rocks, we have further evidence of it. That these rocks were formed in a generally horizontal position, we are as well assured as that they were formed at the bottom of seas. But they are always found greatly inclined in position, tilted up against the slopes of the granitic masses which are beneath them in geological order, though often shooting up to a higher point in the atmosphere. No doubt can be entertained that these granitic masses, forming our prin. cipal mountain ranges, have been protruded from below, or, at least, thrust much further up, since the deposition, of the primary rocks. The protrusion was what tilted up the primary rocks ; and the inference is, of course, unavoidable, that these mountains have risen chiefly, at least, since the primary rocks were laid down. It is remarkable that, while the primary rocks thus incline towards granitic nuclei or axes, the strata higher in the series rest against these again, generally at a less inclination or none at all, showing that these strata were laid down after the swelling mountain eminences had, by their protrusion, tilted up the primary strata. And thus it may be said an era of local upthrowing of the primitive and (perha:ps) central matter of our planet, is established as happen ing ebout the close of the primary strata, and beginning of 
the next ensuing system. It may be called the Era of the Oldest Mountains, or more boldly, of the formation of the detached portions of dry land over the hitherto wa. tery surface of the globe-an important part of the designg of Providence, for which the time was now apparently come. It may be remarked, that volcanic disturbanceg and protrusions of trap took place throughout the whole period of the deposition of the primary rocks; but they were upon a comparatively limited scale, and probably all took place under water. It was only now that the central granitic masses of the great mountain ranges were thrown up, carrying up with them broken edges of the primary strata; a process which seems to have had this difference from the other, that it was the effect of a more tremendous force exerted at a lower depth in the earth, and generally acting in lines pervading a considerable portion of the earth's surface. We shall by-and-by see that the protrusion of some of the mountain ranges was not completed, or did not stop at that period. There is no part of geological science more clear than that which refers to the ages of mountains. It is as certain that the Grampian mountains of Scotland are older than the Alps and the Appenines, as it is that civilization had visited Italy and had enabled her to subdue the world, while Scotland was the residence of "roving barbarians." The Pyrenees, Carpathians, and other ranges of continenta] Europe, are all younger than the Grampians, or even the insignificant Mendip Hills of southern England. Stratification tells this tale as plainly as Livy tells the history of the Roman republic. It tells us-to use the words of Professor Philips-that at the time when the Grampians sent streams and detritus to straits where now the Forth and Clyde meet, the greater part of Europe was a wide ocean.

The last three systems-called, in England, the Cumbrian, Silurian, and Devorian, and collectively the palæozoic rocks, from their containing the remains of the earliest inhabitants of the globe-are of vast thickness; in England rot much less than 30,000 feet, or nearly six miles. In other parts of the world, as we have seen, the earliest of these systems alone is of much greater deptharguing an enormous profundity in the ocean in which they were formed. 


\section{SECONDARY ROCKS.-ERA OF THE, CARBO. NIFEROUS FORMATION.}

\section{LAND FORMED,-COMMENCEMENT OF LAND PLANTS}

WE now enter upon a new great epoch in the history of our globe. There was now dry land. As a consequence of this fact, there was fresh water, for rain, instead of immediately returning to the sea, as formerly, was now gathered in channels of the earth, and became springs, rivers, and lakes. There was now a theatre for the existence of land plants and animals, and it remains to be inquired if these accordingly were produced.

The Secondary Rocks, in which our further researches are to be prosecuted, consist of a great and varied series, resting, generally unconformably, against flanks of the upturned primary rocks, sometimes themselves considerably inclined, at others, forming extensive basin-like beds, nearly horizontal; in many places much broken up and shifted by disturbances from below. They have all been formed out of the materials of the older rocks, by virtue of the wearing power of air and water, which is still every day carrying down vast quantities of the elevated matter of the globe into the sea. But the separate strata are each much more distinct in the matter of its composition than might be expected. Some are silicious, or arenaceous (sandstone,) composed mainly of fine grains from the quartz rocks - the most abundant of the primary strata. Others are argillaceous-clays, shales, \&c., chiefly derived, probably, from the slate beds of the primary series. Others are calcareous, derived from the early limestone. As a general feature, they are softer and less crystalline than the primary rocks, as if they had endured less of both heat and pressure than the senior formation. 'There are beds (coal) formed solely of vegetable matter, and some others in which the main ingredient is particles of tron (the iron black band.) The secondary rocks are quite as communicative with regard to their portions of the earth's history as the primitive were.

The first, or lowest group of the secondary rocks, is called the Carboniferous Formation, from the remarkable feature of its numerous interspersed beds of coal It commences with the beds of the mountain limestone, 
which, in some situations, as in Derbyshire and Ireland, are of great thickness, being alternated with chert, (a siliceous sandstone,) sandstones, shales, and beds of coal, generally of the harder and less bituminous kind, (anthracite, the whole being covered in some places by the millstone grit, a siliceous conglomerate composed of the detritus of the primary rocks. The mountain limestone, attaining in England to a depth of eight hundred yards, greatly exceeds in volume any of the primary limestonebeds, and shows an enormous addition of power to the cause formerly suggested as having produced this substance. In fact, remains of corals, crinoidea, and shells, are so abundant in it, as to compose three fourths of the mass in some parts. Above the mountain limestone commence the more conspicuous coal beds, alternating with sandstones, shales, beds of limestone, and ironstone. Coal is altogether composed of the matter of a terrestrial vegetation, transmuted by pressure. Some fresh-water shells have been found in it, but few of marine origin, and no remains of those zoophytes and crinoidea so abundant in the mountain limestone and other rocks. Coal beds exist in Europe, Asia, and America, and have hitherto been esteemed as the most valuable of mineral productions, from the important services which the substance renders in manufactures and in domestic economy. It is to be remarked, that there are some local variations in the arrangement of coal beds. In France, they rest immediately on the granite and other primary rocks, the intermediate strata not having been found at those places. In America, the kind called anthracite occurs among the slate-beds, and this species also abounds more in the mountain limestone than with us. These ?ast circumstances only show that different parts of the earth's surface did not all witness the same events of a certain fixed series exactly at the same time. There had been an exhibition of dry land about the site of America, a little earlier than in Europe.

Some features of the condition of the earth during the deposition of the carboniferous group, are made out with a clearness which must satisfy most minds. First, we are told of a time when carbonate of lime was formed in vast abundance at the bottoms of profound seas, accompanied by an unusually large population of corals and encrinites; while in some parts of the earth there were patches of dry land, covered with a luxuriant vegetation. Next, we 
have a comparatively brief period of volcanic disturbaice (when the conglomerate was formed.) Then the causes favorable to the so abundant production of limestone, and the large population of marine acrita, decline, and we find the masses of dry land increase in number and extent, and begin to bear an amount of forest vegetation, far exceeding that of the most sheltered tropical spots of the present surface. The climate, even in the latitude of Baffin's Bay, was torrid, and perhaps the atmosphere contained a larger charge of carbonic acid gas (the material of vegetation) than it now does. The forests or thickets of the period, included no species of plants now known upon earth. They mainly consisted of gigantic shrubs, which are either not represented by any existing types, or are akin to kinds which are now only found in small and lowly forms. That these forests grew upon a Polynesia, or multitude of small islands, is considered probable, from similar vegetation being now found in such situations within the tropics. With regard to the circumstances under which the masses of vegetable matter were transformed into successive coal strata, geologists are divided. From examples seen at the present day, at the mouths of such rivers as the Mississippi, which traverse extensive sylvan regions, and from other circumstances to be adverted to, it is held likely by some that the vegetable matter, the rubbish of decayed forests, was carried by rivers into estuaries, and there accumulated in vast natural rafts, until it sunk to the bottom where an overlayer of sand or mud would prepare it for becoming a stratum of coal. Others conceive that the vegetation first went into the condition of a peat-moss, that a sink in the level then exposed it to be overrun by the sea, and covered with a layer of sand or mud; that a subsequent uprise made the mud dry land, and fitted it to bear a new forest, which afterwards, like its predecessor, became a bed of peat; that, in short, by repetitions of this process, the alternate layers of coal, sandstone, and shale, constituting the carboniferous group, were formed. It is favorable to this last view that marine fossils are scarcely found in the body of the coal itself, though abundant in the shale layers above and below it; also that in several places erect stems of trees are found with their roots still fixed in the shale beds, and crossing the sandstone beds at almost right angles, showing that these, at least, had not been drifted from their uri rinal situations 
On the other hand, it is not easy to admit such repeated risings and sinkings of surface as would be required, on this hypothesis, to form a series of coal strata. Perhaps we may most safely rest at present with the supposition that coal has been formed under both classes of circumstances, though in the latter only as an exception to the former.

Upwards of three hundred species of plants have been ascertained to exist in the coal formation; but it is not necessary to suppose that the whole contained in that system are now, or will be, distinguished. Experiments show that some great classes of plants beoome decomposed in water in a much less space of time than others, and it is remarkable that those which decompose soonest, are of the classes found most rare, or not at all, in the coal strata. It is consequently to be inferred that there may have been grasses and mosses at this era, and many species of trees, the remains of which had lost all trace of organic form before their substance sunk into the mass of which coal was found. In speaking, therefore of the vegetation of this period, we must bear in mind that itmay have comprehended forms of which we have no memorial

Supposing, nevertheless, that, in the main, the ascertained vegetation of the coal system is that which grew at the time of its formation, it is interesting to find that the terrestrial botany of our globe begins with classes of comparatively simple forms and structure. In the ranks of the vegetable kingdom, the lowest place is taken by plants of cellular tissue, and which have no flowers, (cryptogamia,) as lichens, mosses, fungi, ferns, sea-weeds. Above these stand plants of vascular tissue, and bearing llowers, in which again there are two great subdivisions; first, plants having one seed-lobe (monocotyledons,) and in which the new matter is added within (endogenous,) of which the cane and palm are examples; second plants having two seed-lobes (dycotyledons,) and in which the new matter is added on the outside under the bark, (exogenous, ) of which the pine, elm, oak, and most of the British forest-trees are examples; these subdivisions also ranking in the order in which they are here stated. Now it is clear that a predominance of these forms in succession marked the successive epochs developed by fossil geology; the simple abounding first, and the complex afterwards.

Two-thirds of the plants of the carboniferous era are 
of the cellular or cryptogamic kind, a proportion which would probably be much increased if we knew the whole Flora of that era. The ascertained dicotyledons, or higher-class plants, are comparatively few in this formation; but it will be found that they constantly increased as the globe grew older.

The master-form or type of the era was the fern, or breckan, of which about one hundred and thirty species have already been ascertained as entering into the com position of coal.* The fern is a plant which thrives best in warm, shaded, and moist situations. In tropical countries, where these conditions abound, there are many more species than in temperate climes, and some of these are arborescent, or of a tree-like size and luxuriance.t The ferns of the coal strata have been of this magnitude, and that without regard to the parts of the earth where they are found. In the coal of Baffin's Bay, of Newcastle, and of the torrid zone alike, are the fossil ferns arborescent, showing clearly that, in that era, the present tropical temperature, or one even higher, existed in very high !atitudes

In the swamps and ditches of England there grows a plant called the horse-tail, (equisetum,) having a succulent, erect, jointed stem, with slender leaves, and a scaly catkin at the top. A second large section of the plants of the carboniferous era were of this kind, (equisetacece, but, like the fern, reaching the magnitudes of trees. While existing equiseta rarely exceed three feet in height, and the stems are generally under half an inch in diarneter, their kindred, entombed in the coal beds, seem to have been generally fourteen or fifteen feet high, with stems from six inches to a foot in thickness. Arborescent plants of this family, like the arborescent ferns, now grow only in tropical countries, and there being found in the coal beds in all latitudes is consequently held as an additional proof, that at this era a warm climate was extended much farther to the north than at present. It is to be remarked that plants of this kind (forming two genera, the most abundant of which is the calamites) are only represented on the present surface by plants of the same family:

* The nrincipal families are named spenopteris neuropteris and pecopteris.

$t$ A specimen from Bengal, in the staircase of the British Muse um; is forty-five feet high. 
the species which flourished at this era gradually lessen in number as we advance upwards in the series of rocks, and disappear before we arrive at the tertiary formation.

The club-moss family $\left(l_{\mathrm{s}}\right.$ copodiace $)$ are other plants of the present surface, usuálly seen in a lowly and creeping form in temperate latitudes, but presenting species which rise to a greater magnitude within the tropics. Many specimens of this family are found in the coal beds; it is thought they have contributed more to the substance of the coal than any other family. But, like the ferns and equisetaceæ, they rise to a prodigious magnitude. The iepidodendra (so the fossil genus is called) have probably been from sixty-five to eighty feet in height, having at their base a diameter of about three feet, while their leaves measured twenty inches in length. In the forests of the coal era, the lepidodendra would enjoy the rank of firs in our forests, affording shade to the only less stately ferns and calamites. The internal structure of the stem, and the character of the seed-vessels, show them to have been a link between single-lobed and double-lobed plants, a fact worthy of note, as it favors the idea that, in vegetable as well as animal creation, a progiess has been observed, in conformity with advancing conditions. It is also curious to find a missing link of so much importance in a genus of plants which has long ceased to have a living place upon earth.

The other leading plants of the coal era are without representatives on the present surface, and their characters are in general less clearly ascertained. Amongst the most remarkable are-the sigillaria, of which large stems are very abundant, showing that the interior has been soft, and the exterior fluted with separate leaves inserted in vertical rows along the flutings-and the stigmaria plants apparently calculated to flourish in marshes of pools, having a short, thick, fleshy stem, with a domeshaped top, firom which sprung branches of from twenty to thirty feet long. Amongst monocotyledons were some palms, (flabellaria and naggerathia,) besides a few not distinctly assignable to any class.

The dicotyledons of the coal are comparatively few, though on the present surface they are the most numerous sub-class. Besides some of doubtful affinity (annularia: usterophyllites, \&c.) there were a few of the pine family. which seem to have been the highest class, of trees of 
ihis era, and are only as yet found in isolated cases, and in sandstone beds. The first discovered lay in the Craigleith quarry, near Edinburgh, and consisted of a stem about two feet thick, and forty-seven feet in length. Others have since been found, both in the same situation and at Newcastle. Leaves and fruit being wanting, an ingenious mode of detecting the nature of these trees was hit upon by Mr. Witham, of Lartington. Taking thin polished cross slices of the stem, and subjecting them to the microscope, he detected the structure of the wood to be that of a cone-bearing tree, by the presence of certain "reticulations" which distinguish that family, in addition to the usual radiating and concentric lines. That particular tree was concluded to be an arancaria, a species now found in Norfolk Island, in the South Sea, and in a few other remote situations. The coniferæ of this era form the dawn of dicotyledonous trees, of which they may be said to be the simplest type, and to which, it has already been noticed, the lepidoden'ra are a link from the monocatyledons. The concentric rings of the.Craigleith and other coniferæ of this era have been mentioned. It is interesting to find in these a record of the changing seasons of those early ages, when as yet there were no human beings to observe time or tide. They are clearly traced; but it is observed that they are more slightly marked than is the case with their family at the present day, as. if the changes of temperature had been within a narrower range.

Such was the vegetation of the carbonigenous era, composed of forms at the bottom of the botanical scale, flow-rless, fruitless, but luxuriant and abundant beyond what che most favored spots on earth can now show. The rigidity of the leaves of its plants, and the absence of fleshy fruits and farinaceous seeds, unfitted it to afford nutriment to animals ; and, monotonous in its forms, and destitute of brilliant coloring, its sward probably unenlivened by any of the smaller flowering herbs, its shades uncheered by the hum of insects, or the music of birds, it must have been but a sombre scene to a human visitant. But neither man nor any other animals were then in existence to look for such uses or such beauties in this vegetation. It was serving other and equally important ends, clearing (probably) the atmosphere of matter noxious to animal life, and storing up mineral masses which were in long 
subsequent ages to prove of the greatest service to the human race, even to the extent of favoring the progress of its civilization.

The animal remains of this era are not numerous, in comparison with those which go before, or those which come after. The mountain limestone, indeed deposited at the commencement of it, abounds unusually in polypiaria and crinoidea; but when we ascend to the coal-beds themselves, the case is altered, and these marine remains altogether disappear. We have then only a limited variety of conchifer and shell mollusks, with fragments of a few species of fishes, and these are rarely or never found in the coal seams, but in the shales alternating with them. Some of the fishes are of a sauroid character, that is, partake of the nature of the lizard, a genus of the reptilla, a land class of animals, so that we may be said here to have the firstapproach to a kind of animals calculated to breathe the atmosphere. Such is the Megalichthys Hibbertii, found by Dr. Hibbert Ware, in a limestone bed of freshwater origin, underneath the coal at Burdiehouse, near Edinbuigh. Others of the same kind have been found in the coal measures in Yorkshire, and in the low coal shales at Manchester. This is no more than might be expected. as collections of fresh water now existed, and it is presumable that they would be peopled. The chief other fishes of the coal era are named palæothrissum, palæoniscus, diperdus.

Coal strata are nearly confined to the group termed the carboniferous formation. 'Thin beds are not unknown afterwards but they occur only as a rare exception. It is therefore thought that the most important of the conditions which allowed of so abundant a terrestrial vegetation, had ceased about the time when this formation was closed. The high temperature was not one of the conditions which terminated, for there are evidences of it afterwards; but probably the superabundance of carbonic acid gas supposed to have existed during this era was experided before its close. There can be little doubt that the infusion of a large dose of this gas into the atmosphere at the present day would be attended by precisely the same circumstances as in the time of the carboniferous formation. Land animal life would rot have a place on earth; vege. tation would be enormous ; and coal strata would be formed from the vast accumulations of woody matter, which 
would gather in every sea, near the mouths of great rives On the exhaustion of the superabundance of carbonic acid gas, the coal formation would cease, and the earth might again become a suitable theatre of being for land animals.

The termination of the carboniferous formation is marked by symptoms of volcanic violence, which some geologists have considered to denote the close of one system of things and the beginning of another. Coal beds generally lie in basins, as if following the curve of the bottom of seas. But there is no such basin which is not broken up into pieces, some of which have been tossed up on edge, others allowed to sink, causing the ends of strata to be in some instances many yards, and in a few several hundred feet, removed from the corresponding ends of neighboring fragments. These are held to be results of volcanic movements below, the operation of which is further seen in numerous upbursts and intrusions of volcanic rock, (trap.) That these disturbances took place about the close of the formation, and not later, is shown in the fact of the next higher group of strata being comparatively undisturbed. Other symptoms of this time of violence are seen in the beds of conglomerate which occur amongst the first strata above the coal. These, as usual, consist of fragments of the elder rock, more or less worn from being tumbled about in agitated water, and laid down in a mud paste, afterwards hardened. Volcanic disturbances break up the rocks; the pieces are worn in seas; and a deposit of congtomerate is the consequence. Of por. phyry, there are some such pieces in the conglomerate of Devonshire, three or four tons in weight. It is to be admitted for strict truth, that, in some parts of Europe, the - carboniferous formation is followed by superior deposits, without the appearanoe of such disturbances between their respective periods; but apparently this case belongs to the class of exceptions already noticed.* That disturbance was general, is supported by the further and important fact of the destruction of many forms of organic being previously flourishing, particularly of the vegetable kingdom.

* "Some of the most considerable dislocations of the border of the coal fields of Coalbrookdale and Dudley, happened after the deposition of a part of the nev red sandstone; but it is certain that those of Somersetshire and Gloucestershire were completed before the date of that rock."-Philips 


\section{ERA OF THE NEW RED SANDSTONE}

\section{PERRESTRIAL ZOOLOGY COMMENCHS WITH REPTILED. FLRST TRACES OF BIRDS.}

THE next volume of the rock series refers to an era distinguished by an event of no less importance than the commencement of land animals. The New Red Sandstone System is subdivided into groups, some of which are wanting in some places; they are pretty fully developed in the north of England, in the following ascending order : 1. Lower red sandstone; 2. Magnesian limestone; 3 . Red and white sandstones and conglomerate; 4. Variegated marls. Between the third and fourth there is, in Germany, another group, called the Muschelkalk, a word expressing a limestone full of shells.

The first group, containing the conglomerates already adverted to, seems to have been produced during the time of disturbance which occurred so generally after the carbonigenous era. This new era is distinguised by a paucity of organic remains, as might partly be expected from the appearances of disturbance, and the red tint of the rocks, the latter being communicated by a solution of oxide of iron, a substance unfavorable to animal life.

The second group is a limestone with an infusion of magnesia. It is developed less generally than some others, but occurs conspicuously in England and Germany. Its place, above the red sandstone, shows the recurrence of circumstances favorable to animal life, and we accordingly find in it not only zoophytes, conchifera, and a few tribes of fish, but some faint traces of land plants, and a new and . startling appearance-a reptile of saurian (lizard) character, analogous to the now existing family called monitors. Remains of this creature are found in cupriferous (copperbearing) slate connected with the mountain limestone, at Mansfield and Glucksbrun, in Germany, which may be taken as evidence that dry land existed in that age near those places. The magnesia limestone is also remarkable as the last rock in which appears the leptæna, or producta. a conchifer of numerous species which makes a conspicuous appearance in all previous seas. It is likewise to be observed, that the fishes of this age, to the genera of which the names palæoniscus, catopterus, pla- 
tysomus, \&c., have been applied, vanish, and henceforth appear no more.

The third group, chiefly sandstones, variously colored according to the amount and nature of the metallic oxide infused into them shows a recurrence of agitation, and a consequent diminution of the amount of animal life. In the upper part, however, of this group, there are abundant symptoms of a revival of proper conditions for such life. There are marl beds, the origin of which substance in decomposed shells is obvious; and in Germany, though not in England, here occurs the muschelkalk, containing numerous organic remains (generally different from those of the magnesian limestone, ) and noted for the specimens of land animals, which it is the first to present in any considerable abundance to our notice.

'These animals are of the vertebrate sub-kingdom, but of its lowest class next after fishes-namely, reptiles-a portion of the terrestrial tribes whose imperfect respiratory system, perhaps, fitted thern for enduring an atmosphere not yet quite suitable for birds or mammifers.* The specimens found in the muschelkalk are allied to the crocodile and lizard tribes of the present day, but in the latter instance are upon a scale of magnitude as much superior to present forms as the lepidodendron of the coal era was superior to the dwarf club-mosses of our time. These saurians also combine some peculiarities of structure of a most extraordinary character.

The animal to which the name ichthyosaurus has been given, was as long as a young whale, and it was fitted for living in the water, though breathing the atmosphere. It had the vertebral column and general bodily form of a fish, but to that were added the head and breast-bone of a lizard, and the paddles of the whale tribes. The beak, moreover, was that of a porpoise, and the teeth were those of a crocodile. It must have been a most destructive creature to the fish of those early seas.

The plesiosaurus was of similar bulk, with a turtle-like body and paddleis, showing that the sea was its element, but with a long serpent-like neck, terminating in a sau. rian head, calculated to reach prey at a considerable

- The immediate effects of the slow respiration of the reptilia, are, a low temperature in their bodies, and a slow consumption of food. Requiring little oxygen, they could have existed in an at. mosphere containing a less proportion of that gas to carbonic acid gas than what now obtains. 
distance. These two animals, of which many varieties have been discovered, constituting distinct species, are supposed to have lived in the shallow borders of the seas of this and supsequent formations, devouring immense quantities of the finny tribes. It was at first thought that no creatures approaching them in character now ininabit the earth; but latterly Mr. Darwin has discovered in the reptile-peopled Galapagos Islands, in the South Sea, a marine saurian from three to four feet long.

The megalosaurus was an enormous lizard-a land creature, also carnivorous. The pterodactyle was another lizard, but furnished with wings to pursue its prey in the air, and varying in size between a cormorant aid a snipe. Crocodiles abounded, and some of these were herbivorous. Such was the iguanodon, a creature of the character of the inguana of the Ganges, but reaching a hundred feet in length, or twenty times that of its modern representative.

There were also numerous tortoises, some of them reaching a great size; and Professor Owen has found in Warwickshire some remains of an animal of the batrachian order, ${ }^{*}$ to which, from the pecular form of the teeth, he has given the name of labyrinthidon. Thus, three of Cuvier's four orders of reptilia (sauria, chelonia, and $b a$. trachia) are represented in this formation, the serpent order (ophidia) being alone wanting

The variegated marl beds which constitute the uppermost group of the formation, present two additional genera of huge saurians-the phytosaurus and mastodonsaurus.

It is in the upper beds of the red sandstone that beds of salt first occur. These are sometimes of such thickness, that the mine from which the material has been excavated looks like a lofty church. We see in the present world no circurnstances calculated to produce the formation of a bed of rock salt; yet it is not difficult to understand how much strata were formed in an age marked by ultra-tropical heat and frequent volcanic disturbances. An estuary, cut off by an upthrow of trap, or a change of level, and left to dry up under the heat of the sun, would quickly become the bed of a dense layer of rock salt. A second shift of level, or some other volcanic disturbance, connecting it again with the sea, would expose this stratum to being covered over with a layer of sand or mud, destined in time to form the next stratum of rock above it

* The order to which frogs and toads belong 
The plants of this era are few and unobtrusive. Equi seta, calamites, ferns, Voltzia, and a few of the other fa. milies found so abundantly in the preceding formation, here present themselves, but in diminished size and quantity.

This seems to be the proper place to advert to certain memorials of a peculiar and unexpected character respect. . ing these early ages in the sandstones. So low as the bottom of the carboniferous system, slabs are found marked over a great extent of surfaces with that peculiar corrugation or wrinkling which the receding tide leaves upon a sandy beach when the sea is but slightly agitated; and not only are these ripple marks, as they are called, found on the surfaces, but casts of them are found on the under sides of slabs lying above. The phenomena suggests the time when the sand ultimately formed in these stone slabs, was part of the beach of a sea of the carbonigenous era; when, left wavy by one tide, it was covered over with a thin layer of fresh sand by the next, and so on, precisely as such circumstances might be expected to take place at the present day. Sandstene surfaces, ripple-marked, are found throughout the subsequent formations; in those of the new red, at more than one place in England, they further bear impressions of rain drops which have fallen upon them-the rain, of course, of the inconceivably remote age in which the sandstones were formed. In the Greensill sandstone, near Shrewsbury, it has even been possible to tell from what direction the shower came which impressed the sandy surface, the rims of the marks being somewhat raised on one side, exactly as might be expected from a slanting shower falling at this day upon one of our beaches. These facts have the same sort of interest as the season rings of the Craigleith conifers, as speaking of a parity between some of the familiar processes of nature in those early ages and our own.

In the new red sandstone, impressions still more important in the inferences to which they tend, have been cbserved-namely, the footmarks of various animals. In a quarry of this formation, at Corncockle Muir, in Dumfriesshire, where the slabs incline at an angle of thirtyeight degrees, the vestiges of an animal supposed to have been a tortoise, are distinctly traced up and dowr. the slope, as if the creature had had occasion to pass backwards and forwards in that direction only, possibly in its 
aily visits to the sea. Some slabs similarly impressed, in the Stourton quarries in Cheshire, are further marked with a shower of rain which we know must have fallen afterwards, for its little hollows are impressed in the footmarks also, though more slightly than on the rest of the surface, the comparative hardness of a trodden place having apparently prevented so deep an impression being made. At Hessburg in Saxony, the vestiges of four distinct animals have been traced, one of them a web-footed animal of small size, considered as a congener of the crocodile; another, whose footsteps having a resemblance to an impression of a swelled human hand, has caused it to be named the cheirotherium. The footsteps of the cheirotherium have been found also in the Stourton quarries above mentioned. Professor Owen, who stands at the head of comparative anatomy in the present day, has expressed his belief that this last animal was the same batrachian of which he has found fragments in the new red sandstone of Warwickshire. At Runcorn, near Manchester, and elsewhere, have been discovered the tracks of an animal which $\mathrm{Mr}$. Owen calls the rynchosaurus, uniting with the body of a reptile the beak and feet of a bird, and which clearly had been a link between these two classes

If geologists shall ultimately give their approbation to the inferences made from a recent discovery in America, we shall have the addition of perfect birds, though probably of a low type, to the animal forms of this era. It is stated to be in the quarries of this rock, in the valley of Connecticut, that foot-prints have been found, apparently produced by birds of the order grallæ, or waders. "The footsteps appear in regular succession on the continuous track of an animal, in the act of walking or running, with the right and left foot always in their relative places. The distance of the intervals between each footstep on the same track is occasionally varied, but to no greater amount than may be explained by the bird having altered its pace. Many tracks of different individuals and different species are often found crossing each other, and crowded, like impressions of feet upon the shores of a muddy stream, where ducks and geese resort."* Some of these prints indicate small animals, but others denote birds of what would now be an unusually large size. One

* Dr. Buckland, quoting an article by Professor Hitchcock, in the American Journal of Science and Arts, 1836 
nimal, having a foot fifteen inches in lerigth (one-hall enore than that of the ostrich,) and a stride of from tour o six feet, has been appropriately entitled, ornithichnites giganteus.

\section{ERA OF THE OOLITE.}

\section{COMMENCEMENT OF MAMMALIA.}

THE chronicles of this period consist of a series of beds, mostly calcareous, taking their general name (Oolite System) from a conspicuous member of them-the nolite-a limestone composed of an aggregation of small round grains or spherules, and so called from its fancied resemblance to a cluster of eggs, or the roe of a fish. This texture of stone is novel and striking. It is supposed to be of chemical origin, each spherule being an aggregation of particles round a central nucleus. The oolite system is largely developed in England, France, Westphalia, and Northern Italy; it appears in Northern India and Africa, and patches of it exist in Scotland, and in the vale of the Mississippi. It may of course be yet discovered in many other parts of the world.

The series, as shown in the neighborhood of Bath, is (beginning with the lowest) as follows :-1. Lias, a set or . strata, variously composed of limestone, clay, marl, and shale, clay being predominant; 2 . Lower oolitic formation, including, besides the great oolite bed of central England, fullers' earth beds, forest marble, and cornbrash; 3. Middle oolitic formation, composed of two sub-groups, the Oxford clay and coral rag, the latter being a mere layer of the works of the coral polype; 4. Upper oolitic formation, including what are called Kimmeridge clay and Portland oolite. In Yorkshire, there is an additional group above the lias, and in Sutherlandshire, there is another group above that again. In the wealds (moorlands) of Kent and Sussex, there is, in like manner, above the fourth of the Bath series, another additional group, to which the name of the $W$ ealden has been given, from its situation, and which, composed of sandstones and clays, is subdivided into Purbeck beds, Hastings sand and Weald clay. 
There are no particular appearances of disturbance betheen the close of the new red sandstone and the beginnivg of the oolite system, as far as has been observed in England. Yet there is a great change in the materials of the rocks of the two formations, showing that while the bottoms of the seas of the one period had been chiefly arenaceous, those of the other were chiefly clayey and limy. And there is an equal difference between the two periods in respect of both botany and zonlogy. While the new red sandstone shows comparatively scanty traces of organic creation, those in the oolite are extremely abundant, particularly in the department of animals, and more particularly still of sea mollusca, which it has been observed, are always the more conspicuous in proportion to the predominance of calcareous rocks. It is also remarkable that the animals of the oolitic system are entirely different in species from those of the preceding age, and that these species cease before the next. In this system we likewise find that uniformity over great space which has been remarked of the Faunas of earlier formations. "In the equivalent deposits in the Himmalaya Mountains, at Fernando Po, in the region north of the Cape of Good Hope, and in the Run of Cutch, and other parts of Hindostan, fossils have been discovered, which, as far as English naturalists who have seen them can determine are undistinguishable from certain oolite and lias fossils of Europe."

The dry land of this age presented cycadeæ, " a beautiful class of plants between the palms and conifers, having a tall, straight trunk, terminating in a magnificent crown of foliage." $\dagger$ There were three ferns, but in smaller proportion than in former ages ; also equisetaceæ, lilia, and conifers. The vegetation was generally analogous to that of the Cape of Good Hope and Australia, which seems to argue a climate (we must remember a universal climate) between the tropical and temperate. It was, however, sufficiently luxuriant in some instances to produce thin seams of coal, for such are found in the oolite formation of both Yorkshire and Sutherland. The sea, as for ages before, contained algæ, of which, however, only a few species have been preserved to our day. The lower classes of the inhabitants of the ocean were unprecedently abundant. The polypiaria were in such abundance as to form whole

* Murchison's Silurian System, p 583.

t Buckland 
strata of themselves. The crinoidea and echinites wers also extremely numerous. Shell mollusks, in hundreds of new species, occupied the bottoms of the seas of those ages, while of the swimming shell-fish, ammonites, and belemnites, there were also many scores of varieties. The belemnite here calls for some particular notice. It com. mences in the oolite, and terminates in the next formation. It is an elongated, conical shell, terminating in a point, and having, at the larger end, a cavity for the residence of the animal, with a series of air-chambers below. The animal, placed in the upper cavity, could raise or depress itself in the water at pleasure by a pneumatic operation upon the entral air tube pervading its shell. Its tentacula, sent abroad over the summit of the shell, searched the sea for prey. The creature hail an ink-bag, with which it could muddle the water around it, to protect itself from more powerful animals, and strange to say, this has been found so well preserved that an artist has used it in one instance as a paint, wherewith to delineate the belemnite itself.

The crustacea discovered in this formation are less numerous. There are many fishes, some of which (acrodus, psammodus, \&c.,) are presumed from remains of their palatal bones, to have been of the gigantic cartilaginous class, now represented by such as the cestraceon. It has been considered by Prufessor Owen as worthy of notice, that, the cestraceon being an inhabitant of the Austrilian seas, we have, in both the botany and ichthyology of this period, an analogy to that continent. The pycnodontes (thick-toothed) and lepidoides, (having thick srales,) are other families described by M. Agassiz as extensively prevalent. In the shallow waters of the oolitic formation, the ichthyosaurus, plesiosaurus, and other huge saurian carnivora of the preceding age, plied, in increased numbers, their destructive vocation.* To them were added new genera, the cetiosaurus, mososaurus, and some others, all of similar character and habits.

Land reptiles abounded, including species of the pterodactyle of the preceding age-tortoises, trionyces croco-

* In some instances, these fossils arefound with the contents of the stomach faithfully preserved, and even with pieces of the ex ternal skin. The pellets ejected by them (coprolites) are found in vast numbars, each generally enclosed in a nodule ironstone, and cometimes showing remains of the fishes which had formed their food. 
dilians-and the pliosaurus, a creature which appears to have formed a link between the plesiosaurus and the croo codile. We know of at least six species of the flying saurian, the pterodactyle, in this formation.

Now, for the first time, we find remains of insects, an order of animals not well calculated for fossil preservation, and which are therefore amongst the rarest of the animal tribes found in rocks, though they are the most numerous of all living families A single libellula (dragon-fly) was found in the Stonefield slate, a member of the lower oolitic group quarried near Oxford; and this was for several years the only specimen known to exist so early: but now many species have been found in a corresponding rock at Solenhofen, in Germany. It is remarkable, that the remains of insects are found most plentifully near the remains of pterodactyles, to which undoubtedly they served as prey.

The first glimpse of the highest class of the vertebrate sub-kingdom-mammalia -is obtained from the Stonesfield slate, where there has been found the jaw-bone of a quadruped evidently insectivorous, and inferred, from peculiarities in the structure of that small fragment to have belonged to the marsupial family, (pouched animals.) It may be observed. although no specimens of so high a class of animals as mammalia are found earlier, such may nevertheless have existed: the defect may be in our not having found them; but, other things considered, the probability is, that heretofore there were no mammifers. It is an interesting circumstance, that the first mammifers found should have belonged to the marsupialia, when the place of that order in the scale of creation is considered. In the imperfect structure of their brain, deficient in the organs connecting the two hemispheres-and in the mode of gestation, which is only in small part uterine-this family is clearly a link between the oviparous vertebrata (birds, reptiles, and fishes) and the higher mammifers. This is further established by their possessing a faint development of two canals passing from near the anus to the external surface of the viscera, which are fully possessed in reptiles and fishes, tor the purpose of supplying aerated water to the blood circulating in particular vessels, but which are unneeded by mammifers. Such rudiments of organs in certain species which do not require them in any degree, are common in both the animal and vegetable 
kingdoms, but are always most conspicuous in families approaching in character to those classes to which the full organs are proper. This subject will be more particularly adverted to in the sequel.

The highest part of the oolitic formation presents some phenomena of an unusuai and interesting character, which demand special notice. Immediately above the upper oolitic group in Buckinghamshire, in the vicinity of Weymouth, and other situations, there is a thin stratum, usually called by workmen the dirt-bed, which appears, from incontestable evidence, to have been a soil, formed, like soils of the present day, in the course of time, upon a surface which had previously been the bottom of the sea. The dirt-bed contains exuviæ of tropical trees, accumulated through time, as the forest shed its honors on the spot where it grew, and became itself decayed. Near Weymouth there is a piece of this stratum, in which stumps of trees remained rooted, mostly erect, or slightly inclined, and from one to three feet high; while trunks of the same forest, also silicified, lie imbedded on the surface of the soil in which they grew.

Above this bed, lie those which have been called the Wealden, from their full development in the Weald of Sussex; and these as incontestably argue that the dry land forming the dirt-bed had next afterwards become the area of brackish estuaries, or lakes partially connected with the sea; for the Wealden strata contain exuviæ of fresh water tribes, besides those of the great saurians and chelonia. The area of this estuary comprehends the whole south-east province of England. A geologist thus confidently narrates the subsequent events: "Much calcareous matter was first deposited, [in this estuary,] and in it were entombed myriads of shells, apparently analagous to those of the vivipara. 'Then came a thick envelope of sand, sometimes interstratified with mud; and, finally, muddy matter prevailed. The solid surface beneath the waters would appear to have suffered a long continued and gradual depression, which was as gradually filled, or nearly so, with transported matter; in the end, however, after a depression of severai hundred feet, the sea again entered upon the area, not suddenly or violently-for the Wealden rocks pass gradually into the superincumbent cretaceous series-but so quietly, that the mud containing the remains'of terrestrial and fresh-water creatures was tran- 
qquiliy covered up by sands replete with marine exuviæ."* A subsequent depression of the same area, to the depth of at least three hundred fathoms, is believed to have taken place, to admit of the deposition, of the cretaceous beds lying above.

From the scattered way in which remains of the larger terrestrial animals occur in the Wealden, in the intermixture of pebbles of the special appearance of those worn in rivers, it is also inferred that the estuary which once covered the southeast part of England was the mouth of a river of that far descending class of which the Mississippi and Amazon are examples. What part of the earth's sur. face presented the dry land through which that and other similar rivers flowed, no one can tell for certatn. It has been surmised, that the particular one here spoken of may have flowed from a point not nearer than the site of the present Newfoundland. Professor Phillips has suggested, from the analogy of the mineral composition, that anciently elevated coal strata may have crmposed the dry land from which the saridy matters of these strata were washed. Such a deposite as the Wealden almost necessarily implies a local not a general condition; yet it has been thought that similar strata and remains exist in the Pays de Bray, near Beauvais. This leads to the supposition that there may have been, in that age, a series of river-receiving estauries along the border of some such great ocean as the Atlantic, of which that of modern Sussex is only an example.

\section{ERA OF THE CRETACEOUS FORMATION.}

THE record of this period consists of a series of strata, in which chalk beds make a conspicuous appearance, and which is therefore called the cretaceous system or forma. tion. In England, a long stripe, extending from York. shire to Kent, presents the cretaceous beds upon the sur face, generally lying conformably upon the oolite, and in many instances rising into bold escarpments towards the west. The celebrated cliffs of Dover are of this formation. It extends into northern France, and thence north-westward into Germany, whence it is traced into Scandinavia

De la Beche's Geological Researches, p. 344. 
and Russia. The same system exists in Nor.h America, and probably in other parts of the earth not yet geologically investigated Being a marine deposit, it establishes that seas existed at the time of its formation on the tracts occupied by it, while some of its organic remains prove that, in the neighborhood of those seas, there were tracts of dry land.

The cretaceous formation in England presents beds chiefly sandy in the lowest part, chiefly in the clayey in the middle, and chieflv of chalk in the upper part, the chalk beds being never absent, which some of the lower are in several places in the vale of the Mississippi ; again the true chalk is wholly, or all but wholly, absent. In the south of England, the lower beds are, (reckoning from the lowest upwards,) 1. Shankland or greensand, "a triple alternation of sands and sandstones with clay ;" 2. Galt, " a stiff blue or black clay, abounding in shells, which frequently possess a pearly lustre ;" 3. Hard, chalk ; 4 Chalk with flints; these two last being generally white, but in some districts red, and in others yellow. The whole are, in England, about 1200 feet thick, showing the considerable depths of the ocean in which the deposits were made.

Chalk is a carbonate of lime, and the manner of its production in such vast quantities was long a subject of speculation among geologists. Some light seemed to be thrown upon the subject a few years ago, when it was observed, that the detritus of coral reefs in the present tropical seas gave a powder, undistinguishabie, when dried, from ordinary chalk. It then appeared likely that the chalk beds were the detritus of the corals which were in the ocean of that era. Mr. Darwin, who made some curious inquiries on this point, further suggested that the matter might have intermediately passed through the bo dies of worms and fish, such as feed on the corals of the present day, and in whose stomachs he has found impure chalk. This, however, cannot be a full explanation of the production of chalk, if we admit some more recent discoveries of Professor Ehrenberg. That master of microscopic investigation announces, that chalk is composed partly of " inorganic particles of irregular elliptical struc. ture and granular slaty disposition," and partly of shells of inconceivable minuteness, "varying from the onetwelfth to the two hundred and eighty-eighth part of a 
lıne"-a cubic inch of the substance containing above ten millions of them! The chalk of the north of Europe contains, he says, a larger proportion of the inorganic matter; that of the south, a larger proportion of the organic matter, being in some instances almost entirely composed of it. He has been able to classify many of these creaturea some of them being allied to the nautilli, numuli, cyprides, \&c. 'The shells of some are calcareous, of others siliceous. M. Ehrenberg has likewise detected microscopic sea-plants in the chalk.

The distinctive feature of the uppermost chalk beds in England, is the presence of flint nodules. These are generally disposed in layers parallel to each other. It was readily presumed by geologists that these masses were formed by a chemical aggregation of particles of silica, originally held in solution in the mass of the chalk. But whence the silica in a substance so different firom it! Ehrenberg suggests that it is composed of the siliceous coverings of a portion of the microscopic creatures, whose shells he has in other instances detected in their original condition. It remarkable that the chalk with flint abounds in the north of Europe; that without flints in the south; while in the northern chalk, siliceous animalcules are wanting, and in the southern present in great quantities. The conclusion seems but natural, that in the one case the siliceous exuviæ have been left in their original form; in the other dissolved chemically, and aggregated on the common principle of chemical affinity into nodules of flint, probably concentrating, in every instance, upon a piece of decaying organic matter, as has been the case with the nodules of ironstone in the earlier rocks, and the spherules of the oolite.

What is more remarkable, M. Ehrenberg has ascertained that at least fifty-seven species of the microscopic animals of the chalk, being infusoria and calcareous-shelled polythalamia, are still found living in various parts of the earth. These species are the most abundant in the rock. Singly they are the most unimportant of all animals, but in the mass, forming as they do such enormous strata over a large part of the earth's surface, they have an importance greatly exceeding that of the largest and noblest of the beasts of the field: Moreover, these species have a peculiar interest, as the only specific types of that early age which are reproduced in the present day. Spe- 
cies of sea mollusks, of reptiles, and of mamm:fers, have been changed again and again, since the cretaceous era; and it is not till a long subsequent age that we find the first traces of any other of even the humblest species, which now exist; but hère have these humble infusoria and polythalamia kept their place on earth through all its revolutions since that time-are we to say safe in their very humility, which might adapt them to a greater variety of circumstances than most other animals, or are we required to look for some other explanation of the phenomenon?

All the ordinary and more observable orders of the in. habitants of the sea, except the cetacea, have been found in the cretaceous formation-zoophytes, radiaria, mollusks, crustacea (in great variety of species, and fishes in smaller variety. In Europe, remains of the marine saurians have been found; they may be presurned to have become extinct in that part of the globe before this time, their place and destructive office being perhaps supplied by cartilaginous fishes, of which the teeth are found in gieat quantities. In America, however, remains of the plesiosaurus have been discovered in this part of the stratified series. The reptiles, too, so numerous in the two preceding periods, appear to have now much diminished in numbers. One, entitled the mosæsaurus, seems to have held an intermediate place between the monitor and iguana, and to have been about twenty-five feet long, with a tail calculated to assist it powerfully in swimming. Crocodiles and turtles existed, and amongst the fishes were some of a saurian character.

Fuci abounded in seas of this era. Confervæ are found enclosed in flints. Of terrestrial vegetation, as of terres trial animals, the specimens in the European area are comparatively rare, rendering it probable that there war no dry land near. The remains are chiefly of ferns, coni fers, and cycadeæ, but in the two former cases we have only cones and leaves. There have been discovered manj pieces of wood containing holes drilled by the teredo, an thus showing that they had been long drifted about in tho ncean before being entombed at the bottom.

'The series in America corresponding to this, entitled the ferruginous sand formation, presents fossils generally identical with those of Europe, not excepting the frag ments of drilled wood; showing that, in this, as in earli 
er ages, there was a parity of conditions for animal life over a vast tract of the earth's surface. To European reptiles, the American formation adds a gigantic one, styled the saurodon, from the lizard-like character of its teeth.

We have seen that footsteps of birds are considered to have been discovered in America, in the new red sandstone. Some similar isolated phenomena occur in the subsequent formations. Mr. Mantell discovered some bones of birds, apparently waders, in the Wealden. The immediate connexion of that set of birds with land, may account, of course, for their containing a terrestrial organic relic, which the marine beds above and below did not possess. In the slate of Giarus, in Switzerland, cor sponding to the English galt, in the chalk formation, the remains of a bird have been found. From a chalk bed near Maidstone, have likewise been extracted some remains of a bird, supposed to have been of the long-winged swimmer family, and equal in size to the aibatross. These, it must be owned, are less strong traces of the birds than we possess of the reptiles and other tribes; but it must be semembered, that the evidence of fossils as to the absence of any class of animals from a certain period of the earth's history, can never be considered as more than negative Animals, of which we find no remains in a particular formation, may, nevertheless, have lived at the time, and it may only have been from unfavorable circumstances that their remains have not been preserved for our inspection. The single circumstance of their being little liable to be carried down into seas, might be the cause of their nonappearance in our quarries. There is at the same time a limit to uncertainty on this point. We see, from what remains have been found in the whole series, a clear progress throughout, from humble to superior types of being. Hence we derive a light as to what animals may have existed at particular times, which is in some measure independent of the specialties of fossilology. The birds are below the mammalia in the animal scale; and therefore they may be supposed to have existed about the time of the new red sandstone and oolite, although we find but slight traces of them in those formations, and, it may be eaid, till a considerably later period. 


\section{IRA OF THE TERTIARY FORMATION.- MA.MMALIA ABUNDANT.}

Tre chalk-beds are the highest which extend over a considerable space ; but in hollows of these beds, compa ratively limited in extent, there have been formed series of strata-clays, limestones, marls, alternating-to which the name of the Tertiary Formation has been applied. London and Paris alike rest on basins of this formation, and another such basin extends from near Winchester. under Southampton, and re-appears in the Isle of Wight. There is a patch or fragment of the formation in one of the Hebrides. A stripe of it extends along the east coast of North America, from Massachusetts to Florida. It is also found in Sicily and Italy, insensibly blended with formations still in progress. Though comparatively a local formation, it is not of the less importance as a record of the condition of the earth during a certain period. As in other formations, it is marked, in the most distant localities, by identity of organic remains.

The hollows filled by the tertiary formation must be considered as the beds of estuaries left at the conclusion of the cretaceous period. We have seen that an estuary, either by the drifting up of its mouth, or a change of level in that quarter, may be supposed to have become an inland sheet of water, and that by another change, of the reverse kind, it may be supposed to have become an estuary again. Such changes the Paris basin appears to have undergone oftener than once, for, first, we have there a fresh-water formation of clay and limestone beds; then, a marinelimestone formation; next, a second fresh-water formation, in which the material of the celebrated plaster of Paris (gypsum) is included; then, a second marine formation of sandy and limy beds ; and finally, a third series of fresh-water strata. Such alternations occur in other examples of the tertiary formation likewise.

The tertiary beds present all but an entirely new set of animals, and as we ascend in the series, we find more and more of these identical with species still existing upon earth. as if we had now reached the dawn of the present state of the zoology of our planet. By the study of the shells alone, Mr. Lyell has been enabled to divide the whole term into four sub-periods, to which he has given 
names with reference to the proportions which they respectively present of surviving species-first the eocene (fiom ' $\eta \omega_{\varsigma}$, the dawn; $\chi$ aıvos, resent;) second the miocene ( $u \varepsilon \varepsilon \omega \nu$, less :) third older pliocene $(\pi \lambda \varepsilon \iota \omega \nu$, more;) fourth, newer pliocene.

\section{EOCENE SUB-PERIOD.}

The eocene period presents, in three continerlal groups, 1238 species of shells, of which forty-two, or 3.5 per cent., yet flourish. Some of these are remarkable enough; but they all sink into insignificance beside the mammalian remains which the lower eocene deposits of the Paris ba. sin present to us, showing that the land had now become the theatre of an extensive creation of the highest class of animals. Cuvier ascertained about fifty species of those, all of them long since extinct. A considerable number are pachydermata, ${ }^{*}$ of a character approximating to the South American tapir: the names palæotherium, anthracotherium, anoplotherium, lophiodon, \&c., have been applied to them with a consideration of more or less conspicuous peculiarities; but a description of the first may give some general idea of the whole. It was about the size of a horse, but more squat and clumsy, and with a heavier head, and a lower jaw shorter than the upper; the feet, also, instead of hooves, presented three large toes, rounded, and unprovided with claws. These animals were all herbivorous. Amongst an immense number of others are found many new reptiles, some of them adapted for fresh water; species of birds allied to the sea-lark, curlew, quail, buzzard, owl, and pelican; species allied to the dormouse and squirrel; also the opossum and racoon; and snecies allied to the genette, fox, and wolf.

\section{MIOCENE SUB-PERIOD.}

In the mioceno sub-period, the shells give eighteen per cent. of existing species, showing a considerable advance from the preceding exa, with respect to the inhabitants of the sea. The advance in the land animals is less marked, but yet considerable. The predominating forms are still

* Thick-skinned animals. This term has been given by Cuvier to an order in which the hog, elephant, horse, and rhinoceros are included. 
pachydermatous, and the tapir type continues to be con. spicuous. One animal of this kind, called the dinotherium, is supposed to have been not less than eighteen feet long; it had a mole-like form of the shoulder blade, conferring the power of digging for food, and a couple of tusks turn ing down from the lower jaw, by which it could have at. tached itself, like the walrus, to a shore or bank, while its body floated in the water. Dr. Buckland considers this and some similar miocene animals, as adapted for a semi-aquatic life, in a region where lakes abounded. Besides the tapirs, we have in this era animals allied to the glutton, the bear, the dog the horse, the hog, and, lastly several felinæ (creatures of which the lion is the type;, all of which are new forms, as far as we know. There was also an abundance of marine mammalia, seals, dolphins, lamantins, walruses, and whales, none of which had previously appeared.

\section{PLIOCENE SUB·PERIOD,}

The shells of the older plincene give from thirty-five to fifty; those of the newer, from ninety to ninety-five per cent. of existing species. The pachydermata of the preceding era now disappear, and are replaced by others belonging to still existing families-elephant, hippopotamus, rhinoceros-though now extinct as species. Some of these are startling, from their enormous magnitude. The great mastodon, whose remains are found in abundance in America, was a species of elephant, judged from peculiarities of its teeth, to have lived on aquatic plants, and reaching the height of twelve feet. The mammoth was another elephant, but supposed to have survived till com. paratively recent times as a specimen, in all respects entire, was found in 1801, preserved in ice, in Siberia. We are more surprised by finding such gigantic proportions in an animal called the megatherium, which ranks in an order now assuming much humbler forms-the edentata-to which the sloth, ant-eater, and armadillo belong. The megatherium had a skeleton of enormous solidity, with an armor-clad body, and five toes, terminating in huge claws, wherewith to grasp the branches, from which, like its existing congener, the sloth, it derived its food. The megalonyx was a similar animal, only somewhat less than the preceding Finally, the pliocene gives us for the 
first time, oxen, deer, camels, and other specimens of the ruminantia.

Such is an outline of the fauna of the tertiary era, as ascertained by the illustrious naturalists who first devoted their attention to it. It will be observed, that it brings us up to the felinæ, or carnivora, a considerably elevated point in the animal scale, but still leaving a blank for the quadrumana (monkeys) and for man, who collectively form, as will be afterwards seen, the first group in that scale. It sometimes happens, however as we have seen. that a few rare traces of a particular class of animals are in time found in formations originally thought to be destitute of them, displaying as it were a dawn of that department of creation. Such seems to be the case with at least the quadrumana. A jaw-bone and tooth of an animal of this order. and belonging to the genus macacus, were found in the Lcudon clay (eocene,) at Kyson, near Woodbridge, in 1839. Another jaw-bone, containing several teeth, supposed to have belonged to a species of monkey about three feet high, was discovered about the same time in a stratum of marl, surmounted by compact limestone, in the department of Gers, at the foot of the Pyrenees. Asso. ciated with this last were remains of not less than thirty mammiferous quadrupeds, including three species of rhinoceros, a large anoplotherium, three species of deer, two antelopes, a true dog, a large cat, an animal like a weazel, a small hare, and a huge species of the edentata. Both of these places are considerably to the north of any region now inhabited by the monkey tribes. Fossil remains of quadrumana have been found in at least two other parts of the earth-namely, the sub-Himalayan hills, near the Sutlej, and in Brazil (both in the tertiary strata;) the n.st being a large species of semnopithecus, and the second, a still larger animal belonging to the American group of monkeys, but a new genus, and denominated by its discoverer, Dr. Lund, protopithecus. The latter would be four feet in height.

One remarkable circumstance connected with the tcrtiary formation remains to be noticed-namely, the prevalence of volcanic action at that era. In Auvergne, in Catalonia, near Venice, and in the vicinity of Rome and Naples, lavas exactly resembling the produce of existing volcanoes, are associated and intermixed with the lacustrine as well as marine tertiaries. The superficies of ter- 
tiaries in England is disturbed by two great swells, forming what are called anticlinal axes, one of which divides the London from the Hampshire basin, while the other passes through the Isle of Wight, both throwing the strata down at a violent inclination towards the north, as if the subterranean disturbing force had waved forward in that direction. The Pyrenees, too, and Alps, have both undergone elevation since the deposition of the tertiaries; and in Sicily there are mountains which have risen three thousand feet since the deposition of some of the most recent of these rocks. The general effect of these operations was of course to extend the land surface, and to increase the variety of its features, thus improving the natural drainage, and generally adapting the earth for the reception of the higher classes of animals.

\section{ERA OF THE SUPERFICIAL FORMATIONS}

\section{COMMENCEMENT OF PRESEN'T SPECIES.}

WE have now completed our survey of the series of stratified rocks, and traced in their fossils the progress of organic creation down to a time which setms not long antecedent to the appearance of man. There are, nevertheless, monuments of still another era or space of time, which it is all but certain did also precede that event.

Over the rock formations of all eras, in various parts of the globe, but confined in general to situations not very elevated, there is a layer of stiff clay, mostly of a blue coior, mingled with fragments of rock of all sizes travelworn, and otherwise, and to which geologists give the name of diluvium, as being apparently the produce of some vast flood, or of the sea thrown into an unusual agitation. It seems to indicate that, at the time when it was laid down, much of the present dry land was under the ocean, a supposition which we shall see supported by other evidence. The included masses of rock have been carefully inspected in many places, and traced to particular parent beds at considerable distances. Connected with these phenomena are certain rock surfaces on the slopes of hills and elsewhere, which exhibit gronving and scratchings, such as we might suppose would be pro 
uced by a quantity of loose blocks hurried alung over them by a flood. Another associated phenomenon is that called crag and zail, which exists in many places, namely, a rocky muuntain, or lesser elevation, presenting on one side the naked rock in a more or less abrupt form, and on the other a gentle slope; the sites of Windsor, Edinburgh, and Stirling, with their respective castles, are specimens of crag and tail. Finally, we may advert to cer tain long ridges of clay and gravel which arrest the aftention of travellers on the surface of Sweden and Finland, and which are also found in the United States, where, indeed, the whole of these phenomena have been observed over a large surface, as well as in Europe. It is very remarkable that the direction from which the diluvial blocks have generally come, the lines of the groowed rock surfaces, the direction of the crag and tail eminences, and that of the clay and gravel ridges-phenomena, be it observed, extending oper the northern parts of both Europe and America-are all from the north and north-west towards the south-east. We thus acquire the idea of a powerful current moving in a direction from north-west to south-east, carrying, besides mud, masses of rock which furrowed the solid surfaces as they passed along, abrading the north-west faces of many hills, but leaving the slopes in the opposite direction uninjured, and in some instances forming long ridges of detritus along the surface. These are curious considerations, and it has become a question of much interest, by what means, and under what circumstances, was such a current produced. One hypothetical answer has some plausibility about it. From an investigation of the nature of glaciers, and some observations which seem to indicate that these have at one time extended to lower levels, and existed in regions (the Scottish Highlarids an exarnple) where there is no perennial snow, it has been surmised that there was a time, subsequent to the tertiary era, when the circumpolar ice extended far into the temperate zone, and formed a lofty, as well as extensive accumulation. A change to a higher temperature, producing a sudden thaw of this mass, might set free such a quantity of water as would form a large flood, and the southward flow of this deluge, joined to the direction writch it would obtain from the rotary motion of the globe, would of course produce that compound or south-easterly direction which the phenomena require 
All of these speculations are as yet far too deficient in facts, to be of much value; and I must freely own that, for one, I attach little importance to them. All that we can legitimately infer from the diluvium is, that the northern parts of Europe and America were then under the sea, and that a strong current set over them.

Connected with the diluvium is the history of ossiferonos caverns, of which specimens singly exist at Kirkdale, in Yorkshire, Gailenreuth in Franconia, and other places. They occur in the calcareous strata, as the great caverns generally do, but have in all instances been naturally clased up till the recent period of their discovery. The floors are covered with what appears to be a bed of the diluvial clay, over which rests a crust of stalagmite, the result of the droppings from the roof since the time when the clay-bed was laid down. In the instances above specified, and several others, there have been found, under the clay-bed, assemblages of the bones of animals, of many various kinds. At Kirkdale, for example, the remains of twenty-four species were ascertained-namely, pigeon, lark, raven, duck, and partridge ; mouse, water-rat, rabbit, hare, deer, (three species,) ox, horse, hippopotamus, rhinoceros, elephant, weazel, fox, wolf, bear, tiger, hyena. From many of the bones of the gentler of these animals being found in a broken state, it is supposed that the cave was a haunt of hyenas and other predaceous animals, by which the smaller ones were here consumed. This must have been at a time antecedent to the submersion which produced the diluvium, since the bones are covered by a bed of that formation. It is impossible not to see here a very natural series of incidents. First, the cave is frequented by wild beasts, who make it a kind of charneIhouse. Then, submerged in the current which has been spoken of, it receives a clay flooring from the waters containing that matter in suspension. Finally, raised from the water, but with no mouth to the open air it remains unintruded on for a long series of ages, during which the clay flooring receives a new calcareous covering from the droppings of the roof. Dr. Buckland, who examined and described the Kirkdale cave, was at first of opinion that it presented a physical evidence of the Noachian deluge; but he afterwards saw reason to consider its phenomena as of a time far apart from that event, which rests on evi dence of an entirely different kind. 
Our attention is next drawn to the erratic biocks or voulders, which in many parts of the earth are thickly strewn over the surface, particularly in the north of Europe. Some of these blocks are many tons in weight, yet are clearly ascertained to have belonged originally to situations at a great distance. Fragments, for example, of the granite of Shap Fell are found in every direction around, to the distance of fifty miles, one piece being placed high upon Criffel Mountain, on the opposite side of the Solvay estuary ; so also are fragments of the Alps found far up the slopes of the Jura. There are even blocks on the east coast of England, supposed to have travelled from Norway. The only rational conjecture which can be formed as to the transport of such massses from so great a distance, is one which presumes them to have been carried and dropped by icebergs, while the space between their original and final sites was under ocean. Icebergs do even now carry off such masses from the polar coasts, which, falling when the retaining ice melts, must take up situations at the bottom of the sea, analogous to those in which we find the erratic blocks of the present day.

As the diluvium and erratic blocks clearly suppose one last long submersion of the surface, (last, geologically speaking,) there is another set of appearances which as manifestly show the steps by which the land was made afterwards to reappear. These consist of terraces, which have been detected near, and at some distance inland from the coast of Scandinavia, Britain, America, and other regions ; being evidently ancient beaches, or platforms, on which the inargin of the sea at one time rested. They have been observed at different heights above the present sea-level, from twenty to above twelve hundred feet; and in many places they are seen rising above each other in succession, to the number of three, four, and even more. The smooth flatness of these terraces, with generally a slight inclination towards the sea, the sandy composition of many of them, and, in some instances, the preservation of marine shells in the ground, identify them perfectly with existing sea-beaches, notwithstanding the cuts and scoopings which have every here and there been effected in them by water-courses. The irresistible inference from the phenomena is, that the highest was first the coast-line ; then an elevation took place, and the second highest became so, the first being now raised into the air and thrown 
inland. Then, upon another elevation, the sea began to form, at its new point of contact with the land, the third highest beach, and so on down to the platform nearest to the present sea-beach. Phenomena of this kind become comparatively familiar to us, when we hear of evidence that the last sixty feet of the elevation of Sweden, and the last eighty-five of that of Chili, have taken place since man first dwelt in those countries; nay, that the elevation of the former country goes on at this time at the rate of about forty-five inches in a century, and that a thousand miles of the Chilian coast rose four feet in one night, under the influence of a powerful earthquake, so lately as 1822. Subterranean forces, of the kind then exemplified in Chili, supply a ready explanation of the whole phenomena, though some other operating causes have been suggested. In an inquiry on this point it becomes of consequence to learn some particulars respecting the levels. Taking a particular beach, it is generally observed that the level continues the same along a considerable number of miles, and nothing like breaks or hitches has as yet been detected in any case. A second and a third beach are also observed to be exactly parallel to the first. These facts would seem to indicate quiet elevating movements, uniform over a large tract. It must, however, be remarked that the raised beaches at one part of a coast rarely coincide with those at another part forty or fifty miles off. We might suppose this to indicate a limit in that extent of the uniformity of the elevating cause, but it would be rash to conclude positively that such is the case. In the present sea, as is well known, there are different levels at different places, owing to the operation of peculiar local causes, as currents, evaporation, and the influx of large rivers into narrow mouthed estuaries. The differences of level in the ancient beaches might be occasioned by some such causes. But, whatever doubt may rest on this minor point, enough has been ascertained to settle the main one, that we have in these platforins indubitable monuments of the last rise of the land from the sea, and the concluding great event of the geological history.

The idea of such a wide-spread and possibly universal suibrnersion unavoidably suggests some considerations as to the effect which it might have upon terrestrial animal life. It seems likely that this would be, on such an occa- 
sion, extensively, if not universally, destroyed. Nor does the idea of its universal destruction seem the less plausible, when we remark, that none of the species of land animals heretofore discovered can be detected at a subsequent period. The whole seem to have been now changed. Some geologists appear much inclined to think that there was at this time a new development of terrestrial animal life upon the globe, and M. Agassiz, whose opinion on such a subject must always be worthy of attention, speaks all but decidedly for such a conclusion. It must, however, be owned, that proofs for it are still scanty, beyond the bare fact of a subrnersion which appears to have had a very wide range. I must therefore be content to leave this point, as far as geological evidence is concerned, for future affirmation.

There are some other superficial deposits, of less consequence on the present occasion than the diluviumnamely, lacustrine deposits, or filled-up lakes ; alluvium, or the deposits of rivers beside their margins; deltas, the deposits made by great ones at their efflux into the sea; peat mosses; and the vegetable soil. The animal remains found in these generally testify to a zoology on the verge of that which still exists, or melting into it, there being included many species which still exist. In a lacustrine deposit at Market-Weighton, in the vale of York, there have been found bones of the elephant, rhinoceros, bison. wolf, horse, felis, deer, birds, all or nearly all extinct species ; associated with thirteen species of land and fresh water shells, "exactly identical with types now living in the vicinity." In similar deposits in North America, are remains of the mammoth, mastodon, buflalo, and other animals of extinct and living types. In short, these superficial deposits show precisely such remains as might be expected from a time at which the present system of things (to use a vague but not unexpressive phrase) obtained, but yet so far remote in chronology as to allow ot the dropping of many species, through familiar causes, in the interval. Still, however, there is no authentic or satisfactory instance of human remains being found, except in deposits obviously of very modern date; a tolerably strong proof that the creation of our own species is a comparatively recent event, and one posterior (generally speaking) to all the great natural transactions chronicled by geoloury. 


\section{GENERAL CONSIDERATIONS}

\section{RESPECTING THE ORIGIN OF THE ANIMATED TRIBES}

THus concludes the wondrous chapter of the earth's history which is told by geology. It takes up our globe at the period when its original incandescent state had nearly ceased; conducts it through what we have every reason to believe were vast or at least very considerable spaces of time, in the course of which many superficial changes took place, and vegetable and animal life was gradually developed; and drops just at the point when man was apparently about to enter on the scene. The compilation of such a history, from materials of so extraordinary a character, and the powerful nature of the evidence which these materials afford, are calculated to excite our admiration, and the result must be allowed to exalt the dignity of science, as a product of man's industry and his reason.

If there is anything more than another impressed on our minds by the course of the geological history, it is, that the same laws and conditions of nature now apparent to us have existed throughout the whole time, though the operation of some of these laws may now be less conspicuous than in the early ages, from some of the conditions having come to a settlement and a close. That seas have flowed and ebbed, and winds disturbed their surfaces in the time of the secondary rocks, we have proof on the yet preserved surfaces of the sands which constituted margins of the seas in those days. Even the fall of the wind-slated rain is evidenced on the same tablets. The washing down of detached matter from elevated grounds, which we see rivers constantly engaged in at the present time, and which is daily shallowing the seas adjacent to their mouths, only appear to have proceeded on a greater scale in earlier epochs. The volcanic subterranean force, which we see belching forth lavas on the sides of mountains, and throwing up new elevations by land and sea, was only more powerfully operative in distant ages. To turn to organic nature, vegetation seems to have proceeded then txactly as now. The very alternations of the seasons has been read in unmistakeable characters in sections of the trees of those days, precisely as it might be read in a ser. 
Ron of a tree cut down yesterday. 'The system of prey amongst animals flourished throughout the whole of the pre-human period; and the adaptation of all plants and animals to their respective sphere of existence was as perfect in those early ages as it is still.

But, as has been observed, the operation of the laws may be modified by conditions. At one early age, if there was any dry land at all, it was perhaps enveloped in an atmosphere unfit for the existence of terrestrial animals, and which had to go through some changes before that condition was altered. In the carbonigenous era, dry land seems to have consisted only of clusters of islands, and the temperature was much above what now obtains at the same places. Vulcanic forces, and perhaps also the disintegrating power, seem to have been on the decrease since the first, or we have at least long enjoyed an exemp. tion from such paroxysms of the former, as appear to have prevailed at the close of the coal formation in England, and throughout the tertiary era. The surface has also undergone a gradual progress by which it has become always more and more variegated, and thereby fitted for the resider,ce of a higher class of animals.

In pursuing the progress of the development of both plants and animals upon the globe, we have seen an advance in both cases, along the line leading to the higher forms of organization. Among plants we have first seaweeds, afterward land plants: and among these the sim. pler (cellular and cryptogamic) before the more complex. In the department of zoology, we see zoophytes, radiata, mollusca, articulata, existing for ages before there were any higher forms. The first step forward gives fishes, the humblest class of the vertebrata; and, moreover, the earliest fishes partake of the character of the next lowest sub-kingdom, the articulata. Afterward come land animals, of which the first are reptiles, universally allowed to be the type next in advance from fishes, and to be connected with these by the links of an insensible gradation. From reptiles we advance to birds, and thence to mam. malia, which are commenced by marsupialia, acknowledgedly low forms in their class. That there is thus a progress of some kind, the most superficial glance at the geological history is sufficient to convince us. Indeed the doctrine of the gradation of animal forms has received a remarkable support from the discoveries of this science, 
as several types formerly wanting to a completion of the series have been found in a fossil state.*

It is scarcely less evident, from the geological record, that the progress of organic life has observed some correspondence with the progress of physical conditions on the surface. We do not know for certain that the sea, at the time when it supported radiated, molluscous, and articulated families, was incapable of supporting fishes; but causes for such a limitation are far from inconceivable. The huge saurians appear to have been precisely adapted to the low muddy coasts and sea margins of the time when they flourished. Marsupials appear at the time when the surface was generally in that flat, imperfectly variegated state in which we find Australia, the region where they now live in the greatest abundance, and one which has no higher native mammalian type. Finally, it was not till the land and sea had come into their present relations, and the former, in its principal continents had acquired the irregularity of surface necessary for man, that man appeared. We have likewise seen reason for supposing that land animals could not have lived before the carbonigenous era, owing to the great change of carbonic acid gas, presumed to have been contained in the atmosphere down to that time. The surplus of this having gone, as M. Brogniart suggests, to form the vegetation, whose ruins became coal, and the air being thus brought to its present state, land animals immediately appeared. So, also, sea-plants were at first the only specimens of vegetation, because there appears to have been no place where other plants could be produced or supported. Land vegetation followed, at first simple, afterward complex, probably in conformity with an advance of the conditions required by the higher class of plants. In short, we see everywhere throughout the geological history, strons traces of a parallel advance of the physical conditions and the organic forms.

In examining the fossils of the lower marine creation, with a reference to the kind of rock in connexion with which they are found, it is observed that some strata are attended by a much greater abundance of both species and individuals than others. They abound most in calcareous

* Intervals in the series were numerous in the department of the pachydermata; many of these gaps are now filled up from the ex inct genera found in the tertiary formation. 
rocks, which is precisely what might be expected, since lime is necessary for the formation of the shells of the mollusks and articulata, and the hard substance of the crinoidea and corals; next in the carboniferous series; next in the tertiary; next in the new red sandstone; next in slates; and lastly, least of all, in the primary rocks. * This may have been the case without regard to the origination of new species, but more probably it was otherwise; or why, for instance, should the polypiferous zoophyta be found almost exclusively in the limestones? There are, indeed, abundant appearances as if, throughout all the changes of the surface, the various kinds of organic life invariably pressed in, immediately on the specially suitable conditions arising, so that no place which could support any form of organic being, might be left for any length of time unoccupied. Nor is it less remarkable how various species are withdrawn from the earth, when the proper conditions for their particular existence are changed. The trilobite, of which fifty species existed during the earlier formations, was extirpated before the secondary had commenced, and appeared no more. The ammonite does not appear above the chalk. The species, and even genera of all the early radiata and mollusks were exchanged for others long ago. Not one species of any creature which flourished before the tertiary (Ehrenberg's infusoria excepted) now exists; and of the mammalia which arose during that series, many forms are altogether gone, while of others we have now only kindred species. Thus to find not only frequent additions to the previously existing forms, but frequent withdrawals of forms which had apparently become inappropriate-a constant shifting as well as advance-is a fact calculated very forcibly to arrest attention.

A candid consideration of all these circumstances can scarcely fail to introduce into our minds a somewhat different idt: $\iota$ of organic creation from what has hitherto been gen : ally entertained. That God created animated beings as well as the terraqueous theatre of their being, is a fact ! powerfully evidenced, and so universally received, t at $I$ at once take it for granted. But in the particulars of this so highly supported idea, we surely here see cause for some re-consideration. It may now be in.

* Sce paper by Professor Edward Forbes, read to the British Association, 1839 . 
quired-In what way was the creation of animated being effected? The ordinary notion may, I think, be not unjustly described as this-that the Almighty Author produced the progenitors of all existing species by some sort of personal or immediate exertion. But how does this notion comport with what we have seen of the gradual advance of species, from the humblest to the highest? How can we suppose an immediate exertion of this creative power at one time to produce zoophytes, another time to add a few marine mollusks, another to bring in one or two conchifers, again to produce crustaceous fishes, again perfect fishes, and so on to the end? This would surely be to take a very mean view of the Creative Power; to, in short, anthropomorphize it, or reduce it to some such character as that borne by the ordinary proceedings of mankind. And yet this would be unavoidable; for that the organic creation was thus progressive through a long space of time, rests on evidence which nothing can overturn or gainsay. Some other idea must then be come to with regard to the mode in which the Divine Author proceeded in the organic creation. Let us seek in the history of the earth's formation for a new suggestion on this point. We have seen powerful evidence, that the construction of this globe and its associates, and inferentially that of all the other globes of space, was the result, not of any immediate or personal exertion on the part of the Deity, but of natural laws which are expressions of his will. What is to hinder our supposing that the organic creation is also the result of natural laws, which are, in like manner, an expression of his will? More than this, the fact of the cosmical arrangements being an effect of natural law, is a powerful argument for the organic arrangements being so, likewise; for how can we suppose that the august Being who brought all these countless worlds into form by the simple establishment of a natural principle flowing from his mind, was to interfere personally and specially on every occasion when a new shell-fish or reptile was to be ushered into existence on one of these worlds? Surely this idea is too ridiculous to be for a moment entertained.

It will be objected that the ordinary conceptions of Christian nations on this subject are directly derived from Scripture, or, at least, are in conformity with it. If they were clearly and unequivocally supported by Scrip. 
ture, it may readily be allowed that there would be a strong objection to the reception of any opposite hypothe. sis. But the fact is, however startling the present an nouncement of it may be, that the first chapter of the Mosaic record is not only not in harmony with the ordinary ideas of mankind respecting cosmical and organic creation, but is opposed to them, and only in accordance with the views here taken. When we carefully peruse it with awakened minds, we find that all the procedure is represented primarily and pre-eminently as flowing from commands and expressions of will, not from direct acts. Let there be light-let there be a firmament-let the dry land appear-let the earth bring forth grass, the herb, the tree -let the waters bring forth the moving creature that hath life-let the earth bring forth the living creature after his kind-these are the terms in which the principal acts are lescribed. The additional expressions-God made the firmament-God made the beast of the earth, \&c., occur subordinately, and only in a few instances; they do not necessarily convey a different idea of the mode of creation, and indeed only appear as alternative phrases, in the usual duplicative manner of Eastern narrative. Keeping this in view, the words used in a subsequent place, "God formed man in his own image," cannot well be understood as implying any more than what was implied before, namely, that man was produced in consequence of an expression of the Divine will to that effect. Thus the scriptural objection quickly vanishes, and the prevalent ideas about the organic creation appear only as a mistaken inference from the text, formed at a time when man's ignorance prevented him from drawing therefrom a just conclusion. At the same time, I freely own that I do not think it right to adduce the Mosaic record, either in objection to, or support of any natural hypothesis, and this for many reasons, but particularly for this, that there is not the least appearance of an intention in that book to give philosophically exact views of nature.

To a reasonable mind the Divine attributes must appear, not diminished or reduced in any way, by supposing a creation by law, but infinitely exalted. It is the narrowest of all views of the Deity, and characteristic of an humble class of intellects, to suppose him acting constantly in particular ways for particular occasions. It, for one thing, greatly detracts from his foresight, the most unde. 
niable of all the attributes of Omnipotence. It lowers him towards the level of our own humble intellects. Much more worthy of him it surely is, to suppose that all things have been commissioned by him from the first, though neither is he absent from a particle of the current of natural affairs in one sense, seeing that the whole system is continually supported by his providence. Even in human affairs, if I may be allowed to adopt a familiar illustration, there is a constant progress from specific action for particular occasions, to arrangements which, once estab ished, shall continue to answer for a great multitude of occasions. Such plans the enlightened readily form for themselves, and conceive as being adopted by all who have to attend to a multitude of affairs, while the ignorant suppose every act of the greatest public functionary to be the result of some special consideration and care on his part alone. Are we to suppose the Deity adopting plans which harmonize only with the modes of procedure of the less enlightened of our race? Those who would object to the hypothesis of a creation by the intervention of law, do not perhaps consider how powerful an argument in favor of the existence of God is lost by rejecting this doctrine. When all is seen to be the result of law, the idea of an Almighty Author becomes irresistible, for the creation of a law for an endless series of phenomena-an act of intelligence above all else that we can conceive-could have no other imaginable source, and tells, moreover, as powerfully for a sustaining as for an originating power. On this point a remark of Dr. Buckland seems applicable : "If the properties adopted by the elements at the moment of their creation adapted them beforehand to the infinity of complicated useful purposes which they have already answered, and may have still farther to answer, under many dispensations of the material world, such an aboriginal constitution, so far from superseding an intelligent agent, would only exalt our conceptions of the consummate skill and power that could comprehend such an infinity of future uses under future systems, in the original groundwork of his creation."

A late writer, in a work embracing a vast amount of miscellaneous knowledge, but written in a dogmatic style, argues at great length for the doctrine of more immediate exertions on the part of the Deity in the works of his creution. One of the most striking of his illustrations is as 
follows:- "The coral polypi, united by a common an:mal bond, construct a defined form in stone; many kinds construct many forms. An allotted instinct may permit. each polypus to construct its own cell, but there is no superintending one to direct the pattern, nor can the workers unite by consultation for such an end. There is no recipient for an instinct by which the pattern might be constructed. It is God alone, therefore, who is the architect; and for this end, consequently, he must dispose of every new polypus required to continue the pattern, in a new and peculiar position, which the animal could not have discovered by itself:- Yet more, millions of these blind workers unite their works to form an island, which is also wrought out according to a constant general pattern, and of a very peculiar nature, though the separate coral works are numerously diverse. Still less, then, here is an instinct possible. The Great Architect himself must execute what he planned, in each case equally. He uses these little and senseless animals as hands; but they are hands which himself must direct. He must direct each one everywhere, and therefore he is ever acting."* This is a most notable example of a dangerous kind of reasoning. It is now believed that corals have a general life and sensation throughout the whole mass, residing in the nervous tissue which envelopes them; consequently, there is nothing more wonderful in their determinate general forms than in those of other animals.

It may here be remarked that there is in our doctrine that harmony in all the associated phenomena which generally márks great truths. First, it agrees, as we have seen, with the idea of planet-creation by natural law. Secondly, upon this supposition, all inat geology tells us of the succession of species appears natural and intelligible. Organic life presses in, as has been remarked, wherever there was. roum and encouragement for it, the forms being always such as suited the circumstances, and in a certain relation to them, as, for example, where the limestone-forming seas produced an abundance of corals, crinoidea, and shell-fish. Admitting for a moment a rerigination of species after a cataclysm, as has been surmised by some geologists, though the hypothesis is always becoming less and less tenable, it harmonizes with nothing so well as the idea of a creation by law. The more soli-

- Macculloch on tne Attributes of the Deity, iii. 569 
tary commencements of species, which wọuld have oeen the most incoriceivably paltry exercise for an immediately creative power, are sufficiently worthy of one operating by laws.

It is also to be observed, that the thing to be accounted for is not merely the origination of organic being upon this little planet, third of a series which is but one ot hundreds of thousands of series, the whole of which again form but one portion of an apparently infinite globe-peopled space, where all seems analogous. We have to suppose that every one of these numberless globes is either a theatre of organic being, or in the way of becoming so. This is a conclusion which every addition to our knowledge makes only the more irresistible. Is it conceivable, as a fitting mode of exercise for creative intelligence, that it should be constantly moving from one sphere to another, to form and plant the various species which may be required in each situation at particular times? Is such an idea accordant with our general conception of the dignicy, not to speak of the power, of the Great Author? Yet such is the notion which we must form; if we adhere to thi doctrine of special exercise. Let us see, on the other hand, how the doctrine of creation by law agrees with this expanded view of the organic world.

Unprepared as most men may be for such an announcement, there can be no doubt that we are able, in this limited sphere, to form some satisfactory conclusions as to the plants and animals of those other spheres which move at such immense distances from us. Suppose that the first persons of an early nation who made a ship and ventured to sea in it, observed, as they sailed along, a set of objects which they had never before seen-namely, a fleet of other ships-would they not have been justified in supposing that those ships were occupied, like their own, by human beings possessing hands to row and steer, eyes to watch the signs of the weather, intelligence to guide them from one place to another-in short, beings in all respects like themselves, or only showing such differences as they knew to be producible by difference of climate and habits of life. Precisely in this manner we can speculate on the inhabitants of remote spheres. We see that matter has originally been diffused in one mass, of which the spheres are portions, Consequently, inorganic matter must be presumed to be everywhere the same, although 
probably with differences in the proportions of ingredients in different globes, and also some difference of conditions. Out of a certain number of the elements of inorganic matter are composed organic bodies, both vegetable and animal ; such must be the rule in Jupiter and in Sirius, as it is here. We, therefore, are all but certain that herbaceous and ligneous fibre, that flesh and blood, are the constituents of the organic beings of all those spheres which are as yet seats of life. Gravitation we see to be an allpervading principle: therefore there must be a relation between the spheres and their respective organic occupants, by virtue of which they are fixed, as far as necessary, on the surface. Such a relation, of course, involves details as to the density and elasticity of structure, as well as size, of the organic tenants, in proportion to the gravity of the respective planets-peculiarities, however, which may quite well consist with the idea of a universality of general types, to which we are about to come. Electricity we also see to be universal; if, therefore, it be a principle concerned in life and in mental action, as science strongly suggests, life and mental action must everywhere be of one general character. We come to comparatively a matter of detail, when we advert to heat and light; yet it is important to consider that these are universal agents, and that, as they bear marked relations to organic life and structure on earth, they may be presumed to do so in other spheres also. The considerations as to light are particularly interesting, for, on our globe, the structure of one important organ, almiost universally distributed in the animal kingdom, is in direct and precise relation to it. Where there is light there will be eyes, and these, in other spheres, will be the same in all respects as the eyes of tellurian animals, with only such differences as may be necessary to accord with minor peculiarities of condition and of situation. It is but a small stretch of the argument to suppose that, one conspicuous organ of a large portion of our animal kingdom being thus universal, a parity in all the other organs-species for species, class for class, kingdom for kingdom - is highly likely, and that thus the inhabitants of all the other globes of space bear not only a general, but a particular resemblance to those of our own.

Assuming that organic beings are thus spread over all space, the idea of their having all come into existence by the operation of laws everywhere applicable, is only con- 
form ible to that principle, acknowleged to be so generally visible in the affairs of Providence, to have all done by the employment of the smallest possible amount of means Thus, as one set of laws produced all orbs and their mo. tions and geognostic arrangements, so one set of law overspread them all with life. 'The whole productive os creative arrangements are therefore in perfect unity.

\section{PARTICULAR CONSIDERATIONS RESPECTING THE ORIGIN OF ANIMATED TRIBES.}

The general likelihood of an organic creation by law having been shown, we are next to inquire if science has any facts tending to bring the assumption more nearly home to nature. Such facts there certainly are; but it cannot be surprising that they are comparatively few and scattered, when we consider that the inquiry is into one of nature's profoundest mysteries, and one which has hitherto engraged no direct attention in almost any quarter.

Crystallization is confessedly a phenomenon of inorganic matter ; yet the simplest rustic observer is struck by the resemblance which the examples of it left upon a window by frost bear to vegetable forms. In some crystallizations the mimicry is beautiful and complete ; for example, in the well known one called the Arbor Diance. An amalgam of four parts of silver and two of mercury being dissolved in nitric acid and water equal to thirty weights of the metals being added, a small piece of soft amalgam of silver suspended in the solution, quickly gathers to itself the particles of the silver of the amalgam, which form upon it a crystallization precisely resembling a shrub. The experiment may be varied in a way which serves better to detect the influence of electricity in such operations, as noted below.* Vegetable figures are also pre-

* "A glass tube is to be bent into a syphon, and placed with tho curve downwards, and in the bend is to be placed a small portion of mercury, not sufficient to close the connexion between the two legs ; a solution of nitrate of silver is then to be introduced until it rises in both limbs of the tube. The precipitation of the mercury, in the form of an Arbor Dianæ, will then take place, slowly, only when the syphon is placed in a plane perpendicular to the magnetic meridian; but if it be placed in a plane coinciding with the mag. retic ineridian, the action is rapid, and the crystallization particu- 
ented in some of the most ordinary appearances of the slectric fluid. In the marks caused by positive electricity, or which it leaves in its passage, we see the ramifications of a tree as well as of its individual leaves; those of the negative, recall the bulbous or the spreading root, according as they are clumped or divergent. These phenomena seem to say that the electric energies have had something to do in determining the forms of plants. That they are intimately connected with vegetable life is indubitable, for germination will not proceed in water charged with negative electricity, while water charged positively greatly favors it; and a garden sensibly increases in luxuriance, when a number of conducting rods are made to terminate in branches over its beds. With regard to the resemblance of the ramifications of the branches and leaves of plants to the traces of the positive electricity, and that of the roots to the negative, it is a circumstance calling for especial remark, that the atmosphere, particularly its lower strata, is generally charged positively, while the earth is always charged negatively. The correspondence here is curious. A plant thus appears as a thing formed on the basis of a natural electrical operation-the brush. realized. We can thus suppose the various forms of plants as, immediately, the result of a law in electricity variously affecting them according to their organic character, or respective germinal constituents. In the poplar, the brush is unusually vertical, and little divergent ; the reverse in the beech; in the palm, a pencil has proceeded straight up for a certain distance, radiates there, and turns outwards and downwards ; and so on. We can here see at least traces of secondary means by which the Almighty Deviser might establish all the vegetable forms with which the earth is oyerspread.

Vegetable and animal bodies are mainly composed of the same four simple substances or elements-carbon, oxygen, hydrogen, ąnd nitrogen. The first combinations of these in animals are into what are called proximate principles, as albumen, fibrin, urea, alantoin, \&c., out of which the structure of the animal body is composed. larly beautiful, taking place principally in that branch of the sy. phon towards the north. If the syphon be placed in a plane per. pendicular to the magnetic meridian, and a strong magnet brought vear it, the precipitation will commence in a short time, and be most copious in the branch of the syphon nearest to the south pole of the magnet." 
Now the chemist, by the association of two parts ( $/ x y$ gen, four hydrogen, two carbon, and two nitrogen, can make urea. Alantoin has also been produced artificially. Two of the proximate principles being realizable by human care, the possibility of realizing or forming all its established. Thus the chemist may be said to have it in his power to realize the flrst step in organization.* Indeed, it is fully acknowledged by Dr. Daubeny, that in the combinations forming the proximate principles there is no chemical peculiarity. "It is now certain," he says, "that the same simple laws of composition pervade the whole creation; and that, if the organic chemist only takes the requisite precautions to avoid resolving into their ulimate elements the proximate principles upon which he operates, the results of his analysis will show that they are combined precisely according to the same plan as the elements of mineral bodies are known to be." $\dagger$ A particular fact is here worthy of attention. "The conversion of fecula into sugar, as one of the ordinary processes ot vegetable economy, is effected by the production of a secretion termed diastose, which occasions both the rupture of the starch vesicles, and the change of their contained gum into sugar. This diastose may be separately obtained by the chemist, and it acts as effectually in his laboratory as in the vegetable organization. He can also imitate its effects by other chemical agents." $\ddagger$ The writer quoted below adds, " No reasonable ground has yet been adduced for supposing that, if we had the power of bringing together the elements of any organic compound, in their requisite states and proportions, the result would be any other than that which is found in the living body."

It is much to know the elements out of which organic bodies are composed. It is something more to know their first combinations and that these are simply chemical. How these combinations are associated in the structure of living bodies is the next inquiry, but it is one to which as yet no satisfactory answer can be given. The investigation of the minutiæ of organic structure by the microscopo

* Fatty matter has also been formed in the laboratory. The pro cess consited in passing a mixture of carbonic acid, pure hydrogen and carburetted hydrogen in the proportion of one measure of the first, twenty of the second, and ten of the third, thro'agh a red-hot tube.

f Supplement to the Atomic Theory.

¥ Carpenter on Life; Todd's Cyclopædia of Physiology. 
is of such recent origin, that its results cannot be expected to be very clear. Some facts however, are worthy of attention with regard to the present inquiry. It is ascertaired that the basis of all vegetible and animal substances consists of nucleated cells ; that is, cells having granules within them. Nutriment is converted into these before being assimilated by the system. The tissues are formed from them. The ovum destined to become a new creature, is originally only a cell with a contained granule We see it acting this reproductive part in the simplest manner in the cryptogamic plants. "The parent cell arrived at maturity by the exercise of its organic functions, bursts, and liberates its contained granules. These, at orice thrown upon their own resources, and entirely dependent for their nutrition on the surrounding elements, develope themselves into new cells, which repeat the life of their original. Amongst the higher tribes of the cryptogamia, the reproductive cell does not burst, but the first cells of the new structure are developed within it, and these gradually extend, by a similar process of multiplication, into that primary leaf-like expansion which is the first formed structure in all plants."* Here the little cell becomes divectly a plant, the full-formed living body. It is also worthy of remark that, in the sponges, (an animal form,) a gemmule detached from the body of the parent, and trusting for sustentation only to the fluid into which it has been cast, becomes, without further process, the new creature. Farther, it has been recently discovered by means of the microscope, that there is, as far as can be judged, a perfect resemblance between the ovum of the mammal tribes during that early stage when it is passing through the oviduct, and the young of the infusory animalcules. One of the most remarkable of these, the volvoa globator, has exactly the form of the germ which after passing through a long fœtal progress becomes a complete mammifer, an animal of the highest class. It has even been found that both are alike provided with those cilia, which, producing a revolving motion, or its appearance, is partly the cause of the name given to this animalcule. These resemblances are the more entitled to notice, that they were made by various observers, distant from

* Carpenter's Report on the Results obtained by the Microscope in the study of Anatomy and Physiology, 1843. 
each other at the time.* It has likewise been zoted that the globules of the blood are reproduced by the expansion of contained granules; they are, in short, distinct organisms multiplied by the same fissiparous generation. So that all animated nature may be said to be based on this mode of origin; the fundamental form of organic being is a globule, having a new globule forming within itself, by which it is in time discharged, and which is again followed by another and another, in endless succession. It is of course obvious that, if these globules could be produced by any process from inorganic elements, we should be entitled to say that the fact of a transit from the inorganic into the organic had been witnessed in that in: stance; the possibility of the commencement of animated creation by the ordinary laws of nature might be considered as established. Now it was given out some years ago by a French physiologist, that globules could be produced in albumen by electricity. If, therefore, these globules be identical with the cells which are now held to be reproductive, it might be said that the production of albumen by artificial meaus is the only step in the process wanting. This has not yet been affected but it is known to be only a chemical process, the mode of which may be any day discovered in the laboratory, and two compounas perfectly co-ordinate, urea and alantoin, have actually been produced.

In such an investigation as the present, it is not unworthy of notice, that the production of shell is a natural operation which can be precisely imitated artificially. Such an incrustation takes place on both the outside and inside of the wheel in a bleaching establishment, in which cotton cloth is rinsed free of the lime employed in its purification. From the dressing employed by the weaver, the cloth obtains the animal matter, gelatin; this and the lime form the constituents of the iricrustation, exactly as in natural shell. In the wheel employed at Catrine, in Ayrshire, whele the phenomenon was first observed by the eye of science, it had required ten years to produce a coating the tenth on inch in thickness. This incrustation has all the characters of shell, displaying a highly polished surface, beautifully iridescent, and, when bro-

* See Dr. Martin Barry or Fissiparous Generation : Jameson's Journal, Oct., 1843. Appearances precisely similar have been detected in the germs of the crustace a. 
ken, a foliated texture. The examination of it has even thrown some light on the character and mode of formation of natural shell. "The plates into which the substance is divisible have been formed in succession, and certain intervals of time have elapsed between their formation; in general, every two contiguous laminæ are senarated by a thin iridescent film, varying from three to the fifty millionth part of an inch in thickness, and producing all the various colors of thin plates, which corregpond $t_{1}$ intermediate thicknesses: between some of the laminæ no such film exists, probably in consequence of the interval of time between their formation being too short; and between others, the film has been formed of unequal thickness. There can be no doubt that these iridescent films are formed when the dash-wheel is at rest during the night, and that when no film exists between two laminæ, an interval too short for its formation (arising, perhaps, from the stopping of the work during the day) has elapsed during the drying or induration of one lamina and the deposition of another."* From this it has been deduced, by a patient investigation, that those colors of mother-of-pearl, which are inconımunicable to wax, arise from iridescent films deposited between the laminæ of its structure; and it is hence inferred that the animal, like the wheel, rests periodically from its labors in forming the natural substance.

These, it will be owned, are curious and not irrelevant facts; but it will be asked what actual experience says respecting the origination of life. Are there, it will be said, any authentic instances of either plants or animals, of however humble and simple a kind, having come into existence otherwise than in the ordinary way of generation, since the time of which geology forms the record? It may be answered that the negative of this question could not he by any means formidable to the doctrine ot law-creation, seeing that the conditions necessary for the operation of the supposed life-creating laws may not have existed within record to any great extent. On the other hand, as we see the physical laws of early times still acting with more or less force, it might not be unreasonable to expect that we should still see some remnants, or partial and occasional workings of the life-creating energy

* Mr. Leonard Hornor and Sir David Brewster, on a substance resembling shell.-Philosophical Transactions, 1536. 
anidst a system of things generally stable and at res? A t. there, then, any such remnants to be traced in our ow? day, or during man's existence upon earth ? If there br, it clearly would form a strong evidence in favor of the doctrine, as what now takes place upon a confined scale and in a comparatively casual manner, may have formerly taken place on a great scale, and as the proper and eternity-destined means of supplying a vacant globe with suitable tenants. It will at the same time be observed that, the earth being now supplied with both kinds of tenants in great abundance, we only could expect to find the life-originating power at work in some very special and extraordinary circumstances, and probably only in the inferior and obscurer deparments of the vegetable and animal kingdoms.

Perhaps, if the question were asked of ten men of approved reputation in science, nine out of the number would answer in the negative. 'This is becalise, in a great number of instances where the superficial observers of former times assumed a non-generative origin for life, (as in the celebrated case in Virgil's fourth Georgic,) either the direct contrary has been ascertained, or exhaustive experiments have left no alternative from the conclusion that ordinary generation did take place, albeit in a manner which escapes observation. Finding that an erroneous assumption has been formed in many cases, modern inquirers have not hesitated to assume that there can be no case in which generation is not concerned; an assumption not only unwarranted by, but directly opposed to, the principles of philosophical investigation. Yet this is truly the point at which the question now rests in the scientific world.

I have no wish here to enter largely into a subject so wide and so iull of difficulties; but I may remark, that the explanations usually suggested where life takes its rise without apparent generative means, alwavs appear to me to partake much of the fallacy of the petitio principii. When, for instance, lime is laid down upon a piece of waste moss ground, and a crop of white clover for which no seeds were sown is the consequence, the explanation that the seeds have been dormant there for an unknown time, and were stimulated into germination when the lime produced the appropriate circumstances, appears extreinely unsatisfactory, ospecially when we know that (as in 
an authentic case under my notice) the spot is many miles from where clover is cultivated, and that there is nothing for six feet below but pure peat moss, clover seeds being, moreover, known to be too heavy to be transported, as many other seeds are, by the winds. Mushrooms, we know, can be propagated by their seed; but another mode of raising them, well known to the gardener, is to mix cow and horse dung together, and thus form a bed in which they are expected to grow without any seed being planted. It is assumed that the seeds are carried by the atmosphere, unperceived by us, and, finding here an appropriate field for germination, germinate accordingly; but this is only assumption, and though designed to be on the side of a severe philosophy, in reality makes a pretty large demand on credulity. There are several persons eminent in science who profess at least to find great difficulties in accepting the doctrine of invariable generation. One of these, in the work noted below, ${ }^{*}$ has stated several considerations arising from analogical reasoning, which appear to him to throw the balance of evidence in favor of the aboriginal production of infusoria, $\uparrow$ the vegetation called mould, and the like. One seems to be of great force; namely, that the animalcules, which are supposed (altogether hypothetically) to be produced by ova, are afterwards found increasing their numbers, not by that mode at all, but by division of their bodies. If it be the nature of these creatures to propagate in this splitting or fissiparous manner, how could they be communicated to a vegetable infusion? Another fact of very high importance is presented in the following terms: "The nature of the animalcule, or vegetable production, bears a constant relation to the state of the infusion, so that, in similar circumstances, the same are always produced without this being influenced by the atmosphere. There seems to be a certain progressive advance in the productive powers of the infusion, for at the first the animalcules are only of the smaller kinds, or monades, and afterwards they become gradually larger and more complicated in their structure; after a time, the production ceases, although. the materials are by no means exhausted. When the

* Dr. Allen Thomson, in the article Generation, in Todd's Cy clopædia of Anatomy and Physiology.

$\dagger$ The term aboriginal is here suggested, as more correct than spontaneous, the one hitherto generally used. 
quantity of water is very small, and the organic matter abundant, the production is usually of a vegetable nature: when there is much water, animalcules are more frequent. ly produced." It has been shown by the opponents of this theory, that when a vegetable infusion is debarred from the contact of the atmosphere, by being closely sealed up or covered with a layer of oil, no animalcules are produced; but it has been said, on the other hand, that the exclusion of the air may prevent some simple condition necessary for the aboriginal development of life-and nothing is more likely. Perhaps the prevailing doctrine is in nothing placed in greater difficulties than it is with regard to the entozoa, or creatures which live within the bodies of others. These creatures do, and apparently can, live rowhere else than in the interior of other living bodies, where they generally take up their abode in the vis. cera, but also sometimes in the chambers of the eye, the interior of the brain, the serous sacs, and other places having no communication from without. Some are viviparous, others oviparous. Of the latter it cannot reasonably be supposed that the ova ever pass through the medium of the air, or through the blood-vessels, for they are too heavy for the one transit, and too large for the other. of the former, it cannot be conceived how they pass into young animals-certainly not by communication from the parent, for it has often been found that entozoa do not appear in certain generations, and some of peculiar and noted character have only appeared at iare intervals, and in very extraordinary circumstances. A candid view of the less popular doctrine, as to the origin of this humble form of life, is taken by a distinguished living naturalist. "To explain the beginning of these worms within the human body, on the common doctrine that all created beings procecd from their likes, or a primordial egg, is so difficult, that the moderns have been driven to speculate, as our fathers did, on their spontaneous birth ; but they have received the hypothesis with some modification. Thus it is not from putrefaction or fermentation that the entozoa are born, for both of these processes are rather fatal to their existence, but from the aggregation and fit apposition of matter which is already organized, or has been thrown from organized surfaces. * * Their origin in this manner is not more wonderful or more inexplicable than that of many of the inferior animals from sections of 
themselves. * * Particles of matter fitted by digestion, and their transmission through a living body for immediate assimilation with it, or flakes of lymph detached from surfares already organized, seem neither to exceed nor bali below that simplicity of structure which favors this wouderful development; and the supposition that, like morsels of a planaria, they may also, when retained in contact with living parts, and in other favorable circumstances, continue to live and be gradually changed into creatures of analogous conformation, is surely not so absurd as to be brought into comparison with the Metamorphoses of Ovid. ** We think the hypothesis is also supported in some degree by the fact, that the origin of the entozoa is favored by all causes which tend to disturb the equality between the secerning and absorbent systems." Here particles of organized matter are suggest-" ed as the germinal origin of distinct and fully organized animals, many of which have a highly developed reproductive system. How near such particles must be to the inorganic form of matter may be judged from what has been said within the last few pages. If, then, this view of the production of entozoa be received, it must be held as in no small degree farorable to the general doctrine of an organic creation by law.

There is another series of facts, akin to the above, and which deserves not less attention. The pig, in its domestic state, is subject to the attacks of a hydatid, from which the wild animal is free; hence the disease called measles in pork. The domestication of the pig is of course an event subsequent to the origin of man ; indeed, comparatively speaking a recent event. Whence, then, the first progenitor of this hydatid? So also there is a tinea which attacks dressed wool, but never touches it in its unwashed state. A particular insect disdains all food but chocolate, and the larva of the oinopota cellaris lives nowhere but in wine and beer, all of these being articles manufactured by man. There is likewise a creature called the pymelodes cyclopum, which is only found in subterranean cavities connected with certain specimens of the volcanic formation in South America, dating from a time posterior to the arrangements of the earth for our species. Whence the first pymelodes cyclopum? Will it, to a geologist, appear irrational to suppose that, just as the pterodactyle

* Article "Zoophytes," Encyclopædia Britannica, 7th edition. 
was added in the era of the new red sandstone, when the earth had become suited for such a creature, so may these creatures have been added when media, suitable for their existence arose, and that such phenomena may take place any day, the only cause for their taking place seldom being the rarity of the rise of new physical conditions on a globe which seems to have already undergone the principal part of its destined mutations?

Between such isolated facts and the greater changes which attended various geological eras, it is not easy to see any difference, besides simply that of the scale on which the respective phenomena took place, as the throwing off of one copy from an engraved plate is exactly the same process as that by which a thousand are thrown off. Nothing is more easy to conceive than that to Creative ?rovidence the numbers of such phenomena, the time ivhen, and the circumstances under which they take place, are indifferent matters. The Eternal One has arranged for everything beforehand, and trusted all to the operation of the laws of his appointment, himself being ever present in all things. We can even conceive that man, in his many doings upon the surface of the earth, may occasionally, without his being aware of it, or otherwise, act as an instrument in preparing the association of conditions under which the creative laws work; and perhaps some instances of his having acted as such an instrument have actually occurred in our own time.

I allude, of course, to the experiments conducted a few years ago, by $\mathrm{Mr}$. Crosse, which seemed to result in the production of the heretofore unknown species of insect in considerable numbers. Various causes have prevented these experiments and their results from receiving candid treatment, but they may perhaps be yet found to have opened up a new and most interesting chapter of nature's mysteries. Mr. Crosse was pursuing some experiments in crystallization, causing a powerful voltaic battery to operate upon a saturated solution of silicate of potash, when the insects unexpectedly made their appearance. He afterwards tried nitrate of copper, which is a deadly poison, and from that fluid also did live insects emergc Discouraged by the reception of his experiments, M: Crosse soon discontinued them; but they were some years after pursued by $\mathrm{Mr}$. Weekes, of Sandwich, with preciselv the same results. This gentleman, besides trying 
the first of the above substances, employed ferro-cyanet of potash, on account of its containing a larger proportion of carbon, the principal element of organic bodies; and from this substance the insects were produced in increused numbers. A few weeks sufficed for this experiment, with the powerful battery of Mr. Crosse, but the first attempts of Mr. Weekes required about eleven months, a ground of presumption in itself that the electricity was chiefly concerned in the phenomenon. The changes undergone by the fluid operated upon, were in both cases remarkable, and nearly alike. In Mr. Weekes' apparatus, the silicate of potash became first turbid, then of a milky appearance; round the negative wire of the battery, dipped into the fluid, there gathered a quantity of gelatinous matter, a part of the process of considerable importance, considering that gelatin is one of the proximate principles, or first compounds of which animal bodies are formed. From this matter, Mr. Weekes observed one of the insects in the very act of emerging, immediately after which, it ascended to the surface of the fluid and sought concealment in an obscure corner of the apparatus. The insects produced by both experimentalists seem to have been the same, a species of acarus, minute and semi-transparent, and furnished with long bristles, which can only be seen by the aid of the microscope. It is worthy of remark, that some of these insects, soon after their existence had commenced, were found to be likely to extend their species. They were sometimes observed to go back to the fluid to feed, and occasionally they devoured each other.*

The reception of novelties in science must ever be regulated very much by the amount of kindred or relative phenomena which the public mind aready possesses and acknowledges, to which the new can be assimilated. A novelty, however true, if there be no received truths with which it can be shown in harmonious relation, has little chance of a favorable hearing. In fact, as has often been observed, there is a measure of incredulity from our ignorance as well as from our knowledge, and if the most distinguished philosopher three hundred years ago, had ventured to develop any striking new fact which only could harmonize with the as yet unknown Copernican solar system, we cannot doubt that it would have been universally scoffed at in the scientific world, such as it then

* See a pamphlet circulated by Mr. Weekes, in 1842. 
was, or at the best interpreted in a thousand wrong ways in conformity with ideas already familiar. The experiments above described, finding a public mind which had never discovered a fact or conceived an idea at all analogous, were, of course, ungraciously received. It was held to be impious, even to surmise that animals could have been formed through any instrumentality of an apparatus devised by human skill. The more likely account of the phenomena was said to be, that the insects were only developed from ova, resting either in the fluid, or in the wooden frame on which the experiments took place. On these objections the following remarks may be made. The supposition of impiety arises frum an entire misconception of what is implied by an aboriginal creation of insects. The experimentalist could never be considered as the author of the existence of these creatures, except by the most unreasoning ignorance. The utmost that can be claimed for, or Imputed to him, is, that he arranged the natural conditions under which the true creative energy-that of the Divine Author of all things-was pleased to work in that instance. On the hypothesis here brought forward, the acarus Crossii was a type of being ordained from the beginning, and destined to be realized under certain physical conditions. When a human hand brought these conditions into the proper arrangement, it did an act akin to hundreds of familiar ones which we execute every day, and which are followed by natural results; but it did nothing more. The production of the insect if it did take place as assumed, was as clearly an act of the Almighty himself, as if he had fashioned it with hands. For the presumption that an act of aboriginal creation did takeplace, there is this to be said that, in Mr. Weekes's experiment, every care that ingenuity could devise was taken to exclude the possibility of a development of the insects from ova. The wood of the frame was baked in a powerful heat ; a bell-shaped glass covered the apparatus, and from this the atmosphere was excluded by the constantly rising fumes from the liquid, for the emission of which there was an aperture so arranged at the top of the glass, that only these fumes could pass. 'The water was distilled, and the substance of the silicate had been subjected to white heat. 'Thus every source of fallacy seemed to be shut up. In such circumstances, a candid mind, which sees nothing either impious or unphi- 
osophical in the idea of a new creation, will be dispnosed lo think that there is less difficulty in believing in such a creation having actually taken place, than in believing that, in two instances separated in place and time, exactly the same insects should have chanced to arise from concealed ova, and these a species hert tofcre unknown.

\section{HYPOTHESIS OF THE DEVELOPMENT}

\section{OF THE VEGETABLE AND ANIMAL KINGDOMS.}

Ir his been already intimated, as a general fact, that there is an obvious gradation among the families of both the vegetable and animal kingdoms, from the simple lichen and animalcule respectively up to the highest order of dicotyledonous trees and the mammalia. Confining our attention, in the meantime, to the animal kingdomit does not appear that this gradation passes along one line, on which every form of life can be, as it were, strung; there may be branching or double lines at some places, or the whole may be in a circle composed ot minor circles, as has been recently suggested. But still it is incontestable that there are general appearances of a scale beginning with the simple and advancing to the complicated. The animal kingdom was divided by Cuvier into four sub-kingdoms, or divisions, and these exhibit an unequivocal gradation in the order in which they are here enumerated: Radiata (polypes, \&c.;) mollusca (pulpy animals;) articulata (jointed animals;) vertebrata (animals vith internal skeleton.) The gradation can, in like manner, be clearly traced in the classes into which the sub-kingdoms are subdivided, as, for instance, when we take those of the vertebrata in this order-reptiles, fishes, birds, mammals.

While the external forms of all these various animals are so different, it is very remarkable that the whole are, after all, variations of a fundamental plan, which can be traced as a basis throughout the whole, the variations beıng merely modifications of that plan to suit the particular conditions in which each particular animal has been designed to live. Starting from the primeval germ, which as we have seen, is the representative of a particular order 
of full-grown animals, we find all others to be merely advances from that tvpe, with the extension of endowments and modification of forms which are required in each particular case; each form, also, retaining a strong affinity to that which precedes it, and tending to impress its own features on that which succeeds. This unity of structure, as it is called, becomes the more remarkabie, when we observe that the organs, while preserving a resemblance, are often put to different uses. For example: the ribs become, in the serpent, organs of locomotion, and the snout is extended, in the elephant, into a prehensile instrument.

It is equally remarkable that analogous purposes are served in different animals by organs essentially different. Thus, the mammalia breathe by lungs; the fishes, by gills. These are not modifications of one organ, but distinct organs. In mammifers, the gills exist and act at an early stage of the fœtal state, but afterward go back and appear no more; while the lungs are developed. In fishes, again, the gills only are fully developed; while the lung structure either makes no advance at all, or only appears in the rudimentary form of an air-bladder. So, also, the baleen of the whale and the teeth of the land mammalia are different organs. The whale, in embryo, shows the rudiments of teeth; but these, not being wanted, are not developed, and the baleen is brought forward instead. The land animals, we may also be sure, have the rudiments of baleen in their organization. In many instances, a particular structure is found advanced to a certain point in a particular set of animals (for instance, feet in the serpent tribe), although it is not there required in any degree; but the peculiarity, being carried a little farther forward, is perhaps useful in the next set of animals in the scale. Such are called rudimentary organs. With this class of phenomena are to be ranked the useless mammæ of the male human being, and the unrequired process of bone in the male opossum, which is needed in the female for supporting her pouch. Such curious features are most conspicuous in animals which form links between various classes.

As formerly stated, the marsupials, standing at the bot. tom of the mammalia, show their affinity to the oviparous vertebrata, by the rudiments of two canals passing from near the anus to the external surfaces of the viscera, which 
are fully developed in fishes, being required by them for the respiration of aerated waters, but which are not need. ed by the atmosphere-breathing marsupials. We have also the peculiar form of the sternum and rib-bones of the lizards represented in the mammalia in certain white carcilaginous lines traceable among their abdominal muscles. The struphionidæ (birds of the ostrich type) form a link cetween birds and mammalia, and in them we find the Nings imperfectly or not at all developed, a diaphragm and urinary sac (organs wanting in other birds,) and feathers approaching the nature of hair. Again, the ornithorynchus belongs to a class at the bottom of the mammalia, and approximating to birds, and in it behold the bill and the web-feet of that order!

For farther illustration, it is obvious that, various as may be the lengths of the upper part of the vertebral col umn in the mammalia, it always consists of the same parts. The girafie has in its tall neck the same number of bones with the pig, which scarcely appears to have a neck at all.* Man, again, has no tail ; but the notion of a muchridiculed philosopher of the last century is not altogether, as it happens, without foundation, for the bones of a caudal extremity exist in an undeveloped state in the os coccygis of the human subject. 'The limbs of all the vertebrate animals are, in like manner, on one plan, however various they may appear. In the hind leg of a horse, for example, the angle called the hock is the same part which in us forms the heel; and the horse, and all other quadrupeds, with almost the solitary exception of the bear, walk, in reality, upon what answer to the toes of a human being. In this and many other quadrupeds the fore part of the extremities is shrunk up in a hoof, as the tail of a human being is shrunk up in the bony mass at the bottom of the back. 'The bat, on the other hand, has these parts largely developed. The membrane, commonly called its wing, is framed chiefly upon bones answering precjsely to those of the human hand; its extinct congener, the pterodactyle, had the same membrane extended upon the fore-finger only, which in that animal was prolonged to an extraordinary extent. In the paddles of the whale, and other animals of its order, we see the same bones as in the more highly developed extremities of the land

* Daubenton established the rule, that all the viviparous quad rupeds have seven vertebræ in the neck. 
manmifers; and even the serpent tribes, which present no external appearance of such extremities, possess them in reality, but in an undeveloped or rudimental state.

The same law of development presides over the vegetable kingdom. Amongst phanerogamous plants, a certain number of organs appear to be always present, either in a developed or rudimentary state; and those which are rudimentary can be developed by cultivation. The flowers, which bear stamens on one stalk and pistils on another can be caused to produce both, or to become perfect flowers,-by having a sufficiency of nourishment supplied to them. So also, where a special function is required for particular circumstances, nature has provided for it not by a new organ, but by a modification of a common one, which she has effected in development. Thus, for instance, some plants destined to live in arid situations, require to have a store of water which they may slowly absorb. The need is arranged for by a cup-like expansion round the stalk, in which water remains after a shower. Now the pitcher, as this is called, is not a new organ, but simply a metamorphose of a leaf.

These facts clearly show how all the various organic forms of our world are bound up in one-howea fundamental unity pervades and embraces them all, collecting them, from the humblest lichen up to the highest mammifer, in one system, the whole creation of which must have depended upon one law or decree of the Almighty, though it did not all come forth at one time. After what we have seen, the idea of a separate exertion for each must appear totally inadmissible. The single fact of abortive or rudimentary organs condemns it ; for these, on such a supposition, could be regarded in no other light than as blemishes or blunders-the thing of all others most irreconcilable with that idea of Almighty Perfection which a general view of nature so irresitibly conveys. On the other hand, when the organic creation is admitted to have been effected by a general law, we see nothing in these abor tive parts but harmless peculiarities of development, and interesting evidences of the manner in which the Divine Author has been pleased to work.

We have yet to advert to the most interesting class of facts connected with the laws of organic development. It is only in recent times that physiologists have observed that each animal passes, in the course of its germinal his- 
tory, through a series of changes resembling the permanent forms of the various orders of animals inferior to it in the scale. Thus, for instance, an insect, standing at the head of the articulated animals, is, in the larva stite, a true nnelid, or worm, the annelida being the lowest in the same class. The embyro of a crab resembles the perfect nimal of the inferior order myriapoda, and passes through all the forms of transition which characterize the intermediate tribes of crustacea. The frog, for some time after its birth, is a fish with external gills, and other organs fitting it for an aquatic life, all of which are changed as it advances to maturity, and becomes a land animal. The mammifer only passes through still more stages, according to its higher place in the scale. Nor is man himself exempt from this law. His first form is that which is permanent in the animalcule. His organization gradually passes through conditions generally resembling a fish a reptile, a bird, and the lower mammalia, before it attains its specific maturity. At one of the last stages of his fœtal career, he exhibits an intermaxillary bone, which is characteristic of the perfect ape; this is suppressed, and he may then be said to take leave of the simial type, and become a true human creature. Even, as we shall see, the varieties of his race are represented in the progressive development of an individual of the highest, before we see the adult Caucasian, the highest point yet attained in the animal scale.

To come to particular points of the organization. The brain of man, which exceeds that of all other animals in complexity of organization, and fulness of development, is, at one early period, only " a simple fold of nervous matter, with difficulty distinguishable into three parts, while a little tail-like prolongation towards the hinder parts, and which had been the first to appear, is the only representation of a spinal marrow. Now, in this state it perfectly resembles the brain of an adult fish, thus assuming in transitu the form that in the fish is permanent. In-a short time, however, the structure is become more complex, the parts more distinct, the spinal marrow better marked; it is now the brain of a reptile. The change continues; by a singular motion, certain parts, (corpora quadragemina) which had hitherto appeared on the upper surface now pass towards the lower; the former is their permanent situation in fishes and reptiles, the latter in birls 
and mammalia. This is another advance in the scaie, but more remains yet to be done. The complication of the organ increases; cavities termed ventricles are formed, which do not exist in fishes, reptiles, or birds; curiously. organized parts, such as the corpora striata, are added; if is now the brain of the mammalia. Its last and final change alone seems wanting, that which shall render it the brain of maN."* And this change in time takes place.

So also with the heart. This organ, in the mammalia, consists of four cavities, but in the reptiles of only three, and in fishes of two only, while in the articulated animals it is merely a prolonged tube. Now in the mammal foetus, at a certain early stage, the organ has the form of a prolonged tube; and a human being may be said to have ther the heart of an insect. Subsequently it is shortened and widened, and becomes divided by a contraction into two parts a ventricle and an auricle; it is now the heart of a fish. A subdivision of the auricle afterwards makes a triple chambered form, as in the heart of the reptile tribes; lastly, the ventricle being also subdivided, it becomes a full mamma? heart.

Another illustration here presents itself with the force of the most powerful and interesting analogy. Some of the earliest fishes of our globe, those of the Old Red Sandstone, present, as we have seen, certain peculiarities, as the orie-sided tail and an inferior position of the mouth. No fishes of the present day, in a mature state, are so characterized; but some, at a certain stage of their existence, have such peculiarities It occurred to a geologist to inquire if the fish which existed before the Old Red Sandstone had any peculiarities assimilating them to the fotal condition of existing fish, and particularly if they were small. The first which occur before the time of the Old Red Sandstone, are those described by Mr. Murchison, as belonging to the Upper Ludlow Rocks; they are all rather small. Still older are those detected by Mr. Philips, in the Aymestsy Limestone, being the most ancient of the class which have as yet been discovered; these are so extremely minute as only to be distinguishable by the microscope. Here we apparently have very clear demon. strations of a parity, or rather identity, of laws presiding

* Lord's Popular Physiology. It is to Tiedemann that we chief. ly owe these curious ohservations- but ground was first broken in this branch of physiological science by Dr. John Hunter 
ever the development of the animated tribes on the face of the earth, and that of the individual in embryo.

The tendency of all these illustrations is to make us look to develonment as the principle which has been iminediately concerned it. the peopling of this globe, a process extending over a vast space of time, but which is nevertheless connected in character with the briefer process by which an individual being is evoked from a simple germ. What mystery is there here-and how shall I proceed to enunciate the conception which I have ventured to form of what may prove to be its proper solution! It is an idea by no means calculated to impress by its greatness, or to puzzle by its profoundness. It is an idea more marked by simplicity than perhaps any other of those which have explained the great secrets of nature. But in this iies, perhaps, one of its strongest claims to the faith of mankind.

The whole train of animated beings, from the simplest and oldest up to the highest and most recent, are, then, to be regarded as a series of advances of the principle of development, which have depended upen external physical circumstances, to which the resulting animals are appropriate. I contemplate the whole phenomena as having been in the first place arranged in the counsels of Divine Wisdom, to take place not only upon this sphere, but upon all the others in space, under necessary modifications. and as being carried on, from first to last, here and elsewhere, under the immediate favor of the creative will or energy.* The nucleated vesicle, the fundamental form of all organization, we must regard as the meeting-point between the inorganic and the organic-the end of the mineral and the beginning of the vegetable and animal kingdoms, which thence start in different directions, but in perfect parallelism and analogy. We have already seen that this nucleated vesicle is itself a type of mature and independent being in the infusory animalcules, as well as the starting point of the fotal progress of every higher individual in creatior, both animal and vegetable. We have

* When I formed this idea, I was not aware of one which seems faintly to foreshadow it-namely, Socrates's doctrine, afterwards dilated on by Plato, that "previous to the existence of the world, and beyond its present limits, there existed certain archetypes, the einbodirnent (if we may use such a word) of general ideas; and that these archetypes were models, in imitation of which all parti. cular beings were created." 
seen that it is a form of being which electric agency will produce-though not, perhaps, usher into full life-in albumen, one of those compound elements of animal bodies, of which another (urea) has been made by artificial means. Remembering these things, we are drawn on to the supposition, that the first step in the creation of life upon this planet was a chemico-electric operation, by which simple germinal vesicles were produced. This is so much, but what were the next steps? Let a common vegetable infusion help us to answer. There, as we have seen, simple forms are produced at first, but afterwards they become more complicated, until at length the lifeproducing powers of the infusivis are exhausted. Are we to presume that, in this case, the simple engender the complicated? Undoubtedly, this would not be more wonderful as a natural process than one which we never think of wondering at, because familiar to us-namely, that in the gestation of the mammals, the animalcule-like ovum of a few days is the parent, in a sense, of the chick-like form of a few weeks, and that in all the subsequent stages -fish, reptile, \&c. - the one may, with scarcely a metaphor be said to be the progenitor of the other. I suggest, then, as an hypothesis already countenanced by much that is ascertained, and likely to be further sanctioned by much that remains to be known, that the first step was an advance under favor of peculiar conditions, from the simplest forms of being, to the next more complicated, and this through the medium of the ordinary process of generation.

Unquestionably, what we ordinarily see of nature is calculated to impress a conviction that each species invariably produces its like. But I would here call attention to a remarkable illustration of natural law which has been brought forward by $\mathrm{Mr}$. Babbage, in his $\mathcal{N}$ inth Bridgewater Treatise. The reader is requested to suppose himself seated before the calculating machine, and observing it. It is moved by a weight, and there is a wheel which revolyes through a small angle round its axis, at short intervals, presenting to his eye successively, a series of numbers engraved on its divided circumference.

Let the figures thus seen be the series, $1,2,3,4,5$, \&c. of natural $r$ umbers, each of which succeeds its immediate antecedent y unity.

"Now, eader," says Mr. Babbage, "let me ask you 
how ling you will have counted before yox are firmly convinced that the engine has been so adjusted that it will continue, while its motion is maintained, to produce the same series of natural numbers? Some minds are so constituted that, after passing the first hundred terms, they will be satisfied that they are acquainted with the law. After seeing five hundred terms few will doubt, and after the fifty-thousandth term the propensity to believe that the succeeding term will be fifty thousand and one, will be almost irresistible. That the term will be fifty thousand and one; and the same regular succession will continue; the five millionth and the fifty millionth term will still appear in their expected order, and one unbroken chain of natural numbers will pass before your eyes,

- from one up to one hundred million.

"True to the vast induction which has been made, the next succeeding term will be one hundred million and one; but the next number presented by the rim of the wheel, instead of being one hundred million and two, is one hundred million ten thousand and two. 'The whos: series, from the commencement, being thus, -

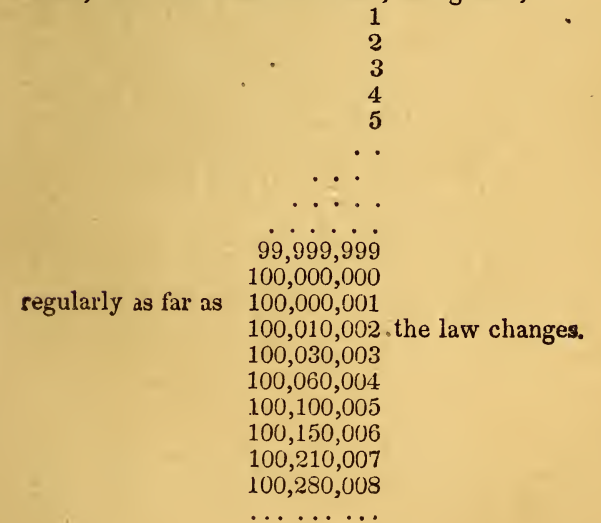

"The law which seemed at first to govern this series failed at the hundred million and second term. This 
Terves ia larger than we expected by 10,000 . The next tersa is larger than was anticipated by 30,000 , and the gxtoris of each term above what we had expected, forms the loitrowng table:

$$
\begin{array}{r}
10,000 \\
30,000 \\
60,000 \\
100,000 \\
150,000
\end{array}
$$

being, in fact, the series of triangular numbers, ${ }^{*}$ each multiplied by 10,000 .

"If we now continue to observe the numbers presented by the wheel, we shall find that for a hundred, or even for a thousand terms, they continue to follow the new law relating to the triangular numbers; but after watching them for 2761 terms, we find that this law fails in the case of the $2762 d$ term.

"If we continue to observe, we shall discover another Jaw then coming into action, which also is dependent, but in a different manner, on triangular numbers. This will continue through about 1430 terms, when a new law is again introduced which extends over about 950 terms, and this, too, like all its predecessors, fails, and gives place to other laws, which appear at different intervals.

"Now it must be observed that the law that each num. ber presented by the engine is greater by unity than the preceding number, which law the observer had deduced from an induction of a hundred million instances, was not the true law that regulated its action, and that the occurrence of the number, 100,010,002 at the 100,000,002d term was as necessury a consequence of the original ad-

* The numbers $1,3,6,10,15,21,28$, \&c., are formed by adding the successive terms of the series of natural numbers thus :

$$
\begin{aligned}
1 & =1 \\
1 \times 2 & =3 \\
1 \times 2 \times 3 & =6 \\
1 \times 2 \times 3 \times 4 & =10, \text { \&c. They are called trian- }
\end{aligned}
$$
gular numbers, because a number of points corresponding to anj term can always be placed in the form of a triangle ; for instance-

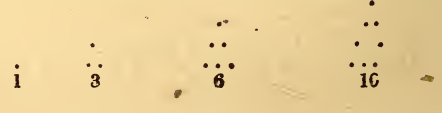


gustment, and might have been as fully foreknown at the commencement, as was the regular succession of any one of the intermediate numbers to its immediate antecedent. The same remark applies to the next apparent deviation from the new law, which was founded on an induction of ¿761 terms, and also to the succeeding law, with this limitation only-that, whilst their consecutive introduction at various definite intervals, is a necessary consequence of the mechanical structure of the engine, our knowledge of analysis does not enable us to predict the periods themselves at which the more distant laws will be introduced."

It is not difficult to apply the philosophy of this passage to the question under consideration. It must be borne in mind that the gestation of a single organism is the work of but a few days, weeks, or months; but the gestation (so to speak) of a whole creation is a matter probably involving enormons spaces of time. Suppose that an ephemeron, hovering over a pool for its one April day of life, were capable of observing the fry of the frog in the water below. In its aged afternoon, having seen no change upon them for such a long time, it would be little qualified to conceive that the external branchiæ of these creatures were to decay, and be replaced by internal lungs, that feet were to be developed, the tail erased, and the animal then to become a denizen of the land. Precisely such may be our difficulty in conceiving that any of the species which people our earth is capable of advancing by generation to a higher type of being. Durıng the whole time which we call the historical era, the limits of species have been, to ordinary observation, rigidly adhered to. But the historical era is, we know, only a small portion of the entire age of our globe. We do not know what may have happened during the ages which preceded its commencement, as we do not know what may happen in ages yet in the distant future. All, therefore, that we can properly infer from the apparently invariable production of like by like is, that such is the ordinary procedure of nature in the time immediately possing before our eyes. Mr. Babbage's illustration powerfully suggests that this ordinary procedure may be subordinate to a higher law which only permits it for a time, and in prooer season interrupts and changes it. We shall soon see some philosophical evidence for this very conclusion.

It has been seen that, in the reproduction of the higher 
animals, the new being passes through stages in which it is successively fish-like and reptile-like. But the reser.blance is not to the adult fish or the adult reptile, but to the fish and reptile at a certain point in their foetal progress ; this holds true with regard to the vascular, nervous, and other systems alike. It may be illustrated by a simple diagram. The fœtus of all the four classes may be supposed to advance in an identical condition to the point A. The fish there diverges and passes $\boldsymbol{M}$ along a line apart, and peculiar to itself, 10 its mature state at $F$. The reptile, sird, and mammal, go on together to $\mathrm{C}$, where the reptile diverges in like manner, and advances by itself to $R$. The bird diverges at $\mathrm{D}$, and goes on to $\mathrm{B}$. The mammal then goes forward in a straight line to the highest point of or- $A$ ganization at $M$. This diagram shows only the main ramifications; but the reader must suppose minor ones, represent the subord1nate differences of orders, tribes, families, genera, \&c., if he wishes to extend his views to the whole varieties of being in the animal kingdom. Limiting ourselves at present to the outline afforded by this diagram, it is apparent that the only thing required for an advance from one type to another in the generative process is that, for example the fish embryo should not diverge at $\mathrm{A}$, but go on to $\mathrm{C}$ before it diverges, in which case the progeny will be not a fish but a reptile. To protract the straightforward part of the gestation over a small space-and from species to species the space would be small indeed-is all that is necessary.

This might be done by the force of certain external conditions operating upon the parturient system. The nature of these conditions we can only conjecture, for their operation, which in the geological eras was so power$f \mathrm{fl}$, has in its main strength been long interrupted, and is now perhaps only allowed to work in some of the lowest departments of the organic world, or under extraordinary casualties in some of the higher, and to these points the attention of science has as yet been little directed. But though this knowledge were never to be clearly attained, it need not much affect the present argument, provided it be satisfactorily shc:wn that there must be some such influence within the range of natural things. 
To this conclusion it must be greatly conducive that the law of organic development is still daily seen at work to certain effects, only somewhat short of a transition from species to species Sex we have seen to be a matter of development. There is an instance, in an humble department of the animal world, of arrangements being made by the animals themselves for adjusting this law to the production of a particular sex. Amongst bees, as amongst several other insect tribes, there is in each community but one true female, the queen bee, the workers being false females or neuters; that is to say, sex is carried on in them to a point where it is attended by sterility. The preparatory states of the queen bee occupy sixteen days, those of the neuters, twenty; and those of males twentyfour. Now it is a fact, settled by innumerable observations and experiments, that the bees can so modify a worker in the larva state, that, when it emerges from the pupa, it is iound to be a queen or true female. For this purpose they enlarge its cell, make a pyramidal hollow to allow of its assuming a vertical instead of a horizontal position, keep it warmer than other larvæ are kept, and feed it with a peculiar kind of food. From these simple circumstances, leading to a shortening of the embryotic condition, results a creature different in form, and also in dispositions, from what would have otherwise been produced. Some of the organs possessed by the worker are here altogether wanting. We have a creature "destined to enjoy love, to burn with jealousy and anger, to be incited to vengeance, and to pass her time without labor," instead of one "zealous for the good of the community, a defender of the public rights, enjoying an immunity from the stimulas of sexual appetite and the pains of parturition ; laborious, industrious, patient, ingenious, skilful; incessantly engaged in the nurture of the young, in collecting honey and pollen, in elaborating wax, in constructing cells and the like!- - paying the most respectfui and assiduous attention to objects which, had its ovaries been developed, it would have hated and pursued with the most vindictive fury till it had destroyed them !"* All these changes may be produced by a mere modification of the embryotic progress, which it is within the power of the adult animals to eflect. But it is important to observe t'lat this modification is different from working a direct 
change upon the embryo. It is not the different food which effects a metamorphosis. All that is done is nereIy'to accelerate the period of the insect's perfection. By the arrangements made and the food given, the embryo becomes sooner fit for being ushered forth in its image or perfect state. Development may be said to be thus arrested at a particular stage-that early one at which the female sex is complete. In the other circumstances, it is allowed to go on four days longer, and a stage is then reached between the two sexes, which in this species is designed to be the perfect condition of a large portion of the community. Four days more make it a perfect male. It is at the same time to be observed that there is, from - the period of oviposition, a destined distinction between the sexes of the young bees. The queen lays the whole of the eggs which are designed to become workers, before she begins to lay those which become males. But probaaly the condition of her reproductive system governs the matter of sex, for it is remarked that when her impregnation is delayed beyond the twenty-eighth day of her entire existence, she lays only eggs which become males.

We have here, it will be admitted, a most remarkable illustration of the principle of development, although in an operation limited to the production of sex only. Let it not be said that the phenomena concerned in the generation of bees may be very different from those concerned in the reproduction of the higher animals. There is a unity throughout nature which makes the one case an instructive reflection of the other.

We shall now see an instance of development operating within the production of what approaches to the character of variety of species. It is fully established that a human family, tribe, or nation, is liable in the course of generations, to be either advanced from a mean form to a higher one, or degraded from a higher to a lower, by the influence of the physical conditions in which it lives. The coarse features, and other structural peculiarities of the negro race, only continue while these people liva amidst the circumstances usually associated with barbarism In a more temperate clime, and higher social state, the face and figure become greatly refined. The few African nations which possess any civilization also exhibit forms approaching the European; and when the same people in the United States of America have enjoyed a 
within-door life for several generations they assimilate to the whites amongst whom they live. On the other hand, there are authentic instances of a people originally well-formed and good-looking, being brought, by imperect diet and a variety of physical hardslips, to a meaner form. It is remarkable, that prominence of the jaws, a recession and diminution of the cranium, and an elongation and atenuation of the limbs, are peculiarities always produced by these miserable conditions for they indicate an unequivocal retrogression towards the type of the lower animals. Thus we see nature alike willing to go back and to go forward. Both effects are simply the result of the operation of the law of development in the generative system. Give good conditions, it advances; bad ones, it recedes. Now, perhaps, it is only because there is no longer a possibility, in the higher types of being, of giving sufficiently favorable conditions to carry on species to species, that we see the operation of the law so far limited.

Let us trace this law also in the production of certain classes of monstrosities. A human fæetus is often left with one of the most important parts of its frame imperfectly developed: the heart, for instance, goes no farther than the three-chambered form, so that it is the heart of a reptile. There are even instances of this organ being left in the two-chambered or fish-form. Such defects are the result of nothing more than a failure of the power of development in the system of the mother, occasioned by weak health or misery. Here we have apparently a realization of the converse of those conditions which carry on species to species, so far, at least, as one organ is concerned Seeing a complete specific retrogression in this one point, how easy it is to imagine an access of favorable conditions sufficient to reverse the phenomenon, and make a fish mother develop a reptile heart, or a reptile mother develop a mammal one. It is no great boldness to surmise that a super-adequacy in the measure of this under-adequacy, (and the one thing seems as natural an occurrence as the other) would suffice in a goose to give its progeny the body of a rat, and produce the ornithorynchus, or might give the progeny of an ornithorynchus the mouth and feet of a true rodent, and thus complete at two stages the passage from the aves to the mammalia.

Perhaps even the transition from species to species does 
still take place in some of the obscurer fields of creation, or under extraordinary casualties, though science professes to have no such facts on record. It is here to be remarked, that such facts might often happen, and yet no record be taken of them, for so strong is the prepossession for the doctrine of invariable like-production, that such circumstances, on occurring, would be almost sure to be explained away on some other supposition, or, if present ed, would be disbelieved and neglected. Science, therefore, has no such facts, for the very same reason that some small sects are said to have no discreditable membersnamely, that they do not receive such persons, and extrude all who begin to verge upon the character. There are, nevertheless, some facts which have chanced to be reported without any reference to this hypothesis, and which it seems extremely difficult to explain satisfactorily upon any other. One of these has already been mentioned-a progression in the forms of the animalcules in a vegetable infusion from the simpler to the more complicated, a sort of microcosm, representing the whole history of the progress of animal creation as displayed by geology. Another is given in the history of the Acarus Crossii, which may be only the ultimate stage of a series of similar transformations effected by electric agency in the solution subjected to it. There is, however, one direct case of a translation of species which has been presented with respectable amount of authority.* It appears that, whenever oats sown at the usual time are kept cropped down during summer and autumn, and allowed to remain over the winter, a thin crop of rye is the harvest presented at the close of the ensuing summer. This experiment has been tried repeatedly, with but one result: invariably the secale cereale is the crop reaped where the avena sativa, a recognised different species, was sown. Now it will not satisfy a strict inquirer to be told that the seeds of the rye were latent in the ground, and only superseded the dead product of the oats; for if any such fact were in the case, why should the usurping grain be always rye? Perhaps those curious facts which have been stated with regard to forests of one kind of trees, when burnt down, being succeeded (without planting) by other kinds, may yet be found most explicable, as this is, upon

* See an article by Dr. Weissenborr, in the New Series of "Ma. gazine of Natural History," vol. i. p. $5 \% 4$. 
the hypothesis of a progression of species which takes place under certain favoring conditions, now apparently of comparatively rare occurrence. The case of the oats is the more valuable, as bearing upon the suggestion as to a protraction of the gestation at a particular part of its course. Here, the generative process is, by the simple mode of cropping down, kept up for a whole year beyond its usual term. The type is thus allowed to advance, and what was oats becomes rye.

The idea, then, which I form of the progress of organic life upon the globe-and the hypothesis is applicable to all similar theatres of vital being-is, that the simplest and most primitive type under a law to which that of like-production is subordinate, gave birth to the type next above it, that this again produced the next higher, and so on to'the very highest, the stages of advance being in all cases very small-namely, from one species only to another; so that the phenomenon has always been of a simple and modest character. Whether the whole of any spe cies was at once translated forward, or only a few parents were employed to give birth to the new type, must remain lindetermined; but, supposing that the former was the case, we must presume that the moves along the line or lines were simultaneous, so that the place vacated by one species was immediately taken by the next in succession, and so on back to the first, for the supply of which the formation of a new germinal vesicle out of inorganic matter was alone necessary. Thus, the production of new forms, as shown in the pages of the geological record, has never been anything more than a new stage of progress in gestation, an event as simply natural, and attended as lit. tle by any circumstanres of a wonderful or startling kind, as the silent advance of an ordinary mother from one week to another of her pregnancy. Yet, be it remembered, the whole phenomena are, in another point of view, wonders of the highest kind, for in each of them we have to trace the effect of an Almighty Will which had arranged the whole in such harmony with external physical circumstances, that both were developed in parallel steps-and probably this development upon our planet is but a sample of what has taken place, through the same cause, in all the other countless theatres of being which are suspended in space.

'This may be the proper place at which to introduce the 
preceding illustrations in a form calculated to bring ther more forcibly before the mind of the reader. 'The following table was suggested to me; in consequence of seeing the scale of animated nature presented in Dr. Fletcher's Rudiments of Physiology. Taking that scale as its basis, it shows the wonderful parity observed in the progress of creation as presented to our observation in the succession of fossils, and also in the fotal progress of one of the principal human organs.* This scale, it may be remarked, was not made up with a view to support such an hypothesis as the present, nor with any apparent regard to the history of fossils, but merely to express the appearance of advancement in the orders of the Cuvierian system, assuming, as the criterion of that advancement, "an increase in the number and extent of the manifestations of

- "It is a fact of the highest interest and moment that as the brain of every tribe of animals appears to pass, during its development, in succession through the types of all those below it, so the brain of man passes through the ty pes of those of every tribe in the creation. It represents, accordingly, before the second month of utero-gestation, that of an avertebrated animal; at the second month, that of an osseous fish; at the third, that of a turtle; at the fourth, that of a bird : at the fifth that of one of the rodentia; at the sixth, that of one of the ruminantia; at the seventh, that of one of the digitigrada ; at the eighth, that of one of the quadrumana; till at length, at the ninth, it compasses the brain of Man! It is hardly necessary to say, that all this is only an approximation to the truth; since neither is the brain of all osseous fishes, of all turtles, of all birds, nor of all the species of any one of the above order of mamals, by any means precisely the same, nor does the brain of the human fotus at any time precisely resemble, perhaps, that of any individual whatever among the lower animals. Nevertheless, it may be said to represent, at each of the above-mention. ed periods, the aggregate, as it were, of the brains of each of the tribes stated ; consisting as it does, about the second month, chiefly of the mesial parts of the cerebellum, the corpora quadrigemina, thalami optici, rudiments of the hemispheres of the cerebrum and corpora striata ; and receiving in succession, at the third, the rudiments of the lobes of the cerebrum; at the fourth those of the fornix, corpus callosum, and septum lucidum; at the fifth; the tubor annulare, and so forth the posterior lobes of the cerebrum in creasing from before to behind, so as to cover the thalami optici about the fourth month, the corpora quadrigemina at sut the sixth and the cerebellum about the seventh. This, then, is another ex ample of an increase in the complexity of an organ succeeding its centralization; as if nature, having first piled up her materials in one spot, delighted afterwards to employ her abundance, not so much in enlarging old parts as in forming new ones upon the old foundations, and thus adding to the complexity of a fabric the rudimental structure of which is in all animals equally simple.". F'letcher's Rudiments of Physiology. 
life, or of the relations which an organized being bears to the external world." "Excepting in the relative situation of the annelida and a few of the mammal orders, the parity is perfect; nor may even these small discrepancies appear when the orider of fossils shall have been further in vestigated, or a more correct scale shall have been formed. Meanwhile, it is a wonderful evidence in favor of our hypothesis, that a scale formed so arbitrarily should coincide, to such a nearness with our present knowledge of the succession of animal forms upon earth, and also 'hat both of these series should harmonize so well with the view given by modern physiologists of the embryotic progress of one of the organs of the highest order of animals.

The reader has seen physical conditions several times referred to, as to be presumed to have in some way governed the progress of the development of the zoological circle. This language may seem vague, and, it may be asked-can any particular physical condition be adduced as likely to have affected development? To this it may be answered, that air and light are probably amongst the principal agencies of this kind which operated in educing the various forms of being. Light is found to be essential to the development of the individual embryo. When tadpoles were placed in a perforated box, and that box sunk in the Seine, light being the only condition thus ab. stracted, they grew to a great size in their original form, but did not pass through the usual metamorphose which brings them to their mature state as frogs. The proteus, an animal of the frog kind, inhabiting the subterraneous waters of Ca:niola, and which never acquires perfect lungs so as to become a land animal, is presumed to be an example of arrested development, from the same cause. When, in connexion with these facts, we learn that human mothers living in dark and close cells under ground, that is to say, with an inadequate provision of air and light-are found to produce an unusual proportion of defective children, ${ }^{*}$ we can appreciate the important effects of both these physical conditions in ordinary reproduction. Now there is nothing to forbid the supposition that the earth has been at different stages of its career

* Some poor people having taken up their abode in the cells ander the fortifications of Lisle, the proportion of defective infants produced by them became so great, that it was deemed necessary to issue an order commanding these cells to be shut up. 
under different conditions, as to both air and light. (on the contrary, we have seen reason for supposing that the proportion of carbonic acid gas (the element fatal to animal life) was larger at the time of the carboniferous formation than it afterwards became. We have also seen that astronomers regard the zodiacal light as a residuum of matter, enveloping the sun, and which was probably at one time denser than it is now. Here we have the indications of causes for a progress in the purification of the atmosphere and in the diffusion of light during the earlier ages of the earth's history, with which the progress of organic life may have been conformable. An accession to the proportion of oxygen, and the effulgence of the central luminary, may have been the immediate prompting cause of all those advances from species to species which we have seen, upon other grounds, to be necessarily supposed as having taken place. And causes of the like nature may well be supposed to operate on other spheres of being, as well as on this. I do not indeed present these ideas as furnishing the true explanation of the progress of organic creation; they are merely thrown out as hints towards the formation of a just hypothesis, the completion of which is only to be looked for when some considerable advances shall have been made in the amount and character of our stock of knowledge.

Early in this century, M. Lamarck, a naturalist of the highest character, suggested an hypothesis of organic progress which deservedly incurred much ridicule, although it contained a glimmer of the truth. He surmised, and endeavored with a great deal of ingenuity, to prove, that one being advanced in the course of generations to another, in consequence merely of its experience of wants calling for the exercise of its faculties in a particular direction, by which exercise new developments of organs took place, ending in variations sufficient to constitute a new species. Thus he thought that a bird would be r.iver by necessity to seek its food in the water, and that, in its efforts to swim, the outstretching of its claws would lead to the expansion of the intermediate membranes, and it would thus become web-footed. Now it is possible that wants and the exercise of faculties have entered in some manner into the production of the phenomena which we have been considering; but certainly not in the way suggested by Lamarck, whose whole notion is obvi. 
ously so inadequate to account for the rise of the urganic kingdoms, that we only can place it with pity among the follies of the wise. Had the laws of organic development been known in his time, his theory might have been of a more imposing kind. It is upon these that the present hypothesis is mainly founded. I take existing natural means, and show them to have been capable of producing all the existing organisms with the simple and easily conceivable aid of a higher generative law, which we perhaps still see operating upon a limited scale. I also go beyond the French philosopher to a very important point, the original Divine conception of all the forms of being which these natural laws were only instruments in working out and realizing. The actuality of such a conception I hold to be strikingly demonstrated by the discoveries of Macleay, Vigors and Swainson, with respect to the affinities and analogies of animal (and by implication vegetable) organisms. * Such a regularity in the structure, as we may call it, of the classification of animals, as is shown in their systems, is totally irreconcilable with the idea of form going on to form merely as needs and wishes in the animals themselves dictated. Had such been the case, all would have been irregular, as things arbitrary necessarily are. But, lo, the whole plan of being is as symmetrical as the plan of a house, or the laying out of an old-fashioned garden! This must needs have been devised and arrranged for beforehand! And what a preconception or forethought have we here! Let us only for a moment consider how various are the external physical conditions in which animals live-climate, soil, temperature, land, water, air-the peculiarities of food, and the various ways in which it is to be sought; the pe-culiar circumstances in which the business of reproduction and the care taking of the young are to be attended toall these required to be taken into account, and thousands of animal - were to be formed suitable in organization and mental cl uracter for the concerns they were to have with these var , us conditions and circumstances-here a tooth fitted for crushing nuts; there a claw fitted to serve as a hook for uspension; here to repress teeth and develop a bony net-work instead; there to arrange for a bronchial apparatus, to last only for a certain brief time; and all these animals were to be schemed out, each as a part of

* These afinities and analogies are explained in the next chapter 
a grtat range, which was on the whole to be rigidly regular - let us, I say, only consider these things, and we shall see that the decreeing of laws to bring the whole about was an act involving such a degree of wisdom and device as we only can attribute, adoringly, to the one Eternal and Unchangeable. It may be asked, how does this reflection comport with that timid philosophy which would have us to draw back from the investigation of God's works, lest the knowledge of them should make us undervalue his greatness and forget his paternal charater ? Does it not rather appear that our ideas of the Deity can only be worthy of him in the ratio in which we advance in a knowledge of his works and ways; and that the acquisition of this knowledge is consequently an available means of our growing in a genuine reverence for him!

But the idea that any of the lower animals have been concerned in any way with the origin of man-is not this degrading? Degrading is a term, expressive of a notion of the human mind, and the human mind is liable to prejudices which prevent its notions from being invariably correct. Were we acquainted for the first time with the circumstances attending the production of an individual of our race, we might equally think them degrading, and be eager to deny them, and exclude them from the admitted truths of nature. Knowing this fact familiarly and beyond contradiction, a healthy and natural mind finds no difficulty in regarding it complacently. Creative Providence has been pleased to order that it should be so, and it must therefore be submitted to. Now the idea as to the progress of organic creation, if we become satisfied of its truth, ought to be received preciseiy in this spirit: It has pleased Providence to arrange that one species should give birth to another, until the second highest gave birth to man, who is the very highest: be it so, it is our part to admire and to submit. The very faintest notion of there being anything ridiculous or degrading in the thenry - how absurd does it appear, when we remember that every individual amongst us actually passes through the characters. of the insect, the fish, and reptile (to speak nothing of others,) before he is permitted to breathe the breath of life! But such notions are mere emanations of folse pride and ignorant prejudice. He who conceives them, little reflects that they, in reality, involve the principle of a contempt for the works and ways of God. For 
it may be asked, if $\mathrm{He}$, as appears, has chosen to employ inferior organisms as a generative medium for the production of higher ones, even including ourselves, what right have we, his humble creatures, to find fault ? There is, also, in this prejudice, an element of unkindliness towards the lower animals, which is utterly out of place. These creatures are all of them part products of the Almighty Conception, as well as ourselves. All of them display wondrous evidences of his wisdom and benevolence. All of them have had assigned to them by their Great Father a part in the drama of the organic world, as well as ourselves. Why should they be held in such contempt? Let us regard them in a proper spirit, as parts of the grand plan, instead of contemplating them in the light of frivolous prejudices, and we shall be altogether at a loss to see how there should be any degradation in the idea of our race having been genealogically connected with them.

\section{MACLEAY SYSTEM OF ANIMATED NATURE.}

THIS SYSTEM CONSIDERED IN CONNEXION WITH THE PROGRESS OF ORGANIC CREATION, AND AS INDICATING THE NATURAL STATUS OF MAN.

Ir is now high time to advert to the system formed by the animated tribes, both with a view to the possible illustration of the preceding argument, and for the light which it throws upon that general system of nature which it is the more comprehensive object of this book to ascertain.

The vegetable and animal kingdoms are arranged upon a scale, starting from simply organized forms, and going on to the more complex, each of these forms being but slightly different from those next to it on both sides. The lowest and most slightly developed forms in the two kingdoms are so closely connected, that it is impossible to say where vegetable ends and animal begins. United at what may be called their bases, they start away in different directions, but not altogether to lose sight of each other. On the contrary they maintain a strict analogy throughout the whole of their subsequent courses, sub. kingdom for sub-kingdnm, class for class: showing a 
beautiful, though as yet obscure relation between the two grand forms of being, and consequently a unity in the laws which brought them both into existence. So complete does this analogy appear even in the present imperfect state of science, that I fully expect in a few years to see the animal and vegetable kingdoms duly ranked up against each other in a system of parallels, which will admit of our assigning to each species in the former the particular shrub or tree corresponding to it in the latter, all marked by unmistakable analogies of the most interesting kind.

It is as yet but a few years since a system of subordinate analogies not less remarkable began to be speculated upon as within the range of the animal kingdom. Probably it also exists in the vegetable kingdom; but to this point nc direct attention has been given; so we are left to infer that such is the case from theoretical considerations only. We are indebted for what we know of these beautiful analogics to three naturalists-Macleay, Vigors, and Swainson, whose labors tempt us to dismiss in a great measure the artificial classifications hitherto used, and make an entirely new conspectus of the animal kingdom, not to speak of the corresponding reform which will be required in our systems of botany also.

The Macleay system, as it may be called in honor of its principal author, announces that, whether we take the whole animal kingdom, or any definite division of it, we shall find that we are examining a group of beings which is capable of being arranged along a series of close affinities, in $a$ circular form-that is to say, starting from any one portion of the group, when it is properly arranged, we can proceed from one to another by minute gradations, till at length having run through the whole, we return to the point whence we set out. All natural groups of animals are, therefore, in the language of Mr. Macleay, circular; and the possibility of throwing any supposed group into a circular arrangement is held as a decisive test of its be ing a real natural one. It is of course to be understood that each circle is composed of a set of inferior circles; for example, a set of tribe circles composes an order, a set of order circles, again, forms a class; and so on. Of each group, the component circles are invariably five in number; thus in the animal kingdom, there are five sub. 
kingdoms-the vertebrata, annulosa,* radiata, acrita, $\uparrow$ mollusca. Take, again, one of these sub-kingdoms, the vertebrata, and we find it composed of five classes-the mammalia, reptilia, piscis, amphibia, and aves, each of the other sub-kingdoms being similarly devisable. Take the mammalia, and it is in like manner found to be composed of five orders - the cheirotheria, $\ddagger$ feræ, cetacea, glires, ungulata. Even in this numerical uniformity, which goes down to the lowest ramifications of the system, there would be something very remarkable, as arguing a definite and preconceived arrangement; but this is only the least curious part of the Macleay theory.

We shall best understand the wonderfully complex system of analogies developed by that theory, if we start from the part of the kingdom in which they were first tracednamely, the class aves, or birds. This gives for its five orders-incessores, (perching birds,) raptores, (birds of prey,) natatores, (swimming birds,) grallatores, (waders,) rasores, (scrapers.) In these orders our naturalists discerned distinct organic characters, of different degrees of perfectness, the first being the most perfect with regard to the general character of the class, and therefore the best representative of that class; whence it was called the typical order. The second was found to be inferior, or rather to have a less perfect balance of qualities; hence it was designated the sub-typical. In this are comprehended the chief noxious and destructive animals of the circle to which it belongs. The other three groups were called aberrant, as exhibiting a much wider departure from the typical standard, although the last of the three is observed to make a certain recovery, and join on to the typical group so as to complete the circle. The first of the aberrant groups (natatores) is remarkable for making the water the theatre of its existence, and the birds composing it are in general of comparatively large bulk. The second (grallatores) are long-limbed and long-billed, that they may wade and pick up their subsistence in the shallows and marshes in which they chiefly live. The third (rasores) are distinguished by strong feet, for walking or running on the ground, and for scraping in it for their food: also by

* Corresponding to the articulata of Cuvier.

t A new sub.kingdom, made out of part of the radiata of Cuvier $\$$ This is a newl- 7 applied term, the reasons for which will be ex clained in the sequel 
wings designed to scarcely raise them off the earth; and, farther, by a general domesticity of character and useful. ness to man.

Now, the most remarkable circumstanee, is, that these organic characters, habits, and moral properties, were found to be traceable more or less distinctly in the corresponding portions of every other group, even of those belonging to distant subdivisions of the animal kingdom, as, for instance, the insects. The incessores (typical order of aves) being reduced to its constituent circles or tribes, it was found that these strictly represented the five orders. In the conirostres are the perfections which belong to the incessores as an order, with the conspicuous external feature of a comparatively small notch in their bills; in the dentirostres, the notch is strong and toothlike, (hence the name of the (ribe,) assimilating them to the raptores; the fissirostres come into analogy with the natatores in the slight development of their feet and their great powers of flight; the tenuirostres have the small mouths and long soft bills of the grallatores. Finally, the scansores resemble the rasores in their superior intelligence and docility, and in their having strong limbs and a bill entire at the tip. This parity of qualities becomes clearer when placed is a tabular form :-

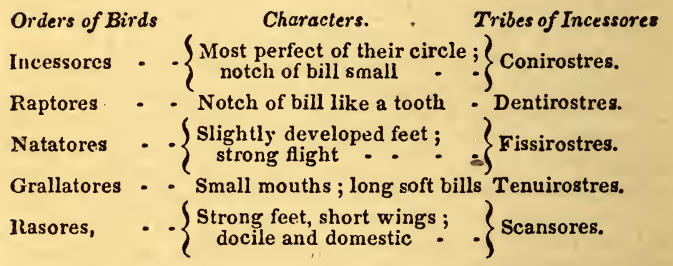

Some comprehensive terms are much wanted tc describe these five characters, so curiously repeated through. out the whole of the animal, and probably also the vegeta ble kingdom. Meanwhile, Mr. Swainson calls then typical, sub-typicai, natatorial, suctorial, ${ }^{*}$ and rascrial. Some of his illustrations of the principle are exceedingly

* This is preferred to grallatorial, as more comprehensive'y de scriptive. There is the same need for a substitute for cor sriel, which is only applicable to birds. 
interesting. He shows that the leading animal of a typical circle usually has a combination of properties concentrated in itself, without any of those preponderating remarkably over others. The sub-typical circles, he says, "do not comprise the largest individuals in bulk, but always those which are the most powerfully armed, either for inflicting injury on their own class, for exciting terror, producing injury, or creating annoyance to man. Their dispositions are often sanguinary, since the forms most conspicuous among them live by rapine, and subsist on the blood of other animals. They are, in short, symbollically types of evil." 'This symbolical character is most conspicuous about the centre of the series of gradations :-

$\begin{array}{ll}\text { Kingdom : } & \cdot \\ \text { Sub-kingdom } \\ \text { Class (Mammalia) } \\ \text { (Aves) }\end{array}$

In the annulosa it is not distinct, although we must also remember that insects do produce enormous ravages and annoyance in many parts of the earth. In the reptilia it is more distinct, since to this class belong the ophidia, (serpents,) an order peculiarly noxious. It comes to a kind of climax in the ferre and raptores, which fulfil the function of butchers among land animals. As we descend through tribes, families, genera. species, it becomes fainter and fainter, but never altogether vanishes. In the dentirostres, for instance, we have in a sublued form the hooked bill and predaceous character of the raptores; to this tribe belongs the family of the shrikes, so deadly to all the lesser field birds. In the genus bos, we have, in the sub-typical group, the bison, "wild, revengeful, and showing an innate detestation of man." In equus, we have, in the same situation, the zebra, which actually shows the stripes of the tiger, and is as remarkable for its wildness as its congeners, the horse and ass, are for their docility and usefulness. To quote again from Mr. Swainson, "the singular threatening aspect which the caterpillars of the sphinx moth assume on being disturbed, is a remarkable modification of the terrific or evil nature which is impressed in one form or another, palpable or remote, upon all sub-typical groups; for this division of the lepidopterous order is precisely of this denomination. In the pre-eminent type of this order of insects, the butterflies, (papilionides,) our associations little prepare us for 
expecting any trace of the evil principle, but here, to , there is a sub-typical division." These, says our naturalist, " are distinguished by their caterpillars being armed with formidable spines or prickles, which in general are possessed of some highly acrimonious or poisonous qualiity, capable of injuring those who touch them. It is only," continues Mr. Swainsun; "when extensive researches bring to light a uniformity of results, that we can venture to believe they are so universal as to deserve being ranked as primary laws. Thus, when a celebrated entomologist denounced as impure the black and lurid beetles forming the saprophayous petalocera of $\mathrm{Mr}$. Ma cleay, a tribe living only upon putrid vegetable matter, and hiding themselves in their disgusting food, or in dark hollows of the earth, neither of these culebrated men suspected the absolute fact, elicited from our analogies of this group, that this very tribe constituded the sub-typical group of one of the primary divisions of coleopterous insects: nor had they any suspicion that, by the filthy habits and repulsive forms of these beetles, nature had intended that they should be types or emblems of hundreds of other groups, distinguished by peculiarities equally indicative of evil. On the other hand, the thalerophagous petalocera, forming the typical group of the same division, present us with all the perfections and habits belonging to their kind. These families of beetles live only upon fresh vegetables; they are diurnal, and sport in the glare of day, pure in their food, elegant in their shapes, and beautiful in their colors."*

The third type, (first of the three aberrant,) called by Mr. Swainson, the natatorial, or aquatic, are chifly re markable for their bulk, the disproportionate size of the nead, and the absence, or slight development of the feet. They partake of the predaceous and destructive character of the adjoining sub-typical group, and the means of their predacity are generally found in the mouth alone. In the primary division of the animal kingdom, we find the type in the radiata, not one of which lives out of water. In the vertebrata, it is in the fishes. In both of these, feet are totally wanting. Descending to the class mammalia, we have this type in the cetacea, which present a comparatively slight development of limbs. In the aves, as we have seen, the type is presented in the natatores, whose

- Distribution and Classification of Animals, p. 248 
name has been adopted as an appropriate term for all the corresponding groups. An enumeration of some other examples of the natatorial type, as the cephalopoda (instanced in the cuttle-fish) in the mollusca; the crustacea (crabs, \&c.) in the annulosa; the owls (which often duck for fish) in the raptores ; the ichthyosaurus, plesiosaurus, \&c., among reptilia, will serve to bring the general character, and its pervasion of the whole animal world, forcibly before the mind of the reader.

The next type is that of meanest and most imperfect organization, the lower termination of all groups, as the typical is the upper. It is called by Mr. Swainson, the suctorial, from a very generally prevalent peculiarity, that of drawing sustenance by suction. The acrita, or polypes, among the sub-kingdoms; the intestina, among the annuIosa; the tortoises, among the reptilia; the armadillo and scaly ant-eater, pig, mouse, jerboa, and kangaroo, among quadrupeds; the waders and tenuirostres, among birds ; the coleoptera, (bug, louse, flea, \&c.,) among insects ; the gastrobranchus, among fishes; are examples which will illustcate the special character of this type. These are smallness, particularly in the head and mouth, feebleness, and want of offensive protection, defect of organs of mastication, considerable powers of swift movement, and often a parasitic mode of living; while of negative qualities, there are, besides, indisposition to domestication, and an unsuitableness to serve as human food.

The rasorial type comprehiends most of the animals which become domesticated and useful to man, as first, the fowls which give a name to the type, the ungulata, and more particularly the ruminantia, among quadrupeds, and the dog among the feræ. Gentleness, familiarity with man and a peculiar approach to human intelligence, are the leading mental characteristics of animals of this type. A mongst external characters, we generally find power of limbs and feet for locomotion on land, (to which the rasorial type is confined,) abundant tail and ornaments for the head, whs:ther in the form of tufts, crests, horns, or bony excrescer ces. In the animal kingdom, the mollusca are the rasor: al type, which, however, only shows itself there in their soft and sluggish character, and their being very generally edible. In the ptilota, or winged insects, the hymenopterous are the rasorial type, and it is not therefore surprising to find amongst them the ants and bees 
the most social, intelligent, and in the latter case, the mos' useful to man, of all the annulose animals."

As yet the speculations on representation are imperfect, in consequence of the novelty of the doctrine, and the defective state of our knowledge of animated nature. It has, however, been so fully proved in the aves, and traced so clearly in other parts of the animal kingdom, and as a general feature of that part of nature, that hardly a doubt can exist of its being universally applicable. Even in the lowly forms of the acrita, (polypes,) the suctorial type of the animal kingdom, representation has been discerned, and with some remarkable results as to the history of our world. The acrita were the first forms of animal lifo upon earth, the starting point of that great branch of organization. Now, this sub-kingdorn consists, like the rest, of five groups, (classes,) and these are respectively representations of the acrita itself, and the other four subkingdoms, which had not come into existence when the acrita were formed. . The polypi vaginati, in the crustaceous covering of the living mass, and their more or less articulated structure, represent the annulosa. In the radiated forms of the rotifera, and the simple structure of the polypi, rudes, we are reminded of the radiata. The mollusca are typified in the soft, mucous, sluggish intestina. And, finally, in the fleshy living mass which surrounds the bony and hollow axis of the polypi natantes, we have a sketch of the vertebrata. The acrita thus appear as a prophecy of the higher events of animal development. They show that the nobler orders of being, including man himself, were contemplated from the first, and came into existence by virtue of a law, the operation, of which had commenced ages before their forms were realized.

The system of representation is therefore to be regarded as a powerful additional proof of the hypothesis of organic progress by virtue of law. It establishes the unity of animated nature and the definite character of its entire constitution. It enables us to see how, under the flowing robes of nature, where all looks arbitrary and accidental, there is an artificiality of the most rigid kind. The natural, we now perceive, sinks into and merges in a Higher Artificial. To adopt a comparison more apt than dignified, we may be said to be placed here as insects are in a garden of old style. Our first unassisted view is limited, and 
we perceive only the irregularities of the minute surface, and single shrubs which appear arbitrarily scattered. But our view at length extending and becoming more comprehensive, we begin to see parterres balancing each other, irees, statues, and arbois placed symmetrically, and that he whole is an assemblage of parts mutually reflective. It can scarcely be necessary to point to the inference hence arising with regard to the origination of nature in some Power, of which man's mind is a faint and humble representation. The insects of the garden, supposing them to be invested with reasoning power, and aware how artificial are their own works, might of course very reasonably conclude that, being in its totality an artificial object, the garden was the work of some maker or artificer. And so also must we conclude, when we attain a knowledge of the artificiality which is at the basis of nature, that nature is wholly the production of a Being resembling, but infinitely greater than, ourselves.

Organic beings are, then, bound together in development, and in a system of both affinities and analogies. Now, it will be asked, does this agree with what we know of the geographical distribution of organic beings and of the history of organic progress as delineated by geology? Let us first advert to the geographical question.

Plants, as is well known, require various kinds of soil, forms of geographical surface, climate, and other conditions, for their existence And it is everywhere found, that, however isc?ated a particular spot may be with regard to these conditions-as a mountain top in a torrid country, the marsh round a salt spring far inland, or an island placed far apart in the ocean-appropriate plants have there taken up their abode. But the torrid zone divides the two temperate regions from each other by the space of more than forty-six deyrees, and the torrid and temperate zones together form a much broader line of division between the two arctic regions. The Atlantic and Pacific Oceans, and the Persian Gulf, also divide the various portions of continent in torrid and temperate zones from each other. Australia is also divided by a broad sea from the continent of Asia. Thus there are various portions of the earth separated from each other in such a way as to preclude anything like a general communication of the seeds of their respective plants towards each other. Hence arises an interesting question-Are the plants of the vari- 
ous isolated regıons which enjoy a parity of climate and other conditions, identical or the reverse? The answer is-that in such regions the vegetation bears a general resemblance, but the species are nearly all different, and there is even, in a considerable measure, a diversity of families.

The general facts have been thus stated; in the arctic and antarctic regions, and in those parts of lower latitudes, which from their elevation, possess the same cold climate, there is always a similar or analogous vegetation, but few species are common to the various situations. In like manner, the intertropical vegetation of Asia, Africa, and America, are specifically different, though generally similar. The southern region of America is equally diverse from that of Africa, a country similar in clime, but separated by a vast extent of ocean. The vegetation of Australia, another region similarly placed in respect of clime, is even more peculiar. These facts are the more remarkable when we discover that, in most instances, the plants of cne region have thriven when transplanted to another of parallel clime. This would show that parity of condition does not lead to a parity of productions so exact as to include identity of species, or even genera. Besides the various isolated regions here enumerated, there are some others indicated by naturalists as exhibiting a vegetation equally peculiar. Some of these are isolated by mountains or the interposition of sandy wastes. For example, the temperate region of the elder continent is divided about the centre of Asia, and the east of that line is diffeent from the west. So also is the same region divided in North America by the Rocky Mountains. Abyssinia and Nubia constitute another distinct botanical region. De Candolle enumerates in all twenty well-marked portions of the earth's surface, which are peculiar with respect to vegetation; a number which would be greatly increased, if remote islands and isolated mountain ranges were to be included.

When we come to the zoology, we find precisely similar results, excepting that man (with, perhaps, some of the less conspicuous forms of being) is universal, and tha: several tribes, as the bear and dog, appear to have passed by the land connexion from the arctic regions of the eastern to those of the western hemisphere. "With these exceptions," says Dr. Prichard, " and without any others, 
as far as zonlogical researches have yet gone, it $\mathrm{n}$ ay be asserted that no individual species are common to distant regions. In parallel climates, analogous species replace each other; sometimes, but not frequently, the same genus is found in two separate continents ; but the species which are natives of one region, are not identical with correspording races indigenous in the opposite hemisphere.

"A similar result arises when we compare the three great intertropical regions, as well as the extreme spaces of the three great continents, which advance into the temperate climates of the southern hemisphere.

"Thus, the tribes of simiæ, (monkeys,) of the dog and cat kinds, of pachyderms, including elephants, tapirs, rhinoceroses, hogs, of bats, of saurian and ophidian reptiles, as well as of birds and other terrene animals are all different in the three great continents. In the lower departments of the mammiferous family we find that the bruta, or edentata (sloths, armadillos, \&c.) of Africa, are differently organized from those of America, and these again from the tribes found in the Maylayan archipelago and Terra Australis."*

It does not appear that the diversity between the similar regions of Africa, Asia, and America, is occasioned in all instances by any disqualification of these countries to support precisely the same genera or species. The ox, horse, goat, sc., of the elder continent have driven and extended themselves in the new; and many of the indigenous tribes of America would no doubt flourish in corresponding climates in Europe, Asia, and Africa. It has, however, been remarked by naturalists unacquainted with the Macleay system, that the larger and more powerful animals of their respective orders belong to the elder continent, and that thus the animals of America, unlike the features of inanimate nature, appear to be upon a small scale. The swiftest and most agile animals, and a large proportion of those most useful to man, are also natives of the elder continent. On the other hand, the bulk of the edentata, a group remarkable for defects and meanness of organization, are American. The zoology of America may be said, upon the whole, to recede from that of Asia, " and perhaps in a greater degree," adds Dr. Prichard, "from that of Africa." A much greater recession

* Researches, 4th edition, j. 95. 
is, however, observed in both the botany and $z$ jogy of Australia.

There "we do not find in the great masses of vegetation, either the majesty of the virgin forests of America, or the variety and elegance of those of Asia, or the delicacy and freshness of the woods of our temperate countries of Europe. The vegetation is generally gloomy and sad; it has the aspect of our evergreens or heaths; the plants are for the most part woody; the leaves of neariy all the plants are linear, lanceolated, small, coriaceous, and spinescent. The grasses, which elsewhere are generally soft and flexible, participate in the stiffiness of the other vegetables. The greater part of the plants of New Holland belong to new genera; and those included in the genera already known are of new species. The natural families which prevail are those of the heaths, the protæ, compositæ, leguminosæ, and Myrthoideæ; the larger trees all belong to the last family."

The prevalent animals of Australia are not less peculiar. It is well known that none above the marsupialia, or pouched animals,"are native to it. The most conspicuous are these marsupials, which exist in great varieties here, though unknown in the elder continent, and only found in a few mean forms in America. Next to them are the monotremata, which are entirely peculiar to this portion of the earth. Now these are animals at the bottom of the mammiferous class, adjoining to that of birds, of whose character and organization the monotremata largely partake, the ornithorynchus presenting the bill and feet of a duck, producing its young in eggs, and having, like birds, a clavicle between the two shoulders. The birds of Australia vary in structure and plumage, but all have some singularity about them-the swan, for instance, is black. The country abounds in reptiles, and the prevalent fishes are of the early kinds, having a cartilaginous structure.

Altogether the plants and animals of this minor continent convey the impression of an early sustem of things, such as might be displayed in other parts of the earth about the time of the oolite. In connexion with this circumstance, it is a fact of some importance, that the geognostic character of Australia, its vast arid plains, its little diversified surface and consequent paucity of streams, 
and the very slight development of volcanic rock on its surtace seem to indicate a system of physical conditions, such as we may suppose to have existed elsewhere in the oolite era; perhaps we see the chalk formation preparing there in the vast coral beds frontiering the coast. Australia thus appears as a portion of the earth which has, from some unknown causes, been belated in its physical and organic development. And certainly the greater part of its surface is not fitted to be an advantageous place of residence for beings above the marsupialia, and judging from analogy, it may yet be subjected to a series of changes in the highest degree inconvenient to any human beings who may have settled upon it.

The general conclusions regarding the geography of organic nature, may be thus stated. (1.) There are numerous distinct foci of organic production throughout the earth. (2.) These have everywhere advanced in accordance with the local conditions of climate, \&c., as far as at least the class and order are concerned, a diversity taking place in the lower gradations. No physical or geographical reason appearing for this diversity, we are led to infer that (3.) it is the result of minute and inappreciable causes giving the law of organic development a particular direction in the lower subdivisions of the two kingdoms. (4) Development has not gone on to equal results in the various continents, being most advanced in the eastern continent, next in the western, and least in Australia, this inequality being perhaps the result of the cornparative antiquity of the various regions, geologically and geographically.

It must at the same time be admitted that the line of organic development has nowhere required for its advance the whole of the families comprehended in the two kingdoms, seeing that some of these are confined to one cortinent, and some to another, without a conceivable possibility of one having been connected with the other in the way of ancestry: The two great families of quadrumana, cebidæ and simiadæ, are a noted instance, the one being exclusively American, while the other belongs entirely to the old world. There are many other cases in which the full circular group can only be completed by taking subdivisions from various continents. This would seem to imply that while the entire system is so remarkable for its unity, it has nevertheless teen produced in lines geogra- 
phically detached, these lines perhaps consisting of particular typical groups placed in an independent succession, or of two or more of these groups. And for this idea there is, even in the present imperfect state of our. knowledge of animated nature, some countenance in ascertained facts, the birds of Australia, for example, being chiefly of the suctorial type, while it may be presumed that the observation as to the predominance of the useful animals in the Old World, is not much different from saying that the rasorial type is there peculiarly abundant. It does not appear that the idea of independent lines, consisting of particular types, or sets of types, is necessarily inconsistent with the general hypothesis, as nothing yet ascertained of the Macleay system forbids their having an independent set of affinities. On this subject, however, there is as yet much obscurity, and it must be left to future inquirers to clear it up.

We must now call to mind that the geographical distribution of plants and animals was very different in the geological ages from what it is now. Down to a time not long antecedent to man, the same vegetation overspread every clime, and a similar uniformity marked the zoology. This is conceived by M. Brogniart, with great plausibility to have been the result of a uniformity of climate, produced by the as yet unexhausted effect of the internal heat of the earth upon its surface; whereas climate has since depended chiefly on external sources of heat, as modified by the various meteorological influences. However the early uniform climate was produced, certain it is that, from about the close of the geological epoch, plants and animals have been dispersed over the globe with a regard to their particular characters, and specimens of both are found so isolated in particular situations, as utterly to exclude the idea that they came thither from any common centre. It may be asked-Considering that, in the geological epoch, species are not limited to particular regions, and that since the close of that epoch, they are very peculiarly limited, are we to presume the present-organisms of the world to have been created $a b$ initio after that time? To this it may be answered-Not necessarily, as it so happens that animals begin to be much varied, or to appear in a considerable variety of species, towards the close of the geological history. It may have been that the multitudes of locally peculiar species only came into being after the 
uniform climate had passed away. It may tiave only been when a -varied climate arose, that the originally few species branched off into the present extensive variety.

A question of a very interesting kind will now probably arise in the reader's mind-What place or status is assigned to man in the new natural system? Before going into this inquiry, it is necessary to advert to several particulars of the natural system not yet noticed.

It is necessary, in particular, to ascertain the grades which exist in the classification of animals. In the line of the aves, Mr. Swainson finds these to be nine, the species pica, for example, being thus indicated :-

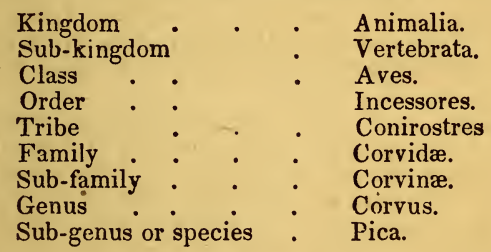

This brings us down to species, the subdivision where intermarriage or breeding is usually considered as natural to animals, and where a resemblance of offspring to parents is generally persevered in. The dog, for instance, is a species, because all dogs can breed together, and the progeny partakes of the appearances of the parents. The human race is held as a species, primarily for the same reason. Species, however, is liable to another subdivision, which naturalists call variety; and variety appears to be subject to exactly the same system of representation which has been traced in species and higher denominations. In canis, for instance, the bull-dog and mastiff represent the ferocious sub-typical group; the water-dog is natatorial; we see the speed and length of muzzle of the suctorial group in the yreyhound; and the bushy tail and gentle and serviceable character of the rasorial in the sheperd's dng and spaniel. Even the striped and spotted skin of the tiger and panther is reproduced in the more ferocious kind of dogs-an indication of a fundamental connexion between physical and mental qaualities which we have also seen in the zebra, and which is likewise 
displayed in the predominance of a yellow color in the vultures and owls in common with the lion and his con geners.

It is by no means clearly made out that this system of nine gradations over and above that of variety applies in all departments of nature. On the contrary, even $\mathrm{Mr}$ Swainson gives series in which several of them are omit. ted. It may be that, in some departments of nature, variation from the class or order has gone down into fewer shades than in others; or it may be, that many of the variations have not survived till our era, or have not been as yet detected by naturalists ; in either of which cases there may be a necessity for shortening the series by the omission of one or two grades, as for instance tribe or subfamily. This, however is much to be regretted, as it introduces an irregularity into the natural system, and consequently throws a difficulty and doubt in the way of our investigating it. With these preliminary remarks, I shall proceed to inquire what is the natural status of man.

That man's place is to be looked for in the class mammalia and sub-kingdom vertebrata admits of no doubt, from his possessing both the characters on which these divisions are founded. When we descend, however, below the class, we find no settled views on the subject amongst naturalists. Mr. Swainson who alone has given a review of the animal kingdom on the Macleay system unfortunately writes on this subject in a manner which excites a suspicion as to his judgment. His arrangement of the first or typical order of the mammalia is therefore to be received with great hesitation. It is as follows:-

Typical - Quadrumana Pre-eminently organized for grasping. Sub-typical Feræ . . Claws retractile; Carnivorous.

Natatorial Cetacea . . Pre-eminently aquatic; feet very short.

Suctorial. Glires . . Muzzle lengthened and pointed.

Rasorial . Ungulata . Crests and other processes on the head.

He then takes the quadrumana, and places it in the following arrangement :

Typical . . Simiadæ . . (Monkeys of Old World ) Sub-typical . Cebidæ . . (Monkeys of New World.) Natatoria . Unknown.

Suctorial Vespertilionidæ (Bats.)

Lasorial . Lemuridæ . (Lemurs.) 
He considers the simiadæ as a complete circle, and arguta thence that there is no room in the range of the animal kingdom for man. Man, he says, is not a constituent part of any circle, for, if he were, there ought to be other animals on each hand having affinity to him, whereas there are none, the resemblance of the orangs being one of mere analogy. Mr. Swainson therefore considers our race as standing apart, and forming a link between the unintelligent order of beings and the angels ! And this in spite of the glaring fact that, in our teeth, hands, and other features grounded on by naturalists as characteristic, we do not differ more from the simiadæ than the bats do from the lemurs-in spite also of that resemblance of analogy to the orangs which he himself admits, and which, at the least, must be held to imply a certain relation. He also overlooks that, though there may be noroom for man in the circle of the simiadæ, (this, indeed, is quite true,) there may be in the order, where he actually leaves a place entirely blank, or unly to be filled up, as he suggests, by mermen !* Another argument in his arrangement is, that it leaves the grades of classification very much abridged, there being at the most seven instead of nine. But serious argument on a theory so preposterous may be considered as nearly thrown away. I shall therefore at once proceed to suggest a new arrangement of this portion of the animal kingdom, in which man is allowed the place to which he is zoologically entitled.

I propose that the typical order of the mammalia should be designated cheirotheria, from the sole character which is universal amongst them, their possessing hands, and with a regard to that pre-eminent qualification for grasping which has been ascribed to them-an analogy to the perching habit of the typical order of birds, which is worthy of particular notice. The tribes of the cheirotheria I arrange as follows :

$$
\begin{aligned}
& \text { Typical • . • • . Bimana. } \\
& \text { Sub-typical : } \quad . \quad \cdot \quad \text {. Simiadæ. } \\
& \text { Natatorial . . . . . Vespertilionidæ. } \\
& \text { Suctorial . . . . . Lemuridæ } \\
& \text { Rasorial . . . . Cebidæ. }
\end{aligned}
$$

* Mr. Swainson's arguments about the entireness of the circle simiadæ are only too rigid, for fossil geology has since added new genera to this group and the cebidæ, and there may be still fur. ther additions. 
Here man is put into the typical place, as the genuine head, not only of this order, but of the whole animal world. The double affinity which is requisite is obtained, tor here he has the simiadæ on one hand and the cebidæ on the other. The five tribes of the order are completed, the vespertilionidæ being shifted (provisionally) into the natatorial place, for which their appropriateness is so far evidenced by the aquatic habits of several of the tribe, and the lemuridæ into the suctorial, to which their length of muzzle and remarkable saltatory power are, highly suitable. At the sarne time, the simiadæ are degraded from the typical place, to which they have no sort of pretension, and placed where their mean and mischievous character seems to require; the cebidæ again being assigned that situation which their comparatively inoffensive dispositions, their arboreal habits, and their extraordinary development of the tail (which with them is like a fifth hand,) render so proper.

The zoological status thus assigned to the human race is precisely what might be expected. In order to understand its full value, it is necessary to observe how the various type peculiarities operate in fixing the character of the animals ranked in them. It is easy to conceive that they must be, in some instances, much mixed up with each other, and consequently obscured. If an animal, for example, is the suctorial member of a circle of species, forming the natatorial type of genera, forming a family or sub-family which in its turn is rasorial, its qualities must evidently be greatly mingled and ill to define. But, on the other hand, if we take the rapacious or sub-typical group of birds, and look in it for the tribe which is again the rapacious or sub-typical group of its order, we may expect to find the qualities of that group exalted or intensified, and accordingly made the more conspicuous. Such is really the case with the vultures, in the rapacious birds, a family remarkable above all of their order for their carnivorous and foul habits. So, also, if we take the typical group of the birds, the incessores or perchers, and look in it for its typical group, the conirostres, and seek there again for the typical family of that group, the corvidæ, we may expect to find a very marked superiority in organization and character. Such is really the case. "The crow," says Mr. Swainson, " unites in itself a greater number of properties than are to be found individually in 
any other genus of birds; as if in fact it had taken from all the other orders a portion of their peculiar qualities, for the purpose of exhibiting in what manner they could be combined. From the rapacious birds this 'type of types,' as the crow has been justly called, takes the power of soaring in the air, and of seizing upon living birds, like the hawks, while its habit of devouring putrid substances, and picking out the eyes of young animals, is borrowed from the vultures. From the scansorial or climbing order it takes the faculty of picking the ground, and discovering its food when hidden from the eye, while the parrot family gives it the taste for vegetable food, and furnishes it with great cunning, sagacity, and powers of imitation, even to counterfeiting the human voice. Next come the order of waders, who impart their quota to the perfection of the crow by giving it great powers of flight, and perfect facility in walking, such being among the chief attributes of the suctorial order. Lastly, the aquatic birds contribute their portion, by giving this terrestrial bird the power of feeding not only on fish, which are their peculiar food, but actually of occasionally catching it.* In this wonderful manner do we find the crow partially invested with the united properties of all other birds, while in its uwn order, that of the incessores or perchers, it stands the pre-eminent type. We cannot also fail to regard it as a remarkable proof of the superior organization and character of the corvidæ, that they are adapted for all climates, and accordingly found all over the world."

Mr. Swainson's description of the zoological status of the crow, written without the least design of throwing any light upon that of man, evidently does so in a remarkable degree. It prepares us to expect in the place among the mammalia, corresponding to that of the corvi$d æ$ in the aves, a being or set of beings possessing a remarkable concentration of qualities from all the other groups of their order, but in general character as far above the corvidæ as a typical group is above an aberrant one, the mammalia above the aves. Can any of the simiadæ pretend to such a place, narrowly and imperfectly endowed as these creatures are-a mean reflection apparently ot something higher? Assuredly not, and in this consideration alone, Mr. Swainson's arrangement must fall to the ground. To fill worthily so lofty a station in the anima-

* See Wilson's American Ornithology ; artice, Fishing Crow 
ted families, man alone is competent. In him only is tc be found that concentration of qualities from all the other groups of his order which has been described as marking the corvidæ. That grasping power, which has been selected as the leading physical quality of his order, is nowhere so beautifully or so powerfully developed as in his hand. The intelligence and teachableness of the simiadæ rise to a climax in his pre-eminent mental nature. His sub-analogy to the feræ is marked by his canine teeth, and the universality of his rapacity, for where is the department of animated nature which he does not without scruple sacrifice to his convenience? With sanguinary, he has also geritle and domesticable dispositions, thus reflecting the characters of the ungulata (the rasorial type of the class,) to which we perhaps see a further analogy in the use which he makes of the surface of the earth as a source of food. To the aquatic type his love of maritime adventure very readily assimilates him; and how far the suctorial is represented in his nature, it is hardly necessary to say. As the corvidæ, too, are found in every part of the earth-almost the only one of the inferior animals which has been acknowledged as universal-so do we find man. He thrives in all climates, and with regard to style of living can adapt himself to an infinitely greater diversity of circumstances than any other animated creature.

Man, then, considered zoologically, and without regard to the distinct characters assigned to him by theology, simply takes his place as the type of all types of the animal kindom, the true and unmistakable head of animated nature upon this earth. It will readily occur, that some more particular investigations into the ranks of types might throw additional light on man's status, and perhaps his nature; and such light we may hope to obtain when the philosophy of zoology shall have been studied as it deserves Perhaps some such diagram as the one given on the next page will be found to be an approximation to the expression of the merely natural or secular grade of man in comparison with other animals. 


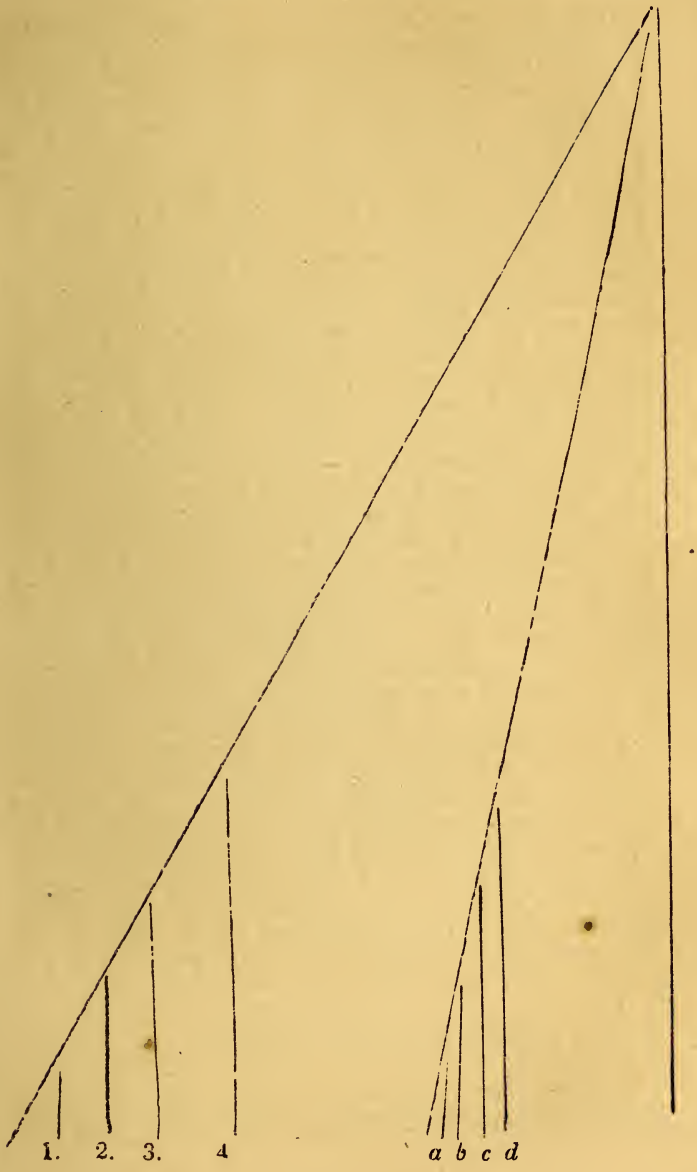


Here the upright lines, $1,2,3,4,5$, may represent the comparative height and grade of organization of both the five sub-kingdoms, and the five classes of each of these; 5 being the vertebrata in the one case, and the mammalia in the other. The difference between the height of the line 1 and the line 5 gives an idea of the difference of being the head type of the aves (corvidæ, ) and the head type of the mammalia (bimana;) $a, b, c, d, 5$, again, represent the five groups of the first order of the mammalia ; $a$, being the organic structure of the highest simia, and 5, that of man. A set of tangent lines of this kind may yet prove one of the most satisfactory means of ascertaining the height and breadth of the psychology of our species.

It may be asked-Is the existing human race the only species designed to occupy the grade to which it is here referred? Such a question evidently ought not to he answered rashly; and I shall therefore confine myself to the admission that, judging by ana'ogy, we might expect to see several varieties of the being, homo. There is no other family approaching to this in importance, which presents but one species. The corvidæ, our parallel in aves, consist of several distinct genera and sub-genera. It is startling to find such an appearance of imperfection in the circle to which man belongs, and the ideas which rise in consequence are not less startling. Is our race but the initial of the grand crowning type? Are there yet to be species superior to us in organization, purer in feeling, more powerful in device and act, and who shall take a rule over us? There is in this nothing improbable on other grounds. The present race, rude and impulsive as it is, is perhaps the best adapted to the present state of things in the world; but the external world goes through slow and gradual changes, which may leave it in time a much serener field of existence. 'There may then be occasion for a nobler type of humanity, which shall complete the geological circle on this planet, and realize some of the dreams of the purest spirits of the present race.

\section{EARLY HISTORY OF MANKIND.}

THE human race is known to consist of different nations displaying considerable differences of external form and 
color, and speaking in general different languages. This has been the case since the commencement of written record. It is also ascertained that the external peculiarities of particular nations do not rapidly change. There is rather a tendency to a persistency of type in all lines of descent, insomuch that a subordinate admixture of various type is usually obliterated in a few generations. Numerous as the varieties are, they have all been found classifiable under five leading ones:-1. The Caucasian, or Indo-European, which extends from India into Europe and Northern Africa; 2. The Mongolian, which occupies Northern and Eastern Asia; 3. The Malayan, which extends from the Ultra-Gangetic Peninsula into the numerous islands of the South Sea and Pacific ; 4. 'The Negro, chiefly confined to Africa; 5. The aboriginal American. Each of these is distinguished by certain general features of so marked a kind as to give rise to a supposition that they have had distinct or independent origins. Of these peculiarities, color is the most conspicuous : the Caucasians are generally white, the Mongolians yellow, the Negroes black, and the Americans red. The opposition of two of these in particular, white and black, is so striking, that of them, at least, it seems almost necessary to suppose separate origins. Of late years, however, the whole of this question has been subjected to a rigorous investigation, and it has been successfully shown that the human $r$ ace might have had one origin, for anything that can be inferred from external peculiarities.

It appears from this inquiry, ${ }^{*}$ that color and other physiological characters are of a more superficial and accidental nature than was at one time supposed. One fact is at the very first extremely startling, that there are nations, such as the inhabitants of Hindostan, known to be one in descent, which nevertheless contain groups of people of almost all shades and color, and likewise discrepant in other of those important features on which much stress has been laid. Sorne other facts, which I may state in brief terms, are scarcely less remarkable. In Africa, there are Neyro nations-that is, nations of intensely black complexion, as the Jolofs, Mandingoes, and Kafirs, whose features and limbs are as elegant as those of the best Eurcpean nations. While we have no proof of Negro races becoming white in the course of generations, the converse

- See Dr. Prichard's Researches into the Physical History of Man 
may be held as established, for there are Arab and Jevish families of ancient settlement in 'Tort'vern Africa who have become as black as the other inhabitants. There are also facts which seem to show the possibility of a natural transition by generation from the black to the white complexion, and from the white to the black. True whites (aprart from Albinoes) are not unfrequently born among the Negroes, and the tendency to this singularity is transmitted in families. There is at least one authentic instance of a set of perfectly black children being born to an Arab couple in whose ancestry no such blood had intermingled. This occurred in the valley of the Jordan, where it is remarkable that the Arab population in general have flatter features, darker skins, and coarser hair than any other tribes of the same nation.*

The style of living is ascertained to have a powerful effect in modifying the human figure in the course of generations, and this even in its osseous structure. About two hundred years ago, a number of people were driven by a barbarous policy from the counties of Antrim and Down, in Ireland, towards the sea-coast, where they hav ever since been settled, but in unusually miserable cir cumstances, even for Ireland; and the consequence, is, tha they exhibit peculiar features of the most repulsive kind, projecting jaws with large open mouths, depressed noses, high cheek bones, and bow legs, together with an ex: tremely diminutive stature. 'These, with an abnormal slenderness of the limos, are the outward marks of a low and barbarous condition all over the world; it is particularly seen in the Australian aborigines. On the other hand, the beauty of the higher, ranks in England is very remarkable, being, in the main, as clearly a result of good external conditions. "Coarse, unwholesome, and illprepared food," says Buffon, "makes the human race de generate. All those people who live miserably are ugly and ill-made. Even in France, the country people are not so beautiful as those who live in towns: and $I$ have often remarked that in those villages where the peis l $l \epsilon$ are richer and better fed than in others, the men are like. wise more handsome, and have better countenances." H€ might have added, that elegant and commodious dwell-

* Buckingham's Travels among the Arabs. This fact is the more valuable to the argument, as having been set down with no regard to any kind of hypothesis. 
ings, cleanly habits, comfortable clothing, and being exposed to the open air only as much as health requires, co-operate with food in increasing the elegance of a race of human beings.

Subject only to these modifying agencies, there is, as has been said, a remarkable persistency in national features and forrns, insomuch that a single individual thrown into a family different from himself is absorbed in it, and Ill trace of him lost after a few generations But while there is such a persistency to ordinary observation, it would also appear that nature has a power of producing sew varieties, though this is only done rarely. Such novslties of type abound in the vegetable world, are seen .nore rarely in the animal circle, and perhaps are least frequent of occurrence in our own race. There is a noted instance in the pioduction, on a New England farm, of a variety of sheep with unusually short legs, which was kept up by breeding, on account of the convenience in that country of having sheep which are unable to jump over low fences. The starting and maintaining a breed of cattle, that is, a variety marked by some desirable peculiarity, are familiar to a large class of persons. It appears only necessary, when a variety has been thus produced, that a union should take place between individuals similarly characterized in order to establish it. Early in the last century, a man named Lambert was born in Suffolk, with semi-horney excrescences of about half an inchlong, thickly growing all over his body. The peculiarity was transmitted to his children, and was last heard of in a third generation. The peculiarity of six fingers on the hand and six toes on the feet, appears in like manner in families which have no record or tradition of such a peculiarity having affected them at any former period, and it is then sometimes seen to descend through several generations. It was Mr. Lawrence's opinion that a pair in which both parties were so distinguished might be the progenitors of a new variety of the race who would be thus marked in all future time. It is not easy to surmise the causes which operate in prorlucing such varieties. Perhaps they are simply types in nature, possible to be realized under certain appropriate conditions, but which conditions are such as altogether to elude notice. I might cite as examples of such possible types, the rise of whites amongst the Negroes, the occilrrence of the family of 
black children in the valley o: the Jordan, and the com paratively frequent birth of $r \in d$-haired children amongst not only Mongolian and Malavan families, but amongst the Negroes. We are ignorant of the laws of variety-production; but we see it going on as a principle in nature, and it is obviously favorable to the supposition that all the great families of men are of one stock.

The tendency of the modern study of the languages of nations is to the same point. The last fifty years have seen this study elevated to the character of a science, and the light which it throws upon the history of mankind is of a most remarkable nature.

Following a natural analogy, philologists have thrown the earth's languages into a kind of classification : a number bearing a considerable resemblance to each other, and in general geographically near, are styled a group, or subfamily; several groups, again, are associated as a family, with regard to more general features of resemblance. Six families are spoken of.

The Indo-European family nearly coincides in geographical limits with those which have been assigned to that variety of mankind which generally shows a fair complexion, called the Caucasian variety. It may be said to commence in India, and thence to stretch through Persia into Europe, the whole of which it occupies, excepting Hungary, the Basque provinces of Spain, and Finland. Its sub-families are the Sanscrit, or ancient language of India, the Persian, the Slavonic, Celtic, Gothic, and Pelasgian. The Slavonic includes the modern languages of Russia and Poland. Under the Gothic, are (1) the Scandinavian tongues, the Norske, Swedish, and Danish; and (2) the Teutonic, to which belong the Modern German, the Dutch, and our own Anglo-Saxon. I give the name of Pelasgian to the group scattered along the north shores of the Mediterranean, the Greek and Latin, including the modifications of the latter under the names of Italian, Spanish, \&c. The Celtic was, from two to three thousand years ago, the speech of a considerable tribe dwelling in Western Europe ; but these have since been driven before superior nations into a few corners, and are now only to be found in the highlands of Scotland, Ireland, Wales, Cornwall, and certain parts of France. The Gaelic of Scotland, Erse of Ireland, and the Welsh, are the only living branches of this sub-far ily of languages. 
The resemblances among languages are of two kindsidentity of words, and identity of grammatical forms; the latter being now generally considered as the most impor. tant towards the argument. When we inquire into the first kind of affinity arnong the languages of the IndoEuropean family, we are surprised at the great number of common terms which exist among them, and these referring to such primary ideas as to leave no doubt of their having all been derived from a common source. Colonel Vans Kennedy presents nine hundred words common to the Sanscrit and other languages of the same family. In the Sanscrit and Persian, we find several which require no sort of translation to an English reader; as, pader, mader, sunu, dokhter, brader, mand, vidhava; likewise asthi, a bone, (Greek, ostoun ;) denta, a tooth, (Latin, dens, dentis ;) eyeumen, the eye; brouwa, the eye-brow, (German, braue ;) nasa, the nose; karu, the hand, (Gr. cheir ;) genu, the knee, (Lat. genu;) ped, the foot, (Lat. pes, pedis ;) hrti, the heart, jecur, the liver, (Lat. jecur ;) stara, a star; gela, cold, (Lat. gelu, ice;) aghui, fire, (Lat. ignis ;) dhara, the earth, (Lat. terra, Gaelic, tir;) arrivi, a river; nau, a ship, (Gr. naus, Lat. navis ;) ghau, a cow ; sarpam, a serpent.

The inferences from these verbal coincidences were confirmed in a striking manner, when Bopp and others investigated the grammatical structure of this family of languages. Dr. Wiseman pronounces that the great philologist just named, "by a minute and sagacious analysis of the Sanscrit verb, compared with the conjugational system of the other members of this family, left no doubt of their intimate and positive affinity" It was now discovered that the peculiar terminations or inflections by which persons are expressed throughout the verbs of nearly the whole of these languages, have their foundations in pronouns; the pronoun was simply placed at the end, and thus became an inflection "By an analysis of the Sanscrit pronouns, the elements of those existing in all the other languages were cleared of their anoma lies; the verb substantive, which in Latin is composed of fragments, referable to two distinct roots, here found both existing in regular form; the Greek conjugations, with all their complicated machinery of middle voice, augments, and redup?.ications were here found an: illustrated in a variety of ways, which a few years aga would 
have appeared chimerical. Even our own language may sometimes receive light from the study of distant mem. bers of our family. Where, for instance, are we to seek for the root of our comparative better? Certainly not in its positive, good, nor in the Teutonic dialects in which the same anomaly exists. But in the Persian we have precisely the same comparative, behter, with exactly the same signification, regularly from its positive beh, good."*

The second great family is the Syro-Phonician, comprising the Hebrew, Syro-Chaldaic, Arabic, and Gheez or Abyssinian, being localized principally in the countries to the west and south of the Mediterranean. Beyond them, again, is the African family, which, as famas research has gone, seems to be in like manner marked by common features, both verbal and grammatical. The fourth is the Polynesian family, extending from Mada. gascar on the west through all the Indian Archipelago, besides taking in the Malayan dialect from the continent of India, and comprehending Australia and the islands of the western portion of the Pacific. This family, however, bears such an affinity to that next to be described, that $\mathrm{Dr}$. Leyden and some others do not give it a distinct place as a family of languages.

The fifth family is the Chinese, embracing a large part of China, and most of the regions of Central and North-

* Wiseman's Lectures on the Connexion between Science and Revealed Religion, i., 44. The Celtic has been established as a member or group of the Indo-European family, by the work of Dr. Prichard, on the Eastern Origin of the Celtic Nations. "First," says Dr. Wisemen, "he has examined the lexical resemblances, and shown that the primary and most simple words are the same in both, as well as the numerals and elementary verbal roots. Then follows a minute analysis of the verb, directed to show its analo. gies with other languages, and they are such as manifest no casual coincidence, but an internal structure radically the same. The verb substantive, which is minutely analyzed, presents more strik. ing analogies to the Persian verb than perhaps any other language of the family. But Celtic is not thus become a mere member of this confederacy, but has brought to it most important aid; for from it alone can be satisfactorily explained some of the conjugational endings in the other languages. For instance, the third person plural of the Latin, Persian, Greek, and Sanscrit ends in nt, nd, $\nu \tau \iota, \nu \tau o$, nti, or nt. Now, supposing. with most grammarians, that the inflections arose from the pronouns of the respective per. sons, it is only in Celtic that we find a pronoun that can explain this termination; for there, too, the same person ends in $\mathrm{nt}$, and this corresponds exactly, as do the others, with its jronoun hwunt, or ynt." 
ern Asia. The leading features of the Chinese are, its consisting altogether of monosyllables, and being destitute of all grammatical forms, except certain arrangements and accentuations, which vary the sense of particular worits. It is also deficient in some of the consonants most conspicuous in other languages, b, d, r, v, and $z$; so that this people can scarcely pronounce our speech in such a way as to be intelligible: for example, the word Christus they call Kuliss-ut-oo-suh. The Chinese, strange to say, though they early attained to a remarkable degree of civilization, and have preceded the Europeans in many of the most important inventions, have a language which resembles that of children, or deaf and dumb people. The sentence of short, simple, unconnected words, in which an infant amongst us attempts to express some of its wants and its ideas-the equally broken and difficult terms which the deaf and dumb express by signs, as the following passage in the Lord's Prayer: "Our Father, heaven in, wish your name respect, wish your soul's kingdom providence arrive, wish your will do heaven earth equality," \&c. - these are like the discourse of the refined people of the so-called Celestial Empire. An attempt was made by the Abbé Sicard to teach the deaf and dumb grammatical signs; but they persisted in restricting themselves to the simple signs of ideas, leaving the structure undetermined by any but the natural order of connexion. Such is exactly the condition of the Chi nese language.

Crossing the Pacific, we come to the last great family in the languages of the aboriginal Americans, which have all of them features in common, proving them to constitute a group by themselves, without any regard to the very different degrees of civilization which these nations had attained at the time of the discovery. The cormmon resemblance is in the grammatical structure as well as in words, and the grammatical structure of this family is of a very peculiar and complicated kind. The general character in this respect has caused the term Polysynthetic to be applied to the American languages. A long many-syllabled word is used by the rude Algonquins and Delawares to express a whole sentence: for example, a woman of the latter nation, playing with a little dog or cat, would perhaps be heard saying, "kuligatschis," meaning, "give me your pretty little paw;" 
the word, on examination, is found to be made up in this manner : $k$, the second personal pronoun; $u l i$, part of the word wulet, pretty; gat, part of the word wichgat, sig nifying a leg or paw; schis, conveying the idea of littleness. In the same tongue, a youth is called pilape, a word compounded from the tirst part of pilsit, innocent, and the latter part of lenape, a man. Thus, it will be observed, a number of parts of words are taken and thrown together, by a process which has been happily termed agglutination, so as to form one word, conveying a complicated idea. There is also an elaborate system of inflection: in nouns, for instance, there is one kind of inflection to express the presence or absence of vitality, and another to express numbers. The genius of the language has been described as accumulative: it "tends rather to add syllables or letters, making further distinctions in objects already before the mind, than to introduce new words."* Yet it has also been shown very distinctly that these languages are based in words of one syllable, like those of the Chinese and Polynesian families; all the primary ideas are thus expressed: the elaborate system of inflection and agglutination is shown to be simply a further development of the language-forming principle, as it may be called-or the Chinese system may be described as an arrestment of this principle at a particular early point. It has been fully shown that between the structure of the American and other families sufficient affinities exist to make a common origin or early connexion extremely likely. The verbal affinities are also very considerable. Humboldt says, "In eighty-three American languages examined by Messrs. Barton and Vater, one hundred and seventy words have been found, the roots of which appear to be the same; and it is easy to perceive that this analogy is not accidental, since it does not rest merely upon imitative harmony, or on that conformity of organs which produces almost a perfect identity in the first sounds articulated by children. Of these one hundred and seventy words which have this connexion, three-fifths resemble the Manchou, the Tongouse, the Mongal, and the Samoyed; and two-fifths, the Celtic and Tchoud, the Biscayan, the Coptic and Congo languages These words have been found by comparing 
the whole of the American languages with the whole of those of the Old World; for hitherto we are acquainted with no American idir in which seems to have an exclusive correspondence with any of the Asiatic, African, or European tongues."* Humboldt and others considered these words as brought into America by recent immigrants; an idea resting on no proof, and which seems at once refuted by the common words being chiefly those which represent primary ideas; besides, we now l:now, what was not formerly perceived or admitted, that there are great affinities of structure also. I may here refer to a curious mathematical calculation by Dr. Thomas Young, to the effect, that if three words coincide in two different languages, it is ten to one they must be derived in both cases from some parent language, or introduced in some other manner. "Six words would give more," he says, "than aeventeen hundred to one, and eight near 100,000 , so that in these cases the evidence would be little short of absolute certainty." He instances the following words to show a connexion between the ancient Egyptian and the Biscayan :

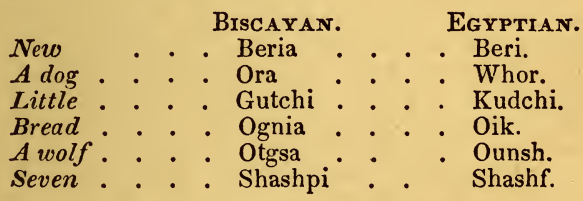

Now, as there are, according to Humboldt, one hundred and seventy words in common between the languages of the new and old continents, and many of these are expressive of the most primitive ideas, there is, by $\mathrm{Dr}$. Young's calculation, overpowering proof of the original connexion of the American and other human families.

This completes the slight outline which I have been able to grive of the evidence for the various rases of men being descended from one stock. It cannot be considered as conclusive, and there are many eminent persons who deem the opposite idea the more probable; but I must say that, wilhout the least regard to any othex kind of evi- 
dence, that which physiology and philology present seems to me decidedly favorable to the idea of a single origin.

Assuming that the human race is one, we are next called upon to inquire in what part of the earth it may most probably be supposed to have originated. One obvious mode of approximating to a solution of this question is to trace backward the lines in which the principal tribes appear to have migrated, and to see if these converge nearly to a point. It is very remarkable that the lines do converge, and are concentrated abnut the region of Hindostan. The language, religion, modes of reckoning time, and some other peculiar ideas of the Americans, are now believed to refer their origin to North-Eastern Asia. Trace them further back in the same direction, and we come to the north of India. The history of the Celts and Teutones represents them as coming from the east, the one after the other, successive waves of a tide of population flowing towards the north-west of Europe ; this line being also traced back, rests finally at the same place So does the line of Iranian population, which has peopled the east and south shores of the Mediterranean, Syria, Arabia, and Egypt. The Malay variety, again, rests its limit in one direction on the borders of India. Standing on that point, it is easy to see how the human farnily, originating there, might spread out in different directions, passing into varieties of aspect and of language as they spread, the Malay variety proceeding towards the Oceanic region, the Mongolians to the east and north, and sending off the red men as a sub-variety, the European population going off to the north-westward, and the Syrian, Arabian, and Egyptian towards the countries which they are known to have so long occupied. The Negro alone is here unaccounted for ; and of that race it may fairly be said, that it is the one most likely to have had an independent origin, seeing that it is a type so peculiar in an inveterate black color, and so mean in development. But it is not necessary to presume such an origin for it, as much good argument might be employed to show that it is only a deteriorated offishoot of the general stock. Our view of the probable original seat of man agrees with the ancient traditions of the race. There is one among the Hindoos which places the cradle of the human family in Thibet; another makes Ceylon the residence of the first man. Our view is also in harmony with the hypothesis detailed 
in the chapter before the last Accorling to that theory, we should expect man to have originated where the highest species of the quadrumana are to be found. Now these are unquestionably found in the Indian Archipelago.

After all, it may be regarded as still an open question, whether mankind is of one or many origins. The first human generation may have consisted of many pairs, though situated at one place, and these may have been considerably different from each other in external characters. And we are equally bound to admit, though this does not as yet seem to have occurred to any other speculator, that there may have been different lines and sources of origination, geographically apart, but which all resulted uniformly in the production of a being one in species, although variously marked.

It has of late years been a favorite notion with many, that the human race was at first in a highly civilized state, and that barbarism was a second condition. 'This idea probably took its origin in a wish to support certain interpretations of the Mosaic record, and it has never yet been propounded by any writer who seemed to have a due sense of the value of science in this class of investigations. The principal argument for it is, that we see many examples of nations falling away from civilization into barbarism, while in some regions of the earth, the history of which we do not clearly know, there are remains of works of art far superior to any which the present unenlightened inhabitants could have produced. It is to be readily admitted that such decadences are common; but do they necessarily prove that there has been anything like a regular and constant decline into the present state, from a state more generally refined ? May not these be only instances of local failures and suppressions of the principle of civilization, where it had begun to take root amongst a people generally barbarous? It is, at least, as legitimate to draw this inference from the facts which are known. But it is also alleged that we know of no such thing as civilization being ever selforiginated. It is always seen to be imparted from one people to another. Hence, of course, we must infer that civilization at the first could only have been of supernatural origin. This argument appears to be founded on false premises, for civilization does sometimes rise in a manner clearly independent amongst a horde of people 
generally barbarous. A striking instance is described in the laborious work of Mr. Catlin on the North-A merican tribes. Far placed among those which inhabit the vast region of the north-west, and quite beyond the reach of any influence from the whites, he found a smali tribe living in a fortified village, where they cultivated the arts of manufacture, realized comforts and luxuries, and had attained to a remarkable refinement of manners, insomuch as to be generally called the polite and friendly Mandans. They were also more than usually elegant in their persons, and of every variety of complexion between that of their compatriots and a pure white. Up to the time of Mr. Catlin's visit, these people had been able to defend themselves and their possessions against the roving bands which surrounded them on all sides; but, soon after, they were attacked by small-pox, which cut them all off except a small party, whom their enemies rushed in upon and destroyed to a man. What is this but a repetition on a small scale of phenomena with which ancient history familiarizes us - a nation rising in arts and elegances amidst barbarous neighbors, but at length nverpowered by the rude majority, leaving only a Tadmor or a Luxor as a monument of itself to beautify the waste? What can we suppose the nation which built Palenque and Copan to have been, but only a Mandan tribe, which chanced to have made its way further along the path of civilization and the arts, before the barbarians broke in upon it? The flame essayed to rise in many parts of the earth; but there were always considerable chances against it, and down it accordingly went, times without number; but there was always a vitality in it, nevertheless, and a tendency to progress, and at length it seems to have attained a strength against which the powers of barbarisin can never more prevail. The state of our knowledge of uncivilized nations is very apt to make us fall into error on this subject. They are generally supposed to be all at one point in barbarism, which is far from being the case, for in the midst of every great region of uncivilized men, such as North America, there are nations partially refined. The Jolofs, Mandingoes, and Kafirs are African examples, where a natural and independent origin for the improvement which exists is as unavoidably to be presumed as in the case of the Mandars

The most conlusive argument against the original civi. 
lization of mankind is to be founi in the fact that we do not now see civilization existing anywhere except in certain conditions altogether different from any we can suppose to have existed at the commencement of our race. To have civilization it is necessary that a people should be numerous and closely placed; that they should be fixed in their habitations, and safe from violent external and internal disturbance; that a considerable number of them should be exempt from the necessity of drudging for immediate subsistence. Feeling themselves at ease about the first necessities of their nature, including self-preservation, and daily subjected to that intellectual excitement which society produces, men begin to manifest what is called civilization; but never in rude and shelterless circumstances, or when widely scattered. Even men who have been civilized, when transferred to a wide wilderness, where each has to work hard and isolatedly for the first requisites of life, soon show a retrogression to barbarism ; witness the plains of Australia, as well as the backwoods of Canada and the prairies of 'Texas. Fixity of residence and thickening of population are perhaps the prime requisites for civilization, and hence it will be found that all civilizations as yet known have taken place in regions physically limited. That of Egypt arose in a narrow valley hemmed in by deserts on both sides. That of Greece took its rise in a small peninsula bounded on the only land side by mountains. Etruria and Rome were naturally limited regions. Civilizations have taken place on both the eastern and western extremities of the elder continent-China and Japan, on the one hand; Germany, Holland, Britain, and France on the other-while the great unmarked tract between contains nations decidedly less advanced. Why is this but because the sea, in both cases, has imposed limits to further migration, and caused the population to settle and condense-the conditions most necessary for social improvement.* Even the simple case of the Mandans affords an illustration of this principle, for Mr. Catlin expressly, though without the least regard to theory, attributes their improvement to

* The problem of Chinese civilization, such as it is-so puzzling when we consider that they are only, as will he presently seen, the child race of mankind-is solved when we look to geographi. cal position producing fixity of residence and density of population 
the fact of their being a smail tribe, obliged, by fear of their more numerous enemies, to settle in a permanent village, so fortified as to ensure their preservation. "By this means," says he, "they have advanced further in the arts of manufacture, and have supplied their lodges more abundantly with the comforts, and even luxuries, of life than any Indian nation I know of. The consequence of this," he adds, "is that the tribe have taken many steps ahead of other tribes in manners and refinements." These conditions can only be regarded as natural laws affecting civilization, and it might not be difficult, taking them into account, to predict of any newly settled country its social destiny. An island like Van Dieman's land might fairly be expected to go on more rapidly to good manners and sound institutions than a wide region like Australia. The United States might be expected to make no great way in civilization till they be fully peopled to the $\mathrm{Pa}$ cific; and it might not be unreasonable to expect that, when that even has occurred, the greatest civilizations of that vast territory will be found in the peninsula of California and the narrow stripe of country beyond the Rocky Mountains. This, however, is a digression. To return : it is also necessary for a civilization that at least a portion of the community should be placed above mean and engrossing toils. Man's mind becomes subdued, like the dyer's hand, to that it works in. In rude and difficult circumstances we unavoidably become rude, because then only the inferior and harsher faculties of our nature are called into existence. When, on the contrary, there is leisure and abundance, the self-seeking and self-preserving instincts are allowed to rest, the gentler and more generous sentiments are evcled, and man becomes that courteous and chivalric being which he is found to be among the upper classes of almost all civilized countries. These, then, may be said to be the chief natural laws concerned in the moral phenomenon of civilization. If I am right in so considering them, it will of course be readily admitted that the earliest families of the human race, although they might be simple and innocent, could not have been in anything like a civilized state, seeing that the conditions necessary for that state could not have then existed. Let us only for a moment consider some of the things requisite for their being civilized, namely, a set of elegant homes ready furnished for their reception, 
helds ready cultivated to yield them food without labor, stores of luxurious appliances of all kinds, a complete social enginery for the securing of life and property,-and we shall turn from the whole conceit as one worthy only of the philosophers of Utopia.

Yet, as has been remarked, the earliest families might be simple and innocent, while at the same time unskilled and ignorant, and obliged to live merely upon such substances as they could readily procure. The traditions of all nations refer to such a state as that in which mankind were at first: perhaps it is not so much a tradition as an idea which the human mind naturally inclines to form respecting the fathers of the race; but nothing that we see of mankind absolutely forbids our entertaining this idea, while there are some considerations rather favorable to it. A few families, in a state of nature, living near each other, in a country supplying the means of livelihood abundantly, are generally simple and innocent; their instinctive and perceptive faculties are also apt to be very active, although the higher intellect may be dormant. If we, therefore, presume India to have been the cradle of our race, they might at first exemplify a sort of golden age; but it could not be of long continuance. The very first movements from the primal seat would be attended with degradation, nor could there be any tendency to true civilization till groups had settled and thickened in particular seats physically limited.

The probability may now be assumed that the human race sprung from one stock, which was at first in a state of simplicity, if not barbarism. As yet we have not seen very distinctly how the various branches of the family, as they parted off, and took up separate ground, became marked by external features so peculiar. Why are the Africans black, and generally marked by coarse features and ungainly forms? Why are the Mongolians generally yellow, the Americans red, the Caucasians white? Why the flat features of the Chinese, the small stature of the Laps, the soft round forms of the English, the lank features of their descendants, the Americans? All of these phenomena appear, in a word, to be explicable on the ground of development. We have already seen that various leading animal forms represent stages in the embryotic progress of the highest-the human being. Our brain goes through the various stages of a fish's, a reptile's, and 
a manımifer's brain, and finally becomes human. There is more than this, for, after completing the animal transformations, it passes through the characters in which it appears in the Negro, Malay, American, and Mongolian nations, and finally is Caucasian. The face partakes of these alterations. "One of the earliest points in which ossification commences is the lower jaw. This bone is consequently sooner completed than the other bones of the head, and acquires a predominance, which, as is well known, it never loses in the Negro. During the soft, pliant state of the bones of the skull, the oblong form which they naturally assume approaches nearly the permanent shape of the Americans. At birth, the flattened face, and broad smooth forehead of the infant, the position of the eyes rather towards the side of the head, and the widened space between, represents the Mongolian form; while it is only as the child advances to maturity that the oval face, the arched forehead, and the marked features of the true Caucasian become perfectly developed."* The leading characters, in short, of the various races of mankind are simply representations of particular rtages in the development of the highest or Caucasian type. The Negro exhibits permanently the imperfect brain, projecting lower jaw, and slender bent limbs of a Caucasian child, some considerable time before the period of its birth. 'The aboriginal American represents the same child nearer birth. The Mongolian is an arrested infant, newly born; and so forth. All this is as respects form; $\dagger$ but whence color? This might be supposed to have depended on climatal agencies only; but it has been shown by overpowering evidence to be independent of these. In further considering the matter, we are met by the very remarkable fact that color is deepest in the least perfectly-developed type, next in the Malay, next in the American, next in the Mongolian, the very order in which the degrees of development are ranged. May not color, then, depend upon development also? We do not, indeed, see that a Caucasian foetus at the stage which the African represents is anything like black; neither is a

* Lord's Popular Physiology, explaining observations by M Serres.

$\dagger$ Conformably to this view, the beard, that peculiar attribute of maturity, is scanty in the Mongolian, and scarcely exists in the Americans and Negroes. 
Caucasian child yellow, like the Mongolian. There may, nevertheless, be a character of skin at a certain stage of development which is predisposed to a particular color when it is presented as the envelope of a mature being. Developinent being arrested at so immature a stage in the case of the Negro, the skin may take on the color as an unavoidable consequence of its imperfect organization. It is favorable to this view, that Negro infants are not deeply black at first, but only acquire the full color tint alter exposure for some time to the atmosphere. Another consideration in its favor is that there is a likelihood of peculiarities of form and color, since they are so coinci dent, depending on one set of phenomena. If it be ad mitted as true, there can be no difficulty in accounting for all the varieties of mankind. They are simply the result of so many advances and retrogressions in the developing power of the human mothers, these advances and retrogressions being, as we have formerly seer, the immediate effect of external conditions in nutrition, hardship, \&c., * and also, perhaps, to some extent, of the suitableness and unsuitableness of marriages, for it is found that parents ton nearly related tend to produce offspring of the Mongolian type-that is, persons who in maturity still are a kind of children. According to this view, the greater part of the human race must be considered as having lapsed or declined from the original type. In the Caucasian or Indo-European family alone has the primitive organization been improved upon. The Mongolian, Malay, American, and Negro, comprehending, perhaps, five-sixths of mankind, are degenerate. Strange that the great plan should admit of failures and aberrations of such portentous magnitude: But pause and reflect; take time into consideration: the past history of mankind may be, to what is to come, but as a day. Look at the progress even now making over the barbaric parts of the earth by the best examples of the Caucasian type, promising not

* Of this we have perhaps an illustration in the peculiarities which distingnish the Arabs residing in the valley of Jordan. They have flatter features, darker skins, and coarser hair than other tribes of their nation; and we have seen one instanee of a thoroughly Negro family being born to an ordinary couple. It may be presumed that the conditions of the life of these people tend to arrest derelopment. We thus see how an offshoot of the human family migrating at an early period into Africa, might is time, from subjection to similar influences, become Negroes 
only to fill up the waste places, but to supersede the imperfect nations already existing. Who can tell what progress may be made, even in a single century, towards reversing the proportions of the perfect and imperfect types? and who can tell but that the time during which the mean types have lasted, long as it appears, may yet be thrown entirely into the shade by the time during which the best types will remain predominant?

We have seen that the traces of a common origin in all languages afford a ground of presumption for the unity of the human race. They establish a still stronger probability that mankind had not yet begun to disperse before they were possessed of a means of communicating their ideas by conventional sounds-in short, speech. This is a gift so peculiar to man, and in itself so remarkable, that there is a great inclination to surmise a miraculous origin for it, although there is no proper ground, or even support, for such an idea in Scripture, while it is clcarly opposed to everything else that we know with regard to the Providential arrangements for the creation of our race. Here, as in many other cases, a little observation of nature might have saved much vain discussion. The real character of language itself has not been thoroughly understood. Language, in its most comprehensive sense, is the communication of ideas by whatever means. Ideas can be communicated by looks, gestures, and signs of various other kinds, as well as by speech. The inferior animals possess some of those means of communicating ideas, and they have likewise a silent and unobservable mode of their own, the nature of which is a complete mystery to us, though we are assured of its reality by its effects. Now, as the inferior animals were all in being before man, there was language upon earth long ere the history of our race commenced. The only additional fact in the history of language, which was produced by our creation, was the rise of a new mode of expressionnamely, that by sound-signs produced by the vocal organs. In other words, speech was the only novelty ir. this respect attending the creation of the human race No doubt it was an addition of great importance, for, in comparison with it, the other natural modes of comminicating ideas sink into insignificance. Still, the main and fundamental phenomenon, language, as the communication of ideas, was no new gift of the Creator to man; and in 
speech itself, when we judge of it as a natural fact, we see only a result of some of those superior endowments of which so many others have fallen to our lot through the medium of an improved or advanced organization.

The first and most obvious natural endowment concerned in speech is that peculiar organization of the larynx, trachea, and mouth which enables us to produce the various sounds required in the case. Man started at first with this organization ready for use, a constitution of the atmosphere adapted for the sounds which that organization was calculated to produce, and, lastly, but not leastly, as will afterwards be more particularly shown, a mental power within, prompting to, and giving directions for, the expression of ideas. Such an arrangement of mutually adapted things was as likely to produce sounds as ar. Eolian harp placed in a draught is to produce tones. It was unavoidable that human beings so organized, and in such a relation to external nature, should utter sounds, and also come to attach to these conventional meanings, thus forming the elements of spoken language. The great difficulty which has been felt was to account for man going in this respect beyond the inferior animals. There could have been no such difficulty if speculators in this class of subjects had looked into physiology for an account of the superior vocal organization of man, and had they possessed a true science of mind to show man possessing a faculty for the expression of ideas which is only rudimental in the lower animals. Another difficulty has been in the consideration that, if men were at first utterly untutored and barbarous, they could scarcely be in a condition to form or employ language-an instrument which it requires the fullest powers of thought to analyze and speculate upon. But this difficulty also vanishes upon reflection-for, in the first place, we are not bound to sup. pose the fathers of our race early attaining to great proficiency in language; and, in the second, language itself seems to be amongst the least difficult to be acquired, if we can form any judgment from what we see in children, most of whom have, by three years of age, while their information and judgment are still as nothing, mastered and familiarized themselves with a quantity of words, infinitely exceeding in proportion what they acquire in the course of any subsequent or similar portion of time.

Discussions as to which parts of speech were first 
formed, and the processes by which grammatical structure and inflections took their rise, appear in a great measure needless, after the matter has been placed in this light. The mental powers could readily connect particular arbitrary sounds with particular ideas, whether thuse ideas were nouns, verbs, or interjections. As the words of all languages can be traced back into roots which are monnsyllables, we may presume these sounds to have all been monosyllabic accordingly. The clustering of two or more together to express a compound idea, and the formation of inflections by additional syllables expressive of pronouns and such prepositions as of, by, and to, are processes which would or might occur as matters of course, being simple results of a mental power called into action, and partly directed, by external necessities. This power, however, as we find it in very different degrees of endowment in individuals, so would it be in different degrees of endowment in nations, or branches of the human family. Hence we find the formation of words, and the process of their composition and grammatical arrangement, in very different stages of development in different races. The Chinese have a language composed of a limited number of monosyllables, which they multiply in use by mere variations of accent, and which they have never yet attained the power of clustering or inflecting; the language of this immense nation-the third part of the human race-may be said to be in the condition of infancy. The aboriginal Americans, so inferior in civilization, have, on the other hand, a language of the most elaborately composite kind, perhaps even exceeding, in this respect, the languages of the most refined European nations. These are but a few out of many facts tending to show that language is in a great measure independent of civilization, as far as its advance and development are concerned. Do they not also help to prove that cultivated intellect is not necessary for the origination of language?

Facts daily presented to our observation afford equally simple reasons for the almost infinite diversification of language. - It is invariably found that, wherever society is at once dense and refined, language tends to be uniform throughout the whole population, and to undergo few changes in the course of time. Wherever, on the contrary, we have a scattered and barbarous people, we have great diversit es, and comparatively rapid alterations 
of language. Insomuch that, while English, French, and German are each spoken with little variation by many millions, there are islands in the Indian archipelago, probably not inhabited by one million, but in which there are hundreds of languages, as diverse as are English, French, and German. It is easy to see how this should be. There are peculiarities in the vocal organization of every person, tending to produce peculiarities of pronunciation; for example, it has been stated that each child in a family of six gave the monosyllable fly in a different manner, (eye, fy, ly, \&c.,) until, when the organs were more advanced, correct example induced the proper pronunciation of this and similar words. Such departures from orthoepy are only to be checked by the power of such example; but this is a power not always present, or not always of suffisient strength. The able and self-devoted Robert Moffat, in his work on South Africa, states, without the least regard to hypothesis, that amongst the people of the towns of that great region, "the purity and harmony of language is kept up by their pichos or public meetings, by their festivals and ceremonies, as well as by their songs and their constant intercourse. With the isolated villages of the desert it is far otherwise. They have no such meetings : they are compelled to traverse the wilds, often to a great distance from their native village. On such occasions fathers and mothers, and all who can bear a burden, often set out for weeks at a time, and leave their children to the care of two or three infirm old people. The infant progeny, some of whom are beginning to lisp, while others can just master a whole sentence, and those still further advanced, romping and playing together, the children of nature, through the livelong day, become habituated to a language of their own. The more voluble condescend to the less precocious, and thus, from this infant Babel, proceeds a dialect composed of a host of mongrel words and phrases, joined together without rule, and in the course of a generation the entire character of the language is changed."* I have been told, that in like manner the children of the Manchester factory workers, left for a great part of the day, in large assemblages, under the care, perhaps, of a single elderly person, and spending the time in amusements, are found to make a great deal of * Missionary Scenes and Labors in South Africa. 
new language. I have seen children in other :ircum. stances amuse themselves by concocting and tr.rowing into the family circulation entirely new words; and I believe I am running little risk of contradiction when I say that there is scarcely a family even amongst the middle classes of this country who have not some peculiarities of pronunciation and syntax, which have originated amongst themselves, it is hardly possible to say how. All these things being considered, it is easy to understand how mankind have come at length to possess between three and four thousand languages, all different, at least as much as French, German, and English, though, as has been shown, the traces of a common origin are observable in them all.

What has been said on the question whether mankind were originally barbarous or civilized, will have prepared the reader for understanding how the arts and sciences, and the rudiments of civilization itself, took their rise amongst men. The only, source of fallacious views on this subject is the so frequent observation of arts, sciences, and social modes, forms, and ideas, being not indigenous where we see them now flourishing, but known to have been derived elsewhere: thus Rome borrowed from Greece, Greece from Egypt, and Egypt itself, lost in the mists of historic antiquity, is now supposed to have obtained the light of knowledge from some still earlier scene of intellectual culture. This has caused to many a great difficulty in supposing a natural or spontaneous origin for civilization and the attendant arts. But, in the first place, several stages of derivation are no conclusive argument against there having been an originality at some earlier stage. In the second, such obssrvers have not looked far enough, for, if they had, they could have seen various instances of crvilizations which it is impossible, with any plausibility, to trace back to a common origin with others; such are those of China and A merica. They would also have seen civilization spring: ing up, as it were, like oases amongst the arid plains of barbarisin, as in the case of the Mandans. A still more attentive study of the subject would have shown, amongst living men, the very psychological procedure on which the origination of civilization and the arts and sciences lepended.

These things, like language, are simply the effects of ute spontaneous working of certain mental faculties, each 
in relation to the things of the external world on which it was intended by creative Providence to be exercised. The monkeys themselves, without instruction from any quarte:, learn to use sticks in fighting, and some build houses-an act which cannot in their case be considered as one of instinct, but of intelligence. Such being the case, there is no necessary difficulty in supposing how man, with his superior mental organization, (a brain five times heavier,) was able, in his primitive state, without instruction, to turn many things in nature to his use, and commence, in short, the circle of the domestic arts. He appears, in the most unfavorable circumstances, to be able to provide himself with some sort of dwelling, to make weapons, and to practice some simple kind of cookery. But, granting, it will be said, that he can go thus far, how does he ever proceed further unprompted, seeing that many nations remain fixed forever at this point, and seem unable to take one step in advance? It is perfectly true that there is such a fixation in many nations; but, on the other hand, all nations are not alike in mental organization, and another point has been established, that only when some favorable circumstances have settled a people in one place do arts and social arrangements get leave to flourish. If we were to limit our view to humbly endowed nations, or the common class of minds in those called civilized, we should see absolutely no conceivable power for the origination of new ideas and devices. But let us look at the inventive class of minds which stand out amongst their fellowsthe men who, with little prompting or none, conceive new ideas in science, arts, morals - and we can be at no loss to understand how and whence have arisen the elements of that civilization which history traces from country to country throughout the course of centuries. See a Pascal, reproducing the Alexandrian's problems at fifteen; a Ferguson, making clocks from the suggestions of his own brain, while tending cattle on a Morayshire heath: a boy Lawrence, in an inn on the Bath road, producing, without a master, drawings which the educated could not but admire; or look at Solon and Confucius, devising sage laws, and breathing the accents of all but divine wisdom, for their barbarous fellow-countrymen, three thousand years ago--and the whole mystery is olved at once Amongst the arrangements of Provi. 
derice, is one for the production of original, inventive, and aspiring minds, which, when circumstances are not decidedly unfavorable, strike out new ideas for the benefit of their fellow-creatures, or put upon them a lasting impress of their own superior sentiments. Nations, improved by these means, become in turn foci for the diffu. sion of light over the adjacent regions of barbarism-theivery passions helping to this end, for nothing can be more clear than that ambitious aggression has led to the civilization of many countries. Such is the process which seems to form the destined means for bringing mankind from the darknsss of barbarism to the day of knowledge and mechanical and social improvement. Even the no. ble art of letters is but, as Dr. Adam Ferguson has remarked, "a natural produce of the human mind, which will rise spontaneously wherever men are happily placed;" original alike amongst the ancient Egyptians and the dimly monumented Toltecans of Yucatan. "Banish," says Dr. Gall, " music, poetry, painting, sculpture, architecture, all the arts and sciences, and let your Homers, Raphaels, Michael Angelos, Glucks, and Canovas be forgotten, yet let men of genius of every description spring up, and poetry, music, painting, architecture, sculpture, and all the arts and sciences, will again shine out in all their glory. Twice within the records of history has the human race traversed the great circle of its entire destiny, and twice has the rudeness of barbarism been followed by a higher degree of refinement. It is a great mistake to supprose one people to have proceeded from another on account of their conformity of manners, customs, and arts The swallow of Paris builds its nest like the swallow of Vienna, but does i: thence follow that the former sprung from the latter. With the same causes we have the same effects; with the same organization we have the manifestation of the same powers."

MENTAL CONSTITUTION OF ANIMALS.

IT has been one of the most agreeable tasks of modern science to trace the wonderfully exact adaptations of the organization of animals to the physical circumstances 
amidst which they are destined to live. From the mandioles of insects to the hand of man, all is seen to be in the most harmonious relation to the things of the outward world, thus clearly proving that design presided in the creation of the whole-design again implying a designer, another word for a CREATOR.

It would be tiresome to present in this place even a selection of the proofs which have been adduced on this point. The Natural Theology of Paley, and the Bridgewater Treatises, place the subject in so clear a light, that the general postulate may be taken for granted. The physical constitution of animals is, then, to be regarded as in the nicest congruity and adaptation to the external world.

Less clear ideas have hitherto been entertained on the mental constitution of animals. The very nature of this constitution is not as yet generally known or held as ascertained. There is, indeed, a notion of old standing, that the mind is in some way connected with the brain; but the metaphysicians insist that it is, in reality. known only by its acts or effects, and they accordingly present the subject in a form which is unlike any other kind of science, for it does not so much as pretend to have nature for its basis. 'There is a general disinclination to regard mind in connection with organization, from a fear that this must needs interfere with the cherished religious doctrine of the spirit of man, and lower him to the level of the brutes. A distinction is therefore drawn between our mental manifestations and those of the lower animals, the latter being comprehended under the term instinct, while our's are collectively described as mind, mind being again a received synonyme with soul, the immortal part of man. There is here a strange system of confusion and error, which it is most imprudent to regard as essential to religion, since candid investigations of nature tend to show its untenableness. There is, in reality, nothing to prevel:! our regarding man as specially endowed with an immo tal spirit, at the same time that his ordinary mental r anifestations are lonked upon as simple phe. nomena esulting from organization, those of the lower animals .jeing phenomena ábsolutely the same in character, though developed within much narrower limits.*

- "Is net God the first cause of matter as well as of mind? Do not the first attributes of matter lie as inscrutable in the bosom of God-of its first author-as those of mind ? Has not even matter 
What has chiefly tended to take mind, in the eyes of learned and unlearned, out of the range of nature, is its apparently irregular and wayward character. How difconfessedly received from God the power of experiencing, in consequence of impressions from the earlier modifications of matter, certain consciousnesses called sensations of the same? Is not, therefore, the wonder of matter also receiving the consciousnesses of other matter called ideas of the mind a wonder more flowing out of and in analogy with all former wonders, than would be, on the contrary, the wonder of this faculty of the mind not flowing out of any faculties of matter? Is it not a wonder which, so far from destroying our hopes of immortality, can establish that doc. trine on a train of inferences and inductions more firmly estab lished and more connected with each other than the former belief can be, as soon as we have proved that matter is not perishable, but is only liable to successive combinations and decombinations?

" Can we look further back one way into the first origin of matter than we can look forward the other way into the last develop. ments of mind? Can we say that God has not in matter itself laid the seeds of every faculty of mind, rather than that he has made the first principle of mind entirely distinct from that of matter ? Cannot the firsf cause of all we see and know have fraught matter itself, from its very beginning, with all the attributes necessary to develop into mind, as well as he can have from the first made the attributes of mind wholly different from those of matter, only in order afterwards, by an imperceptible and incomprehensible link, to join the other two together?

"* * [The decombination of the matter on which mind rests] is this a reason why mind must be annihilated? Is the temporary reverting of the mind and of the sense out of which that mind develops, to their original component elements, a reason for think. ing that they cannot again at another later period, and in another higher globe, be again recombined, and with more splendor than before? ** The New Testament does not after death here promise us a soul hereafter unconnected with matter, and which has no connection with our present mind-a soul independent of time and space. That is a fanciful idea, not founded on its expressions, when taken in their just and real meaning. On the contrary, it promises us a mind like the present, founded on time and space; since it is, like the present, to hold a certain situation in time, and a certain locality in space. But it promises a mind situated in por. tions of time and of space different from the present, a mind composed of elements of matter more extended, more perfect, and more gtorious : a mind which, formed of materials supplied by different globes. is consequently able to see further into the past, and to think further into the future, than any mind here existing: a mind which, from the partial and uneven combination incidental to it on this globe, will be exempt from the changes for evil, to which, on the present globe, mind as well as matter is liable, and will only thenceforth experience the changes for the better which matter more justly poised, will alone continue to experience: a mind which, no longer fearing the death, the total decomposition, to which it is subject on this globe, will thenceforth continue last and immortal."-HopE, on the Origin and Prospects of Mar 1831. 
ferent the manifestations in different beings! how unstable in all ! - at one time so calm, at another so wild and impulsive! It seemed impossible that anything so subtle and aberrant could be part of a system, the main featuses of which are regularity and precision. But the irregusarity of mental phenomena is only in appearance. When we give up the individual, and take the mass, we find as much uniformity of result as in any other class of natural phenomena. The irregularity is exactly of the same kind as tile: of the weather. No man can say what may be ihe weather of to-morrow; but the quantity of rain which falls in any particular place in any fiye years is precisely the same as the quantity which falls in any other five years at the same place. Thus, while it is absolutely impossible to predict of any one Frenchman that during next year he will commit a crime, it is quite certain that about one in every six hundred and fifty of the French people will do so, because in past years the proportion has generally been about that amount, the tendencies to crime in relation to the temptations being everywhere invariable over a sufficiently wide range of time. So also, the number of persons taken in charge by the police in London for being drunk and disorderly on the streets, is, week by week, a nearly uniform quantity, showing that the inclination to drink to excess is always in the mass about the same, regard being had to the existing temptations or stimulations to this vice. Even mistakes and oversights are of regular recurrence, for it is found in the post-offices of large cities that the number of letters put in without addresses is year by year the same. Statistics has made out an equally distinct regularity in a wide range, with regard to many other things concerning the mind, and the doctrine founded upon it has lately produced a scheme which may well strike the ignorant with surprise. It was proposed to establish in London a society for ensuring the integrity of clerks, secretaries, collectors, and all such functionaries as are usually cbliged to find security for money passing through their hands in the course of business. A gentleman of the highest character as an actuary spoke of the plan in the following terms: "If a thousand bankers' clerks were to club together to indemnify their securities, by the payment of one pound a year each, and if each had given security for $500 l$., it is obvious that two in each year 
might become defaulters to that amount, four to half the amount, and so on, without rendering the guarantee fund insolvent. If it be tolerably well ascertained that the instances of dishonesty (yearly) arnong such persons amount to one in five hundred, this club would continue to exist, subject to being in debt in a bad year to an amount which it would be able to discharge in good ones. The only question necessary to be asked previous to the formation of such a club would be,-may it not be feared that the motive to resist dishonesty would be lessened by the existence of the club, or that ready-made rogues, by belonging to it, might find the means of obtaining situations which they would otherwise have been kept out of by the impossibility of obtaining security among those who know them? Suppose this be sufficiently answered by saying that none but those who could bring satisfactory testimony to their previous good character should be allowed to join the club; that persons who may now hope that a deficiency on their parts will be made up and hushed up by the relative or friend who is security, will know very well that the club will have no motive to decline a prosecution, or to keep the secret, and so on. It then only remains to ask whether the sum demanded for the guarantee is sufficient* "The philosophical principle on which the scheme proceeds, seems to be simply thie, that, amongst a given (large) number of persons of good character, there will be within a year or considerable space of time, a determinate number of instances in which moral principle and the terror of the consequences of guilt will be overcome by temptations of a determinate kind and amount, and thus occasion a periodical amount of loss which the association must make up.

This statistical regularity in moral affairs fully establishes their being under the presidency of law. Man is now seen to be an enigma only as an individual; in the mass he is a mathematical problem. It is hardly necessary to say, much less to argue, that mental action, being proved to be under law, passes at once into the category of natural things. Its old metaphysical character vanishes in a moment, and the distinction usually taken between physical and moral is annulled, as only an error in

- Dublin Review, Aug. 1840. The Guarantee Society has since been established, and is likely to become a useful and prosperoug institution 
terms This view agrees with what all observation teaches, that mental phenomena flow directly from the brain. They are seen to be dependent on naturally constituted and naturally conditioned organs, and thus obedient, like all other organic phenomena, to law. And how wondrous must the constitution of this apparatus be, which gives us consciousness of thought and of affection, which makes us familiar with the numberless things of earth, and enables us to rise in conception and communion to the councils of God himself! It is matter which forms the medium or instrument-a little mass which, decomposed, is but so much common dust ; yet in its living constitution, designed, formed and sustained by Almighty Wisdom. How admirable its character! how reflective of the unutterable depths of that Power by which it was so formed, and is so sustained !

In the mundane economy, mental action takes its place as a means of providing for the independent existence and the various relations of animals, each species being furnished according to its special necessities and the demands of its various relations. The nervous system-the more comprehensive term for its organic apparatus-is variously developed in different classes and species, and also in different individuals, the volume or mass bearing a general relation to the amount of power. In the mollusca and crustacea we see simply a ganglionic cord pervading the extent of the body, and sending out lateral filaments. In the vertebrata, we find a brain with a spinal cord, and branching lines of nervous tissue.* But here, as in the general structure of animals, the great principle of unity is observed. The brain of the vertebrata is merely an expansion of one of the ganglions of the nervous cord of the mollusca and crustacea. Or the corresponding ganglion of the mollusca and crustacea may be regarded as the rudiment of a brain, the superior organ thus appearing as only $>$ further development of the inferior. There are many idts which tend to prove that the action of this apparatis is of an electric nature, a modification of that surprising agent which takes magnetism, heat, and light, as other subordinate forms, and of whose general scope in

- The ray, which is considered the lowest in the scale of fishes, or next to the crustaceans, gives the first faint representation of a brain in certain scanty and medullary masses, which appear as merely com josed of enlarged origins of the nerves. 
this great system of things we are only beginning to have a right conception. It has been found that simple eleciricity, artificially produced, and sent along the nerves of a dead body, excites muscular action. 'The brain of a rewiy..killed animal being taken out, and replaced by a cubstance which produces electric action, the operation of digestion, which had been interrupted by the death of the animal, was resumed, showing the absolute identity of the brain with a galvanic battery. Nor is this a very startling idea, when we reflect that electricity is almost as metaphysical as ever mind was supposed to be. It is a thing perfectly intangible, weightless. Metal may be magnetized, or heated to seven hundred of Fahrenheit, without becoming the hundredth part of a grain heavier. $A$ nd yet electricity is a real thing, an actual existence in nature, as witness the effects of heat and light in vegetation-the power of the galvanic current to reassemble the particles of copper from a solution, and make them again into a solid plate-the rending force of the thunderbolt as it strikes the oak; see also how both heat and light observe the angle of incidence in reflection, as exactly as does the grossest stone thrown obliquely against a wall. So mental action may be imponderable, intangible, and yet a real existence, and ruled by the Eternal through his laws.*

Common observation shows a great general superiority of the human mind over that of the inferior animals. Man's mind is almost infinite in device; it ranges over all the world; it forms the most wonderful combinations; it seeks back into the past, and stretches forward into the future; while the animals generally appear to have a narrow range of thought and action But so also has an infant but a limited range, and yet it is mind which works

* If mental action is electric, the proverbial quickness of thought -that is, the quickness of the transmission of sensation and will may be presumed to have been brought to an exact measurement. The speed of light has long been know $n$ to be about 192,000 miles per second, and the experiments of Wheatstone have shown that the electric agent travels (if I may so speak) at the same rate, thus showing a likelihood that one law rules the movements of all the "imponderabie bodies." Mental action may accordingly be presumed to have a rapidity equal to one hundred and ninety: two thousand miles in the second-a rate evidently far beyond what is necessary to make the design and execution of any of our ordinary muscular movements apparently identical in point of ime, which they are. 
there, as well as in the most accomplished adults. The difference between mind in the lower animals and in man is a difference in degree only; it is not a specific difference. All who have studied animals by actual observation, and even those who have given a candid atterition to the subject in books, must attain more or less clear convictions of this truth, notwithstanding all the obscurity which prejudice may have engendered. We see animals capable of affection, jealousy, envy; we see them quarrel, and conduct quarrels, in the very manner pursued by the more impulsive of our own race. We see them liable to flattery, inflated with pride, and dejected by shame. We see them as tender to their young as human parents are, and as faithful to a trust as the most conscientious of human servants. The horse is startled by marvellous objects, as a man is. The dog and many others show tenacious memory. The dog also proves himself possessed of imagination, by the act of dreaming. Horses, finding themselves in want of a shoe, have of their own accord gone to a farrier's shop where they were shod before. Cats, closed up in rooms, will endeavor to obtain their liberation by pulling a latch or ringing a bell. It has several times been observed that in a field of cattle, when one or two were mischievous, and persisted long in annoying or tyrannizing over the rest, the herd, to all ap. pearance, consulted, and then, making a united effort, drove the troublers off the ground. The members of a rookery have also been observed to take turns in supplying the needs of a family reduced to orphanhood. All of these are acts of reason, in no respect different from similar acts of men. Moreover, although there is no heritage of accumulated knowledge amongst the lower animals, as there is amongst us, they are in some degree susceptible of those modifications of natural character, and capable of those accomplishments, which we call education. 'The taming and domestication of animals, and the changes thus produced upon their nature in the course of generations, are results identical with civilization amongst ourselves; and the quiet, servile steer is probably as unlike the original wild cattle of this country as the English gentleman of the present day is unlike the rude baron of the age of King John. Between a young, unbroken horse and a trained one, there is, again, all the difference which exists between a wild yonth reared at 
his own discretion in the country and the same person when he has been toned down by long exposure to the influences of refined society. On the accomplishments acquired by animals it were superfluous to enter at any length: but I may advert to the dogs of $M$. Leonard, as remarkable examples of what the animal intellect may be trained to. When four pieces of card are laid down before them, each having a number pronounced once in connexion with it, they will, after a re-arrangement of the pieces, select any one named by its number. They also play at dominoes, and with so much skill as to triumph over biped opponents, wining if the adversary place a wrong piece, or if they themselves be deficient in a right one. Of extensive combinations of thought we have no reason to believe that any animal is capableand yet most of us must feel the force of Walter Scott's remark, that there was scarcely anything which he would not believe of a dog. There is a curious result of education in certain animals, namely, that habits to which they have been trained in some instances become hereditary. For example, the accomplishment of pointing at game, although a pure result of education, appears in the young pups brought up apart from their parents and kind. The peculiar leap of the Irish horse, acquired in the course of traversing a boggy country, is continued in the progeny brought up in England. This hereditariness of specific habits suggests a relation to that form of psychological demonstration usually called instinct; but instinct is only another term for mind, or is mind in a peculiar stage of development; and though the fact wele otherwise, it could not affect the postulate, that demonstrations, such as have been enumerated are mainly intellectual demonstrations not to be distinguished as such from those of human beings.

More than this, the lower animals manifested mental phenomena long before man existed. While as yet there was no brain capable of working out a-mathematical problem, the economy of the six-sided figure was exemplified by the instinct of the bee. Ere human musician had whistled or piped, the owl hooted in B flat, the cuckoo had her song of a falling third, and the chirp of the cricket was in B. The dog and the elephant prefigured the sagacity of the human mind. The love of a human mother for her babe was anticipated by nearly every 
humbler mammal, the carnaria not excepted. The peacock strutted, the turkey blustered, and the cock fought for victory, just as human being's afterwards did, and still do. Our faculty of imitation, on which so much of our amusement depends, was exercised by the mocking-bird ; and the whole tribe of monkeys must have walked about the pre-human world, playing off those tricks in which we see the comicality and mischief-making of our character so curiously exaggerated.

The unity and simplicity which characterize nature give great antecedent probability to what observation seems about to establish, that, as the brain of the vertebrata generally is just an advanced condition of a particular ganglion in the mollusca and crustacea, so are the brains of the higher and more intelligent mammalia only further developments of the brains of the inferior orders of the same class. Or, to the same purpose, it may be said that each species has certain superior developments, according to its needs, while others are in a rudimental or repressed state. This will more clearly appear. after some inquiry has been made into the various powers comprehended under the term mind.

One of the first and simplest functions of mind is to give consciousness-consciousness of our identity and of our existence. 'This, apparently, is independent of the senses, which are simply media, and, as Locke has shown, the only media through which ideas respecting the external world reach the brain. The access of such ideas to the brain is the act to which the metaphysicians have given the name of perception. Gall, however, has shown, by induction from a vast number of actual cases, that there is a part of the brain devoted to perception, and that even this is subdivided into portions which are respectively dedicated to the reception of different sets of ideas, as those of form, size, color, weight, objects in their totality, events in their progress or occurrence, time, musical sounds, \&c. The system of mind invented by this philosopher - the only one founded upon nature, or which even pretends to or admits of that necessary basisshows a portion of the brain acting as a faculty of comic ideas, another of imitation, another of wonder, one for discriminating or observing differences, and another in which resides the power of tracing effects to causes. There are also parts of the brain for the sentimental part 
of our nature, or the affections, at the head of which stand the moral feelings of benevolence, conscientious ness, and veneration. 'Through these, man stands in re lation to himself, his fellow-men, the external world and his God; and through these comes most of the happiness of man's life, as well as that which he derives from the contemplation of the world to come, and the cultivation of his relation to it (pure religion.) Tre other sentiments may be briefly enumerated, their names being sufficient, in general, to denote their functionsfirmness, hope, cautiousness, self-esteem, love of approbation, secretiveness, marvellousness, constructiveness, imitation, combativeness, destructiveness, concentrativeness, adhesiveness, love of the opposite sex, love of offspring, alimentativeness, and love of life. Through these faculties, man is connected with the external world, and supplied with active impulses to maintain his place in it as an individual and as a species. There is also a faculty, (language,) for expressing, by whatever means (signs, gestures, looks, conventional terms in speech,) the ideas which arise in the mind. There is a particular state of each of these faculties, when the ideas of objects once formed by it are revived or reproduced, a process which seems to be intimately allied with some of the phenomena of the new science of photography, when images impressed by reflection of the sun's rays upon sensitive paper are, after a temporary obliteration, resuscitated on the sheet being exposed to the fumes of mercury. Such are the phenomena of memory, that handmaid of intellect, without which there could be no accumulation of mental capital, but an universal and continual infancy. Conception and imagination appear to be only intensities, so to sleak, of the state of brain in which memory is produced. On their promptness and power depend most of the exertions which distinguish the man of arts and letters, and even in no small measure the cultivator of science.

The faculties above described-the actual elements of the mental constitution-are seen in mature man in an indefinite potentiality and range of action. It is different with the lower animals. They are there comparatively definite in their power, and restricted in their applicsion. The reader is familiar with what are called instincts in some of the humbler species, that is, an uniform and 
unprompted tendency towards certain particular acts, as the building of cells by the bee, the storing of provisions by that insect and several others, and the construction of nests for a coming progeny by birds. This quality is nothing more than a mode of operation peculiar to the faculties in an humble state of endowment, or early stage of development. The cell formation of the bee, the house-building of ants and beavers, the web-spinning of spiders, are but primitive exercises of constructiveness, the faculty which, indefinite with us, leads to the arts of the weaver, upholsterer, architect, and mechanist, and makes us often work delightedly where our labors are in vain, or nearly so. The storing of provisions by the ants is an exercise of acquisitiveness-the faculty which with us makes rich men and misers. A vast number of curious devices, by which insects provide for the protection and subsistence of their young, whom they are perhaps never to see, are most probably a peculiar restricted effort of philo-progenitiveness. The common source of this class of acts, and of common mental operations, is shown very convincingly by the melting of the one set into the other. Thus, for example, the bee and bird will make modifications in the ordinary form of their cells and nests when necessity compels them. Thus, the alimentiveness of such animals as the dog, usually definite with regard to quantity and quality, can be pampered or educated up to a kind of epicurism, that is, an indefiniteness of object and action. The same faculty acts limitedly in ourselves at first, dictating the special act of sucking; afterwards it acquires indefiniteness. Such is the real nature of the distinction between what are called instincts and reason, upon which so many volumes have been written without profit to the world. All faculties are instinctive, that is, dependent on internal and inherent impulses. This term is therefore not specially applicable to either of the recognized modes of the operation of the faculties. We only, in the one case, see the faculty in an immature and slightly developed state; in the other, in its most advanced condition. In the one case, it is definite, in the other, indefinite, in its range of action These terms would perhaps be the most suitable for expressing the distinction.

In the humblest forms of being we can trace scarcely anything besides a definite action in a few of the faculties 
Generally speaking, as we ascend in the scale, we see more and more of the faculties in exercise, and t: ese tending more to the indefinite mode of manifestation. And for this there is the obvious reason in Providence, that the lowest animals have all of them a very limited sphere of existence, born only to perform a few functions, and enjoy a brief term of life, and then give way to another generation, so that they do not need much mental guidance. At higher points in the scale, the sphere of existence is considerably extended, and the mental operations are less definite accordingly. 'The horse, dog, and a few other rasorial types, noted for their serviceableness to our race, have the indefinite powers in no small endowment. Man, again, shows very little of the definite mode of operation, and that little chiefly in childhood, or in barbarism or idiocy. Destined for a wide field of action, and to be applicable to infinitely varied contingencies, he has all the faculties developed to a high pitch of indefiniteness, that he may be rearly to act well in all imaginable cases. His commission, it may be said, gives large discretionary powers, while that of the inferior animals is limited to a few precise directions. But when the human brain is congenitally imperfect or diseased, or when it is in the state of infancy, we see in it an approach towards the character of the brains of some of the inferior animals. Dr. G. J. Davey states that he has frequently witnessed, among his patients at the Hanwell Lunatic Asylum, indications of a particular abnormal cerebration which forcibly reminded him of the specific healthy characteristics of animals lower in the scale of organization ;* and every one must have observed how often the actions of children, especially in their moments of play, and where their selfish feelings are concerned, bear a resemblance to those of certain famiiliar animals. $\dagger$ Behold, then, the wonderful unity of the whole system. 'The grades of mind, like the forms of being, are mere stages of development. In the humbler forms, but a few of the mental faculties are traceable, just as we see in them but a few of the lineaments of universal structure. In man, the system has

* Phrenological Journal, xv., 338.

t A pampered lap-dog, living where there is another of its own species, will hide any nice morsel which it cannot eat, under a rug or in some other by-place, designing to énjoy it afterw'erds. I havo seen children do the same thing. 
arrived at its highest condition. The few gleams of reason, then, which we see in the lower animals are precisely analogous to such a development of the fore-arm as we find in the paddle of the whale. Causality, comparison, and other of the nobler faculties, are in them rudimental.

Bound up as we thus are by an identity in the character of our mental organization with the lower animals, we are yet, it will be observed, strikingly distinguished from them by this great advance in development. We have faculties in full force and activity, which the animals either possess not at all, or in so low and obscure a form as to be equivalent to non-existence. Now these parts of mind are those which connect us with the things that are not of this world. We have veneration, prompting us to the worship of the Deity, which the animals lack. We have hope, to carry us on in thought beyond the bounds of time. We have reason, to enable us to inquire into the chaiacter of the Great Father, and the relation of us, his humble creatures, towards him. We have conscientiousness and benevolence, by which we can in a faint and humble measure imitate, in our conduct, that which he exemplifies in the whole of his wordrous doings. Beyond this, mental science does not carry us in support of religion : the rest depends on evidence of a different kind. But it is surely much that we thus discover in nature a provision for things so important. The existence of faculties having a regard to such things is a good evidence that such things exist. The face of God is reflected in the organization of man, as a little pool reflects the glorious sun.

The affective or sentimental faculties are all of them liable to operate whenever appropriate objects or stimuli are presented, and this they do as irresistibly and unerringly as the tree sucks up moisture which it requires, with only this exception, that one faculty often interferes with the action of another, and operates instead by force of superior inherent strength or temporary activity. For example, alimentiveness may be in powerful operation with regard to its appropriate object, producing a keen appetite, and yet it may not act, in consequence of the more powerful operation of cautiousness, warning against evil consequences likely to ensue from the desired indulgence. This liability to flit from under the control of one feeling to the control of another, constitutes what is 
recognized as free will in man, heing nothing more than a vicissitude in the supremacy of the faculties over each other.

It is a comm on mistake to suppose that the individuals of our own species are all of them formed with similar faculties-similar in power and tendency-and that education and the influence of circumstances produce all the differences which we observe. There is not, in the old systems of mental philosophy, any doctrine more opposite to the truth than this. It is refuted at once by the great differences of intellectual tendency and moral disposition to be observed among a group of young children who have been all brought up in circumstances perfectly identical-even in twins, who have never been but in one place, under the charge of one nurse, attended to alike in all respects. The mental characters of individuals are inherently various, as the forms of their persons and the features of their faces are; and education and circumstances, though their influence is not to be despised, are incapable of entirely aitering these characters, where they are strongly developed. That the original characters of mind are dependent on the volume of particular parts of the brain and the general quality of that viscus, is proved by induction from an extensive range of observations, the force of which must have been long since universally acknowledged but for the unpreparedness of mankind to admit a functional connexion between mind and body. The different mental characters of individuals may be presumed from analogy to depend on the same law of development which we have seen determining: forms of being and the mental characters of particular species. This we may conceive as carrying forward the intellectual powers and moral dispositions of some to a high pitch, repressing those of others at a moderate amount, and thus producing all the varieties which we see in our fellow-creatures. Thus a Cuvier and a Newton are but expansions of a clown, and the person emphatically called the wicked man is one whose highest moral feelings are rudimental. Such differences are not confined to our species; they are only less strongly marked in many of the inferior animals. There are clever dogs and wicked horses, as well as clever men and wicked men, and education sharpens the talents, and in some degree regulates the dispositions of animals, as it does our own 
Here I may advert to a very interesting analogy between the mental characters of the types in the quinary system of zoology and the characters of individual men. We have seen that the pre-eminent type is usually endowed with an harmonious assemblage of the mental qualities be. longing to the whole group, while the sub-typical inclines to ferocity, the rasorial to gentleness, and so on. Now, among individuals, some appear to be almost exclusively of the sub-typical, and others of the rasorial characters, while to a limited number is given the finely as. sorted assemblage of qualities which places them on a parallel with the typical. To this may be attributed the universality which marks all the very highest brains, such as those of Shakspeare and Scott, men of whom it has been remarked that they must have possessed within themselves not only the poet, but the warrior, the statesman, and the philosopher; and who, moreover, appear to have had the mild and manly, the moral and the forci. ble parts of our nature in the most perfect balance.

There is, nevertheless, a general adaptation of the mental constitution of man to the circumstances in which he lives, as there is between all the parts of nature to each other. The goods of the physical world are only to be realized by ingenuity and industrious exertion; behold, accordingly, an intellect full of device, and a fabric of the faculties which would go to pieces or destroy itself if it were not kept in constant occupation. Nature presents to us much that is sublime and beautiful: behold faculties which delight in contemplating these properties of hers, and in rising upon them, as upon wings, to the presence of the Eternal. It is also a world of difficulties and perils, and see how large a portion of our species are endowed with vigorous powers which take pleasure in meeting and overcoming difficulty and dunger. Even that principle on which our faculties are constituted-a wide range of treedom in which to act for all various occasions-necessitates a resentful faculty, by which individuals may protect themselves from the undue and capricious exercise of each nther's faculties, and thus preserve their individual rights $\mathrm{Sc}$ also there is cautiousriess, to give us a tendency to provide against the evils by which we may be assailed; and secretiveness, to enable us to conceal whatever, being divulged, would be offensive to others or injurious to ouraelves- - a function which obriously has a certaj: legiti 
mate range of action, however liable to be abused. 'The constitution of the mind generally points to a state of intimate relation of individuals towards society, towards the external world, and towards things above this world. No individual being is integral or independent, he is only part of an extensive piece of social mechanism. The inferior mind, full of rude energy and unregulated impulse, does not more require a superior nature to act as its mas. ter and its mentor, than does the superior nature require to be surrounded by such rough elements on which to exercise its high endowments as a ruling and tutelary power. This relation of each to each produces a vast portion of the active business of life. It is easy to see that, if we were all alike in our moral tendencies, and all placed on a medium of perfect moderation in this respect, the world would be a scene of everlasting dulness and apathy. It requires the variety of individual constitution to give moral life to the scene.

The indefiniteness of the potentiality of the human faculties, and the complexity which thus attends their relations lead unavoidably to occasional error. If we consider for a moment that there are not less than thirty such faculties, that they are each given in different proportions to different persons, that each is at the same time endowed with a wide discretion as to the force and frequency of its action, and that our neighbors, the world, and our connexions with something beyond it, are all exercising an ever-varying influence over us, we cannot be surprised at the irregularities attending human conduct. It is simply the penalty paid for the superior endowment. It is here that the imperfection of our nature resides. Causality and conscientiousness are, it is true, guides over all; but even these are only faculties of the saine indeterminate constitution as the rest, and partake accordingly of the same inequality of action. Man is therefore a piece of mechanism, which never can act so as to satisfy his own ideas of what he might be-for he can imagine a state of moral perfection, (as he can imagine a globe formed of diamonds, pearls, ind rubies,) though his constitution forbids him to realize it. There ever will, in the best disposed and most disciplined minds, be occasional discrepancies between the amount of templation and the power summoned for regulation or resistance, or between the stimulus and the mobility of the faculty; 
and hence those errors, and shortcomings, and excesses; without end, with which the good are constantly finding cause to charge themselves. There is at the same time even here a possibility of improvement. In infancy, the impulses are all of them irregular; a child is cruel, cunning, and false, under the slightest temptation, but in time learns to control these inclinations, and to be habitually humane, frank, and truthful. So is human society, in its earliest stages, sanguinary, aggressive, and deceitful, but in time becomes just, faithful and benevolent. To such improvements there is a natural tendency which will operate in all fair circumstances, though it is not to be expected that irregular and undue impulses will ever be altogether banished from the system.

It may still be a puzzle to many, how beings should be born into the world whose organization is such that they unavoidably, even in a civilized country, become malefactors. Does God, it may be asked, make criminals? Does he fashion certain beings with a predestination to evil ? He does not do so; and yet the criminal type of brain, as it is called, comes into existence in accordance with laws which the Deity has established. It is not, however, as the result of the first or general intention of those laws, but as an exception from their ordinary and proper action. The production of those evilly-disposed beings is in this manner. The moral character of the progeny depends in a general way (as does the physical character also,) upon conditions of the parents,-both general conditions, and conditions at the particular time of the commencement of the existence of the new being, and likewise external conditions affecting the fotus through the mother. Now, the amount of these conditions is indefinite. The faculties of the parents, as far as these are concerned, may have oscillated for the time towards the extreme of tensibility in one direction. The influences upon the foetus may have also been of an extreme and unusual kind. Let us suppose that the conditions upon the whole have been favorable for the development, not of the higher but of the lower sentiments, and of the propensities of the new being, the result will necessarily be a mean type of brain. Here it will be observed, God no more decreed an immoral being than he decreed an immoral paroxysm of the sentiments. Our perplexity is in considering the ill-disposed being by 
himself. $\mathrm{He}$ is only a part of a series of phenomena, traceable to a principle good in the main, but which admits of evil as an exception. We have seen that it is for wise ends that God leaves our moral faculties to an inc fie nite range of action; the general good results of this arrangement are obvious; but exceptions of evil are insép. arable from such a system, and this is one of them. To come to particular illustration-when a people are op. pressed, or kept in a state of slavery, they invariably contract habits of lying, for the purpose of deceiving and outwitting their superiors, falsehood being a refuge of the weak under difficulties. What is a habit in parents becomes an inherent quality in children. We are not, therefore, to be surprised when a traveller tells us that black children in the West Indies appear to lie by instinct, and never answer a white person truly even in the simplest matter. Here we have secretiveness roused in a people to a state of constant and exalted exercisia; an over-tendency of the nervous energy in that direction is the consequence, and a new organic condition is established. This tells upon the progeny, which comes into the world with secretiveness excessive in volume and activity. All other evil characteristics may be readily conceived as being implanted in a new generation in the same way. And sometimes not one, but several generations, may be concerned in bringing up the result to a pitch which produces crime. It is, however, to be observed, that the general tendency of things is to a limitation, not the extension of such abnormally constituted beings. The criminal brain finds itself in a sociai scene where all is against it. It may struggle on for a time, but the medium and superior natures are never long at a loss in getting the better of it. The disposal of such beings will always depend much on the moral state of a community, the degree in which just views prevail with regard to human nature, and the feelings which accident may have caused to predominate at a paricular time. Where the mass was littie enlightened or refined, and terrors for life or property were highly excited, malefactors have ever been treated severely But when order is generally triumphant, and reason allowed sway, men begin to see the true case of criminals-rıamely, that while one large department are victims of erroneous social conditions, another are brought to error by tendencies which 
they are only unfortunate in having inherited from nature. Criminal jurisprudence, then, addresses itself less to the direct punishment than to the reformation and care-taking of those liable to its attention. And such a treatment of criminals, it may be further remarked, so that it stop short of affording any encouragement to crime (a point which experience will determine,) is evidently no more than justice, seeing how accidentally all forms of the moral constitution are distributed, and how thor.. oughly mutual obligation shines throughout the whole frame of society-the strong to help the weak, the good to redeem and restrain the bad.

The sum of all we have seen of the psychical const Itution of man is, that its Almighty Author has destined it, like everything else, to be developed from inherent qualities, and to have a mode of action depending solely on its own organization. Thus the whole is complete on one principle. The masses of 'space are formed by law; law makes them in due time theatres of existence for plants and animals; sensation, disposition, intellect, are all in like manner developed and sustained in action by law. It is most interesting to observe into how small a field the whole of the mysteries of nature thus ultimately resolve themselves. The inorganic has one final comprehensive law, GRAvitation. The organic, the other great department of mundane things, rests in like manner on one law, and that is-DEVELOPMENT. Nor may even these be after all twain, but only branches of one still more comprehensive law, the expression of that unity which man's wit can scarcely separate from Deity itse]f

\section{PURPOSE AND GENERAL CONDITION OF THE ANIMATED CREATION}

WE have now to inquire how this view of the constitution and origin of nature bears upon the condition of man upon the earth, and his relation to supra-mundane things

That enjoyment is the proper attendant of animal existence is pressed upon us by all that we see and all we experience. Everywhere we perceive in the lower creatures, in their ordinary condition, symptoms of enjoyment. Their whole being is a system of needs, the supplying of 
which is gratification, and of faculties, the exercise of which is pleasurable. When we consult our own sensations, we find that, even in a sense of a healthy performance of all the functions of the animal econorny, God has furnished us with an innocent and very high enjoyment. The mere quiet consciousness of a healthy play of the mental functions, a mind at ease with itself and all around it-is in like manner extremely agreeable. This negative class of enjoyments, it may be remarked, is likely to be even more extensively experienced by the lower animals than by man, at least in the proportion of their absolute endowments, as their mental and bodily functions are much less liable to derangement than ours. To find the world constituted on this principle is only what in reason we would expect. We cannot conceive that so vast a system could have been created for a contrary purpose. No averagely constituted human being would, in his own limited sphere of action, think of producing a similar system upon an opposite principle. But to form so vast a range of being, and to make being everywhere a source of gratitication, is conformable to our ideas of a Creator in whom we are constantly discovering traits of a nature of which our own is but a faint and far-cast shadow at the best.

It appears at first difficult to reconcile with this idea the many miseries which we see all sentient beirgs, ourselves included, occasionally enduring. How, the sage has asked in every age, should a Being so transcendently kind have allowed of so large an admixture of evil in the condition of his creatures? Do we not at length find an answer to a certain extent satisfactory, in the view which has now been given of the constitution of nature? We there see the Deity operating in the most august of his works by fixed laws, an arrangement which, it is clear, only admits of the main and primary results being good, but disregards exceptions. Now the mechanical laws are so definite in their purposes, that no exceptions ever take place in that department; if there is a certain quantity of nebulous matter to be agglomerated, and divided, and set in motion as a planetary system, it will te so with hair'sbreadth accuracy, and cannot be otherwise. But the laws presiding over meteorology, life, and mind, are necessarily less definite, as they have to produce a great variety of mutually related resilts. I.eft to art indenendentlv of 
ach other, each according to its separate commission, and each with a wide range of potentiality to be modified by associated conditions, they can only have effects generally beneficial : often there must be an interference of one law with another, often a law will chance to operate in excess, or upon a wrong object, and thus evil will be produced. Thus, winds are generally useful in many ways, and the sea is useful as a means of commurication between one country and another; but the natural laws which produce winds are of indefinite range of action, and sometimes are unusually concentrated in space or in time, so as to produce storms and hurricanes, by which much damage is done; the sea may be by these causes violently agitated, so that many barks and many lives perish. Here, it is evident, the evil is only exceptive Suppose, again, that a boy, in the course of the lively sports proper to his age, suffers a fall which injures his spine, and renders him a cripple for life. Two things have been concerned in the case : first, the love of violent exercise, and second, the law of gravitation. Both of these things are good in the main. In the rash enterprises and rough sports in which boys engage, they prepare their bodies and minds for the hard tasks of life. By gravitation, all moveable things, our own bodies included, are kept stable on the surface of the earth. But when it chances that the playful boy loses his hold, (we shall say) of the branch of a tree, and has no solid support immediately below, the law of gravitation unrelentingly pulls him to the ground, and thus he is hurt. Now it was not a primary object of gravitation to injure boys; but gravitation could not but operate in the circumstances, its nature being to be universal and invariable. The evil is, therefore, only a casual exception from something in the main good.

The same explanation applies to even the most conspicuous of the evils which afflict society. War, it may be said, and said truly, is a tremendous example of evil, in the misery, hardship, waste of human life, and misspending of human energies, which it occasions. But what is it that produces war? Certain tendencies of human nature, as keen assertion of a supposed right, resentment of a supposed injury, acquisitiveness, desire ef admiration, combativeness, or mere love of excitemeni. All of these are tendencies which are every day, in a le- 
gitimate extent of action, producing great and indispensable benefits to us. Man would be a tame, indolent, unserviceable being without them, and his fate would be starvation. War, then, huge evil though it be, is, after all, but the exceptive case, a casual misdirection of properties and powers essentially good. God has given us the tendencies for a benevolent purpose. He has only not laid down any absolute obstruction to our misuse of them. That were an arrangement of a kind which he has lowhere made. But he has established many laws in our nature which tend to lessen the frequency and destructiveness of these abuses. Our reason comes to see that war is purely an evil, even to the conqueror. Be. nevolence interposes to make its ravages less mischievous to humain comfort, and less destructive to human life Men begin to find that their more active powers can be exercised with equal gratification on legitimate objects; for example, in overcoming the natural difficulties of their path through life, or in a generous spirit of emulation in a line of duty beneficial to themselves and their fellow-creatures. Thus, war at length shrinks into a comparatively narrow compass, though there certainly is no reason to suppose that it will be at any early period, if ever, altogether dispensed with, while man's constitution remains as it is. In considering an evil of this kind, we must not limit our view to our own or any past time. Placed upon earth with faculties prepared to act, but in.. experienced, and with the more active propensities ne. cessarily in great force to suit the condition of the globe, man was apt to misuse his powers much in this way at first, compared with what he is likely to do when he advances into a condition of civilization. In the scheme of Providence, thousands of years of frequent warfare, all the so-called glories which fill histcry, may be only an exception to the general rule.

The sex-passion in like manner leads to great evils; but the evils are only an exception from the vast mass of good connected with this affection. Providence has seen it necessary to make very ample provision for the preservation and utmost possible extension of all species. The aim seems $t$, be to diffuse existence as widely as possible, to fill up every vacant piece of space with some sentient being to be a vehicle of enjoyment. Hence this oassion is conferred in great force. But the relation be- 
tween the number of beings, and the means of supporting them, is only on the footing of general law. There may be occasional discrepancies between the laws operating for the multiplication of individuals and the laws opera.ting to supply them with the means of subsistence, and evils will be endured in consequence, even in our own highly favored species. But against all these evils, and against those numberless vexations which have arisen in all ages from the attachment of the sexes, place the vast amount of happiness which is derived from that sourcethe basis of the whole circle of the domestic affections, the sweetening principle of life, the prompter of all our most generous feelings, and even of our most virtuous resolves-and every ill that can be traced to it is but as dust in the balance. And here, also, we must be on our guard against judging from what we see in the world at a particular era. As reason and the higher sentiments of man's nature increase in force, this passion is put under better regulation, so as to lessen many of the evils connected with it. The civilized man is more able to give it due centrol ; his attachments are less the result of impulse; he studies more the weal of his partner and offspring. There are even some of the resentful feelings connected in early society with love, such as hatred of successful rivalry, and jealousy, which almost disappear in an advanced stage of civilization. The evils springing, in our own species at least, from this passion may therefore be an exception mainly peculiar to a particular term of the world's progress, and which may be expected to decrease greatly in amount.

With respect, again, to disease, so prolific a cause of suffering to man, the human constitution is merely a complicated but regular process in electro-chemistry, which goes on well, and is a source of continual gratification, so long as nothing occurs to interfere with it injuriously, but which is liable every moment to be deranged by various external agencies, when it becomes a source of pain, and, if the injury be severe, ceases to te capable of retaining life. It may be readily admitted that the evils experienced in this way are very great; but, after all, such experiences are no more thin occasional, and not necessarily frequent--exceptions from a general rule of which the direct action is to confer happiness. The human constitution might have been made 
of a more hardy character; but we always see hardiness and insensibility go together, and it may be of course presumed that we only could have purchased this immunity from suffering at the expense of a large portion of that delicacy in which lie some of our most agreeable sensations. Or man's faculties might have been restricted to definiteness of action, as is greatly the case with those of the lower animals, and thus we should have been equally safe from the aberrations which lead to disease; but in that event we should have been incapable of acting to so many different purposes as we are, arid of the many high enjoyments which the varied action of ous faculties places in our power: we should not, in short, have been human beings, but merely on a level with the inferior animals. Thus it appears that the very fineress of man's constitution, that which places him in such a high relation to the mundane economy, and makes him the vehicle of so many exquisitely delightful sensations-it is this which makes him liable to the sufferings of disease. It might be said, on the other hand, that the noxiousness of the agencies producing disease might have been diminished or extinguished; but the probability is, that this could not have been done withou such a derangement of the whole economy of nature as would have been attended with more serious evils. For example-a large class of diseases are the result of effluvia from decaying organic matter. This kind of matter is known to be extremely useful, when mixed with earth, in favoring the process of vegetation. Supposing the noxiousness to the human constitution done away with, might we not also lose that important quality which tends so largely to increase the food raised from the ground? Perhaps (as has been suggested) the noxiousness is even a matter of special design, to induce us to put away decaying organic substances into the earth, where they are calculated to be so useful. Now man has reason to enable him to see that such substances are beneficial under one arrangement, and noxious in the other $\mathrm{He}$ is, as it were, commanded to take the right method in dealing, with it. In point of fact, men do not always take this method, but allow accumulations of noxious matter to gather close about their dwelling:, where they generate fevers and agues. But their doing so may be regarded as only a temnorary exception from the opera. 
tion of mental laws, the general tendency of whick is to mak $\geq$ men adopt the proper measures. And these measures will probably be-in time universally adopted, so that one extensive class of diseases will be altogether or searly abolished.

A nother large class of diseases spring from mismanagement of our personal economy. Eating to excess, eating and drinking what is noxious, disregard to that cleanliness which is necessary for the right action of the functions of the skin, want of fresh air for the supply of the lungs, undue, excessive, and irregular indulgence of the * mental affections, are all of them rerognize.l modes of creating that derangement of the system in which disease consists. Here also it may be said that a limitation of the mental faculties to definite manifestations, vulgo, instincts) might have enabled us to avoid many of these erıors ; but here, again, we are met by the consideration that, if we had been so endoived, we should have been only as the lower animals are, wanting that transcendently higher character of sensation and power by which our enjoyments are made so much greater. In making the desire of food, for example, with us an indefinite mental manifestation, instead of the definite one which it is amongst the lower animals, the Creator has given us a means of deriving far greater gratifications from food (consistently with health) than the lower animals appear to be capable of. He has also given us Reason to act as a guiding and controlling power over this and other pro pensities, so that they may be prevented from becoming causes of malady. We can see that excess is injurious, and are thus prompted to moderation. We can see that all the things which we feel inclined to take are not healthful, and are thus exhorted to avoid what are pernicious. We can also see that a cleanly skin and a constant supply of pure air are necessary to the proper performance of sorne of the most important of the organic functions, and thus are stimulated to frequent ablution, and to a right ventilation of our parlors and sleeping apartments. And so on with the other causes of disease. Reason may not operate very powerfully to these purposes in an early state of society, and prodigious evils may therefore have been endured from disease in past ages ; but these are not necessarily to be endured always. As civilization advances, reason requires a greater as- 
cendency; the causes of the evils are seen and avorded, and disease shrinks into a comparatively narrow compass. The experience of our own country places this in a striking light. In the Middle Ages, when, large towns had no police regulations, society was every now and then scourged by pestilence. The third of the people of Europe are said to have been carried off by one epidemic. Even in London, the annual mortality has greatly sunk within a century. The improvement in human life, which has taken place since the construction of the Northampton tables by Dr. Price, is equally remarkable. Modern tables still show a prodigious n.ortality among the young in all civilized countries-evidently a result of some prevalent error in the usual modes of rearing them. But to remedy this evil there is the sagacity of the human mind, and the sense to adopt any reformed plans which may be shown to be necessary. By a change in the management of an orphan institution in London, during the last fifty years, an immense reduction in the mortality took place. We may of course hope to see measures devised and adopted for producing a similar improvement of infant life throughout the world at large.

In this part of our subject, the most difficult point certainly lies in those occurrences of disease where the afficted individual has been in no degree concerned in bringing the visitation upon himself. Daily experience shows us infectious disease arising in a place where the natural laws in respect of cleanliness are neglected, and then spreading into regions where there is no blame of this kind. We then see the innocent suffering equally with those who may be called the guilty. Nay, the benevolent physician who comes to succor the miserable beings whose error may have caused the mischief is sometimes seen to fall a victim to it, while many of his patients recover. We are also only too familiar with the transmission of diseases from erring parents to innocent children, who, accordingly, suffer, and perhaps die prematurely, as it were, for the sins of others. After all, however painful such cases may be in contemplation, they cannot be regarded in any other light than as exceptions from arrangements, the general working of which is beneficial

With regard to the innocence of the suffering parties, 
there is one important consideration which is pressed upon us from many quarters, namely, that moral conditions have not the least concern in the working of these simply physical laws. These laws proceed with an entire independence of all such conditions, and desirably so, for otherwise there could be no certain dependence placed upon them. Thus it may happen that two persons ascending a piece of scaffolding, the one a virtuous, the other a vicious man, the former, being the less cautious of the two, ventures upon an insecure place, falls, and is killed, while the other, choosing a better footing, remains uninjured. It is not in what we can conceive of the nature of things, that there should be a special exemption from the ordinary laws of matter to save this virtuous man. So it might be that, of two physicians, attending fever cases in a mean part of a large city, the one, an excellent citizen, may stand in such a position with respect to the beds of the patients as to catch the infection, of which he dies in a few days, while the other, a bad husband and father, and who, unlike the other, only attends such cases with selfish ends, takes care to be as much as possible out of the stream of infection, and accordingly escapes. In both of these cases man's sense of good and evil - his faculty of conscientiousness-would incline him to destine the vicious man to destruction and save the virtuous. But the Great Ruler of Nature does not act on such principles. He has established laws for the operation of inanimate matter, which are quite unswerving, so that when we know them we have only to act in a certain way with respect to them in order to obtain all the benefits and avoid all the evils connected with them. He has likewise established moral laws in our nature, which are equally unswerving (allowing for their wider range of action,) and from obedience to which unfailing good is to be derived. But the two sets of laws are independent of each other. Obedience to each gives only its own proper advantage, not the advantage proper to the other. Hence it is that virtue forms. no protection against the evils connected with the physical laws; while, on the other hand, a man skilled in and attentive to these, but unrighteous and disregardful of his neighbor, is in like manner not protected by his attention to physical circumstances from the proper consequences of neglect or breach of the moral laws. 
Thus it is that the innocence of the party suffering for the faults of a parent, or of any other person or set of persons, is evidently a consideration quite apart from that suffering.

It is clear, moreover, from the whole scope of the natu ral laws, that the individual, as far as the present sphere of being is concerned, is to the Author of Nature a consideration of inferior moment. Everywhere we see the arrangements for the species perfect; the individual is left, as it were, to take his chance amidst the mêlée of the various laws affecting him. If he be found inferiorly endowed, or ill befalls him, there was at least no partiality against him. The system has the fairness of a lottery, in which every one has the like ehance of drawing a prize.

Yet it is also to be observed that few evils are altogether unmixed. God, contemplating apparently the unbending action of his great laws, has established others which appear to be designed to have a compensating, a repairing, and a consoling effect. Suppose, for instance, that, from a defect in the power of development in a mother, her offspring is ushered into the world destitute of some of the most useful members, or blind, or deaf, or of imperfect intellect, there is ever to be found in the parents and other relatives, and in the surrounding public, a sympathy with the sufferer, which tends to make up for the deficiency, so that he is in the long run not much the loser. Indeed, the benevolence implanted in our nature seems to be an arrangement having for one of its principal objects to cause ns, by sympathy and active aid, to remedy the evils unavoidably suffered by our fellow. creatures in the course of the operation of the other nat ural laws. And even in the sufferer himself, it is often found that a defect in one point is made up for by an extra power in another. The blind come to have a sense of touch much more acute than those who see. Persong born without hands have been known to acquire a power of using their feet for a number of the principal offices usually served by that member. I need hardly say how remarkably fatuity is compensated by the more than usual regard paid to the children born.with it by their parents, and the zeal which others usually feel to protect and succor such persons. In short, we never see evil of any kind take place where there is not some 
remedy or compensating principle ready to interfere for its alleviation. And there can be no doubt that in this manner suffering of all kinds is very much relieved.

We may, then, regard the globes of space as theatres designed for the residence of animated sentient beings, placed there with this as their first and most obvious purpose-namely, to be sensible of enjoyments from the exercise of their faculties in relation to external things. The faculties of the various species are very different, but the happiness of each depends on the harmony there may be between its particular faculties and its particular circumstances. For instance, place the small-brained sheep or ox in a good pasture, and it fully enjoys this harmony of relation; but man, having many mure faculties, cannot be thus contented. Besides having a sufficiency of food and bodily comfort, he must have entertainment for his intellect, whatever be its grade, objects for the domestic and social affections, objects for the sentiments. He is also a progressive being, and what pleases him to-day may not please him to-morrow; but in each case he demands a sphere of appropriate conditions in order to be happy. By virtue of his superior organization, his enjoyments are much higher and more varied than those of any of the lower animals; but the very complexity of circumstances affecting him renders it at the same time unavoidable that his nature should be often inharmoniously placed and disagreeably affected, and that he should therefore be unhappy. Still, unhappiness among mankind is the exception from the rule of their condition, and an exception which is capable of almost infinite diminution, by virtue of the improving reason of man, and the experience which he acquires in working out the problems of society.

To secure the immediate means of happiness, it would seem to be necessary for men first to study with all care the constitution of nature, and, secondly, to accommodate themselves to that constitution, so as to obtain all. the realizable advantages from acting conformably to it, and to avoid all likely evils from disregarding it. It will be of no use to sit down and expect that things are to operate of their own accord, or through the direction of a partial Deity, for our benefit; equally sn were it to expose ourselves to palpable dangers, under the notion that we shall, for some reason, have a dispensation or exemp 
tion from them; we must endeavor so to place ourselven, and so to act, that the arrangements which Providence has made impartially for all may be in our favor, and not against us; such are the only means by which we can obtain good and avoid evil here below. And, in doing this, it is especially necessary that care be taken to avoid interfering with the like efforts of other men, beyond what may have been agreed upon by the mass as necessary for the general good. Such interferences, tending in any way to injure the body, property, or peace of a neighbor, or to the injury of society in general, tend very much to reflect evil upon ourselves, through the re-action which they produce in the feelings of our neighbor and of society, and also the offence which they give to our own conscientiousness and benevolence. On the other hand, when we endeavor to promote the efforts of our fellow-creatures to attain happiness, we produce a reaction of the contrary kind, the tendency of which is towards our own benefit. The one course of action tends to the injury, the other to the benefit of ourselves and others. By the one course the general design of the Creator towards his creatures is thwarted; by the other it is favored. And thus we can readily see the most sub stantial grounds for regarding all inoral emotions and do. ings as Divine in their nature, and as a means of rising tc and communing with God. Obedience is not selfishness, which it would otherwise be-it is worship. 'The inerest barbarians have a glimmering sense of this philosophy, and it continually shines out more and more clearly in the public mind as a nation advances in intelligence Nor are individuals alone concerned here. The same rule applies as between one great body or class of men and another, and also between nations. Thus, if one set of men keep others in the condition of slaves-this being a gross injustice to the subjected party, the mental manifestations of that party to the masters will be such as to nar the comfort of their lives; the minds of the masters themselves will be degraded by the association with beings so degraded; and thus, with some immediate or apparent benefit from keeping slaves, there will be in a far greater degree an experience of evil. So also, if one portion of a nation, engaged in a particular department of industry, grasp at some advantages injurious to the other sections of the people, the first effect will be an in. 
'ury to those other portions of the nation, and the second a reactive injury to the injurers, making their guilt their punishment. And so when one nation commits an aggression upon the property or rights of another, or even pursues towards it a sordid or ungracious policy, the effects are sure to be redoubled evil from the offended party. All of these things are under laws which make the effects, on a large range, absolutely certain; and an individual, a party, a people, can no more act unjustly with safety, than I could with safely place my leg in the track of a coming wain, or attempt to fast thirty days. We have been constituted on the principle of only being able to realize happiness for ourselves when our fellowcreatures are also happy; we must therefore both do to others only as we would have others to do to us, and endeavor to promote their happines's as well as our own, in order to find ourselves truly comfortable in this field of existence. These are words which God speaks to us as truly through his works, as if we heard them uttered in his own voice from heaven.

It will occur to every one that the system here unfolded does not imply the most perfect conceivable love or regard on the part of the Deity towards his creatures. Constituted as we are, feeling how vain our efforts often are to attain happiness or avoid calamity, and knowing that much evil does unavoidably befall us from no fault of ours, we are apt to feel that this is a dreary view of the Divine economy; and before we have looked further, we might be tempted to say, Far rather let us cling to the idea, so long received, that the Deity acts continually for special occasions, and gives such directions to the fate of each individual as he thinks meet; so that, when sorrow comes to us, we shall have at least the consolation of believing that it is imposed by a Father who loves us, and who seeks by these means to accomplish our ultimate good. Now, in the first place, if this be an untrue notion of the Deity and his ways, it can be of no real benefit to us; and in the second, it is proper to inquire if there be necessarily in the doctrine of natural law any peculiarity calculated materially to affect our hitherto supposed relation to the Deity. It may be that, while we are committed to take our chance in a natural system of undeviating operation, and are left with apparent ruthlessness to endure the con. wequences of every collision into which we knowingly or 
unknowingly come with each law of the system, there is a system of Mercy and Grace behind the screen of nature, which is to make up for all casualties endured here, and the very largeness of which is what makes these casualties a matter of indifference to God. For the existence of such a system the actual constitution of nature is itself an argument. The reasoning may proceed thus : The system of nature assures us that benevolence is a leading principle in the Divine mind. But that system is at the same time deficient in a means of making this benevolence of invariable operation. To reconcile this to the recognized character of the Deity, it is necessary to suppose that the present system is but a part of a whole, a stage in a Great Progress, and that the Redress is in reserve. Another argument here occurs - the economy of nature, beautifully arranged and vast in its extent as it is, does not satisfy even man's idea of what might be; he feels that, if this multiplicity of theatres for the exemplification of such phenomena as we see on earth were to go on forever unchanged, it would not be worthy of the Being capable of creating it. An endless monotony of human generations, with their humble thinkings and doings, seems an object beneath that august Being. But the mundane economy might be very well as a portion of some greater phenomenon, the rest of which was yet to be evolved. It therefore appears that our system, though it may at first appear at issue with other doctrines in esteem amongst mankind, tends to corre into harmony with them, and even to give them support. I would say, in conclusion, that, even where the two above arguments may fail of effect, there may yet be a faith derived from this view of nature sufficient to sustain us under all sense of the imperfect happiness, the calamities, the woes, and pains of this sphere of being. For let us but fully and truly consider what a system is here laid open to view, and we cannot ivell doubt that we are in the hands of One who is both able and willing to do us the most entire justice. And in this faith we may well rest at ease, even though life should have been to us but a protracted disease, or though every hope we had built on the secular materials within our reach were felt to be melting from our grasp. Thinking of all the contingencies of this world as to be in time melted into or lost in the greater system, to which the present is only subsidiary, let us wait the end with patience, and be of good cheer 


\section{NOTE CONCLUSORY.}

Thus ends a book, composed in solitude, and almost. without the cognizance of a single human being, for the sole purpose (or as nearly so as may be) of improving the knowledge of mankind, and through that medium their happiness. For reasons which need not be specified, the author's name is retained in its original obscurity, and, in all probability, will never be generally known. I do not expect that any word of praise which the work may elicit shall ever be responded to by me, or that any word of censure shall ever be parried or deprecated. It goes forth to take its chance of instant oblivion, or of a long and active course of usefulness in the world. Neither contingency can be of any importance to me, beyond the regret or the satisfaction which may be imparted by my sense of a lost or a realized benefit to my fellow-creatures. The book, as far as I am aware, is the first attempt to connect the natural sciences into a history of creation. The idea is a bold one, and there are many circumstances of time and place to render its boldness more than usually conspicuous. But I believe my doctrines to be in the main true; I believe all truth to be valuable, and its dissemination a blessing. At the same time, I hold myself duly sensible of the common liability to error, but am certain that no error in this line has the least chance of veing allowed to injure the public mind. Therefore I publish. My views, if correct, will most assuredly stand, and may sooner or later prove beneficial ; if otherwise, they will as surely pass out of notice without doing any harm.

My sincere desire in the composition of the book was to give the true view of the history of nature, with as little disturbance as possible to existing beliefs, whether philosophical or religious. I have made little reference to any doctrines of the latter kind which may be thought inconsistent with mine, because to do so would have been to enter upon questions for the settlement of which our knowledge is not yet ripe. Let the reconciliation of whatever is true in my views with whatever is true in other systems come about in the fulness of calm and careful inquiry. I cannot but here remind the reader of what Dr. Wiseman has shown so strikingly in his Lee- 
tures, how different new philosophic doctrines are apt to appear after we have become somewhat familiar with them. Geology at first seems inconsisent with the authority of the Mosaic record. A storm of unreasoning indignation rises against its teachers. In time, its truths, being found quite irresistible, are admitted, and mankind continue to regard the Scriptures with the same respect as before. So also with several other sciences. Now the only objection that can be made on such a ground to this book, is, that it brings forward some new hypothesis, at first sight, like geology, not in perfect harmony with that record, and arranges all the rest into a system which partakes of the same character. But may not the sacred text, on a liberal interpretation, or with the benefit of a new light refiected from nature, or derived from learning, be shown to be as much in harmony with the novelties of this volume as it has been with geology and natural philosophy? What is there in the laws of organic creation more startling to the candid theologian than in the Copernican system or the natural formation of strata? And if the whole series of facts is true, why should we shrink from inferences legitimately flowing from it? Is it not a wiser course, since reconciliation has come in so many instances, still to hope for it, still to go on with our new truths, trusting that they also will in time be found harmonious with all others? Thus we avoid the damage which the very appearance of an opposition to natural truth is calculated to inflict on any system presumed to require such support. Thus we give, as is meet, a respectful reception to what is revealed through the medium of nature, at the same time that we fully reserve our reverence for all we have been accustomed to hold sacred, not one title of which it may ultimately be found necessary to alter. 


\section{EXPLANATIONS.}

WHEN the work to which this may be regarded as a supplement was published, my design was not only to be personally removed from all praise or censure which it might evoke, but to write no more upon the subject. I said to myself, Let this book go forth to be received as truth, or to provoke others to a controversy which may result in estallishing or overthrowing it; but be my task now ended. I did not then reflect that, even though written by one better informed or more skilled in argument than I can pretend to be, it might leave the subject in such a condition that the author should have to regret seeing it, in a great measure, misapprehended in its general scope, and also so much excepted to, justly and unjustly, on particular points, that ordinary readers might be ready to suppose its whole indications disproved. Had I bethought me of such possible results. I might have announced, from the beginning, my readiness to enter upon such explanations of points objected to, and such re-enforcements of the general argument, as might promise to be serviceable. And this would have seemed the more necessary, in as far as it may be expected that there are many points in a new and startling hypothesis which no one can be so well qualified to clear up and strengthen as its author. 1 might have felt at the same time that a new adventure, for whatever purpose, in the same field was hazardous, with regard to any favorable impression previously produced; yet such an objection would, again, have been at once overruled, seeing that public favor and disfavor were alike beyond the regard of an author who bore no bodily shape in the eyes of his fellow-countrymen, and was likely to remain forever unknown. Such reflections now occur to me, and I am consequently induced to take up the pen for the purpose of endeavoring to make good what is deficient, and reasserting and confirming whatever has been unjustly challenged in my book. In doing so, I shall study to direct attention solely to fact and argument, or what appear as such, overlooking the uncivil expres 
sions which the work has drawn forth in various quarters, and which, of course, can only be a discredit to their authors.

I must start with a more explicit statement of the general argument of the Vestiges, for this has been exter. sively misunderstood. The book is not primarily de. signed, as many have intimated in their criticisms, and as the title might be thought partly to imply, to establish a new theory respecting the origin of animated nature; nor are the chief arguments directed to that point. The object is one to which the idea of an organic creation in the manner of natural law is only subordinate and ministrative, as likewise are the nebular hypothesis and the doctrine of a fixed natural order in mind and morals. This purpose is to show that the whole revelation of the works of God presented to our senses and reason is a system based in what we are compelled, for want of a better term, to call LAw ; by which, however, is not meant a system independent or exclusive of Deity, but one which only proposes a certain mode of his working. The nature and bearing of this doctrine will be afterwards adverted to; let me, meanwhile, observe, that it has long been pointed to by science, though hardly anywhere broadly and fully contemplated. And this was scarcely to be wondered at, since, while the whole physical arrangements of the universe were placed under law by the discoveries of Kepler and Newton, there was still such a mysterious conception of the origin of organic nature, and of the character of our own fitful being, that men were almost forced to make at least large exceptions from any proposed plan of universal order. What makes the case now somewhat different is, that of late years we have attained much additional knowledge of nature, pointing in the same direction as the physical arrangements of the world. The time seems to have come when it is proper to enter into a reexamination of the whole subject, in order to ascertain whether, in what we actually know, there is most evidence in favor of an entire or a partial system of fixed order. When led to make this inquiry for myself, I soon became convinced that the idea of any exception to the plan of law stood upon a narrow, and constantly narrowing foundation, lepending, indeed, on a few difficulties or obscurities, rather than objections, which were certain soon to be swept away by the advancing tide of knowl 
edge. It appeured, at the same time, that there was a want in the state of philosophy amongst us, of an impulse in the direction of the consideration of this theory, so as to bring its difficulties the sooner to a bearing in the one way or the other; and hence it was that I presumed to enter the field.

My starting-point was a statement of the arrangements of the bodies of space, with a hypothesis respecting the mode in which those arrangements had been effected. It is a mistake to suppose this (nebular) hypothesis essential, as the basis of the entire system of nature developed in my book. That basis lies in the material laws found to prevail throughout the universe, which explain why the masses of space are globular; why planets revolve round suns in elliptical orbits ; how their rates of speed are high in proportion to their nearness to the centre of attraction, and so forth. In these laws arises the first powerful presumption that the formation and arrangements of the celestial bodies were brought about by the Divine will, act ing in the manner of a fixed order or law, instead of any mode which we conceive of as more arbitrary. It is a pre. sumption which an enlightened mind is altogether unable to resist, when it sees that precisely similar effects are every day produced by law on a small scale, as when a drop of water spherifies, when the revolving hoop bulges out in the plane of its equator, and the sling, swung round in the hand, increases in speed as the string is shortened. The philosopher, on observing these phenomena, and finding incontestible proof that they are precisely of the same nature as those attending the formation and arrangement of worlds, learns his first great lesson-that the natural laws work on the minutest and the grandest scale indifferently; that, in fact, there is no such thing as great and small in nature, but world spaces are as a hairbreadth, and a thousand years as one day. Having thus all but demonstration that the spheres were formed and arranged by natural law, the nebular hypothesis becomes important, as shadowing forth the process by which matter was so transformed from a previous condition, but it is nothing more; and, though it were utterly disproved, the evidence which we previously possessed that physical creation, so to speak, was effected by means of, or in the manner of law, would remain exactly as it was. We should onl be left in the dark with regard to the previous condition of 
matter, and the steps of the process by which it acquired its present forms.

It would nevertheless strengthen the presumption, and, indeed, place it near to ascertained truths, if we were to obtain strong evidence for what has hitherto been called the nebular hypothesis. The evidence for it is sketched in the Vestiges : it is exhibited with greater clearness, and in elegant and impressive language, in Professor Nichol's Views of the Architecture of the Heavens. The position held by this hypothesis in the philosophical world when my book was written, is shown with tolerable distinctness in the Edinburgh Review for 1838, where it is spoken of in the following general terms: "These views of the origin and destiny of the various system of worlds which fill the immensity of space, break upon the mind with all the interest of novelty, and all the brightness of truth. Appealing to our imagination by their grandeur, and to our reason by the severe principles on which they rest, the mind feels as if a revelation had been vouchsafed to it of the past and future history of the universe." It may also be remarked, that this writer considered the hypothesis as " confirming, rather than opposing the Mosaic cosmogony, whether allegorically or literally interpreted." With this testimnny to the mathematical expositions of MM. La Place and Comte, I rest content, as the expositions themselves would be unsuitable in a popular treatise. But the hypothesis has been favorably entertained in many authoritative quarters during the last few years, and probably would have continued to be so, if no attempi had been made to enforce by it a system of nature on the principle of universal order.

The chief objection taken to the theory is, that the existence of nebulous matter in the heavens is disproved by the discoveries made by the Earl of Rosse's telescope. By this wond"ous tube, we are told, it is shown to be "an unwarrantable assumption that there are in the heavenly spaces any masses of matter different from solid bodies composing planetary systems."* The nebulæ, in short, are said to be now shown as clusters of stars, rendered apparently nebulous only by the vast distance at which they are placed. There is often seen a greater vehemence and rashness in objecting to than in presenting hypotheces, and we appear to have here an instance of such hasty

* North British Review, iii., 477. 
counter-generalization. The fact is, that the nebulæ were always understood to be of two kinds: 1 , nebulæ which were only distant clusters, and which yielded, one after another, to the resolving powers of telescopes, as these powers were increased; 2, nebulæ comparatively near, which no increase of telescopic power affected. Two classes of objects wholly different were, from their partial resemblance, recogrised by one name, and hence the confusion which has arisen upon the subject. The resolution of a great quantity of the first kind of nebulæ by Lord Rosse's telescope was of course expected, and it is a fact, though in itself interesting, of no consequence to the neb ular hypothesis. It will be only in the event of the secand class being also resolved, and its being thus shown that there is only one class of nebulæ, that the hypothesis will suffer. Such, at least, I conclude to be the sense of a passage which I take leave to transfer, in an abridged form, from a recent edition of Professor Nichol's work

"I. By far the greater number of the milky streaks, or spots, whose places have hitherto been recorded, lie at the outermost, or nearly at the outermost boundary of the sphere previously reached by our telescopes; and in this case there is no certain principle on the ground upon which a pure nebula can be distinguished from a cluster so remote that only the general or fused light of its my riads of constituent orbs can be seen. Sometimes--resting on a peculiarity of form or other characteristic-the astronomer may venture a guess that such an object is probably a firmament; as, indeed, I was bold enough to do in former editions of this work with regard to several which have since been resolved; but in the main he can tell little concerning them, or have any other belief than.that, as with similar masses near him, a great, probably the greater number, are true clusters, grand arrangements of stars, incredibly remote, but resembling in all things our own home galaxy. Now the application to such objects of a new and enlarged power of vision could be attended only by one resultmagnificent, but far from unexpected : and it is here that the six feet mirror has achieved its earliest triumphs. Under its piercing glance, great numbers of the milky specks have unfolded their starry constituents ; some of these, which previously were almost unresolved, shining with a lustre equivalent to that of our brightest orbs to the naked eye. How far it will go with its resolving power has not yet been ascertained; but I perceive that Sir James South has given his authority that some spots examined by it continue intractable.

"II. The influence of the new discoveries either to impair or strengthen the foundations of the nebular hypothesis, must clearly be looked for among their bearings on less remote and ambiguous objects. Now the new aspects of these may lead us to question our former opinions as to the existence of the supposed filmy self. luminous inasses; or they may throw doubt on the reality of those 
forms according to which we have arranged them, and which seem to indicate the steps of a stupendous progress

"1. Astronomers have never rested their belief in the reality and wide diffusion of the nebulous matter on the objects referred to in the first paragraph, but on others much within the range of our previous vision. In so far as we have hitherto understood the nature of cluster', the telescopic power required to resolve them is never very much higher than that which first descries them as dim milky spots. But there are many most remarkable objects which, in this essential feature, are wholly contrasted with clusters. For instance, the nebula in Orion, as I have fully shown in the text, is visible to the naked eye, as also is the gorgeous one in Andromeda; while the largest instrument heretofore turned to them has given no intimation that their light is stellar, but rather the contrary; although small stars are found buried amidst their mass. Now, if Lord Rosse's telescope resolves these, and others with similar attributes, such as some of the streaks among the following plates, we shall thereby be informed that we have generalized too hastily from the character of known firmaments-that schemes of stellar being exist, infinitely more strange and varied than we had ventured to suppose; and certainly we shall then hesitate in averring further concerning the existence, or at least the diflusion of the purely nebulous modification of matter.

“ 2. Lord Rosse's telescope may also, as I have said, disprove reality of our arrangement of the forms of the nebulæ as steps 0. ' progression. And in regard to this question, there seem two chisses of objects meriting attention.

"First. I shall refer to the nebulous stars properly so called, or to that form in which the diffused matter has reached the condition of almost pure fixed stars. Now, of these objects there are two distinct sets, presenting at first to the telescope very much the same appearance, but in regard of which our knowledge is very different. It will readily be conceived that a distant cluster, with strong concentration about the centre of its figure, must, to the telescope which first descries it, look like a star with a halo around it. Whèn a higher power is applied, that central star, however, will appear as a disk, and to a still higher power the cluster will be revealed. A very great number of what are called nebulous stars are doubtless of this class; and we have hitherto had no means of accurately ascertaining the fact, just because our largest telescopes were required to descry them; but there are multitudes of others-the true 'photospheres'-quite of a different descrip. tion. Many of these are easily seen as fixed stars with haloes of difterent sizes diminishing to the mere 'bur ;' and under the greatest power as yet applied, the apparent central star never expands into a disk, or departs from tlie stellar character. It is by its effect on these that the new instrument will at all bear on this portion of the nebular hy pothesis.

"Secondly. The foregoing being our grounds of belief in the existence of nebulæ-first, in a diffused or chaotic state, and again in a condition proximate to pure stars; the only remaining point has reference to nebulæ in an intermediate state-when the roundish masses seem to have begun a process of organization or concentration, and carried it onwards through several stages; a state to which we have every variety of aralogon in the varas as 
furms and densities of cometic nuclei. Sir William Herschel certainly was not ignorant that round or spherical clusters abound in the skies, which, when first seen, present all the appearances of such nebulæ-nay, he grounded on the fact of their approximate sphericity and varying degrees of concentration some of the boldest and most engrossing of his conjectures; nor would he have doubted that multitudes which, even to his instruments, seemed only general lights, would, in after times, be resolved ; but here, as before, the gist of the question is not, can you resolve round nebulæ never resolved before; but can you resolve such as, quite within the range of former vision, have contınued intractable under the scrutiny of powers which, judging from the aver. age of our experience, must surpass what ought to have resolved them?

"Such are my views as to the present condition of this important question; and if they are correct, it will. appear that, notwithstanding the resolutions achieved by the new instruments, they are, as yet, quite as likely-by accumulating new objects belonging to the three foregoing classes, and by more surely and distinctly establishing their characteristic features-to strengthen, as to invalidate the grounds of the nebular hypothesis. Eagerly, but patiently, let us watch the approaching revelations."

Various minor objections have been presented to the nebular hypothesis ; but, before adverting to any of them, I may give a brief abstract of certain recent experiments, by which it has been remarkably illustrated. Here it is peculiarly important to bear in mind that the phenomena of nature are, if I may so speak, indifferent to the scale on which they act. The dew-drop is, in physics, the picture of a world. Remembering this, we are prepared, in some measure to hear of a Belgian professor imitating the supposed formation and arrangement of a solar syslem, in some of its most essential particulars, on the table of a lecture-room! The experiments were first conlucted by Professor Plateau of Ghent, and afterwards repeated by our own Dr. Faraday.

The following abstract of Professor Plateau's experiments is also presented in the fifth edition of the Vestiges. Its being repeated here is, that it may meet the eyes of many who are not likely to see any edition of that work nesides those from which it is absent:

Placing a mixture of water and alcohol in a glass box, and therein a sinall quantity of olive oil, of density precisely equal to the mixture, we have in the latter a liquid mass relieved from the operation of gravity, and free to take the exterior form given by the forces which may act upon it. In point of fact, the oil instantly takes a globu lar form by virtue of molecular attraction. \& vertica. 
axis being introduced through the box, with a small disk upon it, so arranged that its centre is coinciclent with the centre of the globe of oil, we turn the axis at a slow rate, and thus set the oil sphere into rotation. "We then presently see the sphere flatten at its poles and swell out at its equator, and we thus realize, on a small scale, an effect which is admitted to have taken place in the planets." The spherifying forces are of different natures, that of molecular attraction in the case of the oil, and of universal attraction in that of the planet, but the results are "analogous, if not identical." Quickening the rotation makes the figure more oblately spheroidal. When it comes to be so quick as two or three turns in a second, " the liquid sphere first takes rapidly its maximum of flattening, then becomes hollow above and below, around the axis of rotation, stretching out continually in a horizontal direction, and finally, abandoning the disk, is transformed into a perfectly regular ring." At first this remains connected with the disk by a thin pellicle of oil ; but on the disk being stopped this breaks and disappears, and the ring becomes completely disengaged. The only observable difference between the latter and the ring of Saturn is, that it is rounded, instead of being flattened: but this is accounted for in a satisfactory way.

A little after the stoppage of the rotatory motion of the disk, the ring of oil, losing its own motion, gathers once more into a sphere. If, however, a smaller disk be used, and its rotation continued after the separation of the ring, rotatory motion and centrifugal force will be generated in the alcoholic fluid, and the oil ring, thus prevented from returning into the globular form, divides itself into "several isolated masses, each of which immediately takes the globular form." These are "almost always seen to assume, at the instant of their formation, a movement of rotation upon themselves-a movement which constantly takes place in the same direction as that of the ring. Moreover, as the ring, at the instant of its rupture, had still a remainder of velocity, the spheres to which it has given birth tend to fly off at a tangent; but as, on the other side, the disk, turning in the alcoholic liquor, has impressed on this a movement of rotation, the spheres are especially carried along by this last movement, and revolve for some time round the disk Those which revolve at the same time upon themselves, consequently, 
then present the curious spectacle of planets revolving at the same time on themselves and in their orbits. Finally, another very curious effect is also manifested in these circumstances: besides three or four large spheres into which the ring revolves itself, there are almost always produced one or two very small, ones, which may thus be compared to satellites. The experiment which we have thus described presents, as we see, an image in miniature of the formation of the planets, according to the hypothesis of Laplace, by the rupture of the cosmical rings attributable to the condensation of the solar atmosphere."*

Such illustrations certainly tend to take from the nebular cosmogony the character of a "splendid vision," which one of my critics has applied to it. I may here also remind the reader that there are other grounds for this hypothesis, besides observations on the nebulæ. Overlooking the zodiacal light, which has been thought a residuum of the nebulous fluid of our system, we find. geology taking us back towards a state of our globe which cannot otherwise be explained. It was clearly at one time in a stateof igneous fluidity-the state in which its oblately spheroidal form was assumed under the law of centrifugal force. Since then it has cooled, at least in the exterior crust. We thus have it passing through a chemical process attended by diminishing heat. Whence the heat at first, if not from the causes indicated in the nebular hypothesis? But this is not all. In looking back along the steps of such a process, we have no limit imposed. There is nothing to call for our stopping till we reach one of those extreme temperatures which would vaporize the solid materials; and this gives us exactly that condition of things which is implied by the nebular cosmogony.

Of particular objections it is not necessary to say much. That there should be difficulties attending such a hypothesis is only to be expected; but where general evidence is o strong, we should certainly be scrupulous about allowing them too much weight. It is represented, for initance, that the matter of the solar system could not, in iny conceivable gaseous form, fill the space comprehend-

* Dr. Plateau on the Phenomena presented by a free Liquid Mass withdrawn from the action of gravity.-Taylor's Scientifin: Bemoirs. November, 1844. 
ed by the orbit of Uranus. If this be the case, let it be allowed as a difficulty. It is pointed out that the planets do not increase regularly in density from the outermost to the innermost. Their sizes are also not in a regular progression, though the largest, generally speaking, are towards the exterior of the system. It was not, perhaps, to be expected that such gradations should be observed; but grant there was some reason to look for them, their absence constitutes only another and a slight difficulty. Then we know no law to determine the particular "stages at which rings are formed and detached." Be it soalthough something of the kind there dountless is, as the distances of the planets, according to Bode's law, observe a geometrical series of which the ratio of increase is 2 . From these objections, which cannct now be answered, let us pass to some which can.

It has been said that a confluence of atoms towards a central point, as presumed by the nebular hypothesis, would result, not in a rotation, but in a state of rest." According to the North British Review-". . . Supposing the uniformly distributed atnms to agglomerate round their ringleader, the space left blank by the slow advance of the atoms in radial lines converging to the nucleus must be a ring bounded by concentric circles, the outer most circle being the limit of the nebulous matter not drawn to the centre of the nascent sun. Now as all the forces which act upon the agglomerating particles, whether they proceed from the circumference of the undisturbed nebulous matter, or from the gradually increasing nucleus, must have their resultants in the radial lines above mentioned-there can be no cause whatever capable of giving a rotatory motion to the mass. It must remain at rest."

Now there can be no doubt that a confluence proceeding precisely to a centre has this result; but this is only an abstract truth, not an exact and absolute description of any actual confluence of the kind. The explanation was afforded by Professor Nichol, long before the objection was started, and it could not be given in better language on the present occasion: "When we reflect on the solar nebula in the act of condensing, it appears that the act consists in a flow or rush of the nebulous matter from all

- North British Review, No. 6 Atlas Newspaper, Aug. 30, 184b. 
sides towards a central region; which is virtually equivalent, in a mechanical point of view, to what we witness so firequently, both on a small and large scale-the meeting and intermingling of opposite gentle currents of water. Now what do we find on occasion of such a meeting? Herschel's keen glance lighted at once on this simple phenomenon, and drew from it the secret of one of the most fertile processes of Nature! In almost no case do streams meet and intermingle, without occasioning, where they intermingle, a dimple or whirlpool; and, in fact, it is barely possible that such a flow of matter from opposite sides could be so nicely balanced in any case that the opposite momenta or floods would neutralize each other, and produce a condition of central rest. In this circumstance, then-in the whirlpool to be expected where the nebulous ffoods meet-is the obscure and sim. ple germ of rotatory movement. The very act of the condensation of the gaseous matter as it flows towards a central district, almost necessitates the commencement of a process, which, though slow and vague at first, has, it will be found, the inherent power of reaching a perfect and definite condition ...."*

The exception presented by the satellites of Uranus to the otherwise uniform orbitual movements of the planetary bodies, is brought forward as a startling difficulty. $\dagger$ It is, in reality, only a trifling objection, seeing that so many other movements follow one rule, and that we may any day be able to fix upon a cause for this exception, perfectly in harmony with all the associated facts. 'There was once a similar difficulty in geology-strata uppermost where they ought to have been lowermost; but it was in time cleared. Geologists found that there had been a folding over of the strata, so as to reverse their proper and original positions. May we not rest in hope that a similar exception in astronomy may find a similar solution? I have thrown out the hint of a possible bouleversement of the whole of that planet's system : it has been scoffed at; but it is only the supposition of a greater degree of obliquity in the inclination of the axis of the planet to the plane of its orbit than what we find in several others. The same causes which made the inclination of the axis

* Views of the Architecture of the Heavens. First edition, 837 f Edinburgh Review, No. 165, p. 24. 
of Venus towards her orbit 75 degrees, may have turned that of Uranus a little further along, and so reversed the positicn of his poles. The admitted inclination of the axis of Uranus towards the plane of his orbit is 79 degrees, the greatest found in any of the planets. This implies only the necessity for an increase of inclination to the extent of $2: 2$ degrees, or about one-fourth of the quadrin:, in order to account for the surmised reverse arrangement. Nor are causes for such a phenomenon far to seek In the? revolution of the presumed nebular mass, there would be great undulations, as I venture to say there would be found in any similar body which we might set into a similar rotatory motion. Such I esteem as the causes of the departure of the planetary axis from the vertical. A curve in the outermost portion, amounting to a foldlike the curl of a high wave-would cause the bouleversement of Uranus, and the consequent (apparent) retrogression of his satellites.

It appears, then, that, overlooking a few minor unexplained difficulties, the objections to the nebular hypoth. esis are not formidable to it. It approaches the region of ascertained truths, and may reasonably be held as a stong corroboration of what first appears from the material laws of the universe, that the whole Uranographical arrangements were effected in the manner of natural law. Itis, however, altogether a mistake to regard this conclusion, as far as it is one, as equivalent to a superseding of Deity in the history of creation. It proposes nothing beyond a view of the mode in which the Divine will has been pleased to act, in this fir'st and most important of its works. The formation of worlds and their arrangement now appear but as steps in a Historical Progress, for matter is necessarily presumed to have existed before in a different form. By what means and under what circumstances creation, in the true'sense of the word, took place-that is, how existence was given to the matter which we suppose to have been capable of such evolutions-no one can as yet tell; we only are sure, if any trust can be placed in the laws of our minds, that it had a Cause, or an Author. Jeaving such an inquiry as one in which we have not at present ground for a single step, it is surely a great gratification that we can at least trace the operations of the Great Firsi Cause, from a condition of matter anterior to 1 ts present forms, and learn with certainty that these 
operations were in no way arbitrary or capricious, that they were not single and detached phenomena, but the result of principles flowing rrom the Eternal and Immutable, and which prevailed over all the realms of Infinity at once

We have fixed mechanical laws at one end of the system of nature. If we turn to the mind and morals of man, we find that we have equaliy fixed laws at the other. The human being, a mystery considered as an individual, becomes a simple natural phenomenon when taken in the mass, for a regularity is observed in every peculiarity of our constitution and every form of thought and deed of which we are capable, when we only extend our view over a sufficiently wide range. It is to M. Quetelet, of Brussels, that we are indebted for the first satisfactory explication of this great truth; it is presented in his wellknown and very able treatise, Sur L'Homme, et le Developpement de ses Facultés. He first shows the regularity which presides over the births and deaths of a community, liabie to be affected in some degree by accidental circumstances, but fixed again when these are uniform. He then makes it clear that the stature, weight, strength, and other physical peculiarities of men are likewise reg: ulated by fixed principles of nature. Afterwards, the moral qualities - the impulses of all our various sentiments and passions-even the tendency to yield to those temptations which give birth to crime-are proved to be of no less determinate character, however impossible it may be to predict the conduct of any single person. These are doctrines not to be resisted by inconsiderate prejudices They rest on the most powerful of all evidence, that of numbers. If they appear to take from the personal responsibility of individuals, it is merely an appearance, for the doctrine immediately steps forward to show that laws, education, and moral influences of every kind exercise an equally determinate control over men; so that the need for their being called into use becomes even more palpable than before. We are not, however, required at this moment to argue respecting the bearing which this doctrine may have upon human interests. What we are at present concerned with is the simple fact, that Moralsthat part of the system of things which seemed least under natural regulation or law-is as thoroughly ascertained to be wholly so, as the arrangements of the heavenly bodies 
Now we have here two most remarkable truths. Th.e wondrous masses which people the Mighty Void are under the control of natural law. The workings of the little world of the human mind--the opposite extreme of the system-are under law likewise. We have thus the character of the limits of the system fixed. So far we proceed upon solid ground. Now it has been seen that phenomena precisely the same as the formation and arrangement of worlds take place daily before our eyes, under the influence of the laws of matter, showing that the whole cosmogony might have been effected-proving, indeed, that it was effected-by the Divine will acting in that manner. Having attained this point, we are called upon to remember the many appearances of unity in nature; how, when we take a sufficiently wide view, there is nothing discrepant and exceptive in it; how a noble and affecting simplicity breathes from it in every part. So reflecting, we ask, "Can it be that, as the first and the last parts of the system are under law, and the first (this being also the greatest) was manifestly created in that manner, so the whole is under law, and has been produced in that manner ?"It is at the moment when we have arrived at this question, that the origin of the organic world becomes a point of importance. The skeptic of science steps in, and says, "No; the idea of an entire system under law, and produced by it, here breaks down, for who can pretend to penetrate the mysteries of vitality and organization? and who can say that species have had other than a miraculous origin?" The tone in which this objection is usually made seems to me inappropriate, considering that the objectors stand on a mere fragment of nature, and one which the discoveries of science are every day lessening. It is but in a nook, to which light las not yet penetrated, that the opponen's of the theory of universal order take refuge. On coming to the consideration of the question, I am at the very first struck by the great a priori unlikelihood that there can have been two modes of Divine working in the history of naturenamely, a system of fixed order or law in the formation of rlobes, and a system in any degree different in the peopling of these globes with plants and animals. Laws govern both: we are left no room to doubt that laws were the immediate means of making the first; is it to be 1 eadily admitted that laws did 1 ot preside at 
the creation of the second also, particularly when we find that laws equally at this moment govern and sustain both? Most undoubtedly, it would require very powerful evidence to justify such an admission. And, on the other hand, it would require very decisive counter-evidence to forbid the conclusion that the organic creation originated in law. How actually stands the evidence on either side? Simply thus: that no actual evidence has ever yet been offered to prove that the Divine will acted otherwise than in the usual natural order in the organic creation; while, on the other hand, geology and physiology exhibit lively vestiges or traces of that mode having actually been followed. On this narrow ground, it appears, is the great question to be debated. If the opponents of the hypothesis of an organic creation by law can bring, from these or any other sciences, facts which appear as powerful objections to any such conclusion, then it must, at the very least, be held in suspense. If, again, the other party can show these sciences as preseuting far more argument for a law creation of organisms than against it, the hypothesis must be admitted to have the advantage. I have so presented these sciences; the evidence has been disputed, and some obscure points have been largely insisted upon in objection. It is now my duty to enter into the consideration of these objections, and see if they are really of the importance which has been attributed to them.

Fifty years ago science possessed no facts regarding the origin of organic creatures upon earth; as far as knowledge acquired through the ordinary means was concerned, all was a blank antecedent to the first chapters of what we usually call ancient history. Within that time, by researches in the crust of the earth, we have obtained a bold outline of the history of the globe, during what appears to have been a vast chronology intervening between its formation and the appearance of the human race upon its surface. It is shown, on powerful evidence, that during this time strata of various thickness were deposited in seas, each in succession being compised of matters worn away from the previous rocks; volcanic agency broke up the strata, and projected chains of mountains; sea and land repeatedly changed conditions; in short, the whole of the arrangements which we on prevailing in the earth's crust took place, and that 
most undoubtedly under the influence of natural laws which we yet see continually operating. The remains and traces of plants and animals found in the succession of strata, show that, while these operations were going on, the earth gradually became the theatre of organic being, simple forms appearing first, and more complicated afterwards. A time when there was no life is first seen. We then see life begin, and go on; but whole ages elapsed before man came to crown the work of nature. This is a wonderful revelation to have come upon the men of our time, and one which the philosophers of the days of Newton could never have expected to be vouchsafed. The great fact established by it is, that the organic creation, as we now see it, was not placed upon the earth at once;-it observed a PRogress. Now we can imagine the Deity calling a young plant or animal into existence instantaneously; but we see that he does not usually do so. The young plant and also the young animal go through a series of conditions, advancing them from a mere germ to the fully developed repetition of the respective parental forms. So, also, we can imagine Divine power evoking a whole creation into being by one word; but we find that such had not been his mode of working in that instance, for geolngy fully proves that organic creation passed through a series of stages before the highest vegetable and animal forms appeared. Here we have the first hint of organic creation having arisen in the manner of natural order. The analogy does not prove identity of causes, but it surely points very broadly to natural order or law having been the mode of procedure in both instances.

But the question is, Does geology really show such a progress of being? This has been denied in some quarters, and particularly in the elaborate criticism upon the Vestiges, which appeared in the Edinburgh Review." In reality, the whole of the geologists admit that we have first the remains of invertebrated animals; then with these, fish, being the lowest of the vertebrated; next, reptiles and birds, which occupy higher grades; and, finally, along with the rest, mammifers, the highest of all; and yet controversialists will be found gravely telling their readers, "It is not true that only the lowest forms of arimal life are found in the lowest fossil bands, July, 1845. 
and that the more complicated structures are gradually developed among the higher bands, in what we might call a natural ascending scale ;"* the pretext for giving this unqualified contradiction to the above grand fact being, that when we take the special groups of animals, as the invertebrata, the fishes, the reptiles, \&c., there are some real or apparent grounds for denying that the low forms of these groups came before the higher. The fallacy consists in sinking the great broad palpable facts of the case, about which not the least doubt anywhere exists, and giving prominence to certain facts of far inferior magnitude, and comparatively obscure, but in whose obscurity there is a possibility of creating a kind of diversion. I trust to be able to show that, even in the special groups of fossils, there is no real obstacle to the theory of a gradual natural development of life upon our planet.

The view which the Edinburgh critic gives of the earliest stratified rocks is much the same as my own account of them. There is a Hypozoic formation, or series, devoid of remains of plants and animals; then a formation (Lower Silurian) called in my early editions the Clayslate and Grawacke system, in which we find " no animals of the higher classes, with a regular skeleton and a backbone;" only corals, encrinites, crustaceans, and molJusks. "Vegetable appearances," he says, "do not ap pear among the British rocks ; but there must have been a rnass of vegetable life in the ancient sea, as no fauna can appear without a flora to uphold it." This last inference is of little immediate consequence; but I may remark, that it coincides with one which $I$ ventured to make, prompted thereto by some of the recent papers of Mr. Murchison. We here see it sanctioned by a writer who is understood to be a distinguished investigator of the lowest fossiliferous beds. It is from no wish to amuse the reader, but merely as a pleading in behalf of sereral of the alleged geological misstatements in my book, that I bring forward another distinguished reviewer of the Vestiges of Creation, (North British Review, No. 6,) taxing me with having been driven to make this very surrnise as an escape from a difficulty! More than this : the North British Reviewer is at odds with his Edinburgh orother, in bringing bones and teeth of fish into the first 
fossiliferous formation; grounding the statement upon Sir Henry de la Beche's Manual, published about eleven years ago, and contrasting with it, in a foot-note, my remark, "Neither fishes nor any higher vertebiata as yet roamed through the marine wilds." The fact is, that this last critic-understood to be a very eminent philosophical writer, was not aware that, since the publication of De la Beche's Manual, the lower fossiliferous rocks lad been divided into several distinct formations, in the lowest of which, it is fully admitted, there are no vertebrata. More than this still : a body called the Literary and Philosophical Society of Liverpool had brought before them (January, 1845) a set of letters which one of their members had drawn with reference to my book from several of the chief geologists of the day. We there find $\mathrm{Mr}$. Lyell stating upon hearsay that I represented fish beginning in the coal, and Mr. Murchison speaking of me as beginning with zoophytes and polypiaria alone; statements, I need hardly say, conveying the most erroneous impressions regarding the book, This, however, is not the immediate point. The two gentlemen here named will be allowed to stand in the very first rank as geologists. They are able men, of marvellous industry, and unimpeached zeal for science. These men, nevertheless, in the correspondence to which I am pointing, give entirely opposite views of the first fossiliferous formation. Mr. Murchison says, "No trace of a vertebrated animal has been found in the lower Silurian rocks." Mr. Lyell says, "The fact that, with the earliest type of organization, we meet with vertebrated animals, true fish, so far from being explained away since I affirmed it in my book, is confirmed and extended by fresh evidence." The very latest affirmation we have on this point from Mr. Murchison-an affirmation made after examining Silurian rocks in Russia, where they are presented in vast extent-contains these words : " The absence of even the lowest of the vertebrata in the inferior Silurian rocks-an absence which is total, so far as can be inferred from the researches of geologists in all parts of the world-gives them a true Protozoic character."* These extracts speak for themselves. The orly thing calling for further remark is the surprising circumstance of this correspondence having been brought betore

- Abstract of a paper by Mr. Murchison, Report of British As sociation of 1844 , page 54 . 
a learned society as wholly and nothing else but a condemnation of the Vestiges !*

A leading objection, with regard to the first fossiliferous formation (Lower Silurian) is, that it does not solely prosent animals of the lowest sub-kingdom, as corals and encrinites, but also examples of the two next higher subkingdoms, the articulata and mollusca, some of the latter being of the highest order, the cephalopods. The latter particular is what is chiefly insisted upon.

At the time when I wrote, it was understood that the highest orders of mollusca were not found in the first fossiliferous rocks. Professor Phillips, in 1839 (Treatise on Geology,) said, expressly, with regard to what was then called the Clay-slate and Grawacke system, "No gasteropods or cephalopods are as yet mentioned in these rocks in Britain; and we do not feel sufficiently acquainted with the geological age of the limestones of the Hartz to introduce any of the fossils of that argillaceous range of mountains." So much as a justification of the view given of the Clay-slate fossils in my first edition. Since then, this formation, as it exists in England, has been found to contain gasteropods and cephalopods, though not of such high forms as afterwards appeared. I might here repeat what was remarked in the later editions of the Vestiges, s- Even though the cephalopoda could be shown as pervading all the lowest fossiliferous strata, what more would the fact denote than that, in the first seas capable of containing any kind of animal life, the creative energy advanced it, in the space of one formation (no one can tell how long a time this might be,) to the highest forms possible in that element, excepting such as were of vertebrate structure." I might add, that this was no great advance in comparison with the whole line of the animal kingdom, if we may take as a criterion on this point the analogous progress of an embryo of the highest animals, as the portion of that progress representing the organization of the invertebrated animals is only the first month. I might here also revert to the book for some views with respect to the space required for such a development. According to the plan of animated nature, to which I have made approaches in the later editions, we have not

* See Examination of the theory contained in Vestiges of the Natural History of Creation. By the Rev. A. Hume. Liverpool, Whitby, 1845. 
to account for the development of one long line, but of many comparatively short ones. And, as I have also remarked, there is a rapidity of generation amongst the lower animals which may well suggest something like that "rush of life," which, if we were to judge from British strata alone, would seem to have taken place in the early seas. But, fortunately, none of these speculative answers to the objection are required; for the question first arises, Does the lowest band of the English Lower Silurians indicate, beyond all question, the point of time at which animal life commenced upon our planet? Are we quite sure that cephalopoda were among the first of all earth's living creatures ? Far from it. It has only been ascertained that certain comparatively small cephalopods are found as far down as any other animals of inferior organization at certain spots in. Wales and Cumberland. When we remember that, in modern seas, certain kinds of such animals haunt special places suitable for their subsistence-that we may have crustacea and mollusks exclusively at one place, and radiata (as corals and zoophytes) at some other, not perhaps far distant, but different with respect to depth or some other circumstance-we can conceive that cephalopods may occur in the first fossil bands in the places which have been examined in England, and yet remains of inferior animals may be found by themselves on the same or a lower level in some as yet unexplored place not far off; so that a time-interval may there appear to allow for a progressive development. Such seems but a reasonably cautious surmise, when we are told by a high authority that there are " detached Silurian districts in England, presenting particular changes and modifications, arising from difference of depth, and the variety of currents, and chemical combinations in the seas in which they were formed;" and that, "in consequence of this variety of physical condition, there is a corresponding diversity in the traces of organic life in each situation."* What, however, places the matter beyond doubt is, that in North America, where the early stratified rocks are even more amply developed than with us, the highest invertebrated forms do not appear at the first. In the earliest ascertained fossiliferous strata, the ${ }_{\odot}$ Potsdam Sandstone,

* Professor Phillips, British Association, 1845. Athenæum' Report 
the only fossils are lingula (a brachiopodous mol ask) and fucoids. In the next, the Calciferous Sandrocl, are fucuidal layers, encrinital beds, and the brachiopods, orthis, lingula, and bellerophon, together with orthocerata, these being the first examples of the cephalopoda. And in all these cases the fossils are few and obscure; they comprise no crustucea. It is not till we ascend to a fourth fossiliferous series, Trenton Limestone, that fossils become abundant, or that trilobites appear. Perhaps even this is not the most decisively adverse view which could be derived from the American fossils, for lately there have been found, in the Green Mountains of Vermint, strata which, from their metamorphic character, $\mathrm{r}_{\mathrm{*}} \cdot$ believed by some native geologists to be inferior and $a^{\circ}$ course anterior to the Silurians, and these contain tra es of fucoids and of vermiform bodies called Nereites, the last being an humble form of articulata. If this be true, it would at least add materially to the grounds for hesitation before pronouncing definitely, as the Edinburgh reviewer has done, on the commencement of fos. siliferous strata and the nature of the first fossils. Here we must also remember, that in rocks of the elder conti. nent anterior to the Silurians, there are limestones, held by many to be an indication of organic life at the places where they are found: the chemical experiments of Braconnot upon masses of these earlier rocks gave ammoniacal and combustible products, likewise indicative of the presence of organic matter: in the same subsilurian region, "fragments, apparently organic, and resembling cases of infusoria," have been detected, * and in Bohemia actual fossils have been announced. Even dubious traces of life in sub-silurian rocks must be ad. mitted to be of importance, when we consider that they have mostly been subjected to such a degree of heat as could not fail to obliterate organic memorials, seeing that it has even changed the texture of the rocks themselves. From what Mr. Lyell saw of the Silurian rocks in America, he finds himself called upon, in the most emphatic manner, to warn geologists against "the hast” assumption, that in any of these sections we have $p$ sitively urrived at the lowest stratum containing organic remains in the crust of the earih, or have discovered the first living leings which were embedded in sediment."

* Ansted-s Geology, ii., 60. 
"A geologist," he says, "whose observations had been confined to Swizerland, might imagine that the coal measures were the most ancient of the fossiliferous series. When he extended his investigations to Scotland, he might modify his views so far as to suppose that the Old Red Sandstone marked the beginning of the rocks charged with organic remains. He might, indeed, after a search of many years, admit that here and there some few anit faint traces of fossils had been found in still older slates in Scotland; but he might naturally conclude that all pre-existing fossiliferous formations must be very insignificant, since no pebbles containing organic remains have yet been detected in the conglomerates of the Old Red Sandstone. Great would be the surprise of such a theorist when he learned that in other parts of Europe, and still more particularly in North America, a great succession of antecedent strata had been discovered, capable, accord. ing to some of the ablest palæontologists, of constituting no less than three independent groups, each of them as important as the 'Old Red' or Devonian system, and as distinguishable from each other by their organic remains. Yet it would be consistent with methods of generalizing not uncommon on such subjects, if he still took for granted that in the lowest of these 'Transition' or Silurian rocks he had at length arrived at the much-wished-for termination of the fossiliferous series, and that Nature had be. gun her work precisely at the point where his retrospect happened then to terminate.'

It is exactly to such theorizers as the Edinburgh reviewer that his rebuke is applicable. When he asserts the contemporaneousness of the highest mollusks with the origin of organic life, he says_- "We are describing phenomena that we have seen. We have spent years of active life among these ancient strata-looking for (and we might say longing for) some arrangement of the ancient fossils which might fall in with our preconceived notions of a natural ascending scale. But we looked in vain, and we were weak enough to bow to nature." The weakness consisted in looking only in one little portion of the earth, and believing it to be a criterion for all the rest. 'This writer seems yet to have to learn that knowledge is to be acquired by communication as well as examination. Were a philosopher (supposing there could be such a being) to * Travels in North America, ii., 131. 
limit his view of mankind to juvenile schools, he might with equal rationality deny that there is any such thing in the world as infants in arms. "We speak of what we have seen," he might say, "and finding no specimens of humanity under three feet high, we are weak enough to bow to nature and believe that babes are a mere fancy."

Even taking the English Lower Silurians as he and others would have them taken, it still appears that these rocks denote, generally, a low state of the animal kingdom. It is customary for those who take opposite views to speal of the creatures of this period as high-" highly-organizec crustacea and mollusca" is the usual phrase. Some, including the Upper Silurians in their view, tell us that the first formation presents examples of the whole of the great divisions, the fish being held as representing the vertebrata. Of course this is only done through ignorance, or for the purpose of deceiving. Where particulars are overlooked, it is still customary to speak of the earliest fauna as one of an elevated kind. When rigidly examined, it is not found to be so. In the first place, it contains no fish. There were seas supporting crustacean and mollus. can life, but utterly devoid of a class of tenants who seem able to live in every example of that element which supports meaner creatures. This single fact, that only invertebrated animais now lived, is surely in itself a strong proof that, in the course of nature, time was ne.. cessary for the creation of the superior creatures. And, if so, it undoubtedly is a powerful evidence of such a theory of development as that which I have presented. If not so, let me hear any equally plausible reason for the great and amazing fact that seas were for numberless ages destitute of fish. I fix my opponents dow to the consideration of this fact, so that no diversion respecting high mollusks shall avail them. But this is not all. The Silurian is an age, as were several subsequent ones, of only marine animals. It is now incontestible, from a few land-plants found in the Silurians of America, and a fern leaf in our own, that there was dry land; yet no trace of a land animal appears for ages afterwards. Moreover: though we have now a pretty full development of the first sub. kingdom, Radiata, we have but an imperfect ons of the two next-namely, the Articulata and Mollusca. Not to speak of the utter absence of fresh water and land mollusks, and of such land articulata as nsects and spi- 
ders, we do not find any decapedous crustacea (crabs, \&c.,) though these could have lived wherever othe" mollusks and crustacea could. In fact, it is a scanty ar d most defective development of life; so much so, that Mr. Lyell calls it, par excellence, the Age of Brachiopods, with reference to the by no means exalted bivalve shell-fish which forms its predorninant class. Such being the actual state of the case, I must persist in describing even the fauna of this age, which we now know was not the first, as, generally speaking, such an humble exhibition of the animal kingdom as we might expect, upon the development theory, to find at an early stage of the history of organization.*

We now come to the Tpper Silurians, where new species of invertebrated animals appear, besides a few obscure fishes. There is no appearance, according to the Edinburgh reviewer, of a transition from the former species to the present; but does he know the signs by which such a transition could be detected? I am aware of none. He says the new species are sharply defined, that is, strongly distinct; and so they may be, without any prejudice to the transmutation theory-as far, at least, as I understand it. And here he remarks that there are the same difficulties in the way of this theory, "both in the

* Objectors to the development theory have, in the eagerness of counter-theorizing, committed themselves on the subject of the Silurain fossils, in a way which they will yet feel to be extremely atwk ward. The North Brilish Review we have seen placing even fishes in the first fossiliferous rocks, grounding this statement upon an authority which has been antiquated for fully eight years - a vast period in the history of geology. The British Quarterly Review is equally unfortunate. "The Author's theory," says this writer, "requires that these animals should be the lowest in the scale. But no argument can convert $a$ fish, with its back-bone, and highly developed nervous and muscular systems, into an an. imal of low organization." (!) The dogmatic allegations of the Edinburgh reviewer on this point are sufficiently exposed in the text. I have only further to express my surprise at finding Dr Whewell participating in the mere ignorance of the first two of the above-mentioned journals. In the preface to a volume which he has recently published, under the title of Indications of the Creator, he meets my arguments with a crude and incorrect view of the fossil history, commencing with this sentence-" Vertebrate nnimals do exist in the Silurian rocks, from which the asserted law [that of development] excludes them." The existence of a non-pisciferous formation had been unknown to him. Many of the objections made to the developms:it theory, in obscurer quarters, rest on errors of a similar kind. 
grou ing of each separate system, and in the passage from one system to another; and that is true, whatever part of the ascending geological series we choose to take between the lowest formations and the highest." As he does not state the nature of the difficulties, I cannot undertake to say what argument or what reconstruction of my system may be necessary to meet them. Till we are more clear, however, regarding the actual affinities of animals, I would suppose that any judgment as to difficulties in their grouping in geological formations, or succession in different formations, might well be given somewhat less dogmatically than they are by this writer.

The few fish-remains of the Upper Silurians may be associated with the ample development of this class in the next (Devonian or Old Red Sandstone) system. They belong to Agassiz's two orders of placoids (these by them. selves in the Upper Silurians) and ganoids, the former of which are represented by our sharks and rays, the latter by the bony pike of America and the polypterus of the Nile. Such are the only fishes found till we come up to the chalk formation, when the now-predominant orders of cycloids and ctenoids begin.* The Edinburgh reviewer makes a strong point of the placoid and ganoid orders, as unfavorable to the progressive theory. "Taking into account," he says, "the brain, and the whole nervous, circulating, and generative system, the placoids stand at the highest point of a natural ascending scale, and the ganoids are also very highly organized." Of certain families of the first order, found in the Old Red Sandstone of Russia, he savs, "Let the reader bear in mind that these fishes are among the very highest types of their class, and that we can reason upon them with certainty, because some

* The North British Review presents as a strong objection that "several new ctenoids, which bad been found only in the carbo. niferous system, have been discovered among the fishes brought by Mr. Murchison from the Old Red Sandstone of Russia. Resolved to make out his position, the author asserts," \&c. This is an unlucky venture in opposition. The critic evidently meant it to have a very damaging effect, in consideration that the ctenoids are osseous fishes. The fact is, that the fishes brought home by Mr. Murchison are not of the ctenoid order, but belong to a pla. coidan family called Ctenodus. The mistakes made by this writer, in the geological part of his paper, are of a very grave kind, yet only such is many men of scientific eminence may be expected to make when they venture out of their own peculiar denartment, and rashly under-estimate the strength of the arguments to which they are opposed. 
of thern belong to fan tlies now living in our seas." Ho instances a cestraceon-a high kind of placoid-recently found in the Wenlock limestone, a low portion of the Upper Silurians, and therefore near the beginning of fish Some of the ganoids, also, of the Old Red Sandstone make an approach to a higher class-reptilia. Besides the usual row of fish-teeth, they have an inner range, in which we see the form of those organs among the sauria. It appears, in short, according to this writer, that the further back we go among the fishes, we find them possessed of the higher characters. Of the real character of all this hardy assertion I shall enable the reader to judge. The fishes of this early age, and of all other ages previous to the chalk, are for the most part cartilaginous. The cartilaginous fishes-Chondropterigii of Cuvier-are placed by that naturalist as a second series in his descending scale; being, however, he says, " in some measure parallel to the first." How far this is different from their being the highest types of the fish class, need not be largely insisted on. Linnæus, again, was so impressed by the low chararters of many of this order, that he actually ranked them with the worms. ${ }^{*}$ Some of the cartilaginous fishes, nevertheless, have certain peculiar features of organization, chiefly connected with reproduction, in which they excel other fish; but such features are partly partaken of by families in inferior sub-kingdoms, showing that they cannot truly be regarded as marks of grade in their own class. When we look to the great fundamental characters, particularly to the framework for the attachment of the muscles, what do we find?-why, that of these placoids-" the highest types of their class!"-it is barely possible to establish their being vertebrata at all, the back-bone having generally been too slight for preservation, although the vertebral columns of later fossilfishes are as entire as those of any other animals. In many of them traces can be observed of the muscles having been attached to the external plates, strikingly indicating their low grade as vertebrate animals. The Edinburgh reviewer's " highest types of their class" are, in reality, a separate series of that class-generally inferior,

* Dr. Fletcher places the Chondropterigii lowest in a scalo which takes as its criterion "an increase in the number and extent of the manifestations of life, or of the re ations which un organ ized being bears to the external world." 
taking the leading features of organization of structure as a criterion; but, when details of organization are regarded, stretching further both downward and upward than the other series; so that, looking at one extremity, we are as much entitled to call them the lowest, as the reviewer, looking at another extremity, is to call them the highest of their class. Of the general inferiority there can be no room for doubt. Their cartilaginous structure is, in the first place, analogous to the embryotic state of vertebrated animals in general.* The maxillary and intermaxillary bones are in them rudimental. 'Their tales are finned on the under side only, an admitted feature of the salmon in an embryotic stage; and the mouth is placed on the under side of the head, also a mean and embryotic feature of structure. These characters are essential and important, whatever the Edinburgh reviewer may say to the contrary; they are the characters, which, above all, I am chiefly concerned in looking to, for they are features of embryotic progress, and embryotic progress is the grand key to the theory of development. I therefore throw back to my reviewer the charge that I have "clung to feeble analogies," and "lkept out of view the broad and speaking facts of nature."

With regard to the alleged falsity of the crustacean character of some of these fishes, and the discredit of repeating the blunders and guesses made by the first observers, before any good evidence was before them, I can only say that, at the time when my book was written, geologists and inquirer's into fossil ichthyology of the highest character were writing, publicly and privately, of the cephalaspis and coccosteus as apparently links between the crustacea and fish, the vertical mouth of the latter animal being particularly cited as a feature indicating the intermediate character. In what the reviewer calls " the excellent work of our meritorious self-taught countryman," Mr. Hugh Miller, published in 1841, the apparently crustacean character of these fishes is re. peatedly referred to. $\dagger$ Not having access at the time to

* Cartilage, "in many animais, forms the entire structure, and in the eariy state of the human embryo it does the same."--Car perter's Generul Physiology, p. 37.

t Mr. Miller calls upon his readers to "mars the form of the cephalaspis, or buckler-head, a fish of the formation over that in which the remains of the trilobite most abound. He will find," he says, "the fish and crustacean are wonderful" $y$ alike: the fish 
the work of Agassiz, I deemed myself safe in trusting to the report of this industrious inquirer and ingenious writer, whose volume was then newly published. How recent the contradiction of the once-supposed affinity may be, or what faith to place in it, I know not; but the reader will probably hold one who only pretends, in this instance, to the character of a general writer, excused, when he shows so distinguished an expositor of physiology as Dr. Carpenter still more recently countenancing the idea:- "'The bodies of fishes," says he, "are usually covered with scales or plates, which have sometimes a bony hardness, and which, in some species of fish that do not now exist alive, appear to have been of the density of enamel. 'Thus we have a sort of transition to the exiernal skeletons of the invertebrated animals; and in this class, also, we not unfrequently find the internal skeleton so deficient in the stony matter from which bone derives its hardness, that it seems like car. tilage or gristle; and in a few of the lowest species, we do not even find a distinct vertebral column; so that the change of character from the vertebrated to the invertebrated series is a gradual, and not an abrupt one, and would probably be found still more gradual, if we were acquainted, not only with all the forms of animal life which now exist, but also those which have existed in ages long gone by, and are now extinc:."."

The above argument relates to the general fact of the first fishes being placnidean. It is necessary, also, to meet the inquiry why there should be no fossil remains indicating a transition from the lower animals to fish. The reviewer speaks of a recently discovered cestraceon below any other fish-beds in England. "Such," he exclaims, "are nature's first abortive efforts." "We entreat," he adds, "any good naturalist well to consider such facts as these, and tell us whether they do not utterly demolish every attempt to derive such organic structures from any inferior class of animal life found in

is more elongated, but both possess the crescent-shaped head, and both the angular and apparently jointed bocy. They illustrate admirably how two distinct orders may meet. They exhibit the joints, if I may so speak, at which the plated fish is linked to the shelled crustacean. Now the coccosteus is a stage further on ; il is more unequivocally a fish ; it is a cephalaspis, with a scale-covered tail attached to the ungular body, and the horms of the crescent shaped head cut off."-Old Red Sandstone, p. 54. 
the older strata ?". Now I cannot tel! what good naturalists may say in answer to this appeal; but I feel, fo: my own part, that the facts in question-as far as they can be admitted to be so-have no such destructive effect.

In the first place, the cestraceon is only one of those cartilagines, the real character of which had just been explained. It is not the lowest of its order, but neither is it the highest. So far from this being the case, the respiration of the whole family (Selacii, Cuv.; Plagiostomi, Desm.) to which it belongs, and which also includes sharks, is performed in a manner which approximates these fishes to the worms and insects-namely, "by numerous vesicles called internal gills, the entrance to which is from their gullet, while the exit is in general by corresponding apertures on the side of their neck;" * other fishes having free gills, marking a higher organization. The sub-divided form of the stomach-the absence of that concentration, which is, perhaps, the most emphatic mark of animal advancement-belongs to this family alone amongst fishes, as it does to the lowest families of several of the higher orders of the vertebrata. Thus, the cestraceon is, on many considerations, a low fish, though certainly possessing some traits of superior character, and not the lowest of its order. In the second place, I would protest against any inference unfavorable to the hypothesis of development being drawn from a discovery so new, so isolated, and in a branch of inquiry so extremely unsettled. At no time during the last ten years have we had, for a twelvemonth at once, stable views respecting the initiation of fishes. Lately-so lately that part of my book was written at the time-the lowest were understood to be some of a minute size, irnmediately over the Aymestry limestone, in the Upper Silurians.t Now we have a cestraceon announced to us at a lower point in that formation. But how far it is likely that our information is to rest at this point the reader may judge, when he hears of $M$. Agassiz announcing, within the last few months, that, though acquainted with seventeen hundred species of fossil tishes,

* Fletcher's Physiology, part i., p. 20.

+ "The minute and curious fishes in the uppermost bed of the Ludlow rock are the exrliest precursors of many singular ichthyolites which succeed in that enormous formation the Old Red Sandstone."-Murchison's Address to the (Yeological Sx siety, Feb ruar 5,1942 . 
he regards the history of the class as so far from comp.ete, that the is umber of species successively entombed in the crust of the globe might be estimated at thirty thousand, without any chance of approaching the truth !* If such be the case, we may surely expect to hear of other fishes prior to or contemporary with the cestraceon, showing that, humble as that animal was, it is not to be regarded as the initial of its class. $t$ But even although simpler fishes be not found in lower or contemporary strata, this mav only be owing, like the non-discovery of vegetation in the early rocks, to the unsuitableness of these fishes for being preserved. Supposing the inferior tribes, petromyzonidæ (lampreys) to have been then in existence, we should have no trace of them preserved, because of their osteological structure being slight, and their wanting those teeth and spines which form, after all, the chief memorials of the higher families of their own order.

One word more as to these fishes. The critic says ( $p$. 33,) it is shown to demonstration in the Poissons Fossiles of Agassiz, that " the sauroids, in their general osseous structure, and in the development of their nobler organs, run close upon the class of reptiles." There is no doubt that the sauroid fishes partake of reptilian characters, though, perhaps, in a more external and less important way than such writers as the Edinburgh reviewer suppose; but, be it remembered, the sauroids are not the first fishes. There is not one of them in the Silurian formation, where placoideans appear to beyin. Yet I do not, for this reason, suppose that the sauroids arose from placoideans. More probably, they are part of a distinct line of development, which had inferior forms in its first stages, also of too slight a structure to be preserved.

Following this reviewer into his discussion of the $C^{r}$ arboniferous System, we find him commencing with a taunt, that there are now traces of land vegetation in

* Review of Professor Pictet's Traité Elémentaire de Palæeonto logie, translated in Jameson's Journal from the Bibliothèque Universelle de Genève, No. 112, 1815.

† Such shifts are of frequent occurrence in geology. Insects, formerly found first in the oolitic formation, ars ow taken back to the carboniferous. Birds are now inferred from fuot-tracks in the New Red Sandstone, their first place formerly being in the oolite. We have mammifers in the oolite, which, a few years ago, were believed not to oceur before the tertiary. None of these shifts, however, in the least interfere with the general fact of the advance from the lower to the higher classes of animals. 
earlier formations. This is, in reality, a point of no importance for the development theory. 'The question is, with what kind of plants did land vegetation begin? The anxiety of the reviewer to force a verdict in his favor is here strongly shown. "What," he says, " are these first fruits of nature's vegetable germs ? Are they rude, ill-fashioned forms? Far otherwise. We find among them palms and tree-ferns, \&c." In this passage, which substantially conveys the same information as my book, there is an evident design of inducing the belief that the first land vegetation was of a high character. The rigid truth is, that though this was a "grand" in the sense of a luxuriant vegetation, it was composed, as far as positive evidence goes, almost wholly of plants which stand low in the scale of organization. The ascertained dicotyledons (plants having double-lobed seeds and an exterior growth) are extremely rare. On this point, I cannot do better than quote the laborious young Professor of King's College- "'The plants which have hitherto been described [in the carboniferous formation] belong either to the acotyledonous class, as the ferns, or to the monocotyledons, and, on the whole, they constitute the simplest forms of vegetation; but there have also been met with among coal plants unquestionable evidences of dicotyledonous structure, and a genus has been formed under the name of Pinites, to include a number of specimens of fossil wood, \&c."* To the undoubted evidence of Mr. Ansted may be added that of his more eminent contemporary, Mr. Lyell, whose sense of the botanical character of this age is such that he emphatically calls it the Age of Ferns.t It is evident, then, taking the landscape of this era as the first, that it is of a nature to harmonize with the development theory, for its chief forms are humble, and only a few are of higher grade, most of these, too, being of an intermediate character between the low and the high. I am reminded, however, in other quarters of certain experiments of Dr. Lindley, showing that the plants chiefly found in the coal are of the kinds which best resist decomposition in water; whence it is inferred that many trees of a high class may nave existed at that time, but perished in the sea, while *eaker vegetation survived. This evidence would be

* Ansted's Geology, 1844.

+ Travels in North America, ii., 52 
negative at the best; and it says as much for the nonpreservation of mosses and other humble plants as for dicotyledons. It has also been remarked that, consider. ing such facts as the disappearance of equiseturn hyemale in water, a plant containing an unusual quantity of silex, " the proportion of fossil plants in each formation must depend on other circumstances besides their power of resisting decomposition."* "Too much importance has," in the opinion of the author of this observation, "been attached to Dr. Lindley's experiments."

The British Quarterly Review says-"The author admits there were dicotyledons among these plants, and coes not see that, however few they may be, it entirely upsets the theory of progressive advance, especially in the absence of any proof as to whether they were created first or last." This proceeds, as do many similar objections, upon the idea that a formation represents one point in time. A formation, in reality, represents many years, or rather ages. Such expressions as that simple and complex plants occur together in the carboniferous formation, or even (shall we say) in its-first fossil bands, are vague expressions, perhaps conveying an idea substantially false. There is no such precision in the ascertained relations of fossils to particular strata, as to entitle any one to say that the simple and complex plants of this formation are rigidly contemporaneous. They may have followed each other within the space of half a century in a particular region, and yet been preserved in but one stratum, or little group of strata. The actual appearances of the carboniferous formation thus, perhaps, allow full time for a progressive advance in particular regions, from the fleshy luxuriant plants of the marsh and low sea margin to the robust tree of the more elevated regions. We must remember, too, that the vegetation of the carbonigenous era, even if we take it back to include the confer said to have lately been found in the Old Rea of Cromarty, or the fern leaf of the Silurians, was preceded by unequivocally simple plants in the fucoids. Starting with these, and finding the first great burst of land vegetation composed mainly of low cryptogamic anil monocotyledonous plants, - finding, moreover, the exceptions chiefly of the intermediate character, and that

* Mr. C. J. Bunbury, at the British Association, 1845; Athenæ um's Report. 
he dicotyledons increase afterwards while the others decline,-we cannot well resist the conclusion, that we see the traces of a progress in the history of this kingdom of nature. It may be less clear than we could wish; but such light as we have certainly favors the development theory.

We now come to the Magnesiun Limestone deposit, latterly called the Permian System. At this place, the Edinburgh reviewer introduces some general observations, which I hope he will yet acknowledge to be unjust, as I am sure the whole of his substantive charges are. "It may be true," he says, " that sea-weeds came first, but of this we have no proof." How a good geologist cal have allowed himself to speak in this manner, even in eagerness to theorize against theory, I am quite at a loss to understand, for the positive facts of the occurrence of fucoids in the Lower Silurians, and of the very first traces of land vegetation in subsequent formations, are as palpable and undoubted as he himself acknowledges the precedence of fish by invertebrata to be ; nor has any one ever pretended to expect that land vegetation would be found earlier than the marine. I have here ventured no conjecture of my own, but only spoken as all the geolo gical books teach. "Of land plants," he continues, "we have not the shadow of proof that the simpler forms came into being before the more complex." The reader has just been told upon undoubted authority that, in the first great show of land vegetation, taking such positive evidence as we have, the simple forms are vastly more numerous than the complex. Finding that we have first ample marine vegtation, then a land vegetation in which the plants, with only a small exception, are cellular and cryptogamic, while of the exception a very small number are dicotyledonous, and a conspicuous group (the conifers) intermediate-I feel that I am entitled to say that positive evidence speaks for a precedence of high but simple forms; which is what I have done. "It is true," thus proceeds the reviewer, " that we see polypiaria, crinoidea, articulata, and mollusca; but it is not true that we meet with them in the order stated by our author." It is humiliating to have to answer an objection so mean. There is no statement that the animals came in this order. I have only put the words into this arrangement, in accordance with the custom now commonly followed of observing the 
ascending grades of the animal kingdom. With respect, then, to what follows - "The sentence on which we here comment contains three distinct propositions, and all three are false to nature, and no better than a dream,"I believe I may safely leave the reader to say which party is the falsifier and the dreamer. He goes on in the same strain-"It is true that the next step gives us fishes; but it is not true that the earliest fishes link on to the radiata: this is a grand and, at the present day, an unpardonable blunder." 'This is another dream of the reviewer, for certainly such an affinity was not suggested in any edition of the Vestiges hitherto published. In the first four editions, which alone were under his notice, no passage except from the articulata was even hinted at. So much as a proof of the reviewer's recklessness in making charges; there is no need, however, to affirm, with him, that a connection between certain high radiates and some of the lowest fishes does not exist. I venture to predict that affinities of an equally startling nature will yet be made familiar to naturalists. Meanwhile, it is enough to show that this confident critic has raised an accusation for which he has not a shadow of ground.

Taking up the special fossils of the Permian system, he says, "The earliest reptiles are not of such a structure as to link themselves, on a natural scale, to the noble sauroids of the preceding carboniferous epoch." They are not the marine saurians, or fish lizards (ichthyosauri) which occur in a higher formation, but lacertilians, or animals of lizard-like character. Now what first strikes me here is the extraordinary narrowness of a mind which sees nothing indicative of natural procedure, no hint towards great generalizations, in the simple fact of reptiles following upon fish in this grand march of life through the morning time of the world. He knows that, in every classification of the animal kingdom, reptiles rank next above fish, that in some living families there is such a convention and intermixture of both characteis, that naturalists cannot agree to which class they should be assignea. He actually sees, in a general view of the earlier reptiliferous formations, animuls combining the fish and reptile in the most unequivocal manner. Despising, however, the great fact which shines through these obscurities this pers m, and I am sorry to add, geologists generally, can only asten upon such particulars as 
may be inade out to be difficulties in the way of generalization. Passing to the particulars, a few land lacertilians come first, whereas the first, according to my hypothesis, ought to be marine forms, and linked to fish. He says of this difficulty, that I have stated it feebly. Perhaps it would have been well for his own credit that he had stated it somewhat less confidently; for before his sheets had seen the light, a prospect had arisen of his affirmations on this point being tholoughly falsified. In Silliman's Journal, for April, 1845, is an account of sandstone surfaces pretly far down in the Carboniferous formation of Pennsylvania, marked with the vestiges of terrestrial animals. Setting aside, in the meantime, one class of these markings, which are said to indicate wading birds, we have a variety of others plainly denoting REPTILEs. In one group, the foot consists of a ball, with five toes radiating from it in front. In another, the impression resembles that made by a coarse human hand, with the rudiment of a sixth toe at the outside. The reptilian families indicated by these foot-marks have not yet been pronounced. upon, as far as I am aware; but from the extreme resemblance of some of them to the vestiges of the labyrinthidon, there can hardly be a doubt that some of the order batrachia are amongst them. If they prove wholly batrachian, as is not unlikely, for we have living families with feet resembling the first group of vestiges, or even if only a portion of them be certified as of this order, where will be the lacertilians, and where tite confident counter-assertions of the Edinburgh reviewer? The batrachia he has himself allowed to be a low order of rep. tiles (p. 51.) They are so considered by all naturalists. Might I not here, then, take my stand upon the fact of animals, the lowest apparently of the reptile order, being now found at the earliest point of time? I might unquestionably do so with a decided immediate advartage to my hypothesis. It would in a great measure neutralize the whole of the objections of the reviewer with regard to the chronology of the reptiles. But I am, whatever he may think of me, willing to read the book of nature aright. I receive the fact as one liable any day to receive a new aspect from fresh discoveries. In as far as it is so, it only teaches that we are not to be too confident in drawing inferences either for or against the theory of development from the particular succession in which the orders of the 
reptilia occur in those early strata where their remains and vestiges are few. In as far as it may be taken as a positive fact, I only claim a modified benefit fiom it, be cause the view which I take of the affinities and connec tions of the animal kingdom (and by analogy of the vegetable kingdom also) makes it a matter of less consequence than would be generally supposed, which order of any class appears first in the stone record, though still perhaps a matter of some consequence.

This view suggests that development has not proceeded, as is usually assumed, upon a single line which would require all the orders of animals to be placed one after another, but in a plurality of lines in which the orders, and even minuter subdivisions of each class, are ranged side by side. It also suggests that the development of these various lines has proceeded independently in various regions of the earth, so as to lead to forms not everywhere so like as to fall within our ideas of specific character, but generally, or in some more vague degree, alike. The progress of the lines becomes clearest when we advance into the vertebrate sub-kingdom. We can there trace several of them with tolerable distinctness, as they singly pass through the four classes of Fishes, Reptiles, Birds, and Mammals ; the Birds, however, being a branch in some part derived equaliy with the reptiles from fishes, and thus leaving some of the mammal order in immediate connection with the reptiles. The lines or stirpes have all of them peculiar characters which persist throughout the various grades of being passed through, one presenting carnivorous, another gentle arid innocent animals, and so on. We have, therefore, in the animal kingdom, not one long range of affinities, but a number of short series, in each of which a certain general character is observable, though not always to the exclusion of the organic peculiarities of families in neighboring lines, especially in the class of reptiles.

According to this view, the matrix of organic life is, speaking generally, the sea. Fluid, required for all $\mathrm{cm}$ pryotic conditions, is also necessary to the origination of the various stirpes of both kingdoms. The whole of the jowest animal sub-kingdom (Radiata) is aquatic; so are nearly the Mollusca and a very large proportion of the Articulata. In the Vertebrata, the lowest class also is 
whily aquatic. The arrangement appears to be thisthe basis of each line is a series of marine forms; the remainder consists of a series designed to breathe the atmosphere and live upon land, these being all of improved organization. The classification which this system implies may be said to be transverse to all ordinary classifications. The invertebrate, ichthyic, reptilian, ornithoid, and mammalian characters are horizontal grades, through which the lines pass, and where they send off branche.3; not separate and independent divisions. In any of these branches where we have a clear knowledge of the various forms, it is possible to trace the affinities, in conjunction with an improved organization, through genera which are adapted to a partially marine life, to a residence in the mouths of rivers, or on shores and muddy shallows, then through genera which are, in succession, appropriate to marshes, jungles, dry elevated plains, and mountains. And it is this series of external conditions and adaptations which has caused that system of analogies between various families of animals which has of late attracted attention. But the immediate cause of the development of each line through its various general grades of being is to be sought in an internal impulse, the nature of which is unknown to us, but which resembles the equally mysterious impulse by which an individual embryo is passed through its succession of grades until ushered into mature existence. Geology shows us each line taking a long series of ages to advance from its humble invertebrate effluents to its highest mammalian forms; and this I have ventured to call "the universal gestation of Nature."

The traces of this order of the animal kingdom have been seen in all ages of science. Every zoologist acknowledges the gradations and affinities which appear amongst animals. Prompted by what so palpably meets observation, many have tried to range the various orders or families in one line, or (to use the favorite phrase) chain of being; but they have always failed, which is not to be wondered at. One cause why zoologists have not up to this time thought of trying any different arrangement, is the confusion arising from prevalence amnngst many families of parallelisms of structure, which have been regarded as affinities, when in reality they are only identical characters demanded by common 
conditions, or resulting from equality of grade in the scale. True affinities-and these are the affinities of genealogy-are not to be looked for horizontally amongst orde rs, but vertically, from an order in one class to the corresponding order in the class next higher. Generally, the first and lowest forms of the orders in a class are marine, and often these are of comparatively large size. We usually see in them a vestige of the essential charac. ters of the class next below. Thus, the perennibranchiate batrachia in their order, the ichthyosauri in the series of crocodilia, and the divers among birds, all exhibit an affinity to fish. The cetacea and phocidæ, which I regard as the immediate basis of the pachydermata, carnivora, and other orders of terrestial mammals, ought, according to this view, to show an alliance to the reptiles; and such a connection does exist between the cetacea and certain marine sauria, but from the general extinction of the marine reptiles, the linking of the mammals to that lower class is less clearly seen than might be wished. It must be kept in view that only an outline of the progress of the animal kingdom is here designed. Exceptions as to the course which development has taken appear to be by no means few; leading to the idea that the grades of organization are not determinate in this respect, but may be reached by steps of unequal length. Thus, for example, the marsupials appear very clearly a development from certain birds; probably the rodent and edentate orders are derived through the same channel. From the approach made by certain of the reptilia to birds, we may surmise that there also there are exceptions to the rule. In short, the progress of animality in the different stirpes has been attended by peculiarities which evidently affix peculiar characters to each, and make the idea of a difference in time not only probable, but unavoidable.

Regarding the animal kingdom simply as a combination of independent stirpes, each with its distinct affinities, the theory of transmutation puts on a totally new aspect; so truly is this the case, that transmutation is hardly any longer a term appropriate to the idea. The difficulty of supposing such changes as that from the rodent to the ruminant, or the carnivorous animal to the quadrumane, vanishes, leaving only transitions from one form to another of a scries generally similar-from the aquatic 
pachydernı, for instance, to the terrestrial, from the otary to the otter, from certain phocæ to the bear, and so on. There is a unity in all instances in the moral as well as physical characters of the various members of one stirps; we only see it advancing from low to high characters, just as we see the fœtus of a high animal passing througk various inferior stages before it reach its proper mature character. The lines, moreover, being independent of each other, and not quite uniform as to the stages of animality through which they pass, it follows that, unless we know of some law governing their different gestative periods, we are not entitled to look for the first occurrence of their various ichthyic, reptilian, and mammalian sections, in any order as regards each other, even though we could be sure (which we are not) that we are surveying a geographical region where they all started fair in the race of progressive organization. Hence it is that, though the batrachia are usually placed by zoologists at the bottom of the list of reptilian orders, I attach little importance to their vestiges being now found so low All that I think we can expect is, triat, in a particular area where we have reason to believe that the lines have started abreast, they should all reach their various grades nearly about one time, or what may be considered as one time compared with the whole extent of geological chronology. And such appears to be pretty much the case in those regions which geologists have explored.

The Edinburgh reviewer will observe that this view of the animal kingdom leaves much of his opposition in a very awkward predicament. He has everywhere assumed that the genealogy of the orders of each class was supposed to be en suite, which it certainly never was in my book. In the early editions I spoke with diffidence of the course of the supposed development, * because I had not then seen or conceived any arrangement of the animal kingdom which answered to that hypothesis, although I thought proper to attempt to show that the quinarian and circular classification, which I found in vogue at the time when I was writing, did not necessarily militate against it. In the third edition, the pres-

* ". . it does not appear that this gradation passes along one line, on which every animal form can be, as it were, sfrung; there may be branching or double lines at some places," \&c.-Vestiges, is: ed., p. 130 
ent view was first hinted at; and in the fourth it was sketched, though with liability to correction; thus anticipating by some months the publication of the criticism to which I am adverting. I need hardly remark, that in all criticism, the actual subject criticised must be brought forward for comment, and nothing else; otherwise the commentaries become of no imaginable use but to obscure true judgment. Now the Edinburgh reviewer has presented his subject, in this instance, in lineaments entirely of his own imagining, and directly in contradiction to those which belong to it. He had no title to assume any plan of development and to represent his victory over that as a triumph over the hypothesis of his author. In such conduct he has thoroughly vitiated the whole fabric of his criticism, and left it, in reality, no pretension to remain for a moment in court. My immediate object, however, is not to take such exceptions against him, but to show how the ascertained facts of a limited portion of the field of nature may be reconciled with that conception to which a view of what appears over the whole field may lead an honest inquirer.

If the hypothesis of a plurality of genetic lines be admitted, we are not of course to ask which order of reptiles, or of any other class, first existed (such being the language of the old classification;) but, having first settled the whole affinities of the animal kingdom on the new plan, we are to inquire if the geological presentment of the families was accordant with the scheme, allowing for the negative nature of much of the geological evidence of this kind. Niow, in the first place, the affinities of the animal kingdom are only in part made out; in the second, geological evidence is only partial. We are clearly, therefore, not to expect in nature's museum a full exhibition of any one entire stirps, as it may be supposed to have passed through its successive stages up to our time All that we can expect is a succession of fossils marking out portions of what we may suppose likely yet to be established as lines of animal descent. Blanks, and large ones too, must be allowed for; possible errors as to the animal pedigrees must be contemplated. But if we have any ground for generalizing in a particular direction, as I think there is in this case, we may be held as called upon not to conclude hastily and rashly on the unfavorable side, but to look and consider patiently, and to suspend 
ladgment wherever the adverse evidence may appear to be of a nature likely to be reversed. Let us now see how all this applies to the conduct of the Edinburgh reviewer, with regard to the early reptilian fossils. The formations where these occur have only been examined in such a degree, that they are almost every year giving forth new responses: for example, the existence of birds at this era was not dreamt of ten years ago; the existence of tortoises in the time of the New Red Sandstone was equally unknown only two or three years earlier. It is a still less time since the labyrinthidonts of the Keuper of Germany were discovered; and we have just seen that the unqualified affirmations of the Edinburgh reviewer, as to the oldest reptiles, were overturned by intelligence from America, before his sheets had seen the light. When these things are considered, we must see the objections of the reviewer to be extremely rash. It might be allowed that the earliest known lacertilia are not of strictly marine forms or allied to fish ; it might equally be admitted of the first batrachians, that "their near affinities are not with fishes," as this writer takes upon him to say. Yet we should still see the absurdity of affirming that either these batrachia or lacertilia were the first created of their respective orders, seeing that their relics were so few and the discovery of these so accidental, that we might look for new and superseding facts every day.*

But, as the case actually stands, is this line of defence more than hypothetically necessary? I doubt it very much. 'The lacertilia of the magnesian limestone, and these labyrinthidonts of the Trias (perhaps also of the carboniferous formation,) are they so far removed from fish characters as the reviewer would make them ? Let any naturalist who has ever studied the transmutation of the individual batrachian, passing in a few weeks from the branchiated fish to the lunged and limbed frog or newt, its circulatory and alimentary system entirely

I It is necessary to guard against a supposition that I undervalue such isolated relics, as inferring the positive fact of the existence of particular orders of animals at particular times. For this purpose, the smallest fragment betraying the character of the organization is often sufficient. What is really meant is, that, withen we find a few outlying relics belonging to a class which does not appeor in any force till afterwards, we cannot be sure that we have acquired the means of forming a distinct idea of the time of the origin of that class or the orders with which the class started, as further discoveries on these ooints may be looked for. 
changed, and then say if the labyrinthidon nay not be the very first step from some ichthyic form. What though the proportions of the head remind Mr. Owen of the sauria, and remove the animal, as he thinks, above the present batrachian type! Against any such inferences we have the positive fact, in the organization of this batrachian, of a biconcave form of the vertebræ, the form peculiar to fishes, - arguing, by Mr. Owen's own acknowledgment, aquatic if not marine habits,-also a decidedly piscine character in the arrangement and even microscopic structure of the teeth, together with that position of the breathing apertures near the end of the snout which we see in crocodiles, for the purpose of allowing them to drag their prey under water without ceasing to respire. With regard to the lacertilia. we have this same fish-like biconcave form of the vertebræ, and the same fish-like arrangement of the teeth, equally arguing that. alliance to the lower vertebrate class which it is the pleasure of this hardy critic to deny,-the biconcave structure of the reptiles, showing, as Mr. Owen himself owns, that these animals, which the Edinburgh reviewer deems so utterly separated from fish, had probably " $a$ more aquatic, if not marine theatre of life,"* than was assigned to their successors. In subsequent and present reptiles, this form is superseded by the ball and socket, or concavo-convex form; but it is remarkable that, in the embryo state, the frog and crocodile (if not others) exnibit the double hollow form still, resembling in this resyect the mature animal of the secondary rocks. Such is the actual character of reptiles which our critic would set up as high: he has, after this, only to speak of the annelid as above the butterfly, or the proteus as superior to the land salamander, to establish his character as a naturalist. Need I say that these Permian reptiles are, in reality, by these facts degraded to a place in proximity with fishes?

So much for the batrachia and lacertilia. When we come to the great saurian line in the Muschelkalk, Lias, Oolite, and Wealden, we have a case which cannot be isputed, for here the marine character of the earliest of the series, and their intermediateness between fish and rue crocodiles, are admitted by all. The first remove

* On the Reptilian Fossils of South Afric Geological Trano actions, Feb., 1845. 
worn the fish is the ichthyosaur, its name declaring the convention of class characters for which it is remarkable. With piscine body and tail, and fins advanced into a paddle form, it has a true crocodilian head. In the pliosaur, which is later in appearing, we have a stage of advance to the true sauria, which come forward in the oolite, in the forms of teleosaurus, steneosaurus, \&c. Afterwards, chiefly in the Wealden, we have the dinosauria, which betray an approach to the mammalian type in the pachydermatous order. Another oolite saurian, the cetiosaur, exhibits in the form of the vertebræ a verging towards the cetaceous mammalia. Here there is the most perfect and even striking harmony with the theory of a progressive development. Below these formations, fish; then, low in these formations, fish saurians; above them, true and complete saurians ; finally, higher still, saurians advancing to a more elevated grade of animality; and where do these more elevated types occur? In the next formation passing over one which hardly represents any but deep-sea life. Nay, cetaceous relics have been found before we leave the strata so remarkable for the saurians. Thus it appears that the whole of this chapter of palæontology, when read by a light from nature, and not from man's capricious humor, so far from being opposed to the natural genesis of animals, gives it support. Men, however, and of lively parts too, might go on for an age misreading such palpable facts, if they be determined against putting them into the collocation in which a sense can be made of them, just as we might puzzle forever over a Latin or Greek sentence, if obstinately resolved against making English out of it except in its original construction.

After presenting the case of the reptilian fossils of the secondary formation in this way, I feel it hardly gecessary to track the Edinburgh reviewer through all his particular objections. They are a mass of confusion, resulting from erroneous assumptions on his own part respecting the development theory, as that the orders of animais are all "to be affiliated to each other, and every parental form held as extinguished by the fact of transmutation (the latter being a peculiarly gratuitous supposition-see p. 50 of the Review :) together with equally rash and unjustified conclusions regarding the earliest forms of the reptilian orders, all mixed up in a way that promised to tell most effectually in favor of his own opinion, and with 
a disregard of everything that pointed in the opposite di rection. The great unquestioned facts of a succession of birds and mammals to the fishes and reptiles, these being also the next higher classes in the scale of the naturalist, tell nothing to this writer, as the succession of the reptiles to the fishes told nothing before. From the slight remarks with which he passes over these facts, an unlearned reader would hardly suppose that they werc of the least siguificance, while, in reality, they are of the greatest. It is much the same as if a historian were to sink all such events as changes of dynasties, and fix attention upon the displacement of under-secreta:ies of state. And what makes this conduct the more marked is, that the minor facts upon which he fastens for the purpose of supporting his own theory are mostly presented to us in circumstances which show their uncertainty and the likelihood of their being superseded.

For example, the earliest traces of birds do not indicate marine forms, which, according to my general views, ought, he says, to be the case. Instead of natatorial birds, they are waders and runners. Let the reader judge of the character of this objection when he learns the real circumstances of the case. The traces of birds here spoken of are merely a few font-prints found upon certain rock surfaces in America. "Not a bone of these animals has been found in this early period. It must thereiore be inferred, either that the circumstances were not favoiable for the entombment of the bodies of these birds, or that our researches in the strata formed at the time when they lived have been insufficient to discover them. If such be the case with birds which lived upon shoresplaces where, as we learn from the nature of the strata, accumelations of sand and mud were constantly taking place, it is of course not to be expected that any remains of natatorial birds should be found, animals mostly living far out at sea. To put the case in its strongest formfoot-prints on shores being the record of the birds of this era, we are not to expect any traces of such birds as, generally speaking, are not in the way of making foot-prints on shores. I might go further than this, and point out that certain natatorial genera have feet not to be distınguished from those of waders, so that certain of these foot-prints may be those of natatorial species after all; but I feel it to be my best duty in the case only to deny that 
we are in circumstances to say that waders and runters were the first created birds. Mr. Lyell, who stands as high as this or any other writer on geology, says, with regard to those very ornithichnites, as they are called-"This sandstone is of much higher antiquity than any formation in which fossil bones or any other indications of birds have been detected in Europe. Still we have no ground for inferring from such facts that the feathered tribe made its first appearance in the western hemisphere at this period. It is too common a fallacy to fix the era of the first creation of each tribe of plants or animals, and even of animate beings in general, at the precise point where our present retrospective knowledge happens to stop."* What now gives force to this observation is, the recent discovery of a new set of bird foot-prints - said to be of waders only-in the carboniferous formation of Pennsylvania. The emergence of such a fact in the midst of the reviewer's speculations on the foot-prints of the Naw Red Sandstone, forms a most emphatic commentary on all decisive inferences where the facts are obviously casual and isolated.

Of a somewhat different character are the reviewer's remarks on the first relics of mammalia-the few bones of cetacea from the Lower Oolite and of marsupials from the Stonesfield Slate. Here the very first mammal family is undoubtedly marine; and, if it were to receive equal consideration with the grallatorial foot-prints, he ought certainly to admit that it fayors the development theory. But he escapes from this claim by a mode of his own. He has not seen these relics! The American foot-prints were good evidence, without being seen; but a fact which makes against his theory requires personal inspection, even though it may come forward with the authority of Baron Cuvier.t $\mathrm{He}$ is more at ease with the marsupials, which are of course unequivocally land animals. I have only here to refer to the fourth edition of my bouk-published two months before the appearance of the review, and while I was unrecking of any great objection being grounded on this point-where it is

* Travels in North America, i., 255.

$f$ "There is in the Oxford Museum an ulna from the freat Oolite of Enstone, near Woodstock, Oxton, which was examined by Cuvier and pronounced to be cetaceous; and also a portion of a very large rib, apparently of a whale, from the same locality."-. Buckland's Eridgew tter Treatise, i., 115, note. 
suggested that the peculiar organization of the riarsu. pials points to their having been derived through a different medium from other mammals. The critic, eager to let nothing escape, tells us that there are other land mammals lower in organic type than the marsupials. One answer to this objection might be found in an explanation of my views respecting the ornithic descent of these animals; but I am unwilling to pause upon such an inferior matter, and will therefore meet him with the question, if any other mammals show that lowly grade of organization which is marked by the absence of a placenta? "There are no other organic types," he says, " to which they [the marsupials] offer the shadow of a near affinity. They are therefore in direct antagonism with the scheme of regular development." To this it may be replied, that the affinity of the marsupials to the oviparous vertebrata is admitted by every naturalist, being shown in the small size of the brain and consequent exposure of the cerebellum, the absence of the ceptum lucidum and corpus callosum in the brain, and various other traits. Professor Rymer Jones, of King's College, whose testimony on such a point will be admitted by the reviewer, speaks of the marsupials as " connecting links between the oviparous and placental vertebrata." Striking traits of their affinity to birds are shown, he says, in the structure of the ear and of the reproductive organs.* In reality, the whole figure of the cursorial bird, the small head upon the long neck, the extreme length of the hindêr limbs, and the imperfect development of the fore extremities, as well as the tendency of the feathers to a hair-like character, speak irresistibly for its approach to certain marsupials. The ornithorhynchus is as clearly an advance from the natatorial bird towards the rodent form, the latter being an order whose osteological structure is allowed by every naturalist to be bird-like. New and curious illustrations of the connection between the birds and the implacental mammalia are constantly appearing. We lately heard of a bird which has a pouch for its young like the kangaroo, $\dagger$ and Mayer has discovered in the female emeu a purse form of certain organs, indicating an approach to the marsupial in that part of structure which is the most dis.

- General View of the structure of the Animal King dom. t Magazine of Natural History. 
tinctive in the case.* It would appear that the reviewer is simply ignorant of this department of natural history, and, with the self-esteem which often attends upon ignorarce, he has somewhat unluckily ventured to give a positive contradiction to that which is incontestably true.

The reviewer at length comes to the organic phenomena of the Tertiary system. "On the theory of development," says he, " "the stages of advance are in all cases very small-from species to species,' and the phenomena, "as shown in the pages of geology, are always of a simple and modest character.' Let us test these assumptions by one single step, from the chalk to the London clay, or any other tertiary deposit. Among the millions of organic forms, from corals up to mammals, we find hardly so much as one single secondary species." The exceptions in reality are, the infusoria of the chalk, and "two or three secondary species," which are said to "straggle into the tertiary system." "Organic nature," he says, " is once more on a new pattern-plants as well ds animals are changed. It might seem as if we had seen transported to a new planet; for neither in the arangement of the genera and species, nor in their affinities vith the types of an older world, is there the shadow of iny approach to a regular plan of organic development." Now the almost total break in the organic creation here .rsisted upon occurs in the interval between the extenaive daposits of the secondary formation and the comparatively isolated deposits of the tertiary. It is an interval which the lithological arrangements clearly, indicate to have been longer than any of those between the other formations, during which minor changes of organic creation had taken place. It is simply, then, a period not represented by strata or by fossils; while it elapsed, the continual advance of the organic world proceeded to a point at which nearly all the old species had died out or been changed. There was nothing more in the "step" of our reviewer than this Such is the geological doctrine. "Is the present creation of life," says Professor Phillips, "a continuation of the previous ones; a term of the same long series of communicated being? I answer, yes." $\dagger$ "There is no break," he says, " in the vast chain of or-

* Reports of Ray Society, I.

$\uparrow \mathrm{He}$ adds-"But not as the offspring is a continuation of the parent." 
ganic development till we reach the existing order of things" The reader will further be able to jucige of the candor of the reviewer respecting the zoology of the tertiary, when he is reminded that it shows exactly those new portions of the animal kingdom which might have been expected, according to the theory of development. Heretofore, we have only few and faint traces of mammalia; but now they are added in abundance, mammalia being the crowning class of the vertebrated form As far as class, therefore, is concerned, it is incortestably a "regular plan of organic development." But this is not all. We have seen the reptile forms of the secondary approaching the cetacean character; and now there is an abundance of the aquatic mammalia, as well as of those land pachyderms which are universally classed with some of the forms of that order, these being the only suite of creatures which my ideas of development would lead ne to expect at this place. Here I must meet the reriewer on a special ground. He admits the dinosaurs to rave been the nearest approach to mammals ; but "they lied away," he says (" if we are to trust to geology,) ages sefore the end of the chalk." These mammals have, herefore, "no zoological base to rest upon;" that is, here is no connection between them and any such animals as the anusaurs, because there is an interval in the creta:eous formation which gives neither these forms nor any intermediate. Now the fact is admitted by Professor Ansted, that the cretaceous system appears to have been " formed, for the most part, by deposits in deep water, and a considerable portion of it not far from the zero of animal life."* And this he states with a particular reference to the results of Professor Edward Forbes's researches in the Egean Sea. We therefore have a satisfactory explanation of the non-appearance of forms intermediate to the reptiles and mammals in the chalk, without being driven to suppose, with our reviewer, that the latter were a creation de novo of animal life. But no such fact as this did it suit our reviewer to state.

"Carnivora," he proceeds to say, " are as old as pachyderms. As far, at least, as we have any evidence bearing on the question, and bimana (monkeys) are found in this division-thus contradicting and stultifying the upper end of our author's grand creative scale." There is here, in

$$
\text { * Ansted's Geology, i., } 502 .
$$


reality, no stultification except in the critic's own mind. It was not my scale which he refers to, but Dr. Fletcher's : adopted into my book, not as a plan of the actual process of development, but as a general indication of the comparative organization of the animal orders. I do not consider the assumed contemporaneousness of the carnivora and monkeys (which the reviewer erroneously calls bimana) as at all contradictory of a true development theory, for I regard them all as distinct lines of development, which might well advance to a certain stage (namely, that of the terrestrial mammala) about the same time. I am not, however, entitled to blame the reviewer for this objection, as the idea of a development in a plurality of lines must be new to him.

"As we ascend," he says, "towards the middle divisions of the [tertiary] series, there is a development of nature's kingdom, nearer and nearer to living types. But it is not a development after our author's scheme. It folows the law of he rise, progress, and decline of the families of the older world, already pointed out. We have no confusion of genera and species, and no shades of structure to make dim their outlines." Now there is here an acknowledgment, in which all geologists acoord, of a constant gradual approach to living types. Is not this, in itself, a fact speaking strongly for some simply natural procedure in the origin of the present tribes? A change бoes on from one set of forms to another, ir the same way as one human generation is changed for another-name$\mathrm{ly}$, by the withdrawal of some and the addition of others, until at length the whole personnel of one age is superseded by that of another. The removal of old species is the result, by our critic's own showing, of law ; and laws for the extinction of species are in operation at the present day. Can we well suppose the rise of the new species to be a phenomenon of an essentially different character ? for here is the whole question at issue. I say no -any ideas I have ever acquired of philosophy, as an expression of our ascertainment of the order of nature or providence, forbid me to form such a conclusion. A "confusion of genera or species" is not to be presumed; there is no need for a shading of structure to make dim their outlines. I suggest that a line of organization analogous to the prugress of the embryo of an elevated species had passed in the course of time through its appointed stages 
of development, each of which is a small advance upon the preceaing, and the type of a form thenceforth to continue permaneni. Each line stands apaí. It may show shadings in a rertical direction, as herween its reptilian and its mammas iorms, but no true affinities connecting horizontaily with the members of other sines. Our critic is here, therefore, completely at fault. I meet him again, however, on special grounds Many of the animals of the tertiary period are of large bulk. We have not only huge exampies of the pachyderm order, in which there are still. existing many bulky species, but we have equally vast creatures De.onging to the rodent, the edentate, and other oraers. Th.ese huge mammals are, indeed, the signaı Iorms of this period, the forms by which the whole tertiary system is most distinguished. Now, if we take the living pachyderm order, we shall find that the largest species are of the lowest organization. For example, the eleonant, with its short metatarsus, is a low form compared with the horse, in which the heel is raised so much above the ground. This is a progress of characters which could be shown in many other families. It is a progress which may be generally described as passing from the phocal form of the hind extremities, through the plantigrade and ascending to its ultimatum in the digitigrade. Now this progress is coincident with the distribution of the various lines of animals in physical geography, for while the first are marine the second are generally found in connection with shores, rivers, and low grounds, and the last (always the smallest) with the more varied surface of the interior. When we find, then, animals of the second kind most conspicuous in this period, we have actual phenomenon remarkably in accordance with the scheme of development. We look in, as it were, upon the world, or at least, its chief zoological province, at the time when the lines had attained to the terrestrial mammal forms fitted for fluviatile and jungle life, and ere from from these had yet sprung the whole of the smaller but more highly organized denizens of nature's common.

Our critic, having now run over the whole series of fossils, summons Cuvier, Agassiz, and Owen to express their opinions against the theory of development. The first " again and again affirms that the extinct fossil species were not produced by any continued natural organic law from other species." His French opponents tried, 
eccording to the reviewer, to overturn his conclusion by experiments in cross-breeding and the ransacking of ancient tombs. And they talked contemptuousiy of la clôture du siècle de Cuvier; for which they fall under a reference to the fable of the ass and the dead lion. Now I disclaim all responsibility for the experiments and anguage of the French theories on this subject. But, while I respect Cuvier, I must not concede ton much tven to his opinion. He was, after all, but a man, with he common liability to prejudices. I would, with all Jue reverence 'or the illustrious baron, remind my reriewer of an opinion which the former expressed in 1826, that a deluge had occurred about six thousand years ago, which broke down and made to disappear the countries which had before been inhabited by men, and the species of animals with which we are best acquainted. T'en years after this belief was expressed by Cuvier, I find Dr. Buckland quietly withdrawing his adnerence to it in the Bridgewater Treatise. At this moment it is not supported by a single geologist of the least repute. May not, then, the Baron Cuvier be wrong also in his opinion regarding the development of species? So much, I trust, may be said without any disparagement to the author of the Regne Animal. The fact is, that the erroneous and imperfect ideas of great men often become an annoyance, from no fault on their part, but only because the weak and narrow-minded are so apt, afterwards, to seize upon such ideas, and brandish them in the faces of advancing truths. For M. Agassiz I likewise entertain great respect; but it happens that his liability to error is equally well established. The doctrines which he persisted for years in maintaining with respect to the constitution and movement of glaciers, are now all but deserted for the more accurate and philosophical deductions of Professor James Forbes. I may, therefore, receive the intelligence which the Neufchatel philosopher brings me regarding the fossil fish, but be cautious in accepting as an infallible dictum what he is pleased to say on the comparatively profound doctrine of organic development. Professor Owen, whose modesty keeps pace with his fame, will hardly pretend to an infallibility which fails in two such noted instances. Besides, the difficulties which this great anatomist and others have found in sanctioning the development theory, chiefly rest in mis- 
taken assumptions with regard to the constitution of $1 . \mathrm{t}$ animal kingdom. It is impossible, as they say, to maks out a genealogy in a line of orders; but lel a fresh ratsralist of equal standing judge of the theory after he has considered the animal kingdom in the arrangement now suggested, and I feel assured that its feasibility will receive a more favorable verdict.

The reviewer, however, would not abate one jot of his opinion, although Cuvier, Agassiz, and Owen were all against him! If such be the state of his mind regarding Cuvier, with what face can he condemn St. Hilaire, who only does that towards the dead lion which our critic would also do, supposing the dead lion were equally opposed to his opinion? The grounds for this strong assurance are in personal and immediate observation of facts. "We have examined," says he, " the old records ... in the spots where nature placed them, and we know their true historical meaning. . . . We have visited in succession the tombs and charnel-houses of these old times, anil we took with us the clew spun in the fabric of development ; but we found this clew no guide through these ancient labyrinths, and, sorely against our will, we were compelled to snap its thread. . . We now dare affirm that geology, not seen through the mist of any theory, but taken as a plain succession of monuments and facts, offers one firm cumulative argument against the hypothesis of development." What first strikes us in this declaration is the tone in which the writer speaks of his own convictions. Cuvier, Agassiz, Owen, may all be wrong; but this writer cannot. He has seen what he speaks of. Against " a dogmatical dictation contrary to the sobe" rules of sound philosophy" (his own words,) there might have surely been some protection in the necessity of retractation to which the best geclogists are occasionally reduced. For example, we have Professor Sedgwick, in $i \delta 31$, undoing a theory he had formerly embraced:

"We now connect the gravel of the plains with the elevation of the newest system of mountains. . . . That these statements militate against opinions but a few years since held almost universally among us, cannot be denied. But theories of diluvial gravel, like all other ardent generalizations of an advancing science, must ever be regarded but as shifting hypothesis to be modified by every new suct, till at length they hecome accordant with all tho 
wheromerse of nature. In retreating, where we have advaliced ton far, there is neither compromise of dignity tur ioss of $s^{4}$ rength; for in doing this we partake but of the common fortune of every one who enters on a field if investigation like our own."

The contrast between the philosophic modesty of this passage and the above extract from the Edinburgh reviewer must be very striking. The reader, who has seen the hollowness of so many of this writer's particular objections to the development theory, can be little at a loss to form an estimate of the personal investigations of which he speaks. He seems to have yet to learn that the necessarily partial investigations which any single geologist may be able personally to make can give no such amount of the requisite knowledge as may be acquired in another mode of study; that the intellectual powers and preparations of the personal inquirer ought also to be known; before we can set such store even by that light which may . be attained by his examinations. It is not uncommon for ordinary mariners to boast of their knowledge of a country from having sailed several times to one of its ports, and or private sentinels to pretend to a superior knowledge of a great battle, in one detachment of which they happened to be engaged. Of such boastings and pretensions I must confess that I am strongly reminded by this writer.

The geological objections to the development theory have now been discussed, and to the public it must be left to decide the question, whether palæontology is favorable or unfavorable to that scheme, I must not advert to the illustrations which the theory derives from physiology, and the objections which have been made to them. The Edinburgh reviewer occupies several of his pages with such objections, but, fortunately, they need not detain us long, as they come to little more than this, that he puts trust in Dr. Clark, of Cambridge, while I have resorted for the support of my general theory to the views advocated by other physiologists.* I may say

* Dr. Whewell (preface to Irdications, \& c.) joins the reviewer and others in reprobating the suggestions which have been made in the Vestiges with regard to a similarity between certain crys. tallizations, as the figures produced by frost upon windows, and the Avbor Diana, to vegetable forms. The logical merits of the reviewer's mind are here fully indicated, for what does he set down as a disproof of these as ' traces of secondary means by which the 
that these views are presented in my book as c. rrectly as it was possible for me to give them, who am nothing but a general student: in one instance I have employed the language of a popular treatise (Dr. Lord's) - ridiculed by our reviewer as a book of no authority-merely because the ideas were there presented in a peculiarly intelligible form. The general aim was, I can honestly declare, to

Almighty deviser might establish" the forms of plants ? that sueh crystallizations grow by simple apposition of new matter, and not from germs, as actual vegetables ilo; the question at issue being merely, whether the electricity concerned in the crystallization might nothave some similar effect in determining the forms of the vegetables. I may here remark that I am not alone in surmising some common root for these phenomena. In Leithead's Electricity (1837) the following passage occurs:- " The form of the routs of free electricity is modified by the medium through which it passes, and also by the electric state of such medium, or of that of the relative electrical condition of two bodies between which it is transmitted. If the medium through which it passes possesses a

- very inferior conducting power, it is obvious that a certain momentum must be requisite to enable the fluid to force its passage to a given distance, and there will be a point at which the momentum of the fluid and the resistance of the body will exactly counterbalance each other; but so soon as the electricity has again accu. mulated to a sufficient degree to overcome the resistance, it will again force its way in another direction, until it arrives at another point of equilibrium. In this way we may readily see the modus operandi of the electric fluid in imparting regular forms to bodies ; and it is highly probable that its action in this respect extends to the vegetable kingdom, and perhaps operates even on animals, from the time in which they exist in the embryo state. . . . Another fact in support of the opinion, that the distinctive forms of bodies are produced by electrical action, is, that crystals, and the twigs and ieaves of vegetables, all terminate in points or sharp edges, so that the electrical action can proceed no further in increasing the growth, or, in other words, in propelling fresh portions of matter for the extension of the plant, o: the crystal, beyond the pointed or edged termination." In a letter of Mr. Crosse to Mr. Leithead, it is stated that, in one of his experiments, there grew in the in. side of an electrified jar filled with hydro-sulphuret of potash a mineral furgus, three-fourths of an inch in length and one-fourth of an inch in diameter, "in the shape of a common trumpet-moutied "ungus, which is found on trees" "In one experiment," says Mr Weekes, in a recent letter to myself, " a singularly beautiful elec. tro-vegetation was produced, a forest in miniature, which, by aid of a good lens. presented inany extraordinary appearances, and continued to interest me during many months." It may suit the reviewer and others to scoff at such "resemblances ;" but scof. fing will not annul, in my mind, the apprehension that there is here some relation of a very high interesting kind, the investigation of which may yet give us a deeper insight than we now enjoy in the mysteries of organic being. 
convey the doctrine of the epigenesis of animals, as M. Serres calls it, as an illustration of my subject, considering myself entitled to do so by the position which it has attained in the world. It is, of course, unfortunate for this, as it is for many other doctrines, that it should have an opponent; but this circumstance is fortunately, on the other hand, no adequate ground of condemnation in the judgment of third parties. I leave, then, the general tenor of this portion of my reviewer's objections, with the remark that, for the one authority which he has called into court, it would be easy to summon many as good on the other side ; for instance, Harvey, Grew, Lister, and Meckel. Our critic's own favorite authority-Mr. Owen - would give good evidence; see his Letters on the Invertebrated Animals, where he says that man's embryotic metamorphosis would not be less striking than those of the butterfly, if subjected like them to observation-and then adds, that the human embryo is first vermiform, next stamped with the characters of the apodal fish, afterwards indicative of the enaliosaur, and so forth. There is another inost respectable English physiologistDr. Roget-who, in his Bridgewater Treatise, explicitly says, "that the animals which occupy the highest stations in each series possess, at the commencement of their existence, forms exhibiting a marked resemblance to those presented in the permanent condition of the lowest animals of the same series; and that during the progress of their development they assume in succession the characters of each tribe, corresponding to their consecutive order in the ascending chain." It is to what has been thus spoken of by such excellent men-what was, I believe, first hinted at by Harvey, and afterwards shadowed forth by John Hunter-thai this writer applies the appellation of " a monstrous scheme, from first to last nothing but a pile of wildly gratuitous hypotheses."

This reviewer and others have been eager to point out that "no anatomist has observed the shadow of any change assimilating the nascent embryo to any of the radiata, mollusca, or articulata. Thus are three whole classes [divisions] of the animal kingdom passed over without any corresponding fotal type, and in defiance of the law of development." The writer here states what is not true, if any faith is to be placed in one of the first uthorities of the age, and one upon which he himself 
depends; for have we not seen $\mathrm{Mr}$. Uwen on the last page affirming that the human embryo is first verme or $m$ ? - this meaning the form of the worms, a portion of the class Annelides, in one of these lower divisions. That all these divisions or sub-kingdoms are not represented in the human embryo is an objection perfectly visionary, for it is not necessary that all should be iuvolved in the ancestry, and therefore analogies to all are not to be looked for. It may be said, then, there is no true difficulty in this quarter.

Perhaps no part of the arguments for the development theory has been more misapprehended, or misrepresented, than this. It is continually said that the embryo, at any of its particular stages, is not in reality the animal represented by that stage. The Edinburgh reviewer remarks, with regard to the fish stage, "Were the embryo of a mammal thrown off at that time into the water (of its own temperature), it could not support life for a moment." The brain of a child in the seventh month is also said to be not the brain of any of the inferior animals, but a true numan brain. The truth is, no one ever pretended that there was such an identity. It is only said that there is a resemblance in general character between the particular embryotic stage of being, and the mature condition and form of the appropriate inferior animal. The particular adaptations, and the character of vital maturity, are all wanting, and therefore it is that the embryo could not live, as the inferior animai represented, if separated from the parent, and really is not that inferior animal.

It may be well, - before leaving this part of the subject, to advert to a special charge which this writer, and at least one other, ${ }^{*}$ have brought forward: it is, that I assume, not only that the organic germs of all creatures are alike, but that they are identical. The Edinburgh Review brings a contradiction to this proposition from Dr. Clark. It is wholly unnecessary, for no such assumption was ever made by me. The phrase used in the book was, "Its primary positions [meaning the doctrines of embryonic development] are that the smbryos of all animals are not distinguishably different from each other;" which is a very different proposition. In sevirul other instances, propositions are thus misrepresented to f $^{\circ}$ ord the glory of a visionary refutation. For exampla, tho * North American Review, Arril, 1845. 
idea that there being light in the planets, any inhabitants of these orbs may be presumed to have eyes, as eyes bear a relation to light, is met by him very gravely with the tact, left for him to discover, that animals have eyes before they are born!

I have now reviewed the vest $\mathrm{g}$ es of creation, presented in both the geological and physiological records, the former presenting memorials of the actual progression of species, in nearly such a conformity with the general arrangements of the organic kingdoms as we might expect in the present state of the science, and the latter affurding us proofs-proofs, at least, satisfactory to many of the best anatomists of our age- of a plan of individual development, which may be called the living picture of the advance of species during the vast ages chronicled by the sedimentary rocks. A third series of vestiges now remains for consideration-namely, those which hint at originations and modifications of organic beings in the current era.

The objections to the occasional production of organic beings, otherwise than $e x$ ovo, do not appear to have been softened by the publication of my former volume. All reviewers, with the single exception of the British and Foreign Medical Review, have intimated their continued skepticism on this point. The experiment of Professor Shulze, of Berlin, with decaying organic matter floating in a flask to which common air was admitted, after passing through sulphuric acid, thereby being deprived of all animal admixtures - an experiment which ended in the non-production of any animalcules or mould-is pointed to as conclusive. Explanations more or less plausible have also been offered for the origin of the entozoa, the parasites of civilization, the pimelodes cyclopum, \&c. I should fear to weary the reader with a new discussion of all these particulars : for the sake of brevity, let me meet the call which the opponents of the development theory usually make, to give it the direct proof which would be afforded by showing one instance, either of the origin of life or the transmutation of species.

The objection of the Edinburgh reviewer to the alleged ransmutation of oats into rye, is that he believes it a fable. This is the opinion of one person, advanced without fact or argument to support it. Let us see, on the other hand, what a greater authority on botanical subjects 
than he- namely, Dr. Lindley-has stated on the same subject. "At the request," says this learned person, " of the Marquis of Bristol, the Reverend I,ord Arthur Hervey, in the year 1843, sowed a handiul of oats, treated them in the manner recommended, by ccntinually stopping the flowering stems, and the produce, in 1844, has been for the most part ears of a very slender barley, having much the appearance of rye, with a little wheat, and some oats; samples of which are, by the favor of Lord Bristol, now before us." The learned writer then adverts to the "extraordinary but certain fact, that in orchidaceous plants forms just as different as wheat, barley, $1^{4}$ ye, and oats have been proved by the most rigorous evidence, to be accidental variations of one common form, brought about no one knows how, but before our eyes, and rendered permanent by equally mysterious agency. Then, says Reason, if they occur in orchidaceous plants, why should they not also occur in corn plants? for it is not likely that such vagaries will be confined to one little group in the vegetable kingdom; it is more rational to believe them to be a part of the general system of creation ... How can we be sure, that wheat, rye, oats, and barley are not all accidental off-sets from some unsuspected species?"* The reader will now be partly able to judge of the value of the unsupported dictum of the reviewer.

There are many other facts that throw a strong light on transmutation, both of plants and animals. So far from there being any decisive proof against this theory, there is no settled conclusion at this moment amongst naturalists as to what constitutes a species. "There is," says Professor Henslow, " no law whatever hitherto established, by which the limits of variation to a given species can bo satisfací.;ily assigned, and until some such law be dis covered, we cannot expect precision in the details of systematic botany." " "We have aĝreed," says Bicheno " that a species shall be that distinct form, originally so created, and producing by certain laws of generation others like itself. There is this inconvenience attending the use of it by naturalists, that it assumes as a fact that which, in the present state of science, is in many cases a fit subject of inquiry ; namely, that species, according to our defi-

* Gardener's Chronicle, August, 1844.

$f$ Magazine of Zoology and Botany, i., 116 
nition, do exist throughout nature. It is too convenient a term to be dispensed with, even as an assumption; only care should be taken that we do not accept the abstract term for the fact."* Mr. Westwood, speaking of insects, says, "In very extensive genera, the distinctions of species are so minute, that it requires the most practiced eye to separate them ; and, indeed, there are some groups, the species of which are so intricately blended together, that no two entomologists are agreed as to their distinctness." According to $\mathrm{Mr}$. Haldeman, author of a learned work on the fresh-water mollusks of America, "There are distinct species in that class-among the Unionidæ, for example [and this is a remark applicable to other departments of the animal kingdom,] actually differing less from each other than the known varieties of certain variable species which a Lamarkian might suppose to be of so recent an origin as not to have yet become settled in the possession of their proper diagnostic characters. Indeed, notwithstanding the assumption to the contrary, by authors who have little practical acquaintance with the details of natural history, the proper discrimination between species and variety, is one of the greatest difficulties which the naturalist has to encounter; and he who is successful in this department is entitled to a rank which comparatively. few can attain."' $\dagger$

Of the extent to which modifications may be carried by palpable external conditions, I may now supply a few illustrations. It is well known that fungi and lichens attain to very different appearances in different situations, in conformity with different conditions. Fries, we are told, "asserts that out of the different states of one species (telephora sulphurea) more than eight distinct genera had been constructed by different authors. It would scem, then, that the absolute number of species among the fungi is not nearly so great as has been usually suposed, and that the kind produced by a decomposing infusion, or a bed of decaying solid matter, will depend as much upon the influence of the material employed as upon the germ itself which is the subject of it.f Among the questions proposed by the Academy of Sci ences at Haarlem, in 1839, was one upon the followirg

* Linnæan Transactions, xv., 482.

$\dagger$ Boston Journal of Natural History

\Carpenter's Physiology, p. 62 
subject-" According to some botanists, Algæ of a very simple structure, placed under favorable circumstances, develop and change into different plants, belonging to genera much more elevated in the scale of organic being, although these same algæ, in the absence of such favcrable circumstances, would be fertile, and reproduce their primitive form."* I would ask if this is a point as yet settled in the negative. The original of our cabbage is well known to be a trailing sea-side plant, entirely different from the cabbage in appearance. The cardoon and artichoke are now admitted to be one, and Mr. Darwin was assured by an intelligent farmer that he has seen, in a deserted garden, the latter plant relapsing into the former.

It is well known that when fresh-water mollusks are exposed for a little time to an influx of the sea, those which can survive the change assume considerably different characters. In a fresh-water tertiary formation of the island of Cos, Professor Edward Furbes and Lieutenant Spratt found various fresh-water molluscan shells-paludina, neretina, melanopsis, \&c - which had passed through surprising modifications in the course of three successive groups of deposits, supposed to have been marked by increasing influxes of sea-water. "The lowermost species of each genus were smooth, those of the centre partially plicated, and those of the upper part strongly and regularly ribbed." $\dagger$ This was apparently a retrogression to marine ty:pes. The differences in the three cases were greater than those which naturalists usually consider as grounds of specific distinction.

Surely there are here ample evidences of species, or what are usually regarded as such, being variable under changed conditions. It will be said, these changes are all mere variations of specific forms, and the facts do nothing but show that that has been called species which is only variety. But where is this to have its limits? If the cabbage and sea-plant are to be now regarded as one species, it seems to me that we have to go very little further to come to the lines of successive forms or stirpes, which my hypothesis suggests. This view becomes the more striking when we remember that any variations which we now see take place within a space of time

* Charlesworth's Magazine of Natural History, ii., 448.

\footnotetext{
t Report of the Proceedings of the British Association, 1845 Laterary Gazelle.
} 
extremely small in comparison with those which geology allows for its phenomena. "Although," says Mr. Haldeman, "we may not be able, artificially, to produce a change beyond a definite point, it would be a hasty inference to suppose that a physical agent acting gradually for ages, could not carry the variation a step or two further."

I may here advert to a fallacy which has been one of the principal difficulties in the way of the supposition of every kind of transmutation. It is always taken for granted that the parental animal must be extinguished in consequence of the change. Thus we find a suggestion by $M$. St. Hilaire that the modern giraffe may be a modification of the sivatherium of the Indian tertiaries, met very complacently by a reference to the discovery of Dr. Fal. coner, that in these tertiaries, the giraffe is associated with the sivatherium. So also the suggestion that the hare of Siberia, with its curtailed ears, shorter hind legs, and absence of tail, may be a modification of the ordinary hare, has been answered by Professor Owen, with a reference to the fact that the tailless hare (Lagomys Spelæus) is found as early in the tertiaries as any species of the true genus, Lepus. * Now it is entirely an assumption on the part of those who oppose the transmutation theory, that the original animal shall perish when the new one is produced; and therefore the difficulty is entirely of their own making. The probable fact is that the modification takes place in an offshoot of the original tribe, which has removed into a different set of circumstances, these circumstances being the cause of the change : thus there is no need to presume that the original tribe is at all affected by any such modification. The case is precisely analogous to that of a colony. We see, for example, the New Englanders change from the original English type, without any necessary effect upon the parent stock. Just so might the giraffe be a changed sivatherium, and yet the sivatherium continue to exist. And in point of fact, there are many animals now living along with their disposed modified descendants. Unless, therefore, it could be proved that the supposed descendant actually preceded in date the animal from which it was said to have sprung, objections of this nature can be of no force. The reader will understand that 1 only adduce the instances of the sivatherium and hare for the sake of illustration, and without undertaking to

* British Fossil Mammalia and Birds, p. 215. 
show that those animals have actually had sucn modified descendants as may have been attributed to them. I would entreat the candid opponent of the transmutation theory to review the subject in the improved light in which it appears, with this most gratuitous assumption set aside.

With regard to the origination of new life from inorganic elements, the Broomfield experiment would be quite decisive, if any evidence could be admitted for what men are unwilling to believe. The Edinburgh reviewer writes two pages which appear to put the alleged fact much out of countenance; and yet it is true that ridicule, which al ways proceeds upon assumption, forms their entire composition. He states that specimens of the insect were sent to Paris, where they set a whole conclave of philosophers a-laughing, because they were found to contain ova. It did not occur to him that independent generation is what the development theory nresumes of every animal family which may have ever had an origin otherwise than ex ovo. Other specimeins were sent to London, but there their fate was sealed by their being fuund to be not a new species, but one then abundant in the country. These circumstances, with a few empty jests, satisfy the critic that there was no independent generation in the case. Against such a conclusion, proceeding upon mere supposition, I adduce careful experiment. During the last three years, Mr. Weekes of Sandwich, has continued to subject solutions to electric action, and invariably found insects produred in these instances, while they as invariably failed to appear where the electric action was not employed, but every other condition fulfilled. The rigid care taken in these experiments to exclude vitiating circumstances gives them a high claim to notice, and I therefore present, as an ap. pendix, two letters from Mr. Weekes upon the subject They cannot fail to be read with interest, and the more so as they exhibit a man pursuing the investigation of an important natural fact under the most discouraging circumstances. If this new presentment of the Acarus Crossii shall still excite ridicule, I can only regret the mood of mind from which that ridicule arises; but the opposite party must excuse my attaching no importance to a: yshing besides fact and argument. 'These alleged phenomend are open, like all others, to the test of counter-experinent Let them be subjected to it in the most rigid manrer, ard set aside in the case of failure But to meet them 
merely with scoffs and jests, or at the most, certain wholly gratuitous assumptions as to a possibly various cause, is not philosophical, and therefore deserves no consiceration.

Having thus presented restiges of laws for the origination and modification of organic being, I must protest against proof of the existence of such laws being held indispensable to the development theory. The earth, we see, has been peopled for ages before man began to observe nature or chronicle his observations. The organic world attained what appears to us completeness, in remote ages. It is a thing done, as individual reproduction is done at the birth of the new creature. We are not, therefore, to expect conspicuous examples of either a new origin of life or a modification of species at the present day. Though, therefore, not one unequivocal instance of such origin and such modification could be presented, it would say nothing positive against the hypothesis that species originated, and made a series of advances in general organization, by the efficacy of law, in times long antecedent to our historical perind. We should still have to say that the evidence of wuch phenomena was to be looked for elsewhere-namely, in the history of the progress of organic being as chronicled for us by geology, and in the history which physiology affords us of the progress of the individual embryo. Seeing, then, that plants and animals came into existence gradually, in the course of a vast period of time, and in a succession conforming generally to their grades in organization, and the stages through which the embryo of one of the highest has to pass before it attains maturity, we might say that we had seen all that could well be expected in the case, and enough to establish a strong probability for the development theory. Irevertheless, it may be admitted that any evidence of the continued existence of the creative and modifying laws is still desirable, for the sake of corroboration. And such is the light in which I regard the facts which we possess regarding variations of type, and the production of some of the lower plants and animals by means independent of generation. As in the progress of an individual being, even after birth, we see the laws which preside over reproduction operating still in a faint degree in the defective nutrition which stunts, and the favoring conditions which advance and glorify, the state of infancy and youth, so might we expect that the laws which originally spread the vegetable and animal king- 
doms crer the earth, would still, perhaps, be traceable as faintly at work, especially in those lower families where life and the modifiable quality are most abundantly imıparted. The evidence for the existence of such laws is patent to the exact observation which will give it philosophical certainty, and to such observation I trust it will, in time, be subjected. Meanwhile, I claim its being re. ceived as a provisional aid to the theory of development.

Thus closes my review of the objections which have been made to the evidences for an organic creation by law. Such a mode of that creation was, I said at the first, rendered likely by the manifestation of a presidency of law both in the physical arrangements of the universe and in the constitution of our own minds. It seemed to me that, with evidences of law in these things, we had a strong probability established that law had been the mode of the divine working in the whole system revealed to our senses and reason, throughout all ages of its existence. And I believe that we were called upon, not to grasp at every objection to this idea which could be conjured out of the darkness of our imperfect knowledge, as if to save us from a disrelished conclusion, but rather to look with candid minds into nature, and endeavor to discover in what we do know the traces of such an origin of orgarization as might harmonize with the conceptions forced upon us from other quarters; trusting that there never could be any disadvantage from embracing that view which the balance of reason might show to be the nearest to truth. The question is, to which view does the balance now incline? Whether is it most likely that the Deity produced Being and its many-staged theatre in the manner of order or law, or by any different mode of a more arbitrary character; whether, consequently, are we to regard him as ruling the affairs of the world in the manner of an invariable order or otherwise? I say likely, because we are not to expect on any such questions the absolute demonstration which attends a mathematical problem or an unchallengeable writing. We must be content if we only can see a preponderance of reasons for regarding the universe and its Author in one or other of those lights. To be prepared for a decision upon this ques. tion, it is proper that the reader should be presented with a sketch of the theory opposed to that of universal order. 
DR. WHEWELL'S PAL ETTOLOGICAL SCIENCES. 263

When we set about describing this system, we are struck by finding it vague and unsteady, varying with every degree of intelligence in its votaries and every addition made to science. The uneducated man regards the whole system of the world as resulting from, ard depending upon, the immediate working and guidance of an Almighty being who acts in each case as'may seem to him most meet, exactly as human creatures do. Persons of intelligence, again, usually admit a system of general laws, but for the most part entertain it under great reservations, or in connection with views totally inconsistent with it. We find Dr. Clark, for instance, admitting a course of nature as the "will of God producing certain effects in a regular and uniform manner," but this will " being arbitrary [an assumption, as far as natural means of knowledge are concerned], is, he says, as easy to be altered at any time as to be preserved."

Others cut off particular provinces of nature as exceptions from the plan of constant order. Whatever part is dubious or obscure, to mankind generally or to themselves in particular, there they rear the torn standard of the arbitrary system of divine rule. Human volitions form such a region to many who know not that Quetelet has reduced these to mathematical formulæ, and that one of our own most popular divines has written a Bridgewater Treatise, to show the predominance of natural law over mind, as a proof of the existence and Wisdom of God. Some who give up this domain to law, find footing in other departments of nature upon which science has not as yet poured any clear light. We shall presently see by what weak argument such exceptions are maintained. Meanwhile, it must be noted as important that all is uncertainty on this side of the question-a strong presumption, were there no other against it.

One of the most remarkable reservations made of late years from the system of invariable order is that presented in Dr. Whewell's History of the Iruductive Sciences. Admitting that nature, as revealed to our senses, is a system of causation, this writer halts when he comes to consider the origin of language and of arts, the origin of species and firmation of globes. These he calls palætiological scifnces, because, in his opinion, we have to seek for an ancient and different class of causes, as affecting them, from any which are now seen operating. "In no palætio. 
logical sciences," savs he, " has man i een able to arrive at a beginning which is homogeneous with the known course of events. We can, in such sciences, often go very far back, determine many of the remote circumstances of the past series of events, ascend to a point which seems to be near their origin, and limit the hypothesis respecting the origin itself; but philosophers have never demonstrated, and, so far as we can judge, probably never will be able to demonstrate, what was the primitive state of things from which the progressive course of the world took its first departure. In all these paths of research, when we travel far backwards, the aspect of the earlier portions becomes very different from that of the advanced part on which we now stand; but in all cases the path is lost in obscurity as it is traced backward to its starting point: it becomes not only invisible, but unimaginable; it is not only an interruption, but an abyss which interposes itself between us and any intelligible beginning of things." *

Here we have the view of exceptions which is entertained by one of the chief writers of the day, and the superior of one of our greatest academical institutions. The professional position of Dr. Whewell may be held to imply that we should receive from him a view at once leaning to the philosophical, and accommodated as far as possible to the prepossessions expected in a large class of persons. It is remarkable, but not surprising, how weak is the barrier which he has raised to stop our course towards a theory of universal arrangement by ordinary natural law.

The necessity alleged by Dr. Whewell for a different set of causes in the early times of our globe, and with regard to the formation of that globe, is at the very first liable to strong suspicion, as reminding us much of that well-known propensity of nations, to fill up the first chapters of their history with mythic heroes and giants. "The subjects of investigation are remote from common research: they are not, and never could have been, chronicled in the manner of modern facts; we are in the regions of the comparatively unknown-hence, something more magnificent or impressive than ordinary must be supposed. Such is the reasoning, or rather no-reasoning. The point. at which extraordinary causes have tc be supposed is evi-

\footnotetext{
* Philosophy of the Inductive Sciences, apud Indications of the Creator
} 
dently quite arbitrary, resting exactly on the limits of the knowledye existing at any time, and always flying $f:$ rther and further back, in proportion as our knowledge increases. Had Dr. Whewell been writing fifty years ago, he would of course have included among his palætiological sciences the formation of strata, and the intrusions of the granitic and trappean among the aqueous rocks, which ingenuity has since explained by existing causes;-for there is not a single argument for his considering the formation of globes and origin of species as palætiological, which would not have applied with equal force to these phenomena before the days of Pallas and Hutton. Against a theory of mere assumption-a reasoning from ignorance to ignorance-such considerations form serious objections But let us come to closer argument. Let us inquire h.w the idea of a different set of causes for the more important of these phenomena agrees with such exact knowledge as we have attained respecting them.

"According to the nebular hypothesis," says Dr. Whewell, " the formation of this our system of sun, planets, and satellites, was a process of the same kind as those which are still going on in the heavens.

But . . the uniformitarian doctrine on this subject rests on most unstable foundations. We have as yet only very vague and imperfect reasonings to show that by such condensation a material system such as ours could result; and the introduction of organized beings into such a material system is utterly out of the reach of our philosophy. Here . . therefore, we are led to regard the present order of the world as pointing towards an origin altogether of a different kind fiom anything which our material science can grasp." Because the nebular hypothesis rests on unstable foundations, and " nothing has been pointed out in the existing order of things which has any resemblance or analogy, of any valid kind, to that creative energy which must be exertec in the production of new species," - therefore, according to Dr. Whewell, we are "driven to assume events not included in the course of nature," as having formerly taken place. Such is his reasoning. Now let us call to mind a fen of the laws ascertained to have veen concerned in the cosmical arrangements, leaving for the meantime all that is doubtful in the nebular hypothesis entirely out of view. The propertion of the equatorial to the polar diameter of the earth 
is exactly what a fluid mass rotating at such a rate of speed would assume any day we might try the experiment The relative distances of the planets have been determined by the relation of two laws of matter, so thoroughly patent in their working to modern observation, that a mathematician could ascertain this their result and an. nounce it from his closet, although he never had heard ot a plenetary system in which it was exemplified. There is surely here anything but a likelihood that different causes from those now existing and acting were the immediate means of producing the cosmical arrangements. May we not rather say that, whatever may have been the details of the formation of globes, we possess ample proof that it was a phenomenon evolved by virtue of exactly the same system of order which we see still operating upon earth? As to the origin of organic beings, our knowledge of geology comes to precisely a similar effect. Admitting that we see not now any such fact as the production of new species, we at least know that, while such facts were occurring upon earth, there were associated phenomena in progress of a character perfectly ordinary. For example, when the earth received its first fishes, sandstone and limestone were forming in the manner excmplified a few years ago in the ingenious experiments of Sir James Hall: basaltic columns rose for the future wonaer of man, according to the principle which D:. Gregory Watt showed in operation before the eyes of our fathers; and hollows in the igneous rocks were filled with crystals, precisely as they could now be by virtue of electric action, as shown within the last few years by Crosse and Becquerel. The seas obeyed the impulse of gentle breezes, and rippled their sandy bottoms as seas of the present day are doing; the trees grew as now by favor of sun and wind, thriving in good seasons and pining in oad; this, while the animals above fishes were yet to be sreated. The movements of the sea, the meteorological agencies, the disposition which we see in the generality of plants to thrive when heat and moisture were most abundant, were kept up in silent serenity, as matters of simply natural order, throughout the whole of the ages which saw reptiles enter in their various forms upon the sea and land. It was about the time of the first mammals that the forest of the Dirt Bed was sinking in natural ruin amids' the sea sludge, as forests of the P:antagenets have 
been doing for several centuries upon the coast of England. In short, all the common operations of the physical world were going on in their usual simplicity, obeying that order which we still see governing them, while the supposed extraordinary causes were in sequisition for the development of the animal and vegetable kingdoms There surely hence arises a strong presumption against any such causes. It becomes much more likely that the latter phenomena were evolved in the manner of law also, and that we only dream of extraordinary causes here, as men once dreamed of a special action of deity in every change of wind and the results of each season, merely because they did not know the laws by which the events in question were evolved.

The writer of the critique in the Edinburgh Review is another representative of opinion on this subject whose ideas are worthy of notice. 'These ideas are not very clear, but I' shall endeavor to gather them from the various parts of his paper where they are expressed. $\mathrm{He}$ says of certain animals (p.60) - "They were not called into being by any law of nature, but by a power above nature." If he means by a law of nature something independent of the Deity, I entirely concur with him. Most unquestionably the animals resulted from a power which is above nature, in the sense of its being the Author of nature. He adds- "They were created by the hand of God, and adapted to the conditions of the period." If he here means a special exertion of the powers of the Deity, having a regard to special conditions, we part company, for my object is to show that animals were indebted for their yradations of advance to a law generally impressed by the Deity upon matter, and that their external peculiarities are owing immediately to the agency of those very conditions to which they are supposed to have been adapted. I contend that there was no more need for a special exertion to produce (for instance) mammalia, than there is for one to carry a human fœetus on from the sixth to the seventh, or from the eighth to the ninth month. I had remarked in no irreverent spirit, but the contrary, that the supposition of frequent special exertion anthropomorphises the Deity; I find a simila idea expressed by one who will not be suspected of irrev. erence on such a subject, the pious and amiable Dod. dridge_-."When we assert," says he, " a perpetual divin6 
agency, we readily acknowledge that matter ire so contrived as not to need a divine interposition ir a different manner from that in which it had been constantly exerted. And it is most evident that an unremitting energy, displayed in such circumstances, greatly exalts our idea of God, instead of depressing it; and therefore, by the way, is so much the more likely to be true." The Edinburgh reviewer denies that there is any lowering of the divine character in supposing a system of special exertion. "The law of creation," he says "is the law of the Divine will, and nothing else besides. . The fiat of the Almighty was sufficient at all times, and for all the phenomena of the universe, material and moral."

"It may be true," he continues, " that in the conception of the Divine mind there is no difference between the creation of dead matter and its unbending laws, and the creation of organic structures subservient to all the functions of individual life. But such views are, and must be, above our comprehension. : . Each organic structure is a miracle as incomprehensible as the creation of a planetary system; and each structure is a microcosm related to all other worlds within the ken of sense; yet governed by laws and revolving cycles within itself, and implied in the very conditions of its existence. What know we of the God of nature (we speak only of natural means,) except through the faculties he has given us, rightly employed on the materials around us ? In this we rise to a conception of material inorganic laws, in beautiful harmony and adjustment; and they suggest to us the conception of infinite power and wisdom. In like manner we rise to a conception of organic laws-of means (often almost purely mechanical as they seem to us, and their organic functions well comprehended) adapted to an end, - and that end only the well-being of a creature endowed with sensation and volition. Thus we rise to a conception both of Divine power and Divine goodness; and we. are constrained to believe, not merely that all material law is subordinate to $\mathrm{His}$ will, but that he has also (in the way he allows us to see His works) so exhibited the attributes of $\mathrm{His}$ will, as to show himself to the mind of inan as a personal and superintending God, concentrating his will on every atom of the universe." The reviewer then cenaures the language used in my book with respect to the idea of special creative efforts. "Does not our author," 
says he, "see that he binds the Divinity (on his dismal material scheme) in chains of tatalism as firmly as the Fiomeric gods were bound in the imagination of the blind ald poet? . . The material system may end in downright atheism ; or, if not, it stops short in the undeviating sequence of second causes. . . Our view, on the contrary, sees from one end of the scale to the other, the manifestation of a great principle of creation external to matter-of final cause, proved by organic structures created in successive times, and adapted to changing conditions of the earth. It therefore gives us a personal and superintending God who careth for his creatures."

If such be the best view of the opposite theory which a clever scholar and a man of science of the present day can give, that theory must certainly be regarded as in a very unpromising condition. He is, we see, for fiats or effort adapted to special conditions. These may be, in the divine conception, identical with natural laws or the system of order; but we cannot comprehend it. It is not given to our faculties to understand a matter so profound. Immediately after, he informs us that we have only these faculties to look to for information on this very subject; and they tell us-what?-that the world is a system of law ! law, however, subordinate to the Divine will. Surely, if our faculties cannot comprehend the point above stated, they must be equally unable to pronounce decisively upon points so abstruse as law being subordinate to will, and the attributes of that will showing us the Deity as a personal and superintending God. Were controversialists entrtled thus to assume that the human faculties can pronounce upon one subject in their own way, but are struck powerless on approaching another tending to an opposite conclusion, there would, of course, be an end of all argument. But even that exercise of the faculties which the reviewer admits of for his own purpose by no means goes to the conclusion at which he arrives. $\mathrm{He}$ refers but to a small portion of the divine works, when he speaks of "organic structures created in successive times and adapted to the changing conditions of the earth." He cannot be permitted to assume that he has proved these to have been produced by special fiats or any other mode of special exertion, "in conformity with changed conditions :" on the contrary, his proposition is disproved, - far we hear ir many instances of conditions suitable for 
new beings countless ages before the sui.able beings Inake their appearance, showing that such was not the principle to which we are solely to look for the genesis of animals. But even though he were more successful on this point, he would still be required to show his theory of fiats, in harmony with a system, the most important facts of which appeur, on the contrary, to have taken their present forms and arrangements under the immediate agency of the "Unremitting Energy." As to results * which may flow from any particular view which reason may show as the best supported, I must firmly protest against any assumed title in an opponent to pronounce what these are. 'The first object is to ascertain truth. No truth can be derogatory to the presumed fountain of all truth. The derogation must lie in the erroneous construction which a weak human creature puts upon the truth. And practically it is the true infidel state of mind which prompts apprehension regarding any fact of nature, or any conclusion of sound argument.

The ingenious Agassiz is equally disposed with Dr. Whewell and the Edinburgh Reviewer to except some part of nature as a domain for special intervention; but he wishes the limits of that domain to be rigidly examined, and reprobates the idea that such inquiries are beyond our province. "If," says he, " it is an obligation on science to proclaim the intervention of a Divine power in the development of the whole of nature, and if it is to that power alone that we must ascribe all things, it is not the less incumbent on science to ascertain what is the influence which physical forces, left to themselves, exercise in all natural phenomena, and what is the part of direct action which we must attribute to the Supreme being in the revolutions to which nature has been subjected. . It is now time for naturalists to occupy themselves likewise, in their domain, in inquiring within what linits we can recognize the traces of a Divine interposition, and within what limits the phenomena take place in consequence of a state of things immutably established from. the beginning of the creation. Let it not be said that it is not given to man to sound these depths: the knowl. edge he has acquired of so many hidden mysteries in past ages promises more extended revelations. It is an error to which the mind, from a natural inclination to indolence, allows itself too easily to incline, to believe impossibio 
what it would take some trouble to investigate. Wr generally would impose limits to our faculties, rather than increase their range by their exercise; and the history of the sciences is present to tell us that there are few of the great truths now recognized which have not been treated as chimerical and blasphemous before they were demonstrated."*

Where men are so much perplexed between two opposite principles, led by science in the one direction and drawn by intellectual indolence or timidity in the other, it is not surprising to find them expressing opinions wholly contradictory. Sir John Herschel some years ago announced views strictly conformable to those subse quently taken of organic creation in my book. "For my part," said he, "I cannot but think it an inadequate conception of the Creator to assume it as granted that his combinations are exhausted upon any one of the theatres of their former exercise, though in this, as in ali his other works, we are led, by all analogy, to suppose that he operates through a series of intermediate causes, and that, in consequence, the origination of fresh species, could it ever come under our cognizance, would be found to be a natural, in contradistinction to a miraculous process, - although we perceive no indications of any process actually in progress which is likely to issue in such a result." In his address to the British Association at Cambridge, (1845,) he said, with respect to my hypothesis of the first step of organic creation-" The transition from an inanimate crystal to a globule capable of such endless organic and intellectual development, is as great a step-as unexplained a one-as unintelligible to usand in any sense of the word as miraculous, as the immediate creation and introduction upon earth of every species and every individual would be !"

The reader will now be able to judge of the views opposed to the theory of universal order. He observes that they are of no distinct unique character, but for the most part follow the measure of ignorance, and are maintained at the expense of consistency. It is not surprising that the idea of an organic creation by special exertion or fiat should be maintained by the advocates of these views, for it is one of the last obscure pieces of scientific ground on which they can show face. One after another the phe- 
nomena of nature, like so many revolted princıpalities, have fallen under the dominion of order or law; but here is one little province still faithful to the Bœotian government; and as it is nearly the last, no wonder it is so vigorously defended. As, in the political world, however, men do not trust in the endurance of a dynasty which is reduced to a single city or nook of its dominions, so may we expect a speedy extinction to a doctrine which has been driven from every portion of nature but one or two limited fields. Several eminent authors of our age have even pronounced upon the question as already settled. "Our most deeply investigated views of the Divine gov ernment," says the Rev. Dr. Pye Smith, "lead to the conviction that it is exercised in the way of order, os what we usually call lav. God reiogns according to immutable principles, that is, by law, in every part of his kingdom-the mechanical, the intellectual, and the moral; and it appears to be most clearly a position arising out of that fact, that a comprehensive germ which shall necessarily evolve all future developments, down to the minutest atomic movements, is a more suitable attribution to the Deity than the idea of a necessity for irregular interferences."*

In Blackwood's Magazine, a writer, understood to be a naturalist of distinguished ability, expresses himself in an equally decided manner :- " To reduce to a system the acts of creation, or the development of the several forms of animal life, no more impeaches the authorship of creation than to trace the laws by which the world is upheld and its phenomena perpetually renewed. The presumption naturally rises in the mind, that the same Freat. Being would adopt the same mode of action in both cases. . . To a mind accustomed, as is every educated mind, to regard the operations of Deity as essentially differing from the limited, sudden, evanescent imptilses of a human agent, it is distressing to be compelled to picture to itself the power of God as put forth in any other manner than in those slow, mysterious, universal laus which have so plainly un eternity to work in; it pains the inragination to be obliged to assimilate those operations for a moment to the brief energy of a human wi!l, or the manipulations of a human hand. . . . The:e are still, indeed, some men of narrow prejudices, whe look

- Letter tu Dr Carpenter, appendix to Phil. Mag., xvi. (1840.) 
upon every fresh attempt to reduce the phenom.ena of nature to general laws, and to limit those occasions on which it is necessary to conceive of a direct and separate interposition of Divine power, as a fresh encroachment on the prerogatives of the Deity, or a concealed attack upon his very existence. And yet these very same men are daily appealing to such laws of the creation as have been already established for their great proofs of the existence and wisdom of God! ..." He adds, "No, there is nothing atheistic, nothing irreligious, in the attempt to conceive creation, as well as reproduction, carried on by universal laws."*

There is, however, no more interesting or valuable testimony to universal causation than that presented in the System of Logic of Mr. Stuart Mill. If, in the following extract; we were to substitute the creation of organisms for human volitions, it would apply remarkably well to the state of the argument presented in the present volume:

"The conviction that phenomena have invariable laws, and follow with regularity certain antecedent phenomena, was only acquired gradually, and extended itself, as knowledye advanced, from one order of phenomena to another, beginning with those whose laws were most accessible to observation. This progress has not yet attained its ultimate point; there being still one class of phenomena [human volitions,] the subjection of which to invariable laws is not yet universally recognized. So long as any doubt hung over this fundamental principle, the various methods of induction which took that principle for granted could only afford results which were admissible conditionally, as showing what law the phenomenon under investigation must follow if it followed any fixed law at all. As, however, when the rules of correct induction had been conformed to, the result obtained never failed to be verified by all subsequent experience, every such inductive operation had the effect of extending the acknowledged dominion of general laws, and bringing an additional portion of the experience of mankind to strengthen the evidence of the universality of the law of causation; until now at length we are fully warranted in considering that law, as applied to all phenomena within the range of human observation, to stand

- Review of Vestiges, Blackwood's Magazine, April, 1845. 
on an equal footing in respect to evidence with the ax. ioms of geometry itself.

"I apprehend that the considerations which give, at the present day, to the proof of the law of uniformity of succession as true of all phenomena without exception, this character of completeness and conclusiveness, are the following: First, that we now know it directly to be true of by far the greatest number of phenomena; that there are none of which we know it not to be true, the utmost that can be said being, that of some we cannot positively, from direct evidence, affirm its truth; while phenomenon after phenomenon, as they become better known to us, are constantly passing from the latter class into the former; and in all cases in which that transition has not yet taken place, the absence of direct proof is accounted for by the rarity or the obscurity of the phenomena, our deficient means of observing them, or the logical difficulties arising from the complication of the circumstances in which they occur; insomuch that, notwithstanding as rigid a dependence upon given conditions as exists in the case of any other phenomenon it was not likely that we should be better acquainted with those conditions than we are. Besides this first class of considerations, there is a second, which still further corroborates the conclusion, and froin the recognition of which the complete establishment of the universal law may reasonably be dated. Although there are phenomena, the production and changes of which elude all our attempts to reduce them universally to any ascertained law yet in every such case the phenomenon, or the objects concerned in it, are found in some instances to obey the known laws of nature. The wind, for example, is the type of uncertainty and caprice, yet we find it in some cases obeying with as much constancy as any phenomena in nature the law of the tendency of fluids to distribute themselves so as to equalize the pressure on every side of each of their particles; as in the case of the trade winds and the monsoons. Lightning might once have been supposed to obey no laws ; but since it has been ascertained to be identical with electricity, we know that the very same phenomenon, in some of its manifestations, is implicitly obedient to the action of fixed causes. I do not believe that there is now one object or event in all our experience of nature, within the bounds of the solar system at least, which has not either been ascertained by direct observation 
to follow laws of its oun, or been proved to be exactly similar to objects and events, which, in more familiar mani. festations, or on a more limited scale, follow strict laws our inability to trace the same laws on the larger scale, and in the more recondite instances, being accounted for by the number and complication of the modifying causes, or by their inaccessibility to observation."**

The whole question, then, stands thus. For the theory of universal order-that is, order as presiding in both the origin and administration of the world-we have the testimony of a vast number of facts in nature, and this one in addition-that whatever is reft from the domain of ignorance and made unloubted matter of science, forms a new support to the same doctrine. The opposite view, once predominant, has been shrinking for ages into lesser space, and now maintains a footing only in a few departments of nature which happen to be less liable than others to a clear investigation. The chief of these, if not almost the only one, is the origin of the organic kingcloms. So long as this remains obscure, the supernatural will have a certain hold upon enlightened persons. Should it ever be cleared up in a way that leaves no doubt of a natural origin of plants and animals, there must be a complete revolution in the view which is generally taken of our relation to the Father of our being.

This prepares the way for a few remarks on the present state of opinion with regard to the origin of organic nature. The great difficulty here is the apparent determinateness of species. These forms of life being apparently unchangeable, or at least always showing a tendency to return to the character from which they may have diverged, the idea arises that there can have been no progression from one to another; each must have taken its special form, independently of other forms, directly from the appointment of the Creator. The Edinburgh reviewer says, "they were created by the hand of God and adapted to the conditions of the period." Now it is, in the first place, not certain that species constantly maintain a fixed character, for we have seen that what were long considered as determinate species have been transmuted into others. Passing, howẽver, from this fact, as it is not generally received among inen of science, there remain some great difficulties in connection with the idea of spe.

* System of Logic. ii., 116. 
cial creation. First, we should have to suppose, as pointed out in my former volume, a most startling diversity of plan in the divine workings, a great general plan or system of law in the leading events of world-making, and a plan of minute nice operation, and special attention in some of the mere details of the process. The discrepancy between the two conceptions is surely overpowering, when we allow ourselves to see the whole matter in a steady and rational light. There is, also, the striking fact of an ascertained historical progress of plants and animals in the order of their organization; marine and cellular plants and invertebrated animals first, afterwards higher examples of both. In an arbitrary system, we had surely no reason to expect mammals after reptiles; yet in this order they came. The Edinburgh reviewer speaks of the animals as coming in adaptation to conditions; but this is only true in a limited sense. The groves which formed the coal beds might have been a fitting habitation for reptiles, birds, and mammals, as such groves are at the present day; yet we see none of the last of these classes, and hardly any trace of the two first in that period of the earth. Where the iguanodon lived, the elephant might have lived; but there was no elephant at that time. The sea of the Lower Silurian era was capable of supporting fish; but no fish existed. It hence forcibly appears that theatres of life must have lain unserviceable, or in the possession of a tenantry inferior to what might have enjoyed them, for many ages; there surely would have been no such waste allowed, in a system where Omnipotence was working upon the plan of minute attention to specialties. The fact seems to denote that the actual procedure of the peopling of the earth was one of a natural kind requiring a long space of time for its evolution. In this supposition, the long existence of land without land animals, and more particularly, without the noblest classes and orders, is only analogous to the fact, not nearly enough present to the minds of a civilized people, that to this day the bulk of the earth is a waste as far as man is concerned.

Another startling objection is in the infinite local variation of organic forms. Did the-vegetable and animal kingdoms consist of a definite number of species adlapted to peculiarities of soil and climate, and universally distributed, the fact would be in harmony with the idea of 
special exertion. But the truth is, that various regions exhibit variations altogether without apparent end or purpose. Professor Henslow enumerates forty-five distinct floras, or sets of plants, upon the surtace of the earth, notwithstanding that many of these would be equally suitable elsewhere. The animals of different continents are equally various, few species being the same in any two, though the general character may conform. The inference at present drawn from this fact is, that there must have been, to use the language of the Rev. Dr. Pye Smith, "separate and original creations, perhaps at different and respectively distant epochs." It seems hardly conceivable that rational men should give an adherence to such a doctrine when we think of what it involves. In the single fact that it necessitates a special fiat of the inconceivable Author of this sand-cloud of worlds to produce the flora of St. Helena, we read its more than sufficient condemnation. It surely harmonizes far better with our general ideas of nature to suppose that, just as all else in this far-spread scene was formed by the laws impressed on it at first by its Author, so also was this. " An exception presented to us in such a light appears admissible only when we succeed in forbidding our minds to follow out those reasoning processes to which, by another law of the Almighty, they tend, and for which they are adapted.

I feel that I have dwelt long enough on this part of the question, and yet there are a few geological facts which here call for special comment, and I am loath to overlook them. As is well known, most of the large carnivores and pachyderms of the late tertiary formations very closely resemble existing species; but they are, nevertheless, determined to be distinct species by Professor Owen and other eminent authorities, in consideration of certain peculiarities. The peculiarities are, in general, trifling, such as differences in the tubercles or groovings of the surface of teeth, or greater or less length of body or extremities; but no matter of what the differences consist. Enough for the present that they are held by Mr. Owen and his friends to be of that character which are never passed in generation, but necessarily imply a new creation, a separate effort of Divine power. Now it so happens that all the tertiary species, or so-called species, have not been changed or extirpated. There is a Badger of the Miocene, which cannot be distinguished from the 
badger of the present day. Our existing Meles Tixus is, therefore, acknowledged by $\mathrm{Mr}$. Owen to be " the oldest known species of mammal on the face of the earth." It is in like manner impossible to discover any difference between the present Wild $\boldsymbol{C a t}$ and that which lived in the bone caves with the hyæna, rhìnoceros, and the tiger of the ante-drift era, all of which are said to be extinct species. So also the otter has survived since an early period in the pliocene, while so many larger animals were shifted. The learned anatomist takes occasion from these facts to speak of a survival by small and weak species of geological changes, which have been accompanied by the extirpation of larger and more formidable animals of allied species. The inference from the facts and doctrines of this school is, that Divine power has seer fit to change the species of elephants, rhinoceroses, tigers, and bears, using special miracles to introduce new ones, one with perhaps an additional tooth, another with a new tubercle or cusp on the third molar, and so forth, while he has seen no occasion for a similar interference with the otter, wild cat, and badger, which accordingly have been left undisturbed in their obscurity. Such may be the belief of men of science anxious to support a theory; but assuredly it will never be received by any ordinary men of fair understandings who may be able to read and comprehend the works of Mr. Owen. It were too much for even a child's faith. Yet the Edinburgh reviewer, a member of this school, talks of "credulity!"

Perhaps it is but justice to Professor Pictet to notice his partial dissent from the reigning doctrine on this point. This learned person, finding that the elder alluvion of the Swiss valleys presents mammals identical with those which now live there, though accompanied by remains of elephants, and considering further that "the bats, shrews, moles, badgers, hares, \&c., of the caverns appear to be identical with our own," concludes that the follow ing was the order of events as they occurred in Europe: "The species now living, and some others, were created at the commencement of the diluvial epoch. Partial inundations and changes of temperature caused some of them to perish, such as the mammoth, the species of bear having an arched forehead, the hyænas, the stag with gigantic horns, the rhinoceros, hippopotamus, \&c. ; but the greater number of the species escaped theso 
causes of destruction, and still live. Beside those which I have mentioned, and others which I have noticed in the body of my work, it is possible, for example, that the Ursus Priscus may be the original of recent bears, \&c. It may be said," he adds, "that this idea is opposed to the theory of the peculiarity of species in each formation, and to that of successive creations . . . but I cannot, on that account, refuse to adopt an explanation of facts which seems to me evident. The state of theoretical palæonlology is still too uncertain to allow of our attaching ourselves too strongly to this or that hypothesis. It is the study of facts which is essential, and we must engage in that study unbiassed by preconceived ideas or particular systems."* I would commend this opinion of one of the first men of science in Europe to those British savans who regard a greater plication of the enamel in a horse's tooth, or a ridge on a turbinated shell, or a spot on a butterfly's wing, as the proof of a special interference of that Deity who wheeled the orbs into space by a tranquil expression of his will. But M. Pictet must himself revise his opinions. He must quickly perceive that the rule which he lays down for there being no new creation since the diluvial epoch is equally conclusive against new creations at any anterior time. There is a persistency of certain shells since the beginning of the tertiaries; if, then, the moles and badger's be in any degree a proof that the present bear is a modification of the Ursus Priscus, so also are these shells a proof that all the present mamrnals are modifications of those of the eocene. Several shells, again, of the secondary formation straggling into tertiaries, are not less conclusive, in rigid reasoning, that all the tertiary species were descended from the secondary, although the wide, unrepresented interval at that point allowed of a greater transition of forms. In short, the whole of the divisions constructed by geologists upon the supposition of extensive introductions of totally new vehicles of life must give way before the application of this rule, and it must be seen that what they call new species are but variations upon the old. What, then, will remain to be done before the theory of progressive development be adopted? Only, as the candid reader will readily surmise, that the

* 'Traité Elémentaire de Paléontologie; i., 359, 1844 . Apud Jameson's Journal, Oct., 1845. 
cultivators of science should allow themselves to follow the dictates of reason, against the behests of prejudices unworthy of them and of their age.

Trme is the true key to difficulties regarding appearances of determinateness in species. Few of us, not even geologists, have ever realized in our minds the extent of time which has elapsed since the beginning of life upon this globe. Mr. Lyell, without intending to favor the development theory, lends us powerful testimony on this point. After showing reason to believe that about thirtyfive thousand years have passed since the Niagara began to cut down the rock through which it flows, during which time the living mollusks, whether marine or terrestrial, are proved to have undergone no change, he thus proceeds - "If such events can take place, while the zoology of the earth remains almost stationary and unaltered, what ages may not be comprehended in those successive tertiary periods during which the Flora and Fauna of the globe have been almost entirely changed! Yet how subordinate a place in the long calendar of geological chronology do the successive tertiary periods themselves occupy! How much more enormous a duration must we assign to many antecedent revolutions of the earth and its inhabitants! No analogy can be found in the natural world to the immense scale of these divisions of past time, unless we contemplate the celestial spaces which have been measiured by the astronomer. Some of the nearest of these within the limits of the solar system, as, for example, the orbits of the planets, are reckoned by hundreds of millions of miles, which the imagination in vain endeavor's to grasp. Yet one of these spaces, such as the diameter of the earth's orbit, is regarded as a mere unit, a mere infinitesimal fraction of the distance which separates our sun fiom the nearest star. By pursuing still further the same investigations, we learn that there are luminous clouds, scarcely distinguishable by the naked eye, but resolvable by the telescope into clusters of stars, which are so much more remote, that the interval between our sun and Sirius may be but a fraction of this laryer distance. To regions of space of this higher order in point of magnitude, we may, probably, compare such an interval of time as that which divides the haman epoch from the origin of the coralline iimestone, over which the Niagara is precipitated 
at the Falls. Many have been the successive revolutions in organic life, and many the vicissitudes in the physical geography of the globe, and often has sea been converted into land since that rock was formed. The Alps, the Pyrenees, the Himalaya, have not only begun to exist as lofty mountain chains, but the solid materials of which they a"e composed have been slowly elaborated beneath the sea within the stupendous interval of ages here alluded to.",*

If time, to anything like the amount here insisted on, have really elapsed between the commencement of life and its attaining its highest forms, we must see that the space comprised by the life of an individual, or even that longer portion during which mankind have been watching the wonders of nature, is not sufficient to allow more than a chance of any transition of species being or having been observed, except perhaps in the humble fields where, as was formerly remarked, reproduction is most active and types least defined. If, however, even in our limited command of this grand element, we can detect such transitions as those amongst the cerealia, or in a common infusion, may we not well suppose that much greater have taken place in the course of the vast series of ages here described? Absolute proof on such a point may be impossible; but nearly the same effect may be reached, if we see vestiges of the supposed facts in living phenomena, just as we conclude upon the formation of stratified and igneous rocks from seeing similar phenomena, gen . erally on a smaller scale, taking place before our eyes.

There is another mode of attaining the means of a tolerably definite conclusion, where perfect parof is unattainable. This is to show a portion or fraction of the entire phenomenon, in conformity with the hypothesis as to the whole. Now this can be done in the case under consideration. There are isolated parts of the earth, which we know to have become dry land more recently than others. Such is the Galapagos group of islands, situated in the Pacific, between five and six hundred miles from the American coast. They are wholly of volcanic origin, and are considered by Mr. Darwin as having been raised out of the sea "within a late geological period." Here, then, is a piece of the world undoubtedly younger, o to speak, than most other portions are in their totality.

* Travels in North America, i., 52 
that is to say, it has been dry land for a much less syace of time, though one still considerable. What are the organic productions of this curious archipelago? In the first place, they are "mostly aboriginal creations, found nowhere else," though with an affinity to those of America. Many of them are even peculiar to particular islands in the group. But the remarkable fact bearing on the present inquiry is, that, excepting a rat or a mouse on two of the islands, supposed to have been imported by foreign vessels, there are no mammals in the Galapagos. The leading terrestrial animals are reptiles, and these exist in great variety, and in some instances of extraordinary size. Lizards and tortoises particularly abound. There are also birds, eleven kinds of swimmers and waders, and twenty-six purely terrestrial. All this harmonizes with our ideas of the world in general at the time of the oolites. It speaks of time being necessary for the completion of the animal series in any scene of its development. The Galapagos have not had the full time required for the completion of the series, and it is incomplete accordingly. ${ }^{*}$ The entire harmony of this

* In the Vestiges, Australia is spoken of, for the same reason, as apparently a new country, one which has been belated in its phys. ical and organic development. We have there an order, or what is called an order, of mammals, namely, the marsupialia, besides a few monotremata ; all of which may be regarded as only mammalian apices of certain bird families. The placental mammalian are wholly wanting. One might suppose that the reasoning on which the comparative recentness of this continent was inferred would nave been readily inteliigible, and that not even the most ingenious perverseness of opposition could have hung a remark upon it. Yet the Edinburgh Reviewer presents a note (p. 58), stating that, on my own scheme of nature, New Holland ought to have been considered as one of the oldest countries. "He might have argued (from its flora, its cestraceonts, its trigoniæ, and its marsupials) that it was as old as our oolites; but this would not have served the good ends of the scheme of development. An amusing exam. pie of inconsistency." By old, I presume, is here meant duration in the condition of dry land. I thoroughly agree with the Westminster Review, when it says of this passage, "A more complete miscomprehension of reasoning we have never met with." Assu. redly it may well be held up, as that Review holds it, "as a warn. ing to believers in exparte criticism." The fact is, since, as Professor Phillips admits, there has been no break in the chain ot life from the beginning, our other continents, whatever minor changes they may have undergone, have continued without any entire submergence since at least the commencement of terrestrial life. They are, therefore, older than Australia could be presumed to $\mathrm{re}$, even upon the principle hinted at by the Edinburgh reviewer. 
fact does, I must confess, strike my mind forcibly. Had there been mammals and no reptiles, it would have been quite different. We should then have said that one decided fact against the development theory had been ascertained. A minor circumstance in the zoology of these islands is worthy of note. 'The swimming and wading birds are less.diverse from those of the rest of the world than the terrestrial species, all of which but one are decidedly peculiar. The same holds good regarding the shells and the insects. Here we have the terrestrial animals spreading out into numerous variations, according to the greater variety ard the more peculiar character of the circumstances determining their organization.* Mr. Darwin has likewise observed such facts in the natural history of solitary islands, as induce him to express his belief that "the waders, after the innumerable web-footed species, are generally the first colonists of small islands." It is his supposition that the birds in those instances are immigrants ; but I must advert to the fact, as strikingly in harmony with my hypothesis of development, which was certainly formed without any knowledge of this illustration.

Another mode of proof in the difficult circumstances with which we are dealing, is to show that the hypothesis will account, on a principle of law, for certain facts which we must otherwise suppose to be wholly capricious and accidental. The hypothesis is, that, as a general fact, the progress of being in both kinds has been from the sea towards the land. Marine species of plants and animals are supposed to be, in the main, the progenitors of terrestrial species. Life has, as it were, crept out of the sea upon the land. This, of course, leads us to consider the distribution of vegetable and animal forms in the sea, and the effect which these may have had in determining the Flora and Fauna of particular detached provinces. We would necessarily suppose that any particu-

But is not that principle utteriy absurd, implying as it does that life had stood still in Australia at one point, while it was advancing to the highest forms in other countries? Nay, that the agencies employed in the formation of rocks had been stopped there, for perhaps a third of the time of the earth's existence? The note would not be worthy of this analysis, but that the self-compla. cency of the writer is so apt to impose upon readers who do not inquire for themselves.

* See Darwin's JournaI ot a Yoyage Round the World, c. xvii. 
iar Flura or Fauna occupying a certain seographical area in the ocean would be apt to become the common source of the Flora or Fauna of any masses of land adjoining to it. Now we shall see how the facts harmonize with this view. Wherever there is a group of islands standing much apart, its plants and animals are never found allied to those of any remote region of the earth, but invariably show an affinity to those of the nearest larger masses of land. Thus, for example, the Galapagos exhibit general characters in common with South America; the Cape de Verd islands, with Africa. 'They are, in Mr. Darwin's happy phrase, satellites to those continents in respect of natural history. Again, when masses of land are only divided from each other by narrow seas, there is usually a community of forms. The European and African shores of the Mediterranean present an example. Our own islands afford another of far higher value. It appears that the flora of Ireland and Great Britain is various, or rather that we have five floras, or distinct sets of plants, and that each of these is partaken of by a-portion of the opposite continent. There are, 1st, a flora confined to the west of Ireland, and imparted likewise to the north-west of Spain; 2d, a flora in the south-west promontory of England and of Ireland, extending across the Channel to the north-west coast of France; $3 d$, one common to the south-east of England, and north of France; 4 th, an Alpine flora developed in the Scottish and Welsh Highlands, and intimately related to that of the Norwegian Alps; 5th, a flora which prevails over a large part of England and Ireland, "mingling with the other floras, and diminishing, though slightly, as we proceed west ward;" this bears intimate relations with the flora of Germany. Facts so remarkable would force the merest fact-collector or species-den Iminator into generalization The really ingenious man who lately brought them under notice, ${ }^{*}$ could only surmise, as their explanation, that the spaces now occupied by the intermediate seas must have peen dry land at the time when these floras were created. In that case, either the original arrangements of the floras, or the selection of land for submergence, must have been apposite to the case in a degree far from usual. The necessity for a simpler cause is obvious, and it is found in

* See a paper, read by Professor Edward Forbes, at Caubridge .une. 1815, in Literary Gazette, No. 1434 
the hypothesis of a spread of terrestrial vegetation from the sea into the lands adjacent. The community of forms in the various regions opposed to each other merely indicates a distinct marine creation in each of the oceanic areas respectively interposed, and which would naturally advance into the lands nearest to it as far as circumstances of soil and climate were found agreeable.*

There is still the difficulty of accounting for the origInation of the first forms of life in the various lines afterwards pursued to a high development. How was the inorganic converted into the first rudiments of the organic ? Whence, and of what nature was the impulse that first kindled sensation and intelligence upon this sphere? A suggestion on these subjects is hazarded in my book; but though we were to consider the matter as an entire mystery, it is, after all, only so in the same degree, and to the same effect, as the commencement of a new being from a little germ is a mystery to us, although we know that it is one of the most familiar of all natural events. This last marvel we know to be under natural law, though we cannot otherwise explain it. If we can regard the origin and development of life upon our planet as having been equally under natural law, the whole point is gained; for we are not so much inquiring in order to say how? as was it within or beyond the natural? We have seen, then, as I conceive, that all the associated truths of science go to this point. The whole concur to say, that to believe an exception in this particular of the history of nature, is an absurdity. Difficulties there may be in treating the case positively; some facts of inferior importance may seem to point to an opposite conclusion; but in the balance of the two sets of evidences, those for a universality of natural law down-weigh the other beyond calculation.

I have now to allude to a class of objections different irom those made on scientific grounds, but fortunately not

* It is, perhaps, hardly necessary here to advert to any explana. tion which might be brought from the diffusion of seeds by ocean currents, because the directness of the opposition of the fields of these floras to each other across the Channel is obviously incon. sistent with that idea. In such a case, the constituents of the various floras would have been confused amongst each other by the diversity of currents in the intermediate seas. Mr. Forbes plainly confesses this explanation to be inadmissible in the present case; and, of course, it is not the right explanation in any other. 
less easily replied to. It has appeared to various critics particularly to the writer in the Edinburgh Review, that very sacred principles are threatened by doctrine of universal law. A natural origin of life, and a natural basis in organization for the operations of the human mind, speak to them of fatalism and materialism. And, strange to sav, those who every day give views of physical cos. mogony altogether discrepent in appearance with that of Moses, apply hard names to my book for suggesting an organic cosmogony in the same way liable to inconsiderante odium. I must firmly protest against this mode of meeting speculations regarding nature. The object of my book, whatever may be said of the manner in which it is treated, is purely scientific. The views which I give of this history of organizätion stand exactly on the same ground upon which the geological doctrines stood fifty years ago. I am merely endeavoring to read aright another chapter of the mystic book which God has placed under the attention of his creatures. A little liberality of judgment would enable even an opponent of my particular hypothesis to see that questions as to reverence and irreverence, piety and impiety, are practically determined very much by special impressions upon particular minds. He would see, for example, that the idea of attaching irreverence to a doctrine of natural law is only likely to arise in a mind which has been trained by habit to regard the divine working as more special in its nature-precisely as, finding the Edinburgh reviewer speaking of the whole works of the Deity as "vulgar nature". (p. 53,) I feel that the impiety which such an idea expresses to my sense is only impiety to me, who cannot separate nature from God himself, but it is not necessarily so to him, whose education has given him peculiar, and as I think erroneous conceptions on this subject. 'The absence, however, ot all liberality on these points in my reviewer's is striking, and especially so in those whose geological doctrines have exposed them to similar misconstructions. If the men newly emerged from the odium which was thrown upon Newton's theory of the planetary motions had rushed forward to turn that odium upon the patrons of the dawning science of geology, they would have been prefiguring the conduct of several ur my critics, themselves hardly escaped firom the rude yands of the narrow-minded, yet eager to juin that rabblo 
against a new and equally unfriended stranger, as if such were the best means of purchasing impunity for themseives. I trust that a little time will enable the public to penetrate this policy, and also the real bearing of all such objections. They must soon see that, if a literal interpretation of Scripture is an insufficient argument against the true geognostic history of our earth, so also must it be against all associated phenomena, supposing they are presented on good evidence.

"Some persons," says one of my reviewers, " have a vague idea that there is something derogatory in the lowest form of animal life to have its origin in merely inorganic elements; an idea which results, perhaps, not so much from any subtle and elevated conceptions of life as from an imagination unawakened to the dignity and the marvel of the inorganic world. What is motion but a sort of life? a life of activity, if not of feeling. Suppose-what, indeed, nowhere exists-an inert matter, and let it be suddenly endowed with motion, so that two particles should fly towards each other from the utmost bounds of the universe; were not this almost as strange a property as that which endows an irritable tissue, or an organ of secretion? Is not the world one-the creature of one God-dividing itself, with constant interchange of parts, into the sentient and the non-sentient, in order, so to speak, to become conscious of itself? Are we to place a great chasm between the sentient and the nonsentient, so that it shall be derogation to a poor worm to have no higher genealogy than the eler ent which is the lightning of heaven, and too much honsr to the subtle chemistry of the earth, to be the father of a crawling subject of some bag, or sack, or imperceptible globule of animal life. No: we have no recoil against this generation of an animalcule by the wonderful chemistry of God; our objection to this doctrine is, that it is not proved." *

As one example of the wealkness of the opposition presented by the Edinburgh reviewer on this ground, I may quote a passage in which he has also aimed at convicting me of being enamored of resemblances, and allowing my senses to be cheated by empty sounds. "Every one," says he, "has heard of the quickness of thonght, and who has no: heard of the velocity of the galvanic fluid? There-

* Blackwood's Magazine, April, 1845 
fore, the speed of thought may be reduced to numbers, and a man may think at the rate of 192,000 miles a second! We well know that the author may shelter himself under the juggle of his own words, and tell us that he speaks only of the transmission of our will through the organs of the body. Let him, then, write in more becoming language." Now a man is surely entitled to be judged by his own words, or all judgment might as well cease. After showing that a galvanic battery produces at least some of the effects of the brain, and endeavuring to reconcile ordinary thinkers to the idea of their partial identity by insisting on the almost metaphysical character of the imponderable agents, I said, in a foot-note, "If mental action is electric, the proverbial quickness of thought, that is, the quickness of the transmission of sensation and will-may be presumed to have been brought to an exact measurement," \&c. I leave the reader to judge if language more direct and less delusive than this could have been employed. With regard to the idea conveyed, the critic has perhaps forgot, or never known, that the merit of suggesting the identity of the electricity-driven clockwork of De. luc with that operation of the brain which produces the pulsations of the heart, is claimed by his " model of philosophic caution," Sir John Herschel.* The expression used by that philosopher on the occasion, "If the brain be an electric pile," \&c., ought doubtless to condemn him in the eyes of our critic as a man enamored of resemblances, and a user of unbecoming phraseology-if our critic be a man of impartiality. But he must (if critics be capable of such weakness) revise his opinion on the subject of resemblances. It might surprise even his self-confident mind to find in what decisive terms their utility as one of the means of advancing in scientific observation is insisted on by this very " model of philosophic caution." He will find the passage at page 94 of the celebrated $D$ iscourse.

After discussing the whole arguments on both sides in so ample a manner, it may be hardly necessary to advert to the objection arising from the mere fact that nearly all the scientific men are opposed to the theory of the Vestiges. As this objection, however, is one likely to be of some avail with many minds, it ought not to be entirely passed over If I did not think there were reasons independent of judg.

* Discourse on Natural Philosophy, p. 343 
ment for the scientific class coming so generally to this conclusion, I might feel the more embarrassed in presenting myself in direct opposition to so many men possessing talents and information. As the case really stands, the ability of this class to give at the present time a true response upon such a subject appears extremely challengeable. It is no discredit to them, that they are, almost without exception, engaged, each in his own little department of science, and able to give little or no attention to other parts of that vast field. From year to year, and from age to age, we see them at work, adding no doubt much to the known, and advancing many important interests, but, at the same time, doing little for the establishment of comprehensive views of nature. Experiments in however narrow a walk, facts of whatever minuteness, make reputations-in scientific societies; all beyond is regarded with suspicion and distrust. The consequence is, that philosophy, as it exists amongst us, does nothing to raise its votaries above the common ideas of their time. There can, therefore, be nothing more conclusive against our hypothesis in the disfavor of the scientific class than in that of any other section of uneducated men. There is even less; for the position of scientific men with regard to the rest of the public is such, that they are rather eager to repudiate than to embrace general views, seeing how unpopular these usually are. The reader may here be reminded that there is such a thing in human nature as coming to venerate the prejudices which we are compelled to treat tenderly, because it is felt to be better to be consistent at the sacrifice of even judgment and conscience than to have a war always going on between the cherished and the avowed. Accordingly, in the case of a particular doctrine, which, however unjustly, is regarded as having an obnoxious tendency, it is not surprising that scientific men view it with not less hostility than the common herd. For the very purpose of maintaining their own respect in the concessions they have to make, they naturally wish to find all possible objections to any such theory as that of progressive development, exaggerating every difficulty in its way, rejecting wherever they can, the evidence in its favor, and extenuating what they cannot reject ; in short, taking ail the well recognised means which have been sc often employed in keeping back advancing truths. If this looks like special plead ing: I can only call upon th ? reader 
to bring to his remembrance the impressions which hava been usually made upon him by the transactions of learned societies and the pursuits of individual men of science. Did he not always feel that, while there were laudable industry and zeal, there was also an intellectual timidity rendering all the results philosophicaliy barren? Perhaps a more lively illustration of their deficiency in the life and soul of Nature-seeking could not be presented than in the view which Sir John Herschel gives of the uses of science, in a treatise reputed as one of the most philosophical ever produced in our country. These uses, according to the learned knight, are strictly material-it might even be said, sordid, namely, " to show us how to avoid attempting impossibilities-to secure us from important mistakes, in attempting what is, in itself, possible, by means either inadequate, or actually opposed to the end in view-to enable us to accomplish our ends in the easiest, shortest, most economical and most effectual manner-to induce us to attempt, and enable us to accomplish objects, which but for such knowledge we should never have thought of undertaking."** Such results, it will be feli, may occasionally be of imporance in saving a country-gentleman from a hopeless mining speculation, or adding to the powers and profits of an iron-foundry or a cotton-mill; but nothing more. When the awaking and craving mind asks what science can do for us in explaining the great ends of the Author of nature and our relations to Him, to good and evil, to life, and to eternity, the man of science turns to his collectinn of shells or butterflies, to his electrical machine, or his retort, and is mute as a child who, sporting on the beach, is asked what lands lie beyond the great ocean which stretches before him. 'The natural sense of men who do not happen to have taken a taste for the coleoptera or for the laws of fluids, revolts at the sterility of such pursuits, and, though fearful of some error on its own part, can hardly help condemning the whole to ridicule. Can we wonder that such, to so great an extent, is their fate in public opinion, when we read the appeal presented in their behalf by the very prince of modern philosophers? Or can we say that where such views of " the uses of divine philosophy" are entertained, there could be any right preparation of mind to receive with candor, or treat with justice, a plan of nature like that presented in the Vestiges

* Discourse on the Study of Natural Philosophy, p. 44. 
of Creation? No, it must be before another tribunal that this new philosophy is to be truly and righteously judged.

It is important that these sentences be not misunder. stood. There is both a necessity for the ascertainment of detached facts, that we may attain to the elimination of principles, and a danger in premature generalization, as tending to mislead men from the true road to that result. But, on the other hand, scientific men are seen spending their time in wrong pursuits, merely for want of the tracings which are often supplied for their direction by happy hypotheses. It is to the chilling repression of all saliency in investigation, which characterizes the scientific men of our country and age, that I object not to a due caution in selecting proper paths in which to venture. The function of hypothesis in suggesting observations and experiments is admitted by one of the most vigorous thinkers of our time. "Without such assumptions, science could never have attained its present state: they are necessary steps in the progress to something more certain. ... The process of tracing regularity in any complicated and at first sight confused set of appearances, is neccssarily tentative: we begin by making any supposition, even a false one, to see what consequences will fullow from it; and by observing how these differ from the real phenomena, we learn what corrections to make in our assumption. . . ' Some fact,' says M. Comte, ' is as yet little understood, or some law is unknown: we frame on the subject an hypothesis as accordant as possible with the whole of the data already possessed; and the science, being thus enabled to move forward freely, always ends by leading to new consequences capable of observation, which either confirm or-refute, unequivocally, the first supposition.' . . . Let any one watch the manner in which he himself unravels any complicated mass of evidence; let him observe how, for instance, he elicits the true history of any concurrence from the inrolved statements of one or many witnesses; he will find that he does not take all the items of evidence into his mind at once, and attempt to weave them together: the human faculties are not equal to such an undertaking; he extemporizes, from a few of the particulars, a first rude theory of the mode in which the facts took place, and then looks at the other statements one by one, to try whether 
they can be seconciled with that provisional theory, sr what additions or corrections it requires to make it square with them. In this way . . . w we arrive, by means of hypotheses, at conclusions not hypothetical."* It was with the design of thus giving a direction to inquiry, and leading to views of nature previously little thought of, but unspeakably grander than those commonly entertained, that, too eager for truth to regard my own imperfections, I ventured upon my late speculation. When an ordinary reader judges of it, let him remember that the question lies, not between two philosophical theories, but between one philosophical theory and a view of nature which does not even profess to look to nature for a basis. As a system moreover, which finds none of the previous labors of science shaped or directed in favor of its elucidation, but all in the contrary way, it obviously calls for every reasonable allowance being made for its defects. It may prove a true system, though one half of the illustrations presented by its first explicator should be wrong.

For any mind competent to judge of the argument, there can be little need to insist upon the superiority of the conclusions to which it leads, over the results which arise from more limited views of ordinary science. Existing philosophy, halting between the notions of the enlightened and the unenlightened man, leaves us only puzzled. We know not how to regard the phenomena of the world, and our own relation to them. Many sink into a. kind of fatalism which paralyzes the faculties; others ascend into fantastic dreams which exercise a not less baleful influence. Some of the disastrous consequences are sufficiently conspicuous; but many more blaze and expend themselves in privacy, known only in the circles where they have been so fatally felt. The entire conduct of a large portion of society, and more or less that of nearly all the rest, is regulated, or rather cast loose from regulation, by the want of definite ideas regarding that fixed plan of the Divine working, on the study and observance of which it is evident that our secular happiness nearly altogether depends. Even acute men of the world are daily seen acting to their own manifest injury, in corisequence of their utter ignorance of any system of law pressing around them. With the great bulk of society, life is mirely a following of a few inferior instincts, with * Mill's System of Logic. 
a perfect blindness to consequences. By individuals and by communities alike, physical and moral evils are patiently endured, which a true knowledge of the system of Providence would cause to be instantly redressed. Daily health and comfort, lif : itself, are sacrificed through the want of this knowledge. It is not in the heyday of cheerful, active, and prosperous existence, or 'when we look only to the things which constitute the greatness of nations, that we become sensible of this truth. We must seek for convictions on the subject beside the death-beds of amiable children, destroyed through ignorance of the rules of health, and hung over by parents who feel that life is nothing to them when these dear beings are ro more; in the despairing comfortlessness of the selfish, who have acted through long years on the supposition that the social affections could be starved hurtlessly; in the pestilences ravaging the haunts of poverty, and revenging, in a spreading contagion, the neglect by the rich of the haplessness of their penury and disease-stricken neighbors; in the canker of discontent and crime, which eats into the vitals of a nation in consequence of an unlimited indulgence of acquisitiveness by those possessing the most ready natural resources and standing in the most fortunate positions; in the national degradation and misery which follows war entered upon in the wantonness of pride, greed, and vanity. Doubtless were the idea vitally present in the minds of all men, that from laws of unswerving regularity every act, thought, and emotion of theirg helps to determine their own future, both by its direct effects on their fate, and its reflection from the future of their fellow-creatures, and this without any possibility of reprieve or extenuation, we should see society presenting a different aspect from what it does, the sum of human misery vastly diminished, and that of the general. happiness as much increased.

I am not to attempt a particular defence of the new view of nature from various odiums thrown upon it, for this can only be rightly done when time has abated prejudice, and shown more clearly the relation of this pnilosophy to all other views cherished by civilized nations. But I may meanwhile remark its harmony with the great practical principle of Christianity, in establishing the universal brotherhood and social communion of man. And not only this, but it extends the principle of human- 
ity to the meaner creatures also. LIFE is everywhere one. The inferior animals are only less advanced types of that form of being perfected in ourselves. Constituted as its head-with a peculiar psychical character and destiny by virtue of that position-we are yet essentially connected with the humbler vehicles of vitality and intelligence and placed in moral relations towards them. We are bound to respect the rights of animals as of our human associates. We are bound to respect even their feelings. And from obeying these moral laws, we shall reap as certain a harvest of benefit to ourselves as by obeying any code of law that ever was penned. The rule of force and of cruelty has hitherto prevailed in this department of the world's economy as between man and man; but the day of true knowledge will bring a better rule here also, and the many good qualities of these patient and unresisting ministers of our convenience will yet be acknowledged and dwelt on by all with admiration and love.

Is our own position affected injuriously by this view, or can our relation to the universe and its Author be presumed to be so? Assuredly not. Our character is now seen to be a definite part of a system which is definite. The Deity himself becomes a defined, instead of a capricious being. Power to make and to uphold remains his as before, but is invested with a character of tranquillity altogether new-the highest attribute we can conceive in ronnection with power. Viewing him as the author of this vast scheme by the mere force of his will, and yet as the indispensably present sustainer of all; seeing that the whole is constructed upon a plan of benevolence and justice, we expand to loftier, more generous and holy emotions, as we feel that we are essential parts of a system so great and good. The place we hold in comparison is humble beyond all statement of a degree; yet it is a certain and intelligible place. We know where we stand, and have some sense also of our chronological place. The years of our existence occupy a space in that mighty series, during some earlier portion of which this globe, since the theatre of glories and of sorrows numberless was moulded into form. Arithmetic could state, if we knew it, the connection between the birth of a babe which saw the light an hour ago and the time when the elements or our astral system began to resolve themselves into those countless orbs, one of which is-Man's, the stage of his long 
descended history, and the bounds within which all his secular phenomena must ever be confined. The unit of each individuality, great or humble in social regard, takes a fixed place in that march of life which rose unreckoned ages ago, and now goes on to a "weird," which no wizard has pretended to know. We feel that, amidst all the disgrace of trouble and trespass, we are still the first form of active being after the Greatest, and therefore may well be assured that, immeasurably as is our distance from God, we are still immediately regarded and cared for by him Surely there is here much to soothe and to encourage. If may be that the individual often suffers innocently to appearance in our present sphere; but then he is part of a system of assured benevolence and justice : having faith in this, he is safe. It may be, as some one has suggested, that there is not only a term of life to the individual, but to the species, and that when the proper time comes, the prolific energy being exhausted, man is transferred to the list of extinct forms. Strange thought, that the beauteous phenomend of personal existence-the thrill of the lover, the mother's smile on cherub infancy, the brightness of loving firesides, the aspirations of generous poets and philosophers, the thought cast up and beyond the earthly, that petard which breaks down every door-the tear of penitence, the meekness of the suffering humble, the ardor of the strong in good causes, all that the great and beneficent of all ages have felt, all that each of us now sees, and muses on, in his home, his people, his age,that all these should be thus resolved; passing away whole " equinoxes" into the past, as far as we particular men are concerned, still passing further back as respects the larger personalities called nations, and still further in inconceivable multiplication with regard to the speciesgone, lost, hushed in the stillness of a mightier death than has hitherto been thought of ! But yet the faith may not be shaken, that that which has been endowed with the power of godlike thought, and allowed to come into communion with its Eternal Author, cannot be truly lost. The vital flame which proceeded from him at first returns to him in our perfected form at last, bearing with it all good and lovely things, and making of all the farextending Past but one intense Present, glorious and everlasting. 


\section{COMMUNICATIONS BY H. WEEKE $\varsigma_{\text {ESQ }}$ \\ Referred to at page 262}

DFar SIR-Since the details of my first experiments on the proruction of acari in close atmospheres were given to the world, txizough the medium of the "Proceedings of the London Electrical Society," session of 1842, \&c., and, about the same time, circulated among my scientific friends, in a reprint from the above-named work, as stated by you in a foot-note to page 187, first edition of the $V$ estiges, the subject has continued to occupy my attention, while the nature of my researches has been frequently modified by variations in regard to the form of the experiments, and their correlative arrangements.

Incident to the period inciuded by the last three years, many experiments on the subject have been completed; others are even yet in progress; and, however rigid were the conditions in any case adopted, thus much is certain, that the acari have invariably appeared in the several solutions under electrical influence, while their absence has been as invariably remarked, in spite of the nicest scrutiny, in all negative tests provided to accompany the respective primary experiments.

The following may be taken as an example of the stringent circumstances under which my latter experiments have been conducted; and although, in my own estimation, the evidence it yields is not one whit more conclusive than the results formerly made known, it is clearly free from certain objections urged against the first experiments, and is selected under an impression that, if these conditions fail to show that the electric current is the agent by which the laws of organization have been promoted, then we have -maugre the Baconian philosophy-already trusted too much to experimental facts, with a view to the establishment of truth.

$\mathrm{I}^{+}$, is by no means easy, even if practicable, independent of siketches, to convey a precise idea of the apparatus employed in the experiment I am about to communicate. I will, nevertheless, attempt to describe it with as much hrevity and plainness as possible. In the first place, I must mention that the arrangements were originally of a three-fold character:-1st. A close vessel containing a saline solution, and above it an artificial atmosphere ; 2d. An open vessel containing the same solution, both acted upon by the same current passing through them from a voltaic battery; 3d. Two glass jass standing on the same table, as negative tests, and in every way corresponding with the respective primary vessels, cxcepting that they had no wire appendages, and were unelectrified.

The close ressel consists of a wide-mouthed glass jar, capable of containing a pint and a half of liquid, and is manufactured from the purest and most transparent material. From the top, or shoul. der of this jar, ascends to the height of an inch from the surround. ing surface, a remarkakly stout and strong neck, which presents 
an opening of two inches diameter. Into this opening a thick me tallic plug, or stopper, cast from "fusible alloy," is fitted perfectly air-tight, by a process of long and careful grinding. Perpendicu. larly through the metallic stopper, and at the distance of an inch from each other, so as to occupy the extremes of an equilateral triangle, are drilled three holes, each rather more than two-tenths of an inch diameter, and into each of these is soldered, air-tight, a corresponding glass tube. The two principal of this series of tubes serve the purpose of insulating a pair of stout copper wires, which pass longitudinally through them, and are united at each end by a joint fusion of the glass and metal. Two other wires of platina proeeed from the lower ends of the copper wires to nearly the bottom of the jar, where they terminate in closely-wound spirals, rather more than an inch apart, while the ends of the copper wires, projecting from the upper ends of their respective tubes, have conical cavitius drilled out for the reception of a globule of mercury, by means of which communication with the voltaic battery is established. 'The third tube, passing first to the depth of an inch below the metallic plug, is bent above the latter into a siphon form, and contains in its curvature a globule of mercury weighing about three drachms, which acts as a valve for the occasional escape of gaseous matter generated within the close vessel, and is, at the same time, a guarantee against the ingress of any species of insect life. The mercury employed to form this valve was cau. tiously distilled from the red sulphuret of that metal.

$\mathrm{By}$ the side of the close vessel above described was placed, in the first instance, a glass tumbler, capable of holding half a pint of liquid. Through two pieces of mahogany, cemented to opposite inner surfaces of this second vessel, were made to pass two stout copper wires, terminating, like those adapted to the close jar, in platina spirals a little more than an inch apart near the bottom of the tumbler. The upper ends of these wires were similarly provided with longitudinal cavities also, drilled out for the reception of small globules of mercury, to complete contact and facilitate intercommunication.

On the $2 d$ of May, 1842, the apparatus, of which a description has been attempted, was set to work after the following manner: A solution of ferrocyanate of potass, prepared by carefully boiling two ounces of the salt in sixteen ounces of distilled water, being in readiness for the occasion, ten ounces of the liquid were transferred to the glass jar, and immediately after an elastic metal pipe, in communication with an iron bottle in a state of white heat, and from which a stream of pure oxygen rapidly proceeded, was dipped into the solution in the jar. In this way, the gas, without passing through water, or being brought in contact with any external agent, continued to be supplied to the jar, until the entire atmo. sphere above the solution consisted of oxygen alone, when the metallic plug was deposited instantly in the neck of the jar, so as to cut off all communication with the external air. The open vessel or tumbler being now placed by the side of the close apparatus, and four ounces of the solution before mentioned having been poured into it, the necessary communication between the two vessels was effected by means of suitable wires, and contact at the same time similarly established $w$ ith the respective poles of a constant battery of ten pairs. By means of this arrangement; the current entered the open vessel first, and then proceeded 
through the solution in the close apparatus, in its way to the nego tive side.

I must here remark, that the electric current, immediately on itx first application, was observed to decompose the solution with such energy, that I deemed it advisable to suspend the operation until the activity of the battery should be somewhat modified, and it was not until the evening of the 6th of May that I could date the commencement of my experiment.

A circumstantial record of all important changes connected with this experiment has been preserved, up to the present day, embracing a period of three years and three months, but I cannot conclude that any extracts from my memoranda would enhance the interest of the present notice. I shall therefore prefer a brief summary of the results; first premising that two excellent constant batteries have been successively worn out in the undertaking, and that the requisite changes were made without interruption to the electric current, which is now transmitted by a water-battery of twenty pairs, working with the characteristic uniformity of this excellent species of voltaic contrivance. I would further remark that, from the commencement of the experiment, the battery and the respective vessels containing the solutions have been strictly excluded from the light, by means of a screen constructed for the occasion, and the entire proceeding has been confined to a retired room kept constantly locked, no one having access unless accompanied by myself. My general habit has been to visit the arrangement once in two days, for the purpose of noting the progress, supplying the battery with crystals of sulphate of copper, making good the loss of fluids caused by the evaporation, \&c.

1. October 19th, 1942-one hundred and sixty-six days from the commencement of the experiment-the first acari seen in connection therewith, six in number and nearly full-grown, were discovered on the outside of the open glass vessel. On removing two pieces of card which had been laid over the mouth of this vessel, several fine-specimens were found inhabiting the under surfaces, and others completely developed and in active motion here and there within the glass.

October 20th.-Making my visit at an hour when a more favora. ble light entered the room, swarms of acari were found on the cards about the glass tumbler, both within and without, and also on the platform of the apparatus. At this identical hour Dr. J. Black favored me with a call, inspected the arrangements, and received six living specimens of the acarus produced from solution in the open vessel. No trace of insect life could at this time be discovered in the close vessel with an oxygen atmosphere. The solution in the open vessel had undergone very slight change of color, but exhibited a multitude of minute and beautifully colored crystals with a prevailing tinge of crimson. The solution beneath the oxygen atmosphere, about ten days after the voltaic current began to traverse it, had assumed a reddish brown appearance, which gradually darkened in color until scarcely any light could be transmitted through it, or the ascent of gas from either of the electrodes perceived.

2. Myriads of acari continued to be developed from the solution in the open vessel until the $20^{\prime} \mathrm{h}$ August, 1843 , when it was found expedient to determine this division of the experiment, and confino the operation of the electric current solely to the close arrange 
ment, in which no appearance of insect life had yet been detected. Before removing the open vessel, I had, however, the satisfaction to supply therefrom abundance of living specimens to my scientific friends who had kindly interested themselves on the subject, in various parts of England. Scotland, France, and America.

3 . In the beginning of the month of June, 1844, rather more than two years from the commencement of these operations, the solution in the close vessel began to manifest signs of a most remarkable change, the results of constant, slow, and almost invisible decomposition. The apparatus was carefully tested, and found, as at first, perfectly air-tight, and the confined liquid was evidently returning to a paler red color, as well as a partially translucent condition. These latter appearances rapidly increased, and about the beginning of September in the same year the solution had acquired a light amber color and perfect transparency, with abun. dant flakes and scroll-like forms of irregular oxyde of iron of a deep orange color, nearly covering the bottom of the jar. Most of these had, doubtless, been detached in succession from the negative platina spiral, and were conspicuous through the altered solution. It was while engaged in examining this singular accu. mulation of oxyde, by means of an excellent lens, that I saw for the first time an unequivocal proof of the existence of insect life within the close vesscl. Several spinous processes of the acari and other remains were detected floating on the surface of the solution, and others attached to the inside of the glass a few liners above the liquid, while, under circumstances somewhat more obscure, several entire dead insects were perceived amidst the flakes resting on the bottom of the jar. An omission-of secondary importance, it is true-was now for the first time apparent in the apparatws : this was the want of a fitting sheif or resting-place for the insects; a cireumstance that my kind friend, Andrew Crosse, Esq., when he favored me with a visit a few weeks after, remarked almost immediately, and said, before he knew that acari had already appeared, "that they would fall in and be drowned almost as fast as they were produced." Mr. Crosse was right in his con. jecture, for although 1 have latterly watched the proceeding with diurnal care, I have never identified the presence of more than two living issects at the same time within the close apparatus, and these have as speedily as invariably shared the fate of their pred ecessors. Notwithstanding the omission alluded to, I enjoy an increase of satisfaction in the knowledge that I have kept from $m y$ arrangements any substance which by its introduction might have been suspected of vitiating the results, while the main object of the undertaking has in no wise suffered in its accomplishment. I have only to add my belief, founded on considerable experience and much observation, that insect life was first developed in this division of my experiment some time in the month of July, 1844, about two years and two months from the commencement.

I am, dear sir, yours faithfully,

W. H. WEEKES

Sandwich, 2d Sept., 1845.

To the Author of "Vestrges of the Natural History of Creation." 


\section{ELECTRO-VEGETATION.}

On the $3 \mathrm{~d}$ of October, 1842, I commenced an electro-chemical experiment, which has constantly, since that period, been in pro. gress, and will probably continue for some time longer. It is not necessary to the present notice that I should detail the objects of this undertaking, as the indications of a successful result induce me to suppose that paticulars may eventually be worth communicating to the scientific public. I shall therefore merely state that a cylindrical glass vessel, capable of containing about ten fluid ounces, with a bottom of porous baked earth, and open at the top, is suspended in a convenient frame, is about three-fourths filled with a solution of refined sugar in distilled water, receiving occasional supplies, and that the poles of a water-battery of twenty-five pairs terminate within an inch of each other in the solution before men. tioned, about an inch also from the bottom of the cylindrical vessel. Through the porous bottom alluded to, the saccharine liquid gradually percolated, during several months-that is, until its minute viaducts became completely obstructed The solution thus filtered fell into a convenient glazed earthen jar placed under the apparatus, and was occasionally returned to the inside of the glass cylinder.

About the beginning of September, 1843, a small patch of fungus, of a peculiar character, was observed to have commenced forming on the outside of the glass, near its lower rim, but yet not in contact with the line of junction between the glass and its earthen bottom. At this period the solution had ceased to drop through the earthen diaphragm, and the incipient fungus occupied a spot on the outside of the glass directly opposite the negative electrode within. This substance having, when first seen, a gelatinous ap. pearance, of a dark.brown color, by slow degrees extended itself round the lower rim of the glass, forming an irregular band or zone, half an inch in breadth, and throwing out numerous protuberances as it approached the positive side of the arrangement. On the 29th of November, in the same year, the following note relative to this singular production occurs among my memoranda ; and as I cannot otherwise better describe its mature appearance, I shall subjoin the extract :

"The substance of this fungus varies in color from a light choco late to that of a dark sanguineous red, and though formerly of a soft texture, it now offers considerable resistance. When viewed with an excellent pocket-lens-the only sort of microscope that san be brought to bear upon it-a most singularly-beautiful species of vegetation is seen to occupy its entire surface, presenting various shades of crimson, green, olive, and green inclining to yellow. In its general appearance it at once suggests the idea of a magnifi cent forest, consisting of trees and flowering shrubs in miniature. In particular spots, fine, downy, needle-like spires occur in vast multitudes, and these otherwise nalsed processes rising from the body of the fungus are surmounted by what appear to be seed vessels in some instances, and irregular feathery tufts in others."*

* Shortly after the above note was entered in my memoranda, a small portion of the fungus, with its incumbent vegetation, was submitted to a powerful microscope, and a sketch made in accord ance, which, for obvious reasons, cannot be here introduced. 
This experiment was not designed with any reference to $\mathrm{my}$ researches on the developinent of the electrical aca! $i$, but swarms of these creatures appeared incidental to its progress, and, at the time the above note was made, many of them were seen inhabiting the miniature forest on the fungus, where they seemed to thrive amazingly, and to attain a larger size than any I have hitherto seen.

About the autumn of the year 1844, the fungus had extended to the positive side of the arrangement, thus forming a continuous circular band; and it is not the least remarkable feature of its brief history, that immediately on the completion of this event, the luxuriance and beauty of its vegetation were observed rapidly to decline. A portion of the fungous mass still adheres to the glass, but it is no longer an object of special interest.

To what extent this singular and beautiful production is indebted to the action of an electric current constantly, and for a long time, traversing the saccharine liquid, in connection with which it ap. peared, I am not prepared, by the assistance of facts, at present to say, but the following suggestions occur to my mind as strong analogical reasons in support of its electrical origin, nature, and progress.

Ist. I am tolerably conversant with most of the known fungi of this country, but am not acquainted with any species with which the one in question can be ideritified, or even be said to resemble.

$2 d$. The glazed earthen jar placed under the porous bottem of the cylinder to catch the filtered liquid, had, at the time the fungus originated, a considerable quantity of dark saccharine matter resembling concrete molasses therein; this was suffered to remain as a negative test to the electrical character of the fungus, presuming the latter to have had its beginning in a portion of sugary deposit derived from the solution through the porous diaphragm; yet, though the surface of the residuum in the earthen jar presented the usual indications of mouldiness, no appearance of a fungoid kind, or that of minute vegetation, could at any time be detected within the unelectrified jar.

3d. The commencement of the fungus at a point precisely cor responding with the negalive pole of the arrangement, its luxuriance and maturity in the intermediate space on the glass cylinder, and its decay on finally reaching the positive side, are in themselves faets pleading strongly in favor of electrical influence over the organization of this remarkable species of vegetation.

Sandwich, 5th Sept., 1845.

W. H. WEEKES.

To the Author of "Vestiges of the Natural History of Creation"

THE IND. 








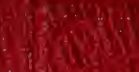

af

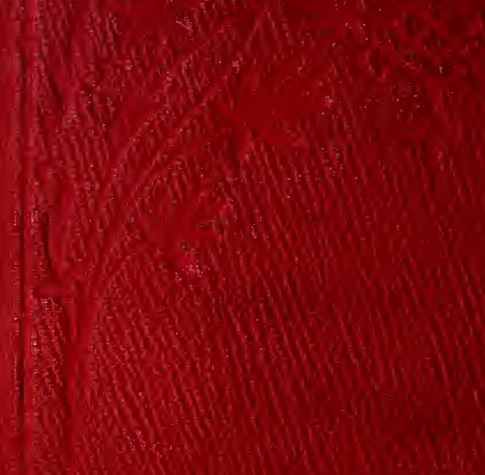

